Universidad de Lima

Facultad de Administración

Carrera de Negocios Internacionales

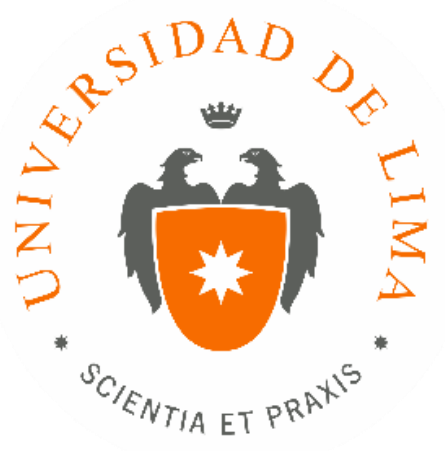

\title{
EXPORTACIÓN DE LOCIÓN CORPORAL DE SACHA INCHI AL MERCADO COLOMBIANO
}

Trabajo de investigación para optar la licenciatura en Negocios Internacionales

\section{María Lucia Gallori Salazar}

Código 20100437

Asesor

Alfredo Estrada Merino

Lima - Perú

Febrero de 2016 


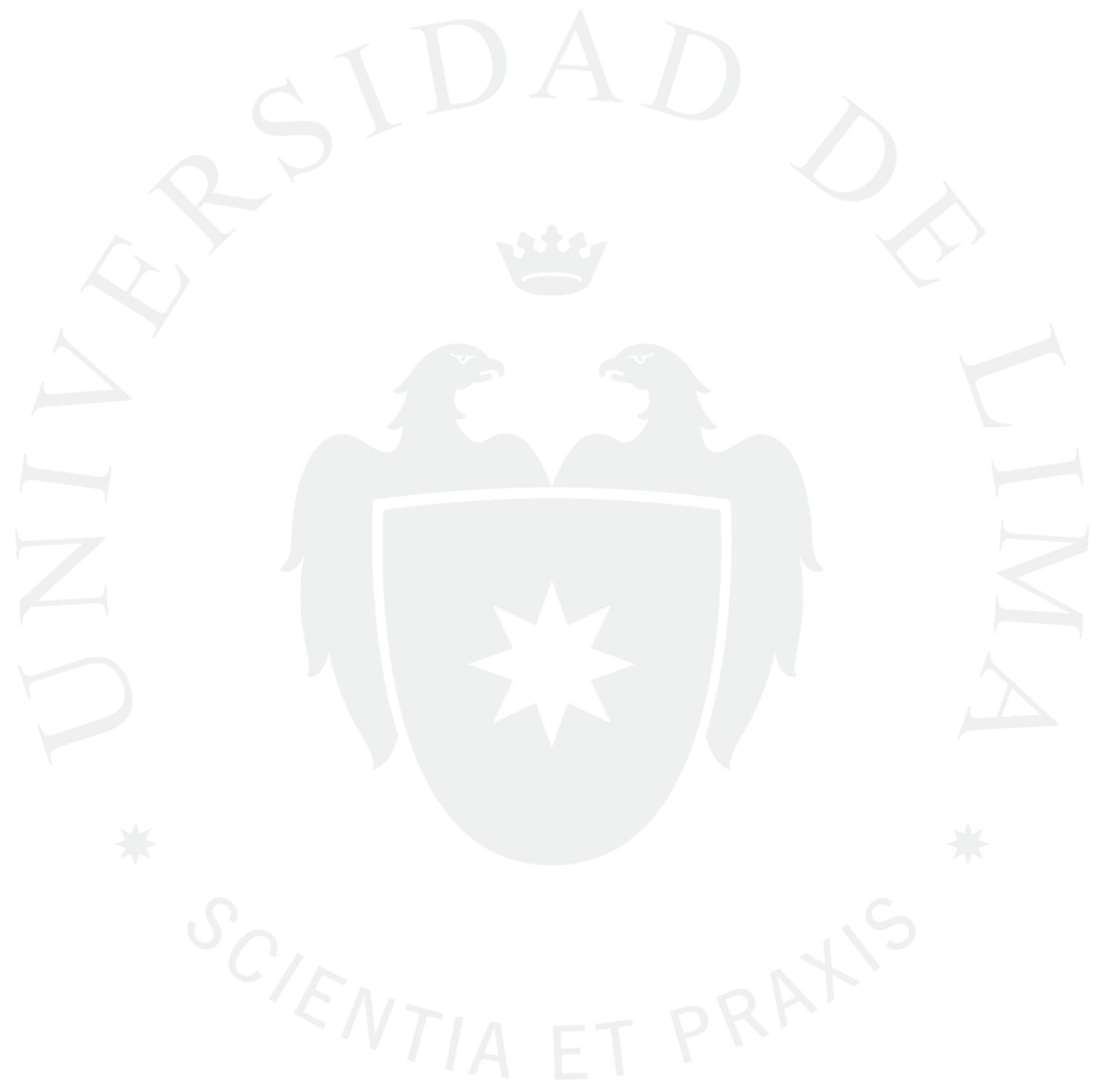




\section{EXPORTACIÓN DE LOCIÓN CORPORAL DE SACHA INCHI AL MERCADO COLOMBIANO}




\section{ÍNDICE}

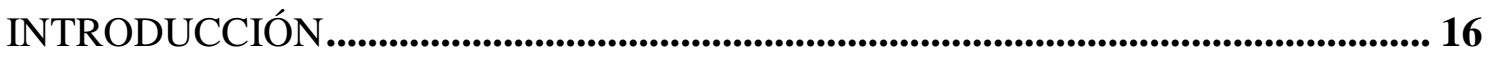

\section{CAPÍTULO I. ANÁLISIS DE LA IDEA, OPORTUNIDAD Y MODELO DEL} NEGOCIO

1.1. Identificación y análisis de la problemática actual (causas y efectos)................ 18

1.2. Descripción de la idea de negocio como alternativa de solución. ...................... 23

1.3. ¿Por qué la idea sería una oportunidad de negocio? ......................................... 23

1.4. Propuestas de innovación en el negocio.............................................................. 27

CAPITULO II. DESARROLLO DEL MARCO EMPRESARIAL ........................ 29

2.1. Nombre, fecha de constitución y principales gerentes. ..................................... 29

2.2. Forma societaria, capital social y accionistas................................................... 29

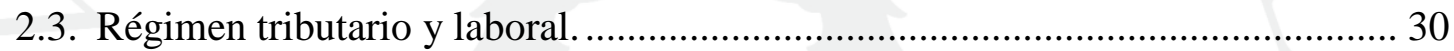

2.4. Actividad, sector y estructura organizacional.................................................. 32

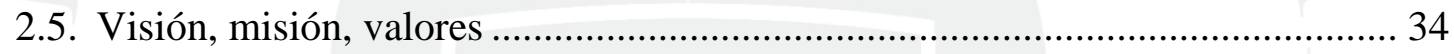

CAPITULO III. ESTUDIO DE MERCADO EXPORTACIÓN................................. 36

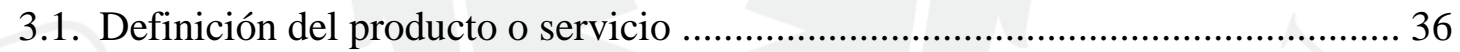

3.2. Selección del mercado internacional .............................................................. 41

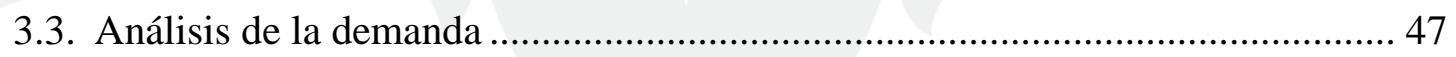

3.3.1. Distribución geográfica del mercado de consumo. ................................... 47

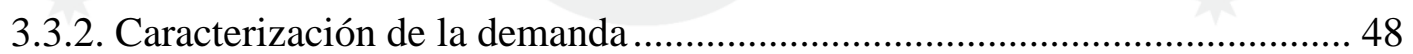

3.3.3. Proyección de la demanda internacional .................................................... 50

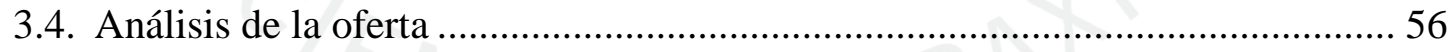

3.4.1. Características de los principales productores o prestadores del servicio.... 56

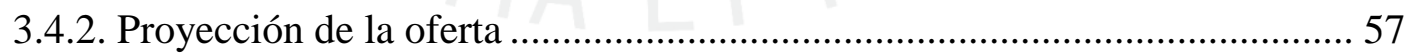

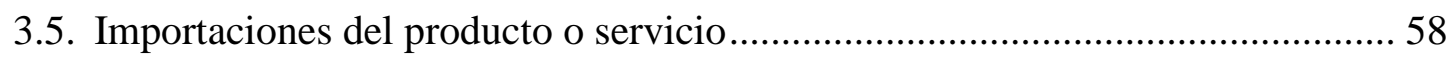

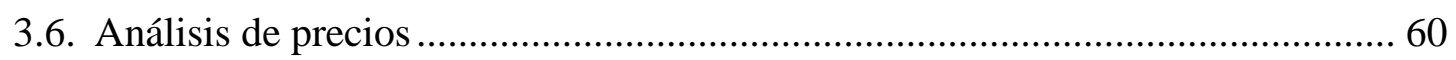

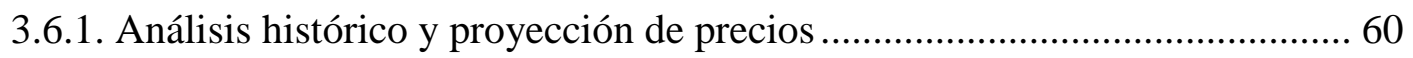

3.7. Canales de comercialización y distribución del producto .................................. 62

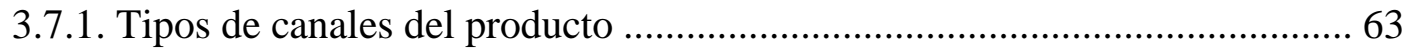




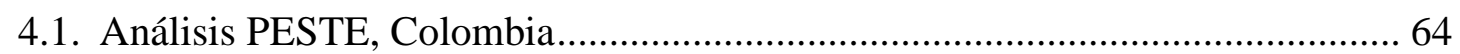

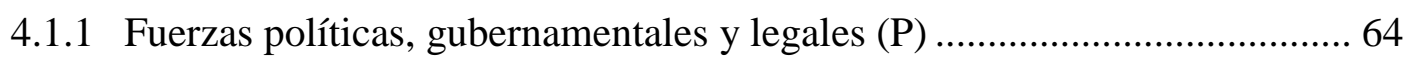

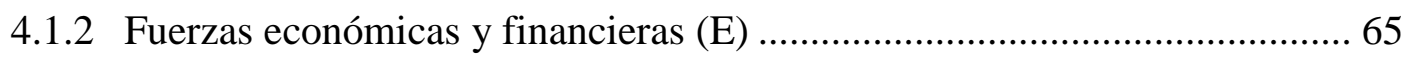

4.1.3 Fuerzas sociales, culturales y demográficas (S) .................................... 74

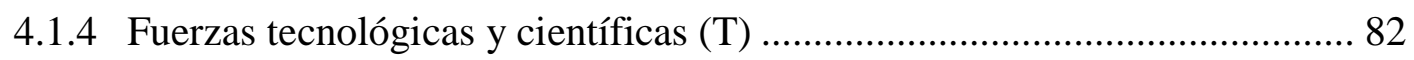

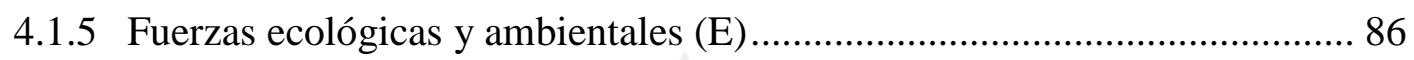

4.2. Matriz de Evaluación de Factores Externos (EFE) .............................................. 88

CAPITULO V. ANÁLISIS COMPETITIVO....................................................... 89

5.1. Análisis de las 5 fuerzas competitivas de Michael Porter ................................. 89

5.2. Principales empresas exportadoras o importadoras peruanas.............................. 94

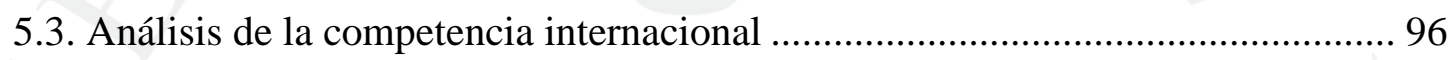

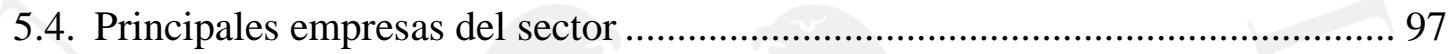

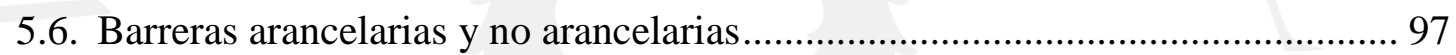

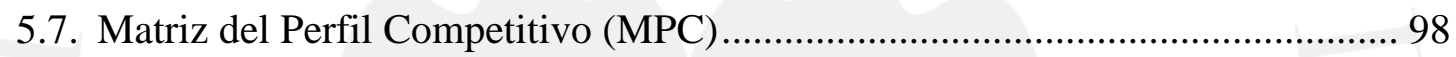

\section{CAPITULO VI. ELECCIÓN DE OBJETIVOS, ESTRATEGIAS Y POLÍTICAS}

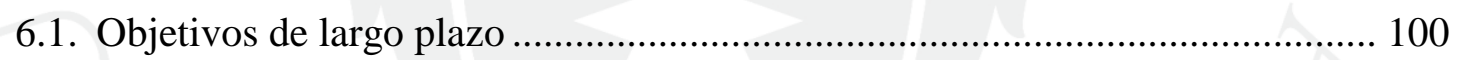

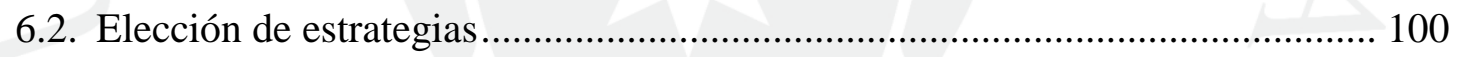

6.2.1. Matriz de Fortalezas, Oportunidades, Debilidades y Amenazas (FODA) . 101

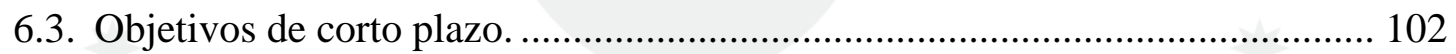

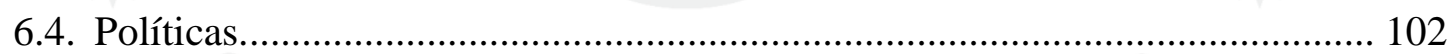

6.5 Matriz de Evaluación de Factores Internos (EFI) .......................................... 103

CAPITULO VII. PLAN DE OPERACIONES Y/O PRODUCCIÓN....................... 106

7.1 Objetivos de Operaciones y/o Producción......................................................... 106

7.2 Tamaño del proyecto y factores determinantes del mismo............................... 106

7.3 Diseño y distribución de planta (flujo de trabajo y flujo de materiales) ........... 111

7.4 Localización, maquinarias, equipos y mobiliario ........................................... 112

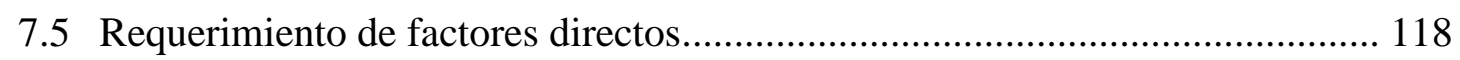

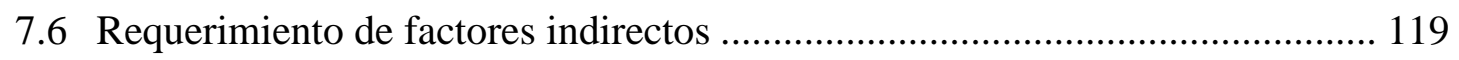

7.7 Diagrama de flujo del proceso de producción y tecnología............................... 120 
7.8 Sistema de control de procesos, calidad y costos operativos.

7.9 Logística, gestión de existencias, compras, logística de entrada y salida, distribución de productos.

7.10 ......... Gestión de mantenimiento correctivo y preventivo, seguridad y salud en el trabajo.

CAPITULO VIII. PLAN DE MARKETING

8.1 Objetivos de Marketing

8.2 Mercado potencial y objetivo

8.3 Segmentación 128

8.4 Posicionamiento. 128

8.5 Posturas Competitivas 129

8.6 Producto (ficha técnica, envase, embalaje, etiquetado) 129

8.7 Precio (método para determinar precios, medios de pago) 133

8.8 Plaza. 137

8.9 Promoción (estrategias de ingreso al mercado) 138

8.10 Presupuesto de Marketing.....

CAPITULO IX. PLAN LOGÍSTICO. 145

9.1 Manejo de mercancía 145

\section{CAPITULO X. PLAN DE ADMINISTRACIÓN Y RECURSOS HUMANOS ... 149}

10.1 Objetivos de Administración y Recursos Humanos 149

10.2 El organigrama y descripción de puestos por área 150

10.3 Definición del perfil del puesto y evaluación de desempeño 151

10.4 Política de selección, contratación, capacitación y desarrollo. 153

10.5 Descripción de los principales procesos del negocio - Flujograma ....... 156

10.6 Diseño de las principales herramientas y/o formatos de control 160

CAPITULO XI. GESTIÓN DE CALIDAD 162

11.1 Política de calidad 162

11.2 Análisis de las principales herramientas de control de calidad 162

11.3 Programa de gestión de calidad para el futuro del negocio. 164 


\section{CAPITULO XII. PLAN DE FINANZAS (PRESUPUESTOS PROYECTADOS Y}

ANÁLISIS DE RENTABILIDAD)

166

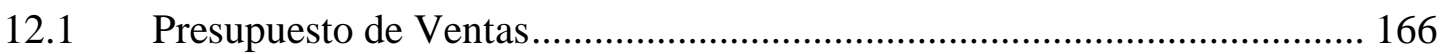

12.2 Presupuesto de Cobranza ........................................................................ 168

12.3 Presupuesto de Producción....................................................................... 170

12.4 Presupuesto de Compras de Materiales de Producción............................... 172

12.5 Presupuesto de Compras de Materiales de Empaque................................ 173

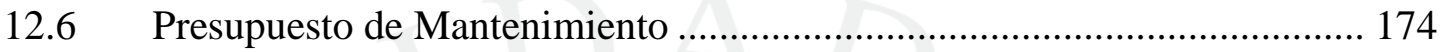

12.7 Presupuesto de Gastos de Mano de Obra .................................................. 175

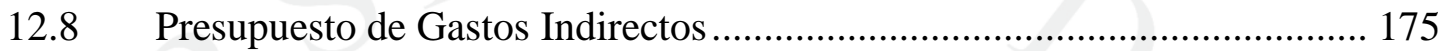

12.9 Presupuesto de Gastos de Administración ............................................... 176

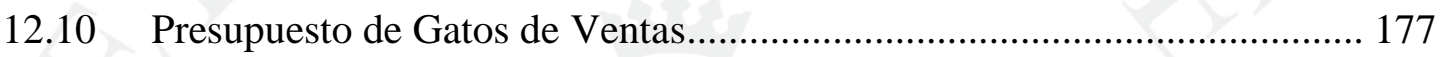

12.11 Presupuesto de Gastos Financieros ........................................................... 177

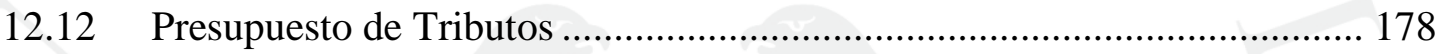

12.13 Flujo de Caja Económico y Financiero Proyectado ................................... 178

12.14 Estructura de Costos Fijos y Variables ...................................................... 179

12.15 Margen bruto y determinación de precio de venta FOB .......................... 181

12.16 Capital de Trabajo................................................................................ 181

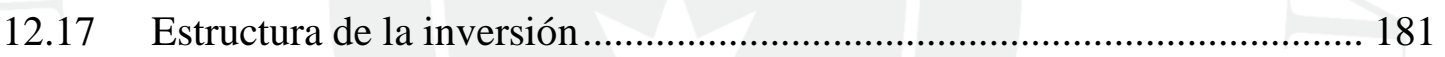

12.18 Financiamiento de la inversión ............................................................... 183

12.19 Estado de Pérdidas y Ganancias ................................................................ 184

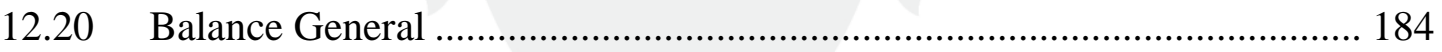

12.21 Evaluación Económica y Financiera del Negocio (TIR, TIRF, VAN Y

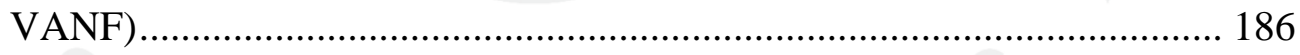

CAPITULO XIII. EVALUACIÓN Y CONTROL ............................................. 189

13.1 Balanced Scorecard (Identificación de Indicadores)................................ 189

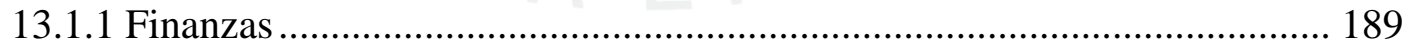

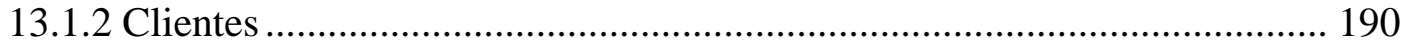

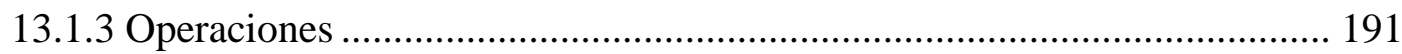

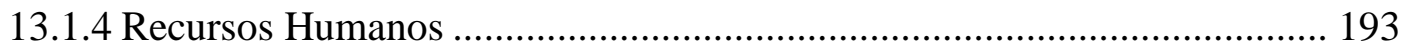

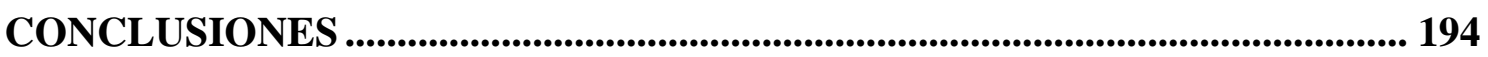

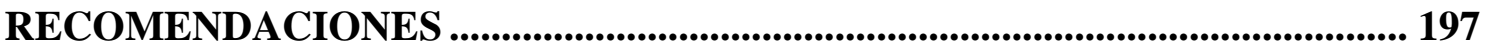


REFERENCIAS .

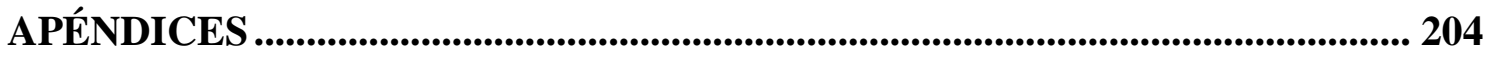




\section{ÍNDICE DE FIGURAS}

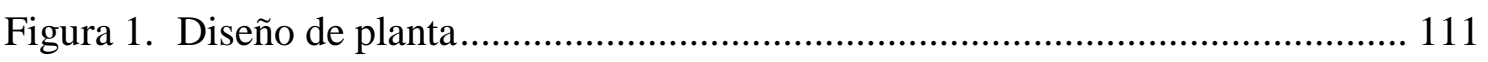

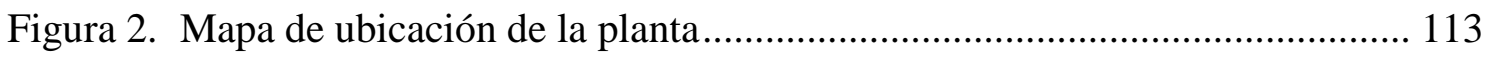

Figura 3. Prototipo de envase de la loción de sacha inchi ........................................... 131

Figura 4. Prospecto de etiqueta de la loción corporal de sacha inchi .......................... 133

Figura 5. Potencial Punto de Venta de la loción corporal de sacha inchi en

Colombia.

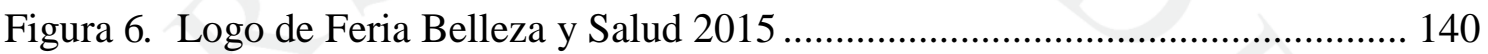

Figura 7. Logo de la Feria Colombia Beauty Show .................................................. 142

Figura 8. Rutas Marítimas Callao - Colombia .......................................................... 146

Figura 9. Mapa de ubicación del Corredor vial Bogotá - Buenaventura..................... 147 


\section{ÍNDICE DE TABLAS}

Tabla 1. Régimen Especial de Renta (RER) 31

Tabla 2. Partida Arancelaria 33.04.99 y su respectiva descripción 40

Tabla 3. Resumen del Test de Selección del Mercado Objetivo 46

Tabla 4. Proyecciones de Población 2015-2020, Total por sexo y Grupos de Edad (25 años hasta 45 años) - Total Nacional 52

Tabla 5. Proyecciones de Población 2015-2020, Total por sexo y Grupos de Edad (25 años hasta 45 años) - Bogotá, D.C.

Tabla 6. Proyección de la Demanda del Producto 2015-2020 ..................................... 54

Tabla 7. Proyección de la Demanda del Producto 2015-2020, ..................................... 55

Tabla 8. Multinacionales de Cosméticos establecidas en Colombia ............................. 57

Tabla 9. Pronóstico de ventas de Productos de Cuidado para la Piel por categoría:

Valores $2014-2019$

Tabla 10. Importaciones desde Colombia para la Partida 330499 Durante el 2014, Valor FOB en miles de USD

Tabla 11. Histórico de precios FOB promedio de la partida 330499 - Exportaciones peruanas con destino a Colombia 60

Tabla 12. Proyección de precios FOB promedio de la partida 330499 - Exportaciones peruanas con destino a Colombia 61

Tabla 13. Principales Indicadores Económicos en los últimos Años 66

Tabla 14. Tipo de Cambio, Serie de datos promedio anual 73

Tabla 15. Matriz EFE 88

Tabla 16. Valor FOB 2014 de las principales empresas peruanas que exportan la partida 330499 al mercado colombiano 94 
Tabla 17. Participación de Mercado de las principales 10 compañías del sector de cuidado de la piel, Categoría ‘General Purpose’ - Según valor 2011 - 201497

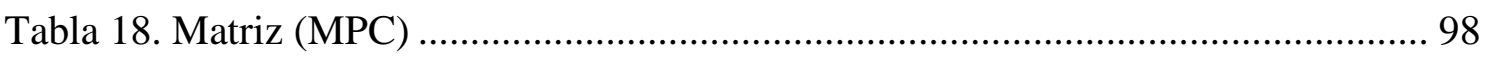

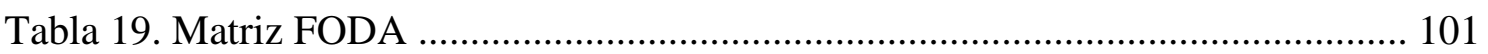

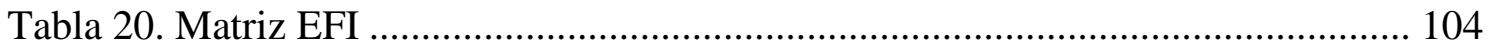

Tabla 21. Componentes de la Loción Corporal ........................................................... 108

Tabla 22. Requerimiento anual de aceite de sacha inchi .......................................... 109

Tabla 23. Resumen del Personal Adm. y Mano de Obra Directa................................. 110

Tabla 24. Especificaciones del local en situación de proyecto.................................... 112

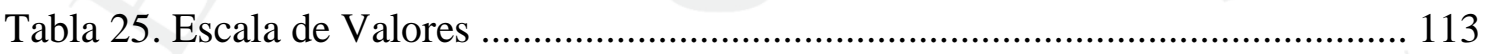

Tabla 26. Matriz de Evaluación de Micro Localización de la planta ............................ 113

Tabla 27. Especificación del local en situación actual ............................................. 114

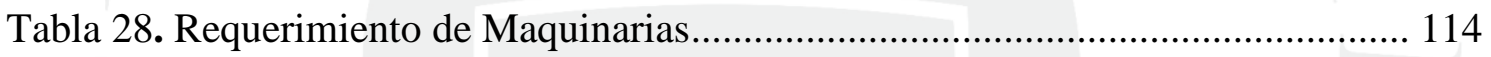

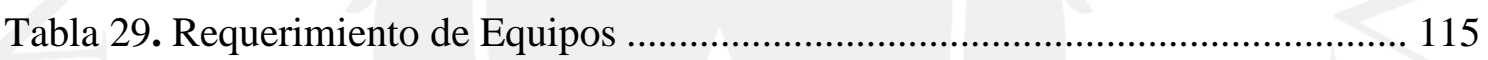

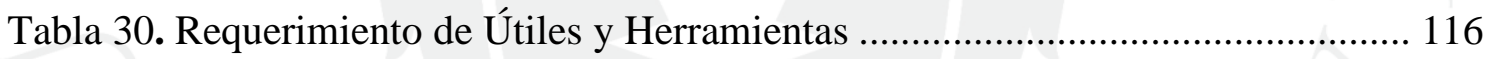

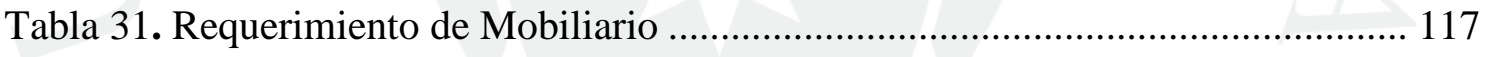

Tabla 32. Requerimiento de Equipos de Seguridad ................................................. 117

Tabla 33. Requerimiento de Materias Primas ........................................................... 118

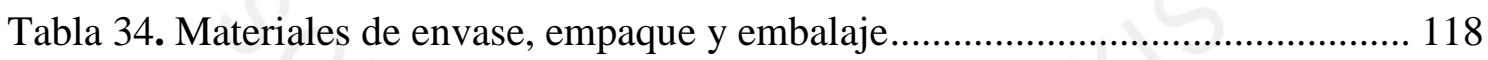

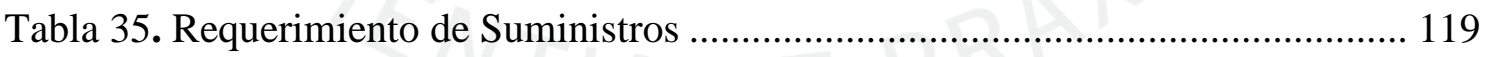

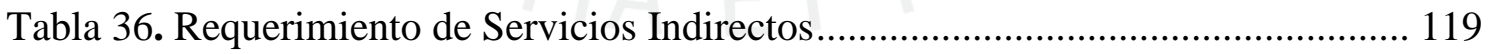

Tabla 37. Descripción del proceso de producción de la Loción corporal ..................... 120

Tabla 38. Diagrama de Gantt del Proceso de Producción ............................................. 123

Tabla 39. Ficha técnica de la loción corporal de Sacha Inchi ................................... 129

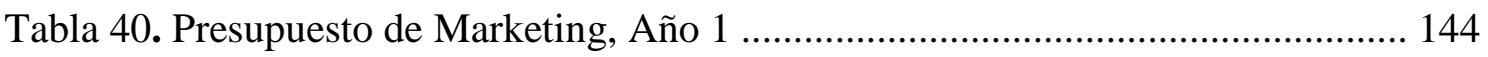


Tabla 41. Proyección de ventas de la empresa

Tabla 42. Proyección de ventas mensuales Año 1.................................................... 167

Tabla 43. Proyección de ventas mensuales Año 2 .................................................... 167

Tabla 44. Proyección de ventas mensuales Año 3.................................................. 167

Tabla 45. Proyección de ventas mensuales Año 4................................................... 168

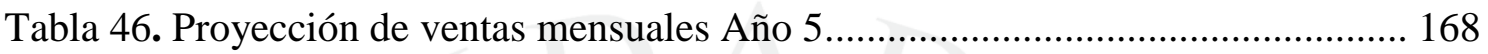

Tabla 47. Proyección de cobranza por cada mes y año (USD) …................................ 169

Tabla 48. Proyección de Producción (en unidades) .................................................... 171

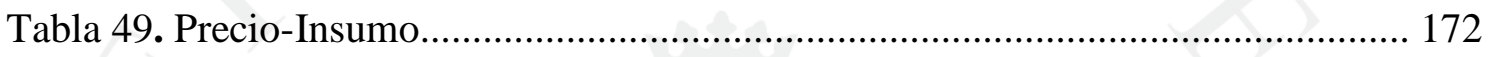

Tabla 50. Presupuesto de Compras de Materiales de Producción ................................ 173

Tabla 51. Precios Materiales de Empaque y Embalaje …........................................ 173

Tabla 52. Requerimiento anual de Materiales de Empaque y Embalaje ....................... 174

Tabla 53. Presupuesto de Compras de Materiales de Empaque .................................. 174

Tabla 54. Presupuesto de Mantenimiento................................................................ 174

Tabla 55. Presupuesto de Gastos de Mano de Obra ................................................ 175

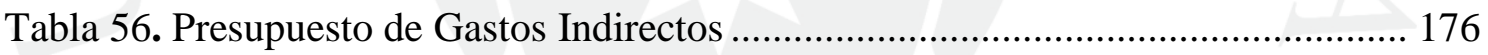

Tabla 57. Presupuesto de Gastos de Administración .................................................. 176

Tabla 58. Presupuesto de Gastos de Ventas ........................................................... 177

Tabla 59. Presupuesto de Gastos Financieros ........................................................ 177

Tabla 60. Presupuesto de Gastos de Tributos......................................................... 178

Tabla 61. Flujo de Caja Económico y Financiero Proyectado ...................................... 178

Tabla 62. Estructura de Costos y Gastos Variables.................................................... 179

Tabla 63. Estructura de Costos y Gastos Fijos ..................................................... 180

Tabla 64. Capital de Trabajo Proyectado .............................................................. 181

Tabla 65. Estructura de Inversión del Proyecto........................................................ 182 
Tabla 66. Capital de trabajo

Tabla 67. Gastos Preoperativos

Tabla 68. Financiamiento de la inversión

Tabla 69. Estado de Pérdidas y Ganancias

Tabla 70. Balance General

Tabla 71. Cálculo del COK Y el WACC

Tabla 72. TIRE, COK y VANE de la empresa BIOPERÚ NATURAL PRODUCTS

S.A.C. 188

Tabla 73. TIRF, WACC y VANF de la empresa BIOPERÚ NATURAL PRODUCTS

S.A.C. 188

Tabla 74. Balanced Scorecard, Análisis Financiero 190

Tabla 75. Balanced Scorecard, Análisis de Percepción de Clientes 191

Tabla 76. Balanced Scorecard, Análisis de Operatividad. 192

Tabla 77. Balanced Scorecard, Análisis de Recursos Humanos 


\section{ÍNDICE DE GRÁFICOS}

Gráfico 1. Evolución del mercado de Beauty and Personal Care por región (2000-2011)

Gráfico 2. Tamaño de mercado de Beauty and Personal Care por país excluyendo a

México y Brasil.

Gráfico 3. Proyección de crecimiento anual del ingreso disponible 2014-2019 21

Gráfico 4. Disposición a pagar por productos de belleza 22

Gráfico 5. Organigrama de la estructura organizativa de la empresa. 33

Gráfico 6. Contenidos excepcionales de AGE presentes en el aceite de sacha inchi..... 38

Gráfica 7. Resultado del test de mercado 46

Gráfico 8. Análisis de Tendencia, Modelo Lineal de Ajuste Óptimo 51

Gráfico 9. Principales países de destino de las exportaciones desde Perú 2010-2014 para la partida 330499, Valor FOB en miles de USD 60

Gráfico 10. Esquema de distribución de cosméticos en Colombia

Gráfico 11. Tasa de crecimiento anual del PIB de Colombia por encima del crecimiento del Mundo y la Región. 67

Gráfico 12. Tasa de desempleo en Colombia: total nacional 67

Gráfico 13. Inflación y meta de inflación

Gráfico 14. Exportaciones mensuales 69

Gráfico 15. Importaciones mensuales 70

Gráfico 16. Balanza comercial mensual 71

Gráfico 17. Flujo trimestral de inversión extranjera directa en Colombia 71

Gráfico 18. Distribución \% de la IED en Colombia por sectores 72

Gráfico 19. Distribución etaria 75

Gráfico 20. Colombia - Análisis Hofstede 78 
Gráfico 21. Diamante Competitivo de Porter.

Gráfico 22. Lista de los mercados proveedores para un producto importado por

Colombia en 2014 96

Gráfico 23. Diagrama de Flujo del proceso de producción 122

Gráfico 24. Estrategia Push 139

Gráfico 25. Ejemplo.- Modelo de Pallet. 145

Gráfico 26. Organigrama..... 150

Gráfico 27. Diagrama Causa Efecto 160

Gráfico 28. Flujo del control de actividades fundamentales en la gestión de calidad.. 162 


\section{INTRODUCCIÓN}

El presente trabajo desarrolla el plan de exportación de lociones corporales a base de insumos de la biodiversidad peruana, particularmente aceite de sacha inchi orgánico, teniendo como destino la ciudad de Bogotá en Colombia, a través de la constitución de la empresa productora y comercializadora BIOPERÚ NATURAL PRODUCTS S.A.

Se presenta un análisis profundo del estudio de la oportunidad de negocio en el mercado seleccionado, y el desarrollo de una oferta exportable, a través de la elaboración de un estudio cuantitativo y cualitativo del mismo, a fin de evaluar la viabilidad del proyecto, así como estimar mediante proyecciones estadísticas la demanda futura para el producto; cabe resaltar que Colombia presenta una tasa de crecimiento sostenible en lo referente al sector de cuidado personal, cuidado de la piel, y que las mujeres colombianas gastan el doble que las mujeres europeas en el cuidado de su apariencia física.

Asimismo, se desarrolló el estudio técnico para el proceso de implementación y puesta en marcha del proyecto; evaluando los requerimientos de material directo, mano de obra directa, suministros, etc., y los proveedores estratégicos con los cuales trabajaremos en este horizonte de cinco años.

De la mano se desarrolla un análisis financiero del proyecto en donde llevamos a cifras cuantitativas la realización del mismo; se calculan los costos de producción, gastos fijos y precio de venta del producto, y se evalúa si éste es rentable o no, a través 
de cálculo del VAN y la TIR, dándonos como resultado ambos indicadores positivos lo cual hace viable y lucrativo el proyecto. 


\section{CAPÍTULO I: ANÁLISIS DE LA IDEA, OPORTUNIDAD Y MODELO DEL NEGOCIO}

\subsection{Identificación y análisis de la problemática actual (causas y efectos).}

Nos encontramos actualmente en un mundo sujeto a una gran variedad de cambios a los que tanto personas como empresas deben aprender a adaptarse; en un mundo globalizado como este, que se debe en mayor parte gracias a la aparición cada vez más constante de nuevas tecnologías, todo parece estar más interconectado y accesible.

Al darse esta situación, la manera de hacer negocios en el mundo ha cambiado: es posible negociar con una mayor variedad de países y clientes, se han acortado las distancias y los tiempos, se han abaratado los costos logísticos, surgieron nuevos requerimientos que se consideran mínimos y con los que los productos deben cumplir para ser competitivos, entre otros sucesos. Es por esto que ahora es indispensable realizar un análisis completo de los países involucrados en una operación comercial.

Tras décadas de haberse mantenido estancada, la población de clase media en América Latina y el Caribe ha aumentado en un 50\% — de 103 millones de personas en 2003 a 152 millones (o un 30\% de la población del continente) en 2009. Durante este periodo, a medida que los ingresos de los hogares iban en aumento y la desigualdad tendía a disminuir en la mayoría de los países, el porcentaje de la población pobre disminuyó notablemente, del $44 \%$ al 30\%. En 
consecuencia, actualmente los porcentajes de la población de clase media y de pobres en América Latina están a la par. Esta situación contrasta con la que prevaleció (durante un largo periodo) hasta hace casi 10 años, cuando el porcentaje de pobres equivalía aproximadamente a 2,5 veces el de la clase media. Siendo los factores más importantes a la hora de favorecer la movilidad ascendente en América Latina, un mayor nivel educativo entre los trabajadores; mayor nivel de empleo formal; más personas viviendo en áreas urbanas; más mujeres en la fuerza laboral y familias más reducidas. (Banco Mundial, 2013)

El curso emergente de una nueva clase media en la mayoría de los países de la región de América Latina, y la creciente participación de las mujeres en el mercado profesional y laboral, contribuyen a generar cambios significativos en el comportamiento de consumo de este target cuando se trata del cuidado de la apariencia. Para muchas de estas mujeres, esta preocupación se ha convertido en una prioridad, lo que provoca un impacto positivo en la demanda de cosméticos. (Euromonitor International, 2014)

El mercado de los productos de belleza y cuidado personal en Latinoamérica es uno de los más dinámicos y diversos, pasando de tener una participación a nivel mundial del 8\% en el año 2000 a un $18 \%$ para fines del 2011. Esto conjugado a la proyección en el aumento de los ingresos de la población y un aumento en el porcentaje del gasto en este tipo de productos categorizados como nonnecessities constituye una oportunidad a explotar. 
Gráfico 1. Evolución del mercado de Beauty and Personal Care por región (2000-2011)

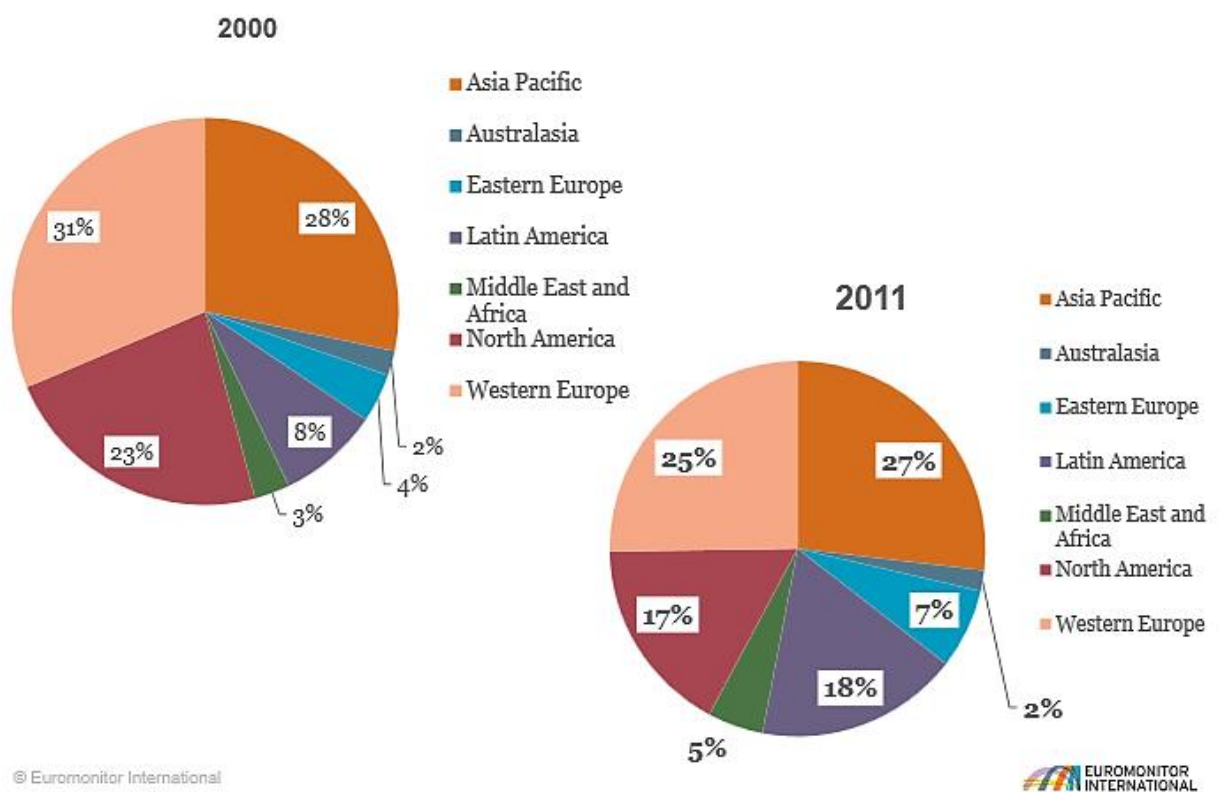

Fuente: Euromonitor International

Gráfico 2. Tamaño de mercado de Beauty and Personal Care por país excluyendo a México y Brasil

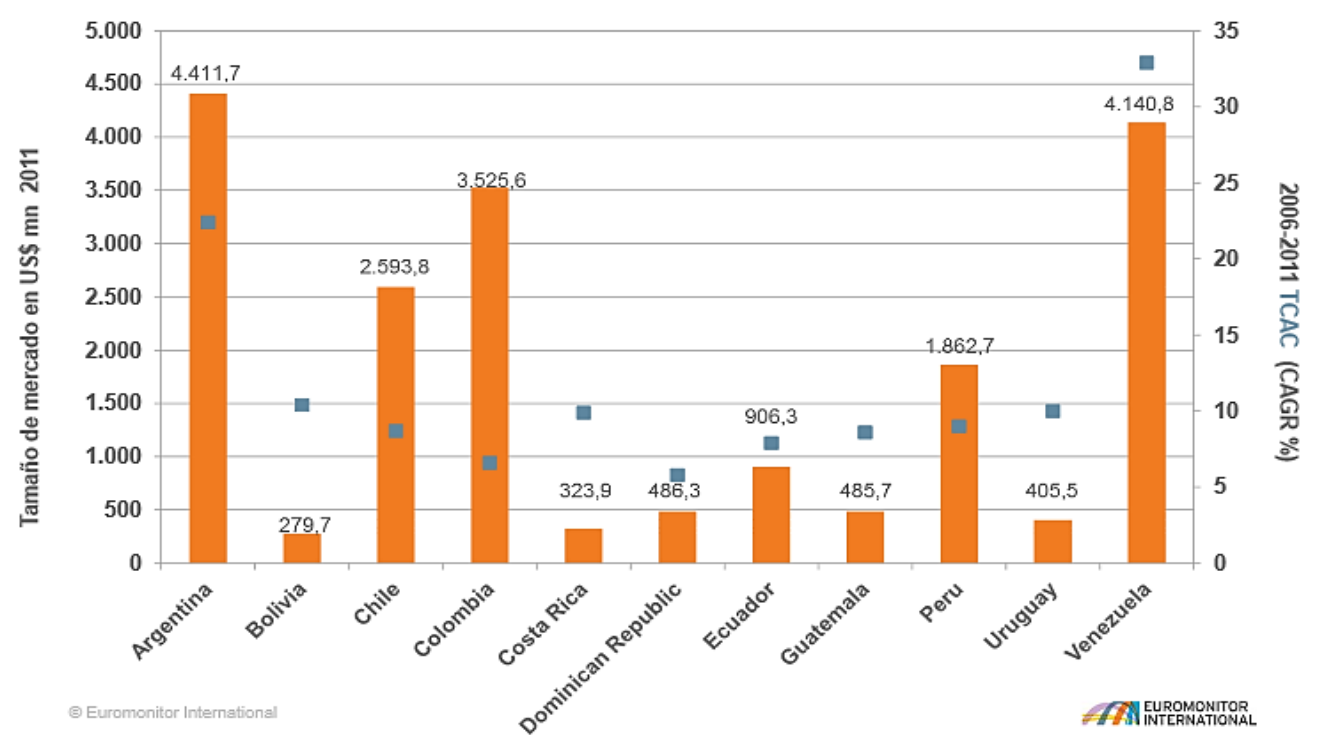

Fuente: Euromonitor International 
Gráfico 3. Proyección de crecimiento anual del ingreso disponible 2014-2019

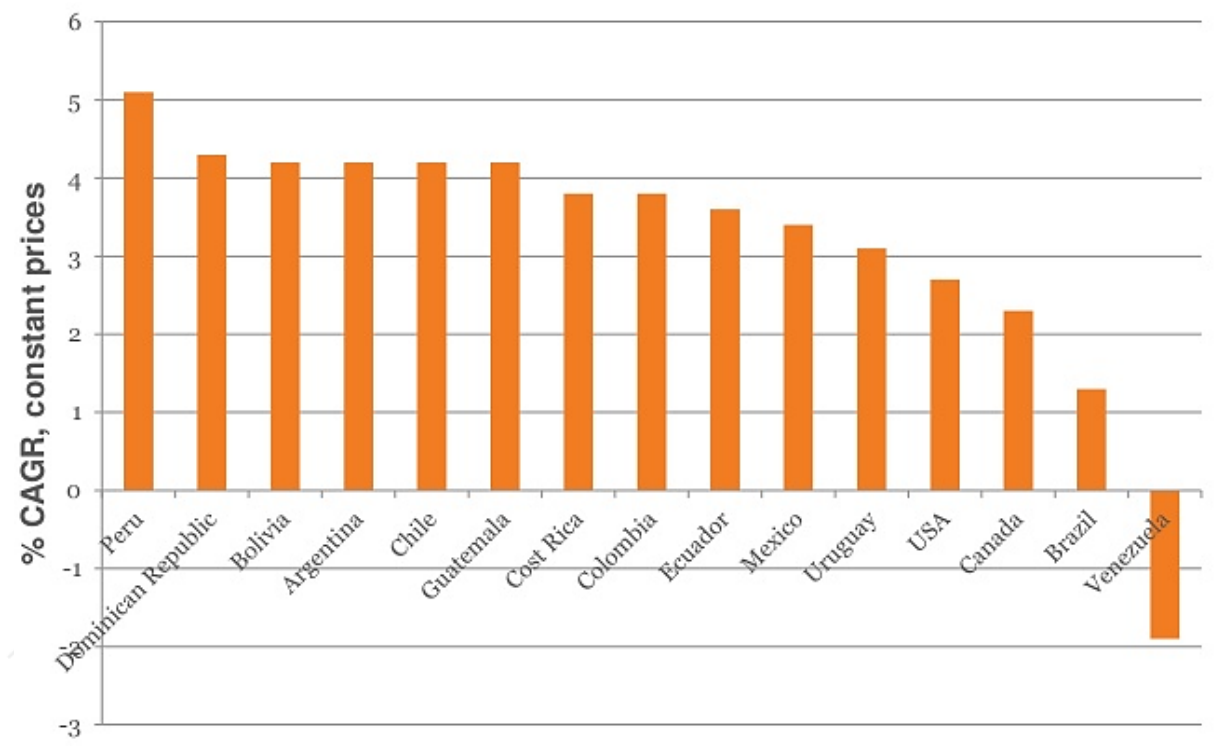

Fuente: Euromonitor International

La tendencia hacia la preferencia de productos naturales para el cuidado personal ha generado interés en la industria desde algún tiempo. Un aumento en la disponibilidad y popularidad de ésta, ha llevado a un número cada vez mayor de jugadores entrar en esta categoría. Si bien el crecimiento en la categoría ha sido impulsado por una parte por la demanda continua de fórmulas más inocuas para la piel, por otro lado, también ha sido promovido debido a la existencia de marcas que resaltan la naturalidad y funcionalidad de sus productos.

Asimismo, ha tenido una repercusión significativa el aumento de la familiaridad del consumidor con ciertos productos químicos percibidos como 'agresivos', y los cambios en los patrones de consumo por productos naturales con beneficios percibidos como más tangibles para los consumidores. (PROMPERÚ, 2013) 
Gráfico 4. Disposición a pagar por productos de belleza Sought-after green features - 2014

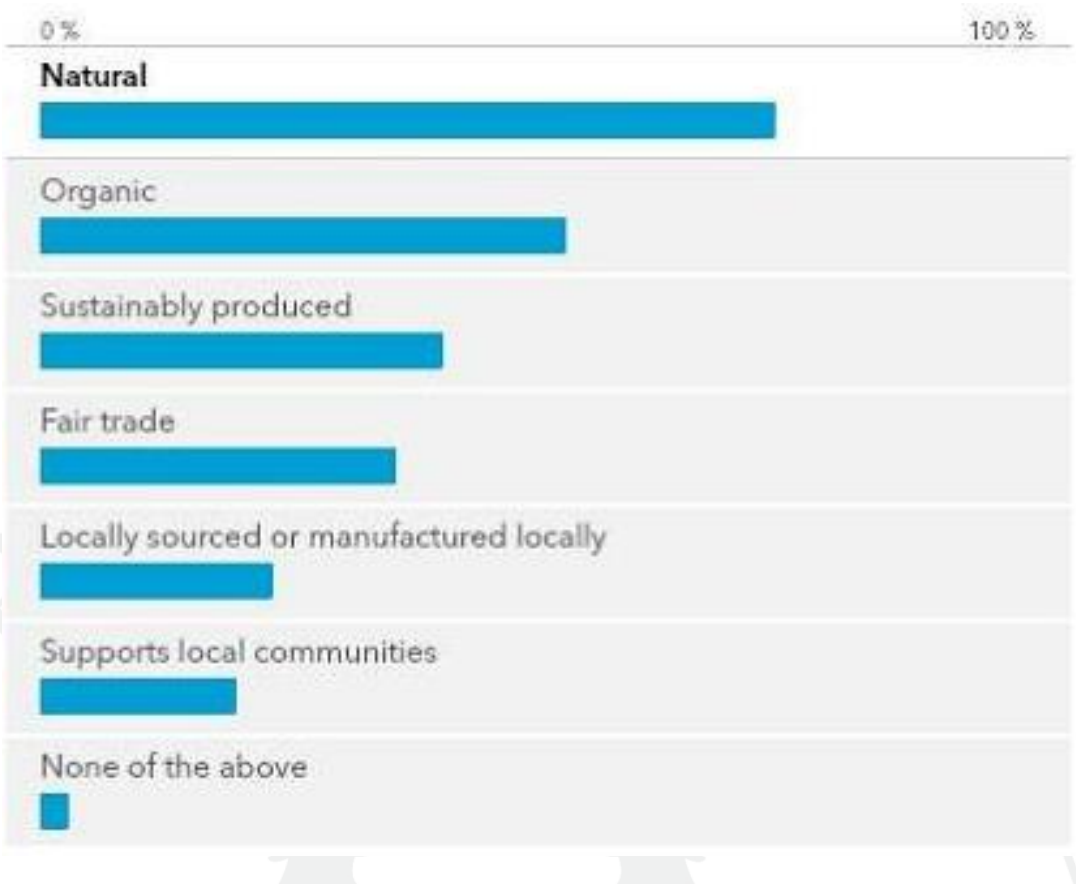

Fuente: Euromonitor International, 2014 (Encuesta a 2,129 personas)

Más allá de las diversas definiciones establecidos por diferentes organismos de certificación, la percepción común entre la mayoría de los consumidores de lo que es "natural" es mucho más amplio en la definición, e incluye productos de origen vegetal e inspirado en la naturaleza, las marcas de farmacia y cuidado de la piel naturales certificadas. (PROMPERÚ, 2013)

La necesidad de exportar esta loción corporal a base de aceite de sacha inchi orgánico, surge por la identificación de oportunidades de las nuevas tendencias en la región de América Latina hacia el consumo de productos de cuidado personal naturales. Si bien, éste es un producto potencial para ese segmento de mercado, el hecho de que sus propiedades y bondades no sean del todo populares, dificulta el proceso de comercialización, para lo que será fundamental 
un plan de internacionalización del producto basado en un modelo estratégico, que permita abarcar clientes dentro del mercado elegido, Colombia.

\subsection{Descripción de la idea de negocio como alternativa de solución.}

La idea de negocio es comercializar la loción corporal de sacha inchi, como producto parte del sector de belleza y cuidado personal colombiano. Para lo cual, se aprovechará la tendencia vigente hacia el consumo de productos cosméticos con contenido de ingredientes naturales, bajo la denominación de orgánico (en la actualidad un mercado muy amplio y en desarrollo).

El producto se denotará como una alternativa más dentro del mercado colombiano - que ya está saturado de productos de cuidado personal a base de insumos derivados químicos- pero con amplias propiedades beneficiadoras en aspectos de belleza y salud. Además se debe tener siempre claro el objetivo por el que este tipo de productos tiene éxito, que es buscar posicionarse como un producto $100 \%$ natural -diferenciado y de valor agregado- a base de ingredientes de la biodiversidad peruana, y que garantiza resultados positivos para el cuidado de la piel y la salud de la misma

\section{3. ¿Por qué la idea sería una oportunidad de negocio?}

Colombia ocupa el tercer puesto en el mundo de consumo de productos de belleza y aseo personal (El Mundo, 2014). Para este mercado el consumo de bienes de belleza y cuidado personal se mantiene dinámico, esto se relaciona 
habitualmente en diversos análisis con factores psicológicos y específicamente a la retribución personal y a la necesidad de destacar y lucir bien en un contexto social competido donde la buena apariencia, la presentación y el cuidado personal juegan un papel importante en el posicionamiento de la persona.

Estrechamente relacionado con esta línea está el avance en la cultura del cuidado personal tanto en mujeres como en hombres en aspectos como peluquería, estética y dermatología; el aumento de la población urbana, el crecimiento de la participación de la mujer en el mercado laboral; la variedad de segmentos a los que se atienden actualmente, que diferencia edades, intereses y niveles de ingreso; la diversidad de canales de distribución existentes e indudablemente, el crecimiento económico y el aumento en el nivel de ingreso per cápita, han contribuido al aumento del consumo y la demanda de productos nacionales y extranjeros. (América Económica, 2014)

Esta tendencia representa una gran oportunidad para la inserción de este producto; debido a que, según las estadísticas para el sector del cuidado de la piel, skin care, ha mostrado un crecimiento sostenido durante los últimos años y se prevé que continuará con este ritmo de crecimiento, asimismo, debemos hacer hincapié en el hecho de que el crecimiento de este sector es directamente proporcional al de su economía. (Euromonitor International, 2015)

Cabe resaltar que el producto en estudio destaca la naturalidad de su contenido. Los consumidores de esta categoría son más sensibles a la denominación de 
'natural', ya que hay una creencia en el poder de los ingredientes naturales ancestrales en la salud y el bienestar.

En el caso de los fabricantes de este sector destacan la importancia de la inclusión de ingredientes naturales extraídos de la región amazónica; debido a que existe la creencia de que al consumir este tipo de productos es una manera de aprovechar las propiedades ancestrales naturales de hierbas y frutas y para apoyar una estrategia de responsabilidad social, que es cada vez más importante para los consumidores más educados; de igual manera, resaltamos el hecho de la existencia de una demanda que no es satisfecha al 100\%, debido a la prevalencia de comercialización y venta de productos con un elevado contenido químico.

Asimismo, debemos resaltar que Colombia presenta la tasa más alta de participación de América Latina de las mujeres económicamente activas (Organización Internacional del Trabajo, 2014) con un 55,3\%, y en comparación con la mujer europea, el gasto en cosméticos es aproximadamente el doble; sobre todo la mujer que vive en los centros urbanos dedican gran parte de su dinero a la belleza y a la apariencia física. De igual manera, el consumo de cosméticos se da casi en un mismo nivel por parte de las mujeres con ingresos económicos como las estudiantes que no son económicamente independientes.

Además, el aceite está ganando popularidad en el sector de belleza y cuidado personal en ese país; las formulaciones acuosas que eran el formato más común en años anteriores para la industria de la belleza y cuidado personal están dando paso a las formulaciones a base de aceite. Los aceites esenciales de origen 
natural, como el aceite de almendras, se han utilizado durante muchos años en la industria de la belleza y el cuidado personal, sobre todo en las categorías tales como el cuidado del cabello, baño y ducha, cuidado de la piel. Varios productos de cuidado del cabello Bio-Oil y basados en aceites, están teniendo éxito debido a la subida de los ingredientes orgánicos (aceite de soja y otros aceites de semillas) en lugar de aceites minerales.

Los aceites minerales en productos tradicionales, tales como Johnson \& Johnson de aceite de bebé se siguen utilizando, pero en cantidades menores y están siendo sustituidos por sustancias más ligeras que reducen la sensación de grasa en la piel y el cabello. Una reducción en esta sensación grasienta abrió estos productos para su uso diario y reduce la necesidad de eliminar el exceso de producto de la piel con una toalla debido a mejores propiedades de absorción de la piel en la formulación.

Las perspectivas respecto al lanzamiento y consumo de formulaciones oleosas para la piel y cuidado del cabello son probables que crezcan durante los próximos años. Productos que combinan extractos naturales y antioxidantes (vitaminas) representarán una propuesta atractiva para los consumidores. Los aceites se continuarán desarrollando no sólo como base de formulación, sino también en la provisión de hidratación y beneficios de protección en función de su origen natural. Las posibilidades son muy abundantes, con la adición de ingredientes miscibles que reducen la necesidad de emulsiones gruesas y más densas. Mejora en formulaciones de aceite también se verá en productos de protección solar, ya sea con FPS alto o bajo para la protección o bronceado. 
Asimismo productos multifuncionales, que proporciona las ventajas de varios ingredientes naturales, tales como hidratantes, aclarando, reafirmante, etc. (Euromonitor International, 2015)

De igual manera, la idea de negocio surge bajo una visión enfocada en innovación y naturalidad, apoyada en diversos viajes realizados por el autor hacia México, Colombia y Venezuela.

Para concluir, debemos mencionar que nuestro país cuenta con los recursos naturales para llevar a cabo la producción, de igual manera nuestra empresa contará con la capacidad física instalada, capacidad económica y financiera, y de gestión exportadora que se requieren como competencias para desarrollar una oferta exportable de productos naturales de cuidado personal.

\subsection{Propuestas de innovación en el negocio.}

La innovación se encuentra en el proceso de impulsar y penetrar el mercado colombiano con un producto de cuidado personal diferenciado -específicamente de la piel- como es la loción corporal a base de aceite de sacha inchi orgánico; considerando sus propiedades, las mismas que aportan grandes beneficios en distintas industrias, fundamentalmente, en la industria cosmética, por los efectos que genera en sobre la salud de la piel; por lo tanto, al no ser muy conocido este insumo como potencial materia prima para el desarrollo de productos cosméticos, la oportunidad es latente. 
De igual manera, este producto al destacar por su naturalidad y funcionalidad, es un producto de valor agregado; útil para el usuario o consumidor final, debido a que contribuye en la mejora de su salud y cuidado personal (vitalidad de la piel), y genera bienestar en él. Será desarrollado bajo un esquema que lo hará competitivo tanto en calidad como en precio. 


\section{CAPITULO II. DESARROLLO DEL MARCO}

\section{EMPRESARIAL}

\subsection{Nombre, fecha de constitución y principales gerentes.}

La empresa "BIOPERÚ NATURAL PRODUCTS" fue constituida en Noviembre del 2014 para poner en marcha la idea de negocio de Lucia Gallori, Gerente General, que consiste en un negocio realizado de forma planificada y como resultado de una investigación detallada y plasmada en el presente Plan de Negocios.

\subsection{Forma societaria, capital social y accionistas.}

La empresa se constituye como una micro empresa y la forma societaria elegida es la Sociedad Anónima Cerrada (SAC), la cual se define como "aquella sociedad mercantil conformada por titulares que tienen una participación en el capital social mediante títulos o acciones".

Justificación de la forma societaria

- A diferencia de la Sociedad Anónima (SA), la cual es de participación ilimitada, la SAC permite un máximo de 20 accionistas, característica que brinda seguridad a cada socio del proyecto.

- En relación al punto anterior, si un accionista desease retirarse de la sociedad, podrá hacerlo mediante una transferencia de acciones a otro accionista de la sociedad a un tercero, siempre y cuando notifique 
previamente a todos los miembros de la sociedad y estos aprueban la transacción.

- En el caso de la responsabilidad de los socios o accionistas, estos no responden personalmente (patrimonio propio) por deudas sociales, en caso cierre el negocio.

- A pesar de que cuenta con un número reducido de accionistas, no es limitada la posibilidad de manejar grandes capitales.

- Finalmente, la SAC está mejor reforzada al proceder de la SA; las entidades financieras le dan mayor preferencia que a otras formas societarias (por ejemplo: SRL).

\subsection{Régimen tributario y laboral.}

\section{Legislación arancelaria-tributaria:}

La Ley General de Aduanas aprobada por el Decreto Legislativo $N^{\circ}$. 821, modificada posteriormente por el Decreto Legislativo $\mathrm{N}^{\circ}$. 809, define la exportación como el "régimen aduanero aplicable a las mercancías en libre circulación que salen del territorio aduanero para su uso o consumo definitivo en el exterior".

\section{- Impuesto a la Renta:}

\section{Supuestos tributarios Micro empresas}

Nuestra empresa aplica al Régimen Laboral Especial como Micro empresa por su volumen anual de ventas. No mayor de 150 UIT (una UIT en el 2014 es de S/. 3,880 nuevos soles).Es decir ventas anuales menores de S/. 570,000 nuevos soles. 
Tabla 1. Régimen Especial de Renta (RER)

Referencia Régimen de la microempresa

Impuestos SUNAT $\quad 1.5 \%$ de los ingresos

(SUNAT, 2015)

\section{Impulso a las micros, pequeñas y medianas empresas}

Respecto a la naturaleza y permanencia en el Régimen Laboral Especial, se señala que es permanente y únicamente aplicable a las micros y pequeñas empresas. Las microempresas que durante dos años consecutivos superen el nivel de ventas establecido en la presente ley, podrán conservar por un año más el mismo Régimen Laboral y para el caso de las pequeñas empresas será de tres.

\section{- Impuesto General a las Ventas:}

Las operaciones de compra local están sujetas al pago del Impuesto General a las Ventas, lo que nos genera el beneficio del crédito fiscal, el mismo que en el caso de exportadores no se puede hacer efectivo. Motivo por el cual el Estado permite ejercer el derecho de recuperar dicho crédito, conocido como saldo a favor del exportador.

\section{- Drawback (Restitución de Aranceles)}

Es un beneficio aduanero para incentivar las exportaciones, al cual nos podemos acoger. Este régimen nos permite solicitar el reembolso del 3\% sobre el valor FOB neto exportado; siempre y cuando, se cumpla los requisitos de ley, estos son i) Que los costos de producción se incrementen por los derechos de importación de elementos incorporados en los procesos productivos y/o ii) que parte de la producción a exportar sea encargada a terceros mediante un acuerdo entre ambas empresas. 
Carga impositiva tributaria laboral

\section{De la Empresa:}

- Remuneración mínima vital en el 2014- S/. 750.

- Compensación por tiempo de servicios (CTS)- No aplica.

- Gratificación de Fiestas Patrias y Navidad- No aplica.

- Seguro Social Público- EsSalud 9\% sobre Remuneración Bruta.

- Participación en utilidades- No aplica.

- Vacaciones- 15 días.

\section{Del Trabajador}

- AFP (Administradora de Fondos de Pensiones) 10\% + Comisión Variable sobre Remuneración Bruta.

- SNP (Sistema Nacional de Pensiones) 13\% sobre Remuneración Bruta.

- Renta de Quinta Categoría corresponde a los ingresos percibidos de una persona natural bajo una modalidad de contrato de dependencia y que se encuentra incluido en la planilla de la empresa.

\subsection{Actividad, sector y estructura organizacional.}

El giro de negocio es la producción y comercialización internacional de Loción Corporal a base de aceite de sacha inchi orgánico, con destino objetivo la ciudad de Bogotá en Colombia; en particular, el producto será dirigido al mercado colombiano, reconocido por su liderazgo en el sector cosmética; y por la tendencia creciente en el consumo de productos de belleza naturales y caracterizados por contener materias primas orgánicas, por medio del canal de comercialización “Spas y Tiendas Especializadas” en Colombia. 


\section{Estructura Organizativa}

Gráfico 5. Organigrama de la estructura organizativa de la empresa

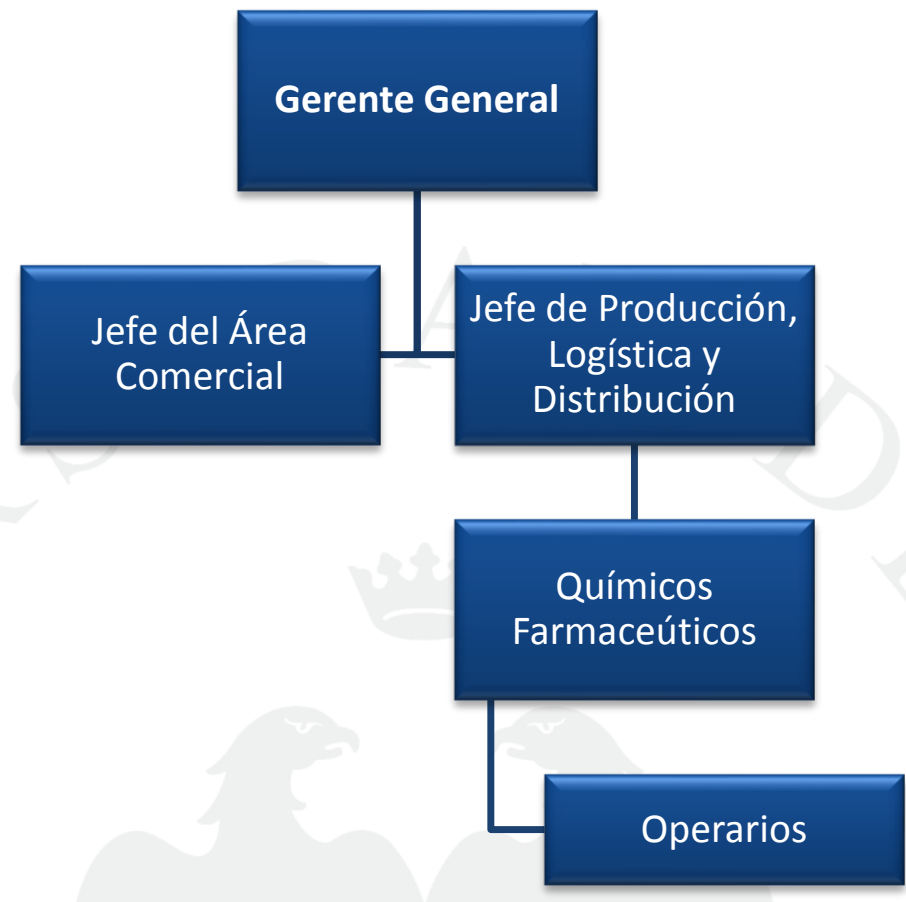

Elaboración Propia

\section{Descripción del organigrama funcional}

La estructura organizacional de la empresa estará constituida por la Gerente General que es la unidad formadora de la empresa, en este caso, M. Lucía Gallori Salazar, encargada de planificar, organizar, dirigir, controlar, coordinar de manera estratégica y a nivel integral la empresa. Asimismo, el negocio contará con un jefe del área comercial que manejará las estrategias de ventas y plan de mercadeo, marketing mix y captación de nuevos clientes en el mercado colombiano.

Por otro lado, encontramos al jefe de producción, logística y distribución, que será el encargado de procesar las órdenes de compra, manejará el control de 
consumo de insumos, proyectará la producción, gestionará la distribución de los productos, etc. Éste tendrá a su cargo la supervisión de los químicos farmacéuticos de la Facultad de Farmacia y Bioquímica de la UNMS, encargados de la formulación y preparación de las lociones corporales, apoyados por los operarios de planta en el manejo de máquinas, procesos de llenado y etiquetado.

\subsection{Visión, misión, valores.}

\section{Visión}

Para el 2020 debemos ser reconocidos como la empresa exportadora líder en Latinoamérica de productos de cuidado personal, de gran valor agregado, a base de ingredientes orgánicos y naturales de la biodiversidad peruana.

\section{Misión}

Desarrollar productos que destacan por su calidad, innovación y de propiedades tangibles, a base de los mejores ingredientes naturales del Perú, resguardando y perseverando la biodiversidad y el medio ambiente.

\section{Valores}

$\checkmark$ Excelencia en la Gestión:

Es la preocupación por lograr o superar los estándares de excelencia establecidos. Incluye el interés por fijarse metas demandantes y la 
disposición de dedicar tiempo para mejorar el rendimiento, ser innovador y perseverar en el logro de un propósito.

$\checkmark$ Responsabilidad:

Es el claro conocimiento de las situaciones, realidades y un compromiso con las consecuencias personales e institucionales de asumir una actitud, de ejecutar una acción o en la toma de decisiones.

Respeto:

Actitud de consideración hacia las demás posiciones, especialmente hacia el otro. Se genera cuando se involucra el concepto de persona, como elemento generador de opciones y acciones en beneficio propio e institucional, que merece atención y reconocimiento.

\section{$\checkmark$ Honestidad:}

Es la cualidad humana que consiste en comportarse y expresarse con sinceridad, coherencia y responsabilidad consigo mismo y con los demás, en relación con sus funciones, con la calidad de su trabajo y el compromiso con la EMPRESA y la COMUNIDAD. 


\section{CAPITULO III. ESTUDIO DE MERCADO EXPORTACIÓN}

\subsection{Definición del producto o servicio.}

\section{Propuesta de valor del producto}

La loción corporal de sacha inchi y verbena, se constituye como un producto innovador y diferenciado; se presenta como una alternativa -con gran potencial dirigida, principalmente, al público femenino colombiano- ante la impetuosa necesidad que se muestra como una tendencia en los últimos años en este país, y la demanda de productos de belleza y cuidado personal a base de ingredientes naturales y exóticos, derivados de la biodiversidad.

Esta loción corporal ofrece un sinnúmero de beneficios para el cuidado de la piel, descritos con mayor precisión líneas abajo.

El producto, al ser diferenciado, con una propuesta de valor única, tiene ventajas sobre sus competidores en el mercado de destino; a pesar que grandes empresas multinacionales compiten en el sector y la industria de belleza y cuidado personal en Colombia, tienen un enfoque más industrializado, y según datos del Consejo de Asociaciones de la Industria de Cosméticos Latinoamericana (CASIC), su oferta de productos es percibida como 'más procesada' y con 'mayor contenido de insumos químicos'. No obstante, Natura, en los últimos años ha querido cambiar y revolucionar este enfoque, y busca posicionarse como una marca más natural. Nuestro producto al ser 
'semi-artesanal' y de ingredientes naturales certificados cuenta con una gran ventaja en el mercado. El producto será vendido bajo la Marca Propia 'Natural Sense' a través de un distribuidor ad-hoc a la manera cómo queremos posicionar el producto, enfocado a un nicho de mercado, a las principales tiendas especializadas, Spas y Centros de Belleza de Colombia.

\section{Sacha Inchi \& Verbena Body Lotion}

\section{Características físicas}

Ligera crema de cuerpo con refrescante aroma Verbena contiene aceite de Sacha inchi $100 \%$ natural y orgánico, una fuente natural de Omega 3 y 6, que nutre e hidrata aún las pieles más secas.

Contenido extra de vitaminas A y E; mejora la textura de la piel y la humecta durante todo el día.

Presentación Sugerida: $250 \mathrm{~g}$.

\section{Ingredientes}

Water, Glyceryl, Myristyl myristate, Cetyl Alcohol, Isopropyl Myristate, Plukenetia Volubilis Seed Oil, Honey Extract, Retinyl Palmitate \& Tocopheryl Acetate, Methylparaben, Disodium EDTA, Verbena Fragrance \& Citral.

\section{Modo de Uso}

Aplicar todos los días después del baño. 


\section{Propiedades del Producto}

Según estudios del Instituto de Investigaciones de la Amazonía Peruana, el aceite de sacha inchi contiene antioxidantes vitamina A y alfa-tocoferol vitamina E. Especialmente indicado para pieles sensibles, deshidratadas, secas, incluyendo inflamaciones e irritaciones (Rioja, 2012). La vitamina E es un componente activo de la regeneración y los ácidos grasos insaturados nutren, previenen y tratan los problemas de la piel. La vitamina A contiene BetaCaroteno un elemento protege y nutre de piel de la influencia negativa del sol (fotoprotector), asimismo ayuda a reconstruir el colágeno de la piel.

Los aceites se diferencian entre sí por sus contenidos de AGE (Ácidos Grasos Escenciales):

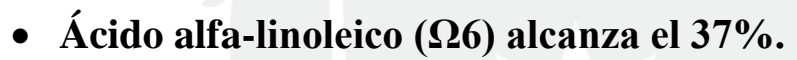

- Ácido alfa-linolénico ( $\Omega 3$ ) alcanza hasta el $58 \%$.

Gráfico 6. Contenidos excepcionales de AGE presentes en el aceite de sacha inchi

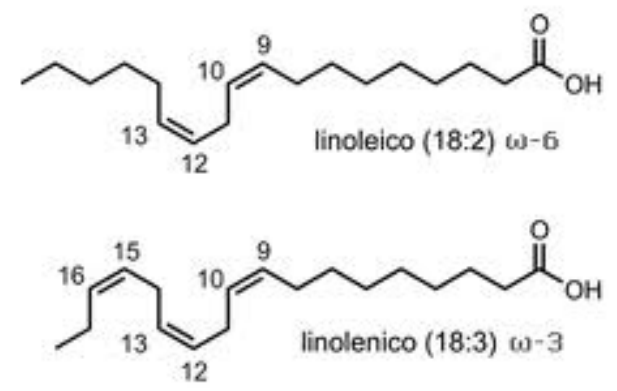

Fuente: Cosmética Natural Kem's S.A.C. 
Estos son contenidos que se presentan de manera excepcional en el aceite obtenido de las semillas de la planta Sacha Inchi.

Se ha comprobado científicamente que el AGE más beneficioso para la piel es el Ácido alfa-linolénico ( $\mathbf{\Omega 3})$, y el Sacha Inchi contiene uno de los más elevados porcentajes de este principio activo que es precursor importante de las ceramidas e indispensable para la función como barrera de la piel. Asimismo, revitaliza la piel, minimizando imperfecciones. (Cosmética Natural Kem's S.A.C., s.f.)

Éstos ácidos grasos esenciales han demostrado su utilidad en la restauración de la piel seca, así como los efectos terapéuticos en los diversos desordenes de la piel, tales como dermatitis atípica, psoriasis y acné.

La aplicación local de los ácidos grasos poliinsaturados conducen a la:

1. Disminución de la perdida de agua transepidermal.

2. Normalización de la función como barrera de la piel.

3. Mejora el proceso de queratinización.

Por último, su contenido de aceite esencial de verbena es utilizado en la aromaterapia; ya que, contiene propiedades relajantes y sedantes, para combatir naturalmente el estrés, la ansiedad y otras patologías asociadas. 
Detalle de la Subpartida arancelaria para el producto en análisis

Tabla 2. Partida Arancelaria 33.04.99 y su respectiva descripción

\begin{tabular}{|l|l|}
\hline PARTIDA & DESCRIPCIÓN DE LA PARTIDA \\
\hline 3304990000 & $\begin{array}{l}\text { Preparaciones de belleza, maquillaje y para el cuidado de la } \\
\text { piel, excepto los medicamentos, incluidas las preparaciones } \\
\text { anti-solares y las bronceadoras; preparaciones para } \\
\text { manicuras o pedicuros, hidratantes corporales. }\end{array}$ \\
\hline
\end{tabular}

Fuente: SUNAT

Elaboración Propia 


\subsection{Selección del mercado internacional.}

\section{Test de Selección del Mercado Objetivo}

El Test de Selección del Mercado Objetivo tiene como finalidad evaluar la idoneidad de uno de los tres mercados potenciales propuestos. A partir de indicadores y parámetros objetivos, y de manera comparativa, se evalúan cuantitativa y cualitativamente las características de cada país en los niveles tanto económicos, comerciales, competitivos y culturales; dando como resultado la elección del mercado con el mayor puntaje entre sus pares.

\begin{tabular}{|c|c|c|c|c|c|c|c|}
\hline & \multirow{2}{*}{$\begin{array}{l}\text { Categoría 1: Compradores, } \\
\text { Capacidad de compra e Importadores }\end{array}$} & \multicolumn{2}{|c|}{ COLOMBIA } & \multicolumn{2}{|c|}{ EE.UU } & \multicolumn{2}{|c|}{ MÉXICO } \\
\hline & & VALOR & CALIFICACIÓN & VALOR & CALIFICACIÓN & VALOR & CALIFICACIÓN \\
\hline \multirow{2}{*}{1} & $\begin{array}{l}\text { Población } \\
\end{array}$ & $48^{\prime} 203,405$ & 1 & $316^{\prime} 128,839$ & 3 & $112^{\prime} 336,538$ & 2 \\
\hline & PBI per cápita (USD) & $7,831.22$ & 1 & $53,042.00$ & 3 & $10,307.30$ & 2 \\
\hline \multirow{2}{*}{2} & Importaciones 2014 (Miles de USD) & 13,064 & 3 & 964 & 2 & 814 & 1 \\
\hline & Importaciones $2014(\mathrm{TN})$ & 1016 & 3 & 59 & 2 & 35 & 1 \\
\hline \multirow{2}{*}{3} & VAR 2013/2014 (USD) & $21 \%$ & 1 & $125 \%$ & 3 & $54 \%$ & 2 \\
\hline & VAR 2013/2014 (TN) & $9 \%$ & 1 & $556 \%$ & 3 & $40 \%$ & 2 \\
\hline 4 & $\begin{array}{c}\text { Crecimiento estimado del consumo de cremas } \\
\text { corporales en valor (Source: } \\
\text { Euromonitor International) }\end{array}$ & $3 \%$ & 3 & $3 \%$ & 3 & $3 \%$ & 3 \\
\hline \multicolumn{2}{|r|}{$\begin{array}{l}\text { RESULTADO } \\
\end{array}$} & & 13 & & 19 & & 13 \\
\hline
\end{tabular}

Dentro de la primera categoría se evalúan los países y se asigna un puntaje del 1 al 3 por cada indicador -representando 3 el puntaje para el país más atractivo- según su nivel de población, PBI per cápita, el valor de las importaciones de la partida y el crecimiento de las importaciones en términos relativos tanto de la partida como del sector. En esta categoría el país más atractivo resulta ser EE.UU, considerando que cuenta con una población que supera los 316 millones de habitantes, representando uno de los más grandes mercados a 
nivel mundial y de gran poder adquisitivo; con un crecimiento de las importaciones de la partida 3304990000 de alrededor de $125 \%$ en términos de valor 556\% en términos de cantidad, que refleja un mercado en proceso de expansión y una gran oportunidad de penetración.

\begin{tabular}{|c|c|c|c|c|c|c|c|}
\hline & \multirow{2}{*}{ Categoría 2: Acceso a Mercado y Ventajas Comerciales } & \multicolumn{2}{|c|}{ COLOMBIA } & \multicolumn{2}{|r|}{ EE.UU } & \multicolumn{2}{|c|}{ MÉXICO } \\
\hline & & VALOR & CALIFICACIÓN & VALOR & CALIFICACIÓN & VALOR & CALIFICACIÓN \\
\hline 5 & Arancel General & $0.00 \%$ & 3 & $0.00 \%$ & 3 & $17.50 \%$ & 1 \\
\hline \multirow{2}{*}{6} & Barreras no Arancelarias & No & 3 & No & 3 & No & 3 \\
\hline & Regulaciones Técnicas & Medio & 2 & Alto & 1 & Medio & 2 \\
\hline 7 & Acceso a la Información es fácil & Alto & 3 & Medio & 2 & Medio & 2 \\
\hline 8 & Número de Consejeros Comerciales & 1 & 1 & 4 & 3 & 1 & 1 \\
\hline \multirow[t]{2}{*}{9} & Ferias comerciales especializadas (Belleza y Cuidado Personal) & SÍ & 3 & Sí & 3 & SÍ & 3 \\
\hline & RESULTADO & & 15 & & 15 & & 12 \\
\hline
\end{tabular}

Respecto a la segunda categoría, se determinaron puntajes para indicadores que evalúan la accesibilidad al mercado de destino de las exportaciones y las ventajas comerciales que se tienen con dicho país; a nivel de aranceles aplicados, barreras no arancelarias, regulaciones técnicas, presencia de oficinas comerciales en el extranjero y ferias especializadas en el sector. Para esta categoría tanto Colombia como EE.UU obtuvieron el mismo puntaje, ambas cuentan con un Ad Valorem del 0\% para la importación de esta partida lo que no encarecerá el precio del producto, manteniéndonos competitivos. Asimismo, no existen cuotas a la importación para estos productos, se constituyen como mercados abiertos al comercio exterior, con libre acceso a la información y un número significativo de Ferias Comerciales Especializadas en la industrial y el sector de Belleza y Cuidado Personal. 


\begin{tabular}{|c|c|c|c|c|c|c|c|}
\hline \multirow{2}{*}{\multicolumn{2}{|c|}{$\begin{array}{c}\text { Categoría 3: Canales de Distribución } \\
\text { y Logística Exportadora }\end{array}$}} & \multicolumn{2}{|c|}{ COLOMBIA } & \multicolumn{2}{|c|}{ EE.UU } & \multicolumn{2}{|c|}{ MÉXICO } \\
\hline & & \multirow{2}{*}{$\begin{array}{c}\text { VALOR } \\
\text { Alto }\end{array}$} & \multirow{2}{*}{$\begin{array}{c}\text { CALIFICACIÓN } \\
3 \\
\end{array}$} & \multirow{2}{*}{$\begin{array}{l}\text { VALOR } \\
\text { Medio }\end{array}$} & \multirow{2}{*}{$\begin{array}{c}\begin{array}{c}\text { CALIFICACIÓ } \\
\mathbf{N}\end{array} \\
2\end{array}$} & \multirow{2}{*}{$\begin{array}{c}\text { VALOR } \\
\text { Medio }\end{array}$} & \multirow{2}{*}{$\begin{array}{c}\text { CALIFICACIC } \\
\mathbf{N} \\
2\end{array}$} \\
\hline 10 & $\begin{array}{l}\text { Conocimiento de los canales de } \\
\text { distribución es amplio }\end{array}$ & & & & & & \\
\hline 11 & Tiempo del Transporte Internacional & 10-12 días & 3 & 19-21 días & 1 & 15-17 días & 2 \\
\hline 12 & Índice de Desempeño Logístico & 2,64 & 1 & 3,92 & 3 & 3,13 & 2 \\
\hline 14 & Requerimientos de envase y embalaje & Medio & 2 & Alto & 1 & Medio & 2 \\
\hline 15 & Conocimientos de contratos de Compra-Venta internacional & Medio & 2 & Alto & 1 & Medio & 2 \\
\hline & RESULTADO & & 13 & & 9 & & 12 \\
\hline
\end{tabular}

Para la tercera categoría que se tomó en consideración para el análisis de selección del mercado objetivo, se evaluaron aspectos relacionados con los canales de distribución en el mercado de destino y la logística exportadora para con ese país. Colombia obtuvo el mayor puntaje, teniendo en cuenta que al ser un país limítrofe, ubicado en Sudamérica, los temas logísticos resultan más sencillos y menos costosos; además se tiene un amplio conocimiento de los canales de distribución (que guardan cierta similitud con nuestro país); asimismo, las regulaciones con respecto a temas de envase y embalaje son manejables y no implican seguir con procedimientos más engorrosos y costosos, como en el caso para Estados Unidos. 


\begin{tabular}{|c|c|c|c|c|c|c|c|}
\hline \multirow{2}{*}{\multicolumn{2}{|c|}{ Categoría 4: Intensidad de la Competencia }} & \multicolumn{2}{|c|}{ COLOMBIA } & \multicolumn{2}{|c|}{ EE.UU } & \multicolumn{2}{|c|}{ MÉXICO } \\
\hline & & VALOR & CALIFICACIÓN & VALOR & CALIFICACIÓN & VALOR & CALIFICACIÓN \\
\hline 16 & $\begin{array}{l}\text { Productores locales no tienen influencia sobre } \\
\text { las políticas comerciales del país }\end{array}$ & $\begin{array}{c}\text { NO } \\
\text { INFLUENCIA }\end{array}$ & 3 & $\begin{array}{c}\text { NO } \\
\text { INFLUENCIA }\end{array}$ & 3 & $\begin{array}{c}\text { NO } \\
\text { INFLUENCIA }\end{array}$ & 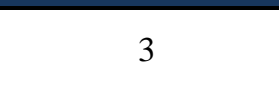 \\
\hline 17 & Competencia Internacional & 0 & 3 & 0 & 3 & 0 & 3 \\
\hline 18 & $\begin{array}{l}\text { Número de empresas peruanas que exportan a } \\
\text { ese país en el } 2014\end{array}$ & 10 & 2 & 12 & 1 & 4 & 3 \\
\hline \multicolumn{2}{|r|}{ RESULTADO } & & 8 & & 7 & & 9 \\
\hline
\end{tabular}

En lo referido a la cuarta categoría, se evaluó la intensidad de la competencia; obteniendo México el mayor puntaje, considerando que sus productores no tienen influencia sobre las políticas comerciales del país. No existe ningún tipo de competencia nacional o internacional directa, debido a que ninguna empresa a nivel mundial exporta una loción corporal a base de aceite de sacha inchi orgánico hacia ese país. Por último, el número de empresas peruanas que exportaron a ese país en el 2014 bajo la partida 3304990000 es menor comparado con Colombia y Estados Unidos, lo que refleja una oportunidad para entrar al mercado mexicano siendo pioneros con este tipo de productos. 


\begin{tabular}{|c|c|c|c|c|c|c|c|}
\hline \multirow{2}{*}{ Categoría 5: Distancia Sicológica } & \multicolumn{2}{c|}{ COLOMBIA } & \multicolumn{2}{c|}{ EE.UU } & \multicolumn{2}{c|}{ MÉXICO } \\
\cline { 3 - 7 } & VALOR & CALIFICACIÓN & VALOR & CALIFICACIÓN & VALOR & CALIFICACIÓN \\
\hline 19 & Experiencia en el mercado de destino & NO & 1 & NO & 1 & NO & 1 \\
\hline 20 & Afinidad cultural y buen trato con el país & Alto & 3 & Medio & 2 & Alto & 3 \\
\hline 21 & Contactos de negocios prevalecidos & Sí & 3 & NO & 1 & NO & 1 \\
\hline 22 & $\begin{array}{c}\text { Mi producto puede ser adaptado a los } \\
\text { requerimientos del mercado, de ser } \\
\text { necesario, sin mayor dificultad }\end{array}$ & Alto & 3 & Medio & 2 & Medio & 2 \\
\hline 23 & Idioma & Español & 3 & $\begin{array}{c}\text { Inglés } \\
\text { Americano }\end{array}$ & 1 & Español & 3 \\
\hline & RESULTADO & & $\mathbf{1 3}$ & & 7 & & \\
\hline
\end{tabular}

Finalmente, en la categoría número cinco, se asignaron puntajes a indicadores relacionados con la distancia sicológica que se tiene con cada uno de los países evaluados; relacionados directamente a temas de afinidad social y cultural, obteniendo Colombia el mayor puntaje entre sus pares. 
Tabla 3. Resumen del Test de Selección del Mercado Objetivo

\begin{tabular}{|c|c|c|c|}
\cline { 2 - 4 } \multicolumn{1}{c|}{} & COLOMBIA & EE.UU & MÉXICO \\
\hline $\begin{array}{c}\text { Categoría 1: Compradores, } \\
\text { Capacidad de compra e } \\
\text { Importadores }\end{array}$ & 13 & 19 & 13 \\
\hline $\begin{array}{c}\text { Categoría 2: Acceso a Mercado } \\
\text { y Ventajas Comerciales }\end{array}$ & 15 & 15 & 12 \\
\hline $\begin{array}{c}\text { Categoría 3: Canales de } \\
\text { Distribución y Logística } \\
\text { Exportadora }\end{array}$ & 13 & 9 & 12 \\
\hline $\begin{array}{c}\text { Categoría 4: Intensidad de la } \\
\text { Competencia }\end{array}$ & 8 & 7 & 10 \\
\hline $\begin{array}{c}\text { Categoría 5: Distancia } \\
\text { Sicológica }\end{array}$ & 13 & 7 & $\mathbf{5 6}$ \\
\hline TOTALES & $\mathbf{6 2}$ & $\mathbf{5 7}$ & 9 \\
\hline
\end{tabular}

Los resultados del Test de Selección de Mercado Objetivo apuntan a Colombia como el país de destino más idóneo para nuestro producto loción corporal de sacha inchi; debido a la facilidad de acceso al mercado y las ventajas comerciales que tiene el Perú para con dicho país, la cercanía a nivel logístico, menor intensidad de la competencia y afinidad cultural e idiomática. Esto se puede ver reflejado en la siguiente gráfica:

Gráfica 7. Resultado del test de mercado

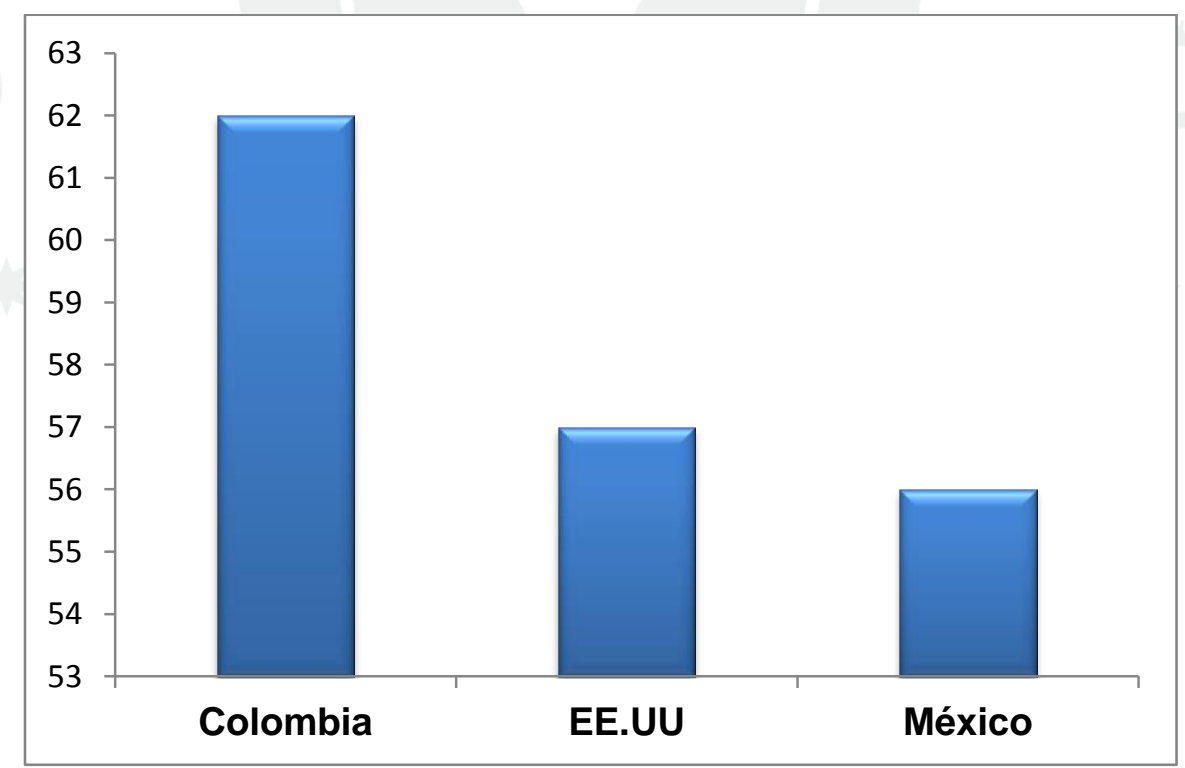

Elaboración Propia 


\subsection{Análisis de la demanda.}

\subsubsection{Distribución geográfica del mercado de consumo.}

En Colombia funcionan 300 empresas dedicadas a la fabricación de productos de belleza, que generan un poco más de un millón de empleos directos e indirectos. (Castro, 2015)

Las plantas de dichas empresas se concentran en Bogotá (40\%), Medellín (30\%) y Cali (30\%), señala. Siendo éstas las ciudades de mayor consumo de este tipo de productos.

Según el Dane, los 17 millones de hogares colombianos invirtieron el último año un poco más de tres billones de pesos en productos de belleza y aseo personal. Asimismo, el mercado de estos productos llega a más de 4.000 millones de dólares en promedio, con un crecimiento de 2,8 por ciento anual; no obstante, dado el desarrollo de nuevos proyectos en esta industria se tiene proyectado que para el 2018 el crecimiento anual pueda llegar al 5,5 por ciento.

El proyecto tiene como mercado objetivo la ciudad de Bogotá-Colombia; esta ciudad tiene más de 2.5 millones de habitantes, y es la principal zona de consumo de artículos de belleza y cuidado personal. Asimismo, es aquí donde están localizadas las principales empresas, tanto productoras como comercializadoras de este tipo de productos; y en donde se concentra la mayor cantidad de mujeres económicamente activas y de un 
nivel socioeconómico medio-alto (target de mercado hacia el cual nuestra empresa está enfocada).

Respecto a los factores que pueden tener incidencia en el proceso de exportación de nuestro producto, a nivel de infraestructura de transporte y almacenamiento, Bogotá cuenta con una Red Vial interconectada y desarrollada; la principal entrada a Colombia es a través del Puerto de Buenaventura, luego se trasladará la mercancía a través del Corredor Vial Buenaventura-Bogotá. (PROMPERÚ, 2014)

\subsubsection{Caracterización de la demanda}

La belleza es un mercado muy dinámico y de gran importancia en Colombia, una mujer tiene un gasto promedio de $\$ 960.000$ al año, equivalente a unos USD 316.03.

El mercado de la belleza en Colombia mueve más de $\$ 600.000$ millones (USD 195.276 millones) al año en tratamientos no quirúrgicos, así lo reveló un estudio de mercado realizado por Raddar, siendo Manizales, Bogotá, Cali, Barranquilla, Cartagena y Medellín las ciudades con mayor dinamismo. (Mercado de Dinero, 2014)

De acuerdo con Armesso -empresa colombiana del sector cosmético, estético y farmacéutico- a pesar de las noticias negativas con respecto a la manipulación y mal asesoramiento en la aplicación de los mismos, los fabricantes de productos ven el mercado con una mayor actividad 
comercial, lo que ha generado cambios en la manera de promocionar sus productos.

Asimismo esta compañía asegura que el dinamismo del sector es considerado importante, pues a nivel empresarial la Cámara de Comercio de Bogotá en el año 2013, registró 10.731 personas naturales y jurídicas con matrículas activas cuyo objeto social es fabricar artículos de peluquería y tratamientos de belleza.

Además, el estudio también reveló que a nivel dermatológico, el 77\% de los consumidores de productos de belleza se encuentran en Bogotá, Medellín, Cali, Barranquilla. La demanda de este sector se está focalizada especialmente en las mujeres entre los 25 y 45 años de ingresos medios y altos. No obstante, Raddar afirma que la mayor solicitud de éste tipo de servicios es realizada por ejecutivas de alto nivel económico y profesional. (Mercado de Dinero, 2014)

Por otra parte la entidad encargada de revelar los datos, aseguró que una colombiana gasta en promedio $\$ 960.000$ (USD 316.03) al año, si semanalmente destina $\$ 20.000$ (USD 6-7) en peluquería y otros servicios prestados por salones de belleza y sumando tratamientos estéticos, por el orden de los \$1.5 millones (UDS 400-500). También evidenció que el género masculino se suma a la demanda como un mercado en ascenso, pues en los últimos dos años consumió cerca de \$18 mil millones (USD 5.8 millones) en tratamientos estéticos. (Mercado de Dinero, 2014) 


\subsubsection{Proyección de la demanda internacional}

Para efectuar la proyección de la demanda internacional se han recabado datos del Departamento Administrativo Nacional de Estadística (DANE, Colombia) respecto a las proyecciones de población para los años 20152020; particularmente del total de mujeres de entre 25 hasta 45 años de la ciudad de Bogotá, de los estratos socioeconómicos medio-alto.

Se debe de tener en cuenta la existencia de una demanda de mercado insatisfecha; debido a que, a pesar que un gran número de empresas multinacionales pueden suplir el mercado de cuidado personal, estas empresas tienen una producción industrial a gran escala, empleando en su mayoría insumos químicos y aceites minerales para la fabricación de sus productos.

Es ahí donde al surgir una nueva tendencia orientada al uso de productos a base de insumos naturales, por la creencia y una mayor confianza de las propiedades derivadas de estos, está la oportunidad para nuestra empresa, de atacar con una estrategia de diferenciación, que resalta la naturalidad del contenido del producto, su funcionalidad y propiedades.

Haciendo uso del programa MINITAB y tomando como fuente data histórica mensual recopilada en TradeMap de los últimos 5 años (2010 2014) de la demanda en Kgs. de la partida a exportar 330499; tabulamos los datos aplicando el modelo lineal de ajuste óptimo, a fin de predecir y 
demostrar la existencia de una tendencia creciente de la demanda del producto.

Gráfico 8. Análisis de Tendencia, Modelo Lineal de Ajuste Óptimo

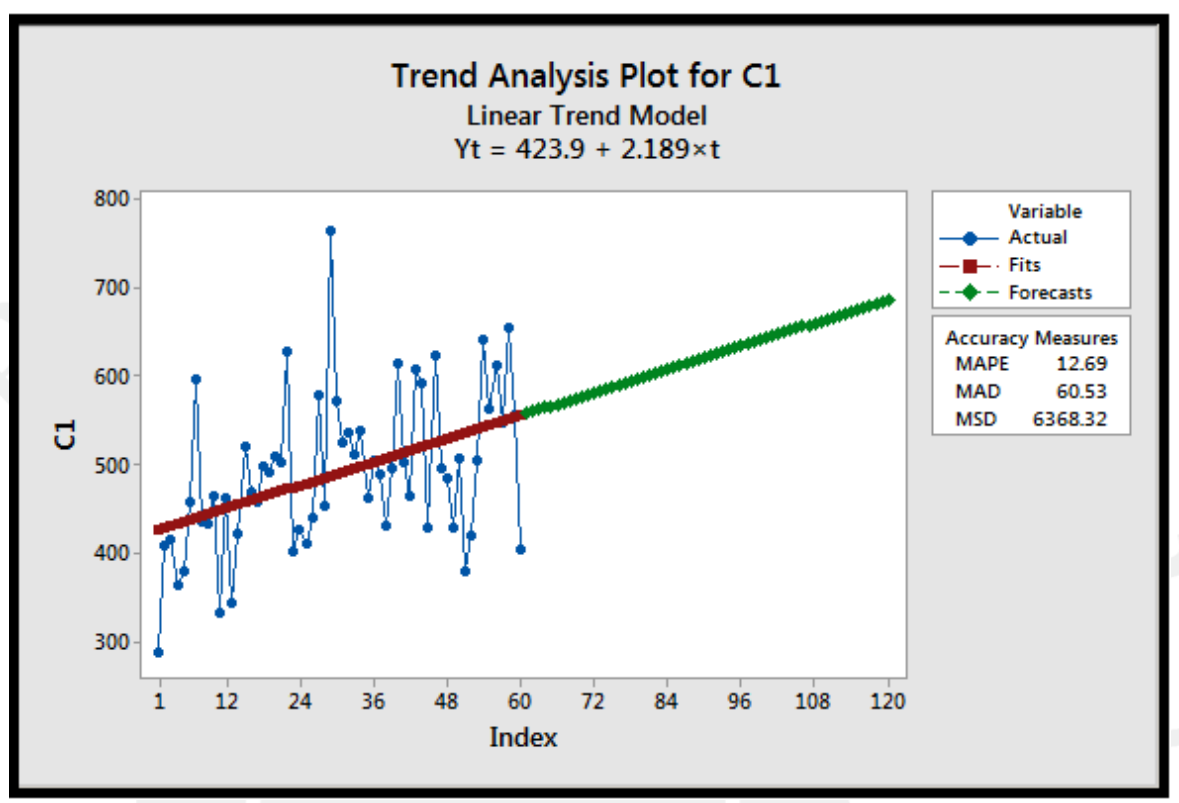

Elaboración Propia 
Proyección de los productos cosméticos naturales por medio del canal

“Minoristas especializados de Salud y Belleza” Bogotá, Colombia (2015-2020)

Tabla 4. Proyecciones de Población 2015-2020, Total por sexo y Grupos de Edad (25 años hasta 45 años) - Total Nacional

\begin{tabular}{|c|c|c|c|c|c|c|}
\hline 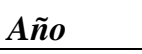 & $\underline{2015}$ & $\underline{2016}$ & $\underline{2017}$ & $\underline{2018}$ & $\underline{2019}$ & $\underline{2020}$ \\
\hline Total & $14,159,151$ & $14,377,888$ & $14,615,631$ & $14,862,843$ & $15,107,624$ & $15,340,365$ \\
\hline Hombres & $6,960,260$ & $7,087,424$ & $7,223,801$ & $7,364,626$ & $7,503,903$ & $7,636,847$ \\
\hline Mujeres & $7,198,891$ & $7,290,464$ & $7,391,830$ & $7,498,217$ & $7,603,721$ & $7,703,518$ \\
\hline
\end{tabular}

Fuente: Departamento Administrativo Nacional de Estadística, DANE

Se recabó información respecto a la proyección de población colombiana de entre 25 a 45 años de edad, para los años 2015-2020; se puede observar que existe una mayor proporción de población de sexo femenino, con una tasa de crecimiento anual compuesto (CAGR) del $1.36 \%$ aprox.

Tabla 5. Proyecciones de Población 2015-2020, Total por sexo y Grupos de

Edad (25 años hasta 45 años) - Bogotá, D.C.

\begin{tabular}{|c|c|c|c|c|c|c|}
\hline 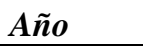 & 2015 & $\underline{2016}$ & 2017 & $\underline{2018}$ & 2019 & $\underline{2020}$ \\
\hline Total & 2,548,871 & $2,578,678$ & $2,612,094$ & $2,646,913$ & $2,679,543$ & $2,707,823$ \\
\hline Hombres & $1,229,717$ & $1,248,054$ & $1,267,821$ & $1,288,030$ & $1,307,073$ & $1,324,043$ \\
\hline Mujeres & $1,319,154$ & $1,330,624$ & $1,344,273$ & $1,358,883$ & $1,372,470$ & $1,383,780$ \\
\hline
\end{tabular}

Fuente: Departamento Administrativo Nacional de Estadística, DANE

Respecto a la ciudad de Bogotá, también se aprecia una mayor proporción de población femenina (de entre 25 a 45 años), con una tasa de crecimiento anual compuesto (CAGR) del 1\% aprox.

\section{Estratos socioeconómicos en Colombia}


La estratificación socio-económica es la clasificación de los inmuebles residenciales que deben recibir servicios públicos. Se realiza principalmente para cobrar de manera diferencial (por estratos) los servicios públicos domiciliarios permitiendo asignar subsidios y cobrar contribuciones. De esta manera, quienes tienen más capacidad económica pagan más por los servicios públicos y contribuyen para que los estratos bajos puedan pagar sus tarifas. Aunque para la estratificación socio-económica no se toman en cuenta los ingresos por persona y las normas relativas a la estratificación ordenan que se deben estratificar los inmuebles residenciales y no los hogares. (Departamento Administrativo Nacional de Estadística, 2015)

En la medida en que identifica geográficamente sectores con distintas características socioeconómicas permite también: orientar la planeación de la inversión pública; realizar programas sociales como expansión y mejoramiento de infraestructura de servicios públicos y vías, salud y saneamiento, y servicios educativos y recreativos en las zonas que más lo requieran; cobrar tarifas de impuesto predial diferentes por estrato y orientar el ordenamiento territorial.

Estratificar con base en las características de las viviendas y su entorno urbano o rural es una opción metodológica fundamentada en que el significante vivienda-entorno expresa un modo socioeconómico de vida demostrable tomando en cuenta las excepciones que lo confirman. 
Cada alcalde debe realizar la estratificación de los inmuebles residenciales de su municipio o distrito.

\section{Estratos socioeconómicos en Colombia}

Los estratos socioeconómicos en los que se pueden clasificar las viviendas y/o los predios son 6 , denominados así:

1. Bajo-bajo

2. Bajo

3. Medio-bajo

4. Medio

5. Medio-alto

6. Alto

Según la Dirección de Estratificación de la Secretaría Distrital de Planeación, encargada de la actualización de la estratificación urbana, se tiene estimado que los estratos cuatro, cinco y seis (Medio-Alto) -para Bogotá- representarían alrededor del $30 \%$, considerando que esta es la capital del país y uno de los principales centros empresariales.

Proyección de la Demanda del Producto 2015-2020, Total por sexo y Grupos de Edad (25 años hasta 45 años) - Bogotá, D.C. - Estratos Socioeconómicos 4,5 y $6^{*}$

Tabla 6. Proyección de la Demanda del Producto 2015-2020

\begin{tabular}{|l|r|r|r|r|r|r|}
\hline$A \tilde{n} \boldsymbol{o}$ & $\underline{\mathbf{2 0 1 5}}$ & $\underline{\mathbf{2 0 1 6}}$ & $\underline{\mathbf{2 0 1 7}}$ & $\underline{\mathbf{2 0 1 8}}$ & $\underline{\underline{2019}}$ & $\underline{\mathbf{2 0 2 0}}$ \\
\hline Total & $\mathbf{2 , 5 4 8 , 8 7 1}$ & $\mathbf{2 , 5 7 8 , 6 7 8}$ & $\mathbf{2 , 6 1 2 , 0 9 4}$ & $\mathbf{2 , 6 4 6 , 9 1 3}$ & $\mathbf{2 , 6 7 9 , 5 4 3}$ & $\mathbf{2 , 7 0 7 , 8 2 3}$ \\
\hline
\end{tabular}




\begin{tabular}{|l|r|r|r|r|r|r|} 
Hombres & $1,229,717$ & $1,248,054$ & $1,267,821$ & $1,288,030$ & $1,307,073$ & $1,324,043$ \\
\hline Mujeres & $1,319,154$ & $1,330,624$ & $1,344,273$ & $1,358,883$ & $1,372,470$ & $1,383,780$ \\
\hline $\mathbf{3 0 \%}$ & $\mathbf{3 9 5 , 7 4 6}$ & $\mathbf{3 9 9 , 1 8 7}$ & $\mathbf{4 0 3 , 2 8 2}$ & $\mathbf{4 0 7 , 6 6 5}$ & $\mathbf{4 1 1 , 7 4 1}$ & $\mathbf{4 1 5 , 1 3 4}$ \\
\hline \multicolumn{5}{c}{$\begin{array}{l}\text { *úmero de personas } \\
\text { Elaboración Propia }\end{array}$}
\end{tabular}

Se calculó el número de mujeres de entre 25 a 45 años de la ciudad de Bogotá de los niveles socioeconómicos Medio y Alto, que representan según estimaciones el $30 \%$ del total. Obteniendo un número significativo de potenciales clientes del target identificado para el producto que se comercializará.

\section{Consumo Per Cápita Lociones Corporales}

La mujer colombiana presenta un consumo per-cápita anual de 2,800 gramos aprox.; de lo cual ascendería a un promedio de 11.2 unidades por año per cápita, considerando presentaciones de 250 gramos. (Cámara Industrial de Cosméticos y Aseo, 2012)

Proyección de la Demanda del Producto 2015-2020, Total por sexo y Grupos de Edad (25 años hasta 45 años) - Bogotá, D.C. - Estratos Socioeconómicos 4, 5 y 6 - En unidades

Tabla 7. Proyección de la Demanda del Producto 2015-2020,

\begin{tabular}{|l|r|r|r|r|r|r|}
\hline Añ $\boldsymbol{o}$ & $\mathbf{2 0 1 5}$ & $\mathbf{2 0 1 6}$ & $\mathbf{2 0 1 7}$ & $\underline{\mathbf{2 0 1 8}}$ & $\mathbf{2 0 1 9}$ & $\mathbf{2 0 2 0}$ \\
\hline Total & $\mathbf{2 , 5 4 8 , 8 7 1}$ & $\mathbf{2 , 5 7 8 , 6 7 8}$ & $\mathbf{2 , 6 1 2 , 0 9 4}$ & $\mathbf{2 , 6 4 6 , 9 1 3}$ & $\mathbf{2 , 6 7 9 , 5 4 3}$ & $\mathbf{2 , 7 0 7 , 8 2 3}$ \\
\hline Hombres & $1,229,717$ & $1,248,054$ & $1,267,821$ & $1,288,030$ & $1,307,073$ & $1,324,043$ \\
\hline Mujeres & $1,319,154$ & $1,330,624$ & $1,344,273$ & $1,358,883$ & $1,372,470$ & $1,383,780$ \\
\hline $30 \%$ & 395,746 & 399,187 & 403,282 & 407,665 & 411,741 & 415,134 \\
\hline $\mathbf{1 1}$ unidades & $\mathbf{4 , 3 5 3 , 2 0 8}$ & $\mathbf{4 , 3 9 1 , 0 5 9}$ & $\mathbf{4 , 4 3 6 , 1 0 1}$ & $\mathbf{4 , 4 8 4 , 3 1 4}$ & $\mathbf{4 , 5 2 9 , 1 5 1}$ & $\mathbf{4 , 5 6 6 , 4 7 4}$ \\
\hline
\end{tabular}

Elaboración Propia 
Como último paso para calcular la Proyección de la Demanda del Producto para el periodo evaluado (2015-2020), se multiplicó -por cada año- el consumo per cápita anual de lociones corporales (11 unidades en promedio) por el número de mujeres de 25 hasta 45 años del estrado socioeconómico medio-alto (30\%) de la ciudad de Bogotá. Resultado una demanda de 4,353,208 unidades para el año 2015, 4,391,059 unidades para el año 2016, 4,436,101 unidades para el año 2017, 4,484,314 unidades para el año 2018, 4,529,151 unidades para el año 2019 y 4,566,474 unidades para el año 2020.

\subsection{Análisis de la oferta.}

\subsubsection{Características de los principales productores o prestadores del} servicio.

La producción de la industria de belleza y cuidado personal colombiana y su dinámica de crecimiento de mercado según la Cámara de Cosméticos de la Andi señala que se ha duplicado en los últimos años desde el año 2000. Este crecimiento constante se podría explicar porque la inversión extranjera directa se ha incrementado y muestra excelentes cifras de resultados. (Propaís, 2014)

Importantes multinacionales se encuentran realizando operaciones en Colombia, y vienen desarrollando inversiones en centros de distribución, innovación, tecnología, plantas de producción, y consecuentemente generando empleo directo. 
Este mercado se dinamiza en fuerte medida; de manera importante se consolidan empresas nacionales e internacionales en el país, ampliando la cobertura de productos exclusivos para las mujeres y hombres colombianos y cubriendo en su totalidad un sector que se desarrolla de manera sólida con el paso del tiempo. (Propaís, 2014)

En el siguiente cuadro se observan algunas de las multinacionales que se han establecido en Colombia.

Tabla 8. Multinacionales de Cosméticos establecidas en Colombia

\begin{tabular}{|c|c|c|c|}
\hline Compañía & Descripción & $\begin{array}{l}\text { País de } \\
\text { Origen }\end{array}$ & Mercados \\
\hline $\begin{array}{l}\text { Kimberly- } \\
\text { Clark }\end{array}$ & $\begin{array}{l}\text { Tercer centro de innovación a nivel mundial } \\
\text { (USD 20MM). }\end{array}$ & $\begin{array}{l}\text { Estados } \\
\text { Unidos }\end{array}$ & Mundial \\
\hline$P \& G$ & $\begin{array}{l}\text { Centro de distribución (USD 25MM - } 600 \\
\text { empleos). }\end{array}$ & $\begin{array}{l}\text { Estados } \\
\text { Unidos }\end{array}$ & Mercado Nacional \\
\hline Unilever & $\begin{array}{l}\text { Oficina central para Centroamérica y la } \\
\text { Región Andina, Centro de Distribución en } \\
\text { el Valle del Cauca (USD 31.5MM y } 300 \\
\text { empleos). }\end{array}$ & UK & $\begin{array}{l}\text { Centro América y } \\
\text { Región Andina }\end{array}$ \\
\hline BELCORP & $\begin{array}{l}\text { Centro de I\&D y planta de producción en } \\
\text { Tocancipá - Cundinamarca (USD 10MM). }\end{array}$ & Perú & $\begin{array}{l}\text { Latinoamérica y } \\
\text { Estados Unidos }\end{array}$ \\
\hline$Y A N B A L$ & $\begin{array}{l}\text { Expansión planta de producción (USD } 10 \\
\text { millones). Centro de distribución en } \\
\text { Facatativá - Cundinamarca (USD } 10 \text { MM). }\end{array}$ & Perú & Región Andina \\
\hline NATURA & $\begin{array}{l}\text { Comercializa en Colombia alrededor de } 400 \\
\text { productos. }\end{array}$ & Brasil & Colombia \\
\hline$A V O N$ & $\begin{array}{l}\text { Centro de Distribución USD 50MM - } 300 \\
\text { empleos. }\end{array}$ & $\begin{array}{l}\text { Estados } \\
\text { Unidos }\end{array}$ & $\begin{array}{l}\text { Mercado Nacional, } \\
\text { Perú y Ecuador }\end{array}$ \\
\hline $\begin{array}{l}\text { BDF } \\
\text { BEIERSDORF }\end{array}$ & $\begin{array}{l}\text { Propietaria de la marca Nivea, realizado } \\
\text { inversiones en Colombia de manera } \\
\text { constante. }\end{array}$ & Alemania & Colombia \\
\hline
\end{tabular}

Fuente: Proexport; Sector Cosméticos y Artículos de Aseo Colombia.

\subsubsection{Proyección de la oferta}

Las ventas de productos para cuidado de la piel en el mercado colombiano crecerán en promedio $2.3 \%$ anual, según estimados de Euromonitor International. 
Cabe resaltar que las ventas de productos de cuidado para la piel de categoría Premium experimentarán un mayor crecimiento, comparado con las ventas de productos de carácter masivo; debido a que esta categoría aún no ha penetrado todo su mercado potencial, tiene mayor posibilidad de expansión, aunado al dinamismo económico que se prevé experimente Colombia en los años subsiguientes.

Tabla 9. Pronóstico de ventas de Productos de Cuidado para la Piel por categoría: Valores $2014-2019$

\begin{tabular}{|l|l|l|l|l|l|l|}
\hline Millones USD & $\mathbf{2 0 1 4}$ & $\mathbf{2 0 1 5}$ & $\mathbf{2 0 1 6}$ & $\mathbf{2 0 1 7}$ & $\mathbf{2 0 1 8}$ & $\mathbf{2 0 1 9}$ \\
\hline Cuidado de la piel & 110.757 & 111.440 & 112.189 & 113.328 & 114.662 & 116.127 \\
\hline Cuidado Facial & 184.573 & 189.032 & 194.207 & 200.130 & 206.412 & 212.954 \\
\hline Cuidado de las Manos & 10.70 & 11.42 & 12.14 & 12.82 & 13.47 & 14.15 \\
\hline CUIDADO DE LA PIEL & $\mathbf{3 0 6 . 0 3 7}$ & $\mathbf{3 1 1 . 8 9 6}$ & $\mathbf{3 1 8 . 5 3 5}$ & $\mathbf{3 2 6 . 2 7 8}$ & $\mathbf{3 3 4 . 5 4 4}$ & $\mathbf{3 4 3 . 2 3 1}$ \\
\hline
\end{tabular}

Fuente: Euromonitor International

Los productos para el cuidado de la piel de las categorías 'multipurpose' o multifuncionales encabezan la lista de productos más demandados.

\subsection{Importaciones del producto o servicio.}

Como se puede observar en el siguiente cuadro, Perú es el segundo proveedor más importante de la partida 330499 para Colombia; representando el 13,9\% del total de sus importaciones, con un total de 17,494 miles de USD y una tasa de crecimiento del 9\% entre los años 2013 y 2014.

El Perú al pertenecer a la CAN, ingresa al mercado colombiano con un arancel preferencial del 0\%, comparado a los aranceles impuestos a países como 
Estados Unidos y Francia (15\%), quieres representan nuestra competencia internacional más significativa.

Asimismo, cabe destacar que Perú y Colombia pertenecen a la Alianza del Pacífico, que se constituye como un proceso de integración, conformado por países con visiones afines de desarrollo y promotores del libre comercio como impulsor de crecimiento, que ofrece ventajas competitivas para los negocios internacionales. (Alianza del Pacífico, 2015)

Tabla 10. Importaciones desde Colombia para la Partida 330499 Durante el 2014, Valor FOB en miles de USD

\begin{tabular}{|c|c|c|c|c|}
\hline \multirow[b]{2}{*}{ Exportadores } & \multicolumn{3}{|c|}{ Indicadores comerciales } & \multirow[b]{2}{*}{$\begin{array}{l}\text { Arancelario } \\
\text { (estimado) } \\
\text { aplicado por } \\
\text { Colombia }\end{array}$} \\
\hline & $\begin{array}{c}\text { Valor importada } \\
\text { en } 2014 \text { (miles } \\
\text { de USD) }\end{array}$ & $\begin{array}{l}\text { Participación de las } \\
\text { importaciones para } \\
\text { Colombia }(\%)\end{array}$ & $\begin{array}{l}\text { Tasa de crecimiento de } \\
\text { los valores importadas } \\
\text { entre 2013-2014 (\%, } \\
\text { p.a.) }\end{array}$ & \\
\hline $\begin{array}{l}\text { Estados Unidos } \\
\text { de América }\end{array}$ & 21,503 & 17,0 & -7 & 15 \\
\hline Perú & 17,494 & 13,9 & 9 & 0 \\
\hline Francia & 17,488 & 13,9 & -9 & 15 \\
\hline México & 11,405 & 9 & 9 & 0 \\
\hline $\begin{array}{l}\text { Resto del } \\
\text { mundo }\end{array}$ & 58,341 & $46,21 \%$ & NA & NA \\
\hline
\end{tabular}

Fuente: TradeMap

Asimismo, respecto a las exportaciones desde Perú para la partida 330499 en el año 2014; Colombia, se consolida como el principal destino con una participación del 36,6\% y un valor FOB de 18,219 miles de USD. Seguido por Ecuador 12,594 miles de USD y Bolivia 7,139 miles de USD. 
Gráfico 9. Principales países de destino de las exportaciones desde Perú 2010-2014 para la partida 330499, Valor FOB en miles de USD

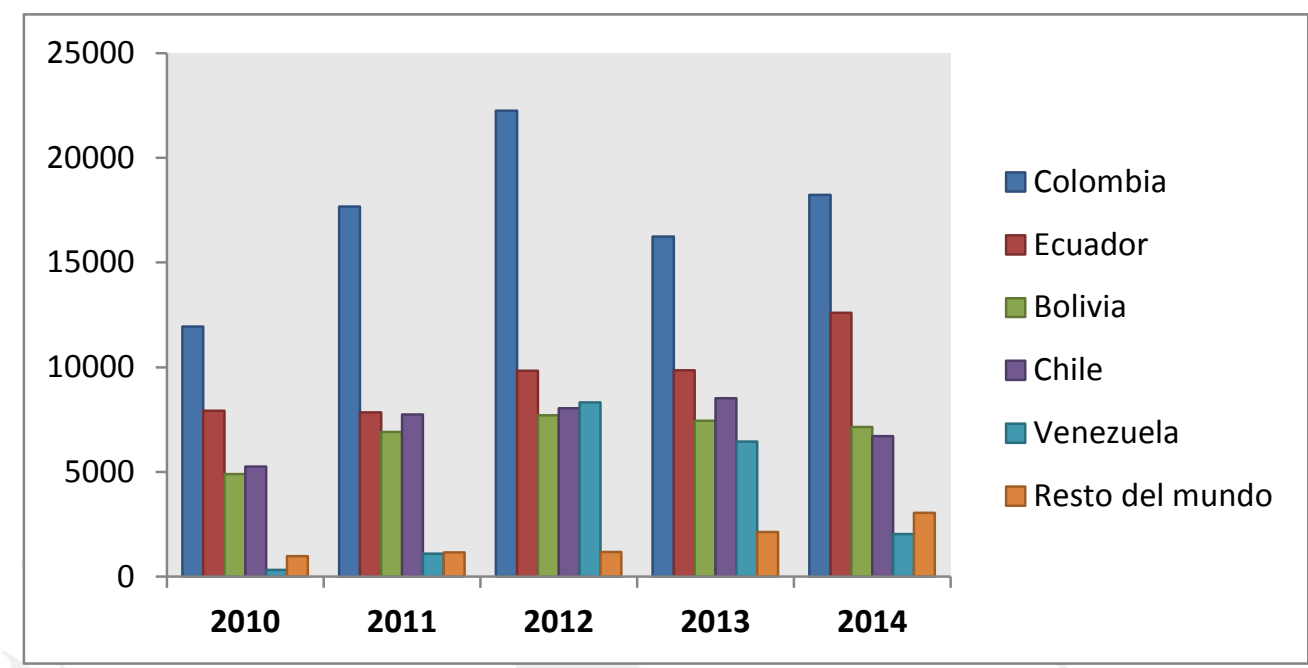

Fuente: TradeMap

\subsection{Análisis de precios.}

\subsubsection{Análisis histórico y proyección de precios}

Según data recabada del portal Infotrade, se pudieron hacer estimaciones aproximadas de los precios FOB promedio para la partida 330499; al realizar una división entre los valores FOB declarados y las cantidades en Kgs. No obstante, es preciso en hacer hincapié en el hecho de que estos datos son muy generales, y no consideran el tipo de presentación, empaque o embalaje del producto; tampoco especifica si corresponde a productos de contenido en su mayoría químico y/o natural.

Tabla 11. Histórico de precios FOB promedio de la partida 330499 Exportaciones peruanas con destino a Colombia

\begin{tabular}{|l|c|c|c|c|c|c|}
\cline { 2 - 7 } \multicolumn{1}{c|}{} & $\mathbf{2 0 1 0}$ & $\mathbf{2 0 1 1}$ & $\mathbf{2 0 1 2}$ & $\mathbf{2 0 1 3}$ & $\mathbf{2 0 1 4}$ & CARG \\
\hline $\begin{array}{l}\text { Precio } \\
\text { FOB/Kg. }\end{array}$ & 11.12 & 12.36 & 12.55 & 11.56 & 12.42 & $\mathbf{2 . 8 2 \%}$ \\
\hline $\begin{array}{l}\text { Precio } \\
\text { FOB/250gr. }\end{array}$ & 2.78 & 3.09 & 3.14 & 2.89 & 3.11 & $\mathbf{2 . 8 2 \%}$ \\
\hline
\end{tabular}

Fuente: Infotrade 
A partir del histórico recabado, se calcula la tasa de crecimiento promedio anual y se procede a realizar una proyección de los precios FOB, basados en ésta.

Tabla 12. Proyección de precios FOB promedio de la partida 330499 -

Exportaciones peruanas con destino a Colombia

\begin{tabular}{|l|c|c|c|c|c|c|}
\cline { 2 - 7 } \multicolumn{1}{c|}{} & $\mathbf{2 0 1 5}$ & $\mathbf{2 0 1 6}$ & $\mathbf{2 0 1 7}$ & $\mathbf{2 0 1 8}$ & $\mathbf{2 0 1 9}$ & $\mathbf{2 0 2 0}$ \\
\hline Precio FOB/Kg. & 12.77 & 13.13 & 13.50 & 13.89 & 14.28 & 14.68 \\
\hline Precio FOB/250gr. & 3.19 & 3.28 & 3.38 & 3.47 & 3.57 & 3.67 \\
\hline
\end{tabular}

Fuente: Infotrade

Respecto a los precios finales de venta en Colombia para este tipo de productos, éstos son muy variados, dependiendo la marca del producto y cómo está posicionada en el mercado; según información recabada de páginas web como LOCATEL -dedicada a la venta de productos para la salud y el bienestar- los precios pueden fluctuar entre $\$ 25.000$ y $\$ 50.000$ aprox. pesos colombianos, equivalente a un rango de precios entre USD 7.50 - USD 15.00 .

Figura 1. Crema Humectante Corporal Natural x250G Con extracto de Caléndula, Aloe Vera, Elastina y Colágeno
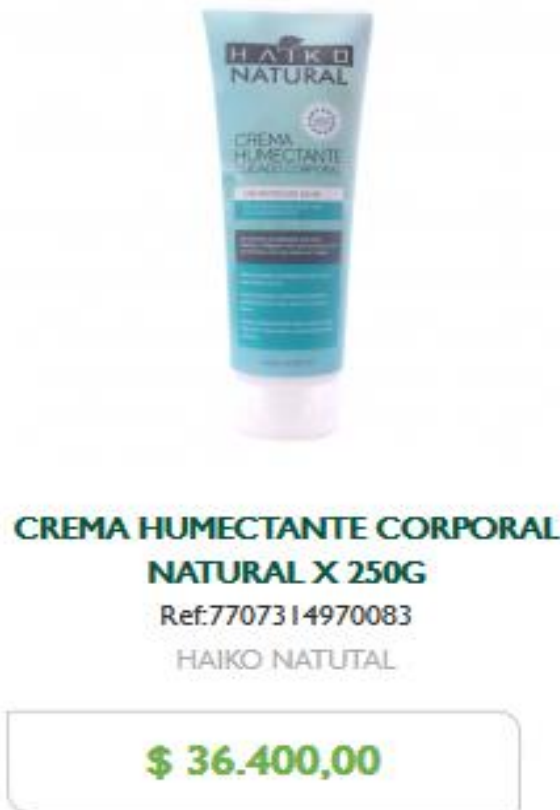

Agregar 
Fuente: http://www.locatelcolombia.com/cuidado-personal-y-de-la-piel/cuidado-de-la-piel/cremahumectante-corporal-natural-x-250g.html

\subsection{Canales de comercialización y distribución del producto.}

En base a una investigación realizada por el Instituto Español de Comercio Exterior (ICEX), en los últimos años se ha transformado la estructura de los canales de distribución; ya que al principio de la década de los noventa la mayoría del mercado se concentraba en supermercados y establecimientos tradicionales como tiendas y misceláneas de barrio. En estos establecimientos se sigue concentrando la distribución y comercialización de productos cosméticos orientados a un segmento de población de ingresos bajos y medios (masivo).

Actualmente, métodos alternativos como la venta directa a través de catálogo (que consiste en un sistema logístico en el cual se establece una relación directa entre el consumidor y el agente de ventas, quien maneja las solicitudes y entregas de los productos), las tiendas de cosmético especializadas y los centros profesionales de estética o dermatología han comenzado a incrementar su participación entre los canales de distribución utilizados por las empresas productoras de cosméticos y productos de aseo. Estos métodos de mercadeo impulsan productos cosméticos orientados a población con ingresos medios y altos. (LEGISCOMEX, 2014) 


\subsubsection{Tipos de canales del producto}

Gráfico 10. Esquema de distribución de cosméticos en Colombia

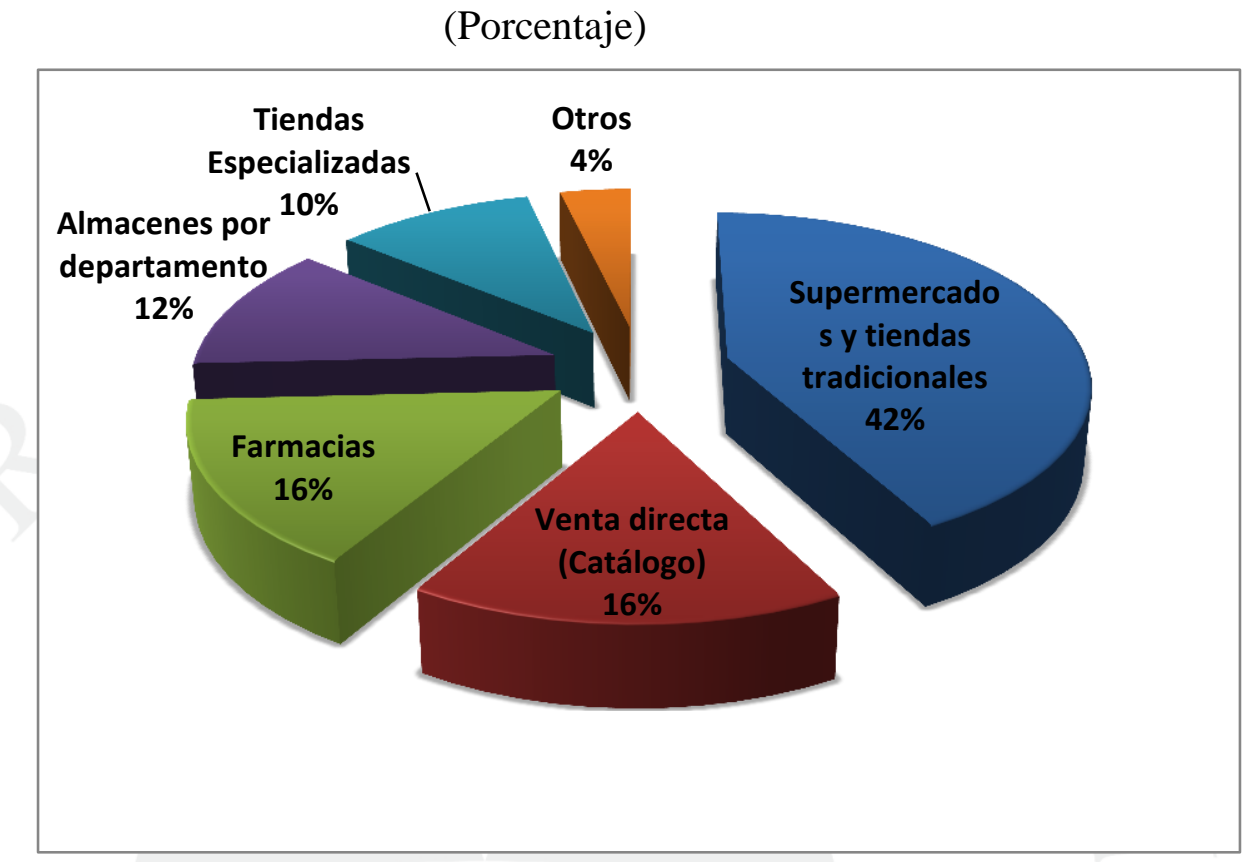

Fuente: Instituto Español de Comercio Exterior (ICEX)

Asimismo, en Colombia el agente local comisionista es una figura bastante común, así como el importador-distribuidor que compra directamente.

Otras alternativas para ingresar al mercado colombiano son la creación de una filial de venta o producción o la delegación de la marca en una empresa colombiana. Esta última puede ser una alternativa interesante, si se tiene en cuenta que en este país los contratos de maquila tienen gran difusión y las compañías tienen gran experiencia en producir bajo pedido cualquier marca del mercado. (LEGISCOMEX, 2014) 


\section{CAPITULO IV. EVALUACIÓN EXTERNA}

\subsection{Análisis PESTE, Colombia.}

\subsubsection{Fuerzas políticas, gubernamentales y legales (P)}

\section{Capital y División Político-Administrativa del país}

Colombia está situada en el extremo noroccidental de Suramérica, siendo el único país del subcontinente con costas sobre los océanos Atlántico y Pacífico.

El territorio está dividido administrativamente en 32 departamentos y un Distrito Especial (Bogotá).

\section{Sistema de Gobierno / Presidente y/o Primer Ministro}

Colombia es un Estado Social de Derecho organizado en forma de República Unitaria con centralización política y descentralización administrativa, en donde el poder público se encuentra separado en tres ramas, legislativa, ejecutiva y judicial. (Naciones Unidas, 2015)

En la actualidad la estructura de gobierno está encabezada por el presidente Sr. Juan Manuel Santos y por el vicepresidente Sr. Germán Vargas Lleras. Elegidos el año 2014, por un periodo de 4 años.

A nivel político, Colombia es un país estable, con una economía de mercado, e instituciones políticas que promueven la inversión de 
capitales externos y la libre competencia. Los productores locales no tienen influencia sobre las políticas comerciales del país y Colombia presenta una calificación de riesgo país de A4.

\subsubsection{Fuerzas económicas y financieras $(\mathrm{E})$}

En el año 2014 la economía colombiana tuvo un comportamiento favorable. El crecimiento para el 2014 se ubicó por encima del 4,5\%. En estas condiciones, podemos decir que, Colombia es de los países que más crece en la región, e incluso, a nivel internacional. Cabe destacar que en este año se mantuvo el buen dinamismo de la inversión productiva; el entorno macroeconómico favorable, con una tasa de cambio más competitiva; una tasa de desempleo de un dígito, donde se resalta que el empleo formal creció más que el empleo informal, y, un nivel de población en situación de pobreza inferior al 30\%. (Asociación Nacional de Empresarios de Colombia, 2014)

El PIB de Colombia ha registrado variaciones positivas en los últimos años pese a la crisis económica mundial. Las proyecciones de crecimiento para el 2015 están entre 4,2 y 4,5 por ciento, pero detrás de ese dato hay una gran variedad de historias.

Algunos indicadores siguen creando buenas condiciones. Por ejemplo, los analistas tienen la expectativa que la inflación continuará muy cerca del 3 por ciento, rango meta fijado por el Emisor. 
Igualmente, se espera que el mercado laboral continúe mejorando, de manera que el desempleo podría rondar el 8,5 por ciento, lo cual se traduce en una mejora en el gasto de las familias.

Es justamente el consumo privado lo que, a juicio de los analistas, seguiría impulsando la economía, pues la confianza de los consumidores ha mejorado y, según el Índice Genworth realizado por Ipsos Morie, el 76 de los colombianos es optimista sobre su situación financiera.

Un informe de Bancolombia señala que si bien habrá una moderación frente al 2014, "las compras de los hogares, seguirían sólidas. Esto, gracias al buen desempeño del empleo asalariado, la estabilización en el crecimiento de la cartera de consumo y la reactivación de la demanda por bienes durables". (PORTAFOLIO, 2014)

Tabla 13. Principales Indicadores Económicos en los últimos Años

\begin{tabular}{|l|c|c|c|c|c|}
\hline DATOS ECONÓMICOS & $\mathbf{2 0 1 0}$ & $\mathbf{2 0 1 1}$ & $\mathbf{2 0 1 2}$ & $\mathbf{2 0 1 3}$ & $\mathbf{2 0 1 4}$ \\
\hline PIB (Miles de MM US\$)* & 287 & 336 & 369 & 378 & 380 \\
\hline PIB per cápita (PPP en miles US\$)* & 6.179 & 7.149 & 7.748 & 8.019 & 7.975 \\
\hline Evolución del PIB (\%) & 4 & 6,6 & 4,2 & 4,5 & 4,6 \\
\hline Exportaciones (MM US\$)*** & 39.713 & 56.915 & 60.125 & 58.822 & 54.795 \\
\hline Importaciones (MM US\$) & 40.486 & 54.233 & 59.111 & 59.397 & 64.029 \\
\hline Inflación (\%)**** & 3,17 & 3,73 & 2,44 & 1,94 & 3,66 \\
\hline Desempleo (\%)**** & 11,8 & 10,8 & 10,4 & 9,6 & 9,1 \\
\hline Tasa de Interés (\%)**** & 3 & 4,75 & 4,25 & 3,25 & 4,5 \\
\hline Tasa de Cambio****(moneda local por US\$) & $1.913,98$ & $1.942,70$ & $1.768,23$ & $1.926,83$ & $2.392,00$ \\
\hline $\begin{array}{l}\text { *Datos extraídos del Banco Mundial } \\
\text { ***uentas Nacionales Trimestrales }\end{array}$ **DANE \\
$\quad \begin{array}{l}\text { Fuente: ProCHILE } \\
\text { Fudín de indicadores económicos del Banco Central de Colombia }\end{array}$
\end{tabular}


Gráfico 11. Tasa de crecimiento anual del PIB de Colombia por encima del crecimiento del Mundo y la Región

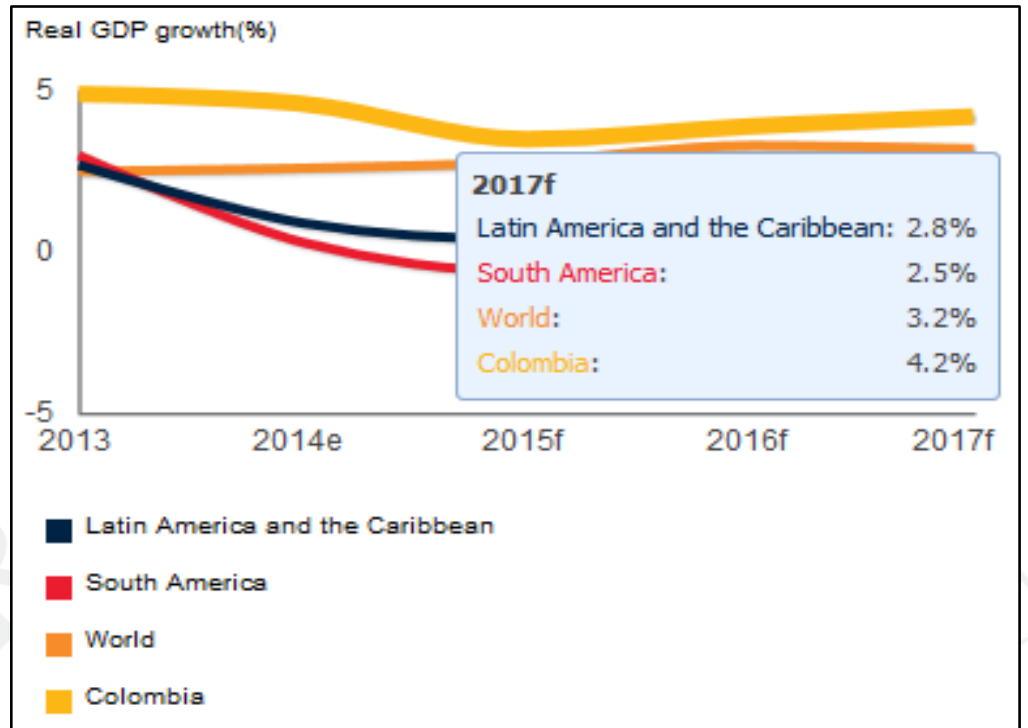

Fuente: Banco Mundial

Como se puede observar en el gráfico anterior, Colombia presenta una tasa estimada de crecimiento anual del PBI del 4.2\%, muy por encima del promedio Mundial, la Región de Latinoamérica y El Caribe y Sudamérica en particular. Indicador que posiciona a este país como uno de los más sólidos a nivel de desarrollo económico.

Gráfico 12. Tasa de desempleo en Colombia: total nacional

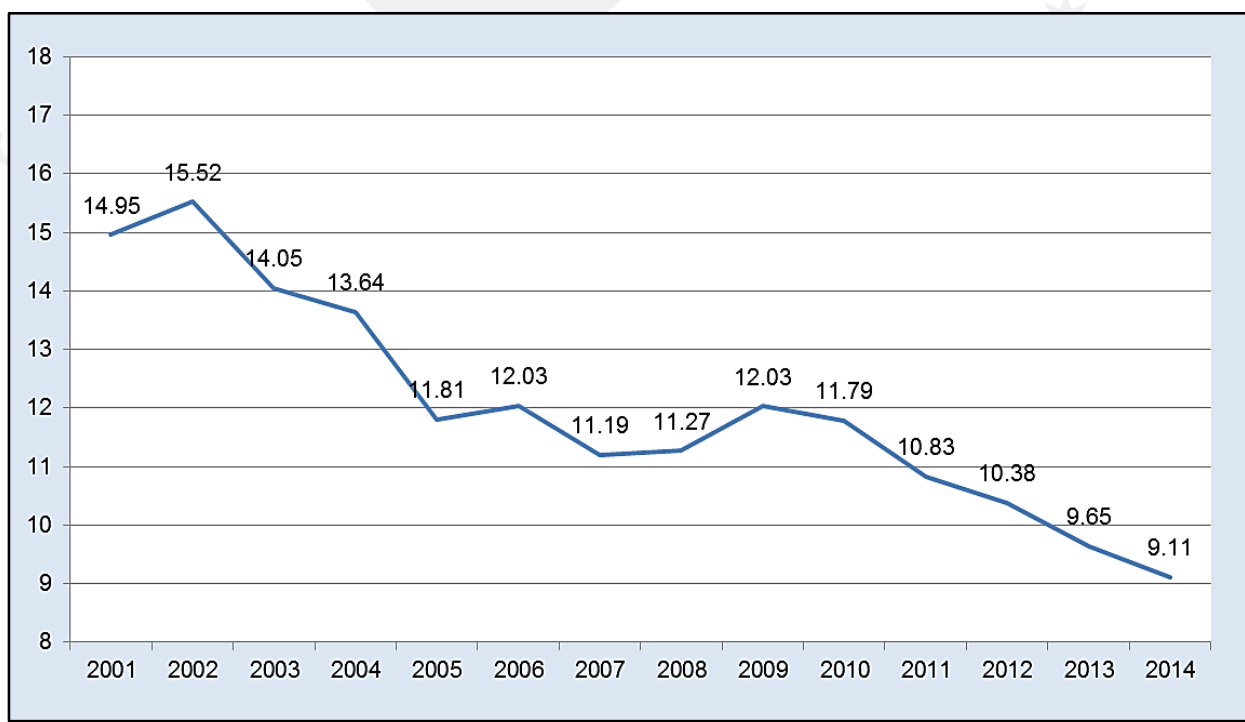


Fuente: Encuesta Continua de Hogares, Departamento Administrativo Nacional de Estadística - DANE

Según estadística del Departamento Administrativo Nacional de Estadística de Colombia, la tasa de desempleo en este país se ha ido reduciendo en el transcurso de los años, principalmente, a partir del año 2009, alcanzando en el 2014 un valor relativo del $9.11 \%$ de la población. Esto se debe en gran parte, al crecimiento sostenido que ha experimentado el país, a las mayores oportunidades que han surgido en el mercado laboral y el incremento del poder adquisitivo de su población. 
Gráfico 13. Inflación y meta de inflación

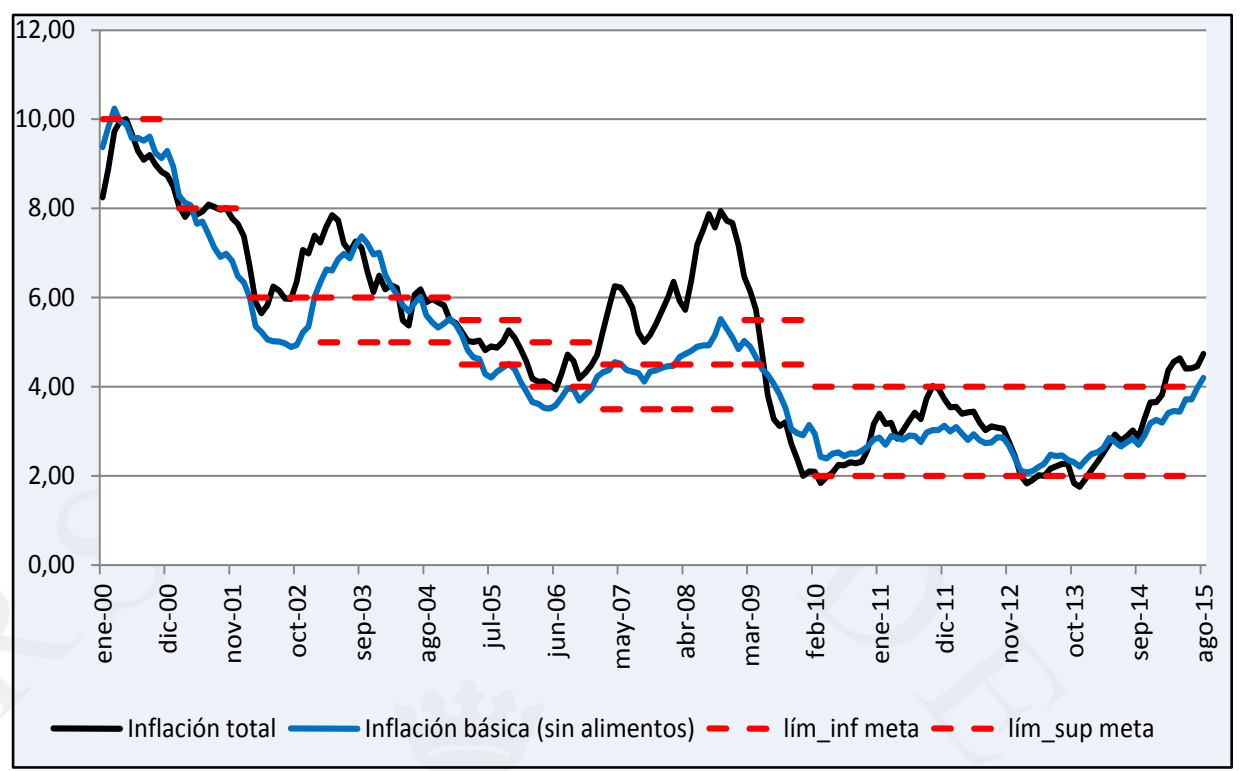

Fuente: IPC: DANE; meta de inflación: Junta Directiva del Bando de la República de Colombia

La tasa de variación anual del IPC en Colombia en agosto de 2015 ha sido del 4,7\%, 2 décimas superior a la del mes anterior. La variación mensual del IPC (Índice de Precios al Consumo) ha sido del 0,5\%, de forma que la inflación acumulada en 2015 es del 4,0\%.

\section{Gráfico 14. Exportaciones mensuales}

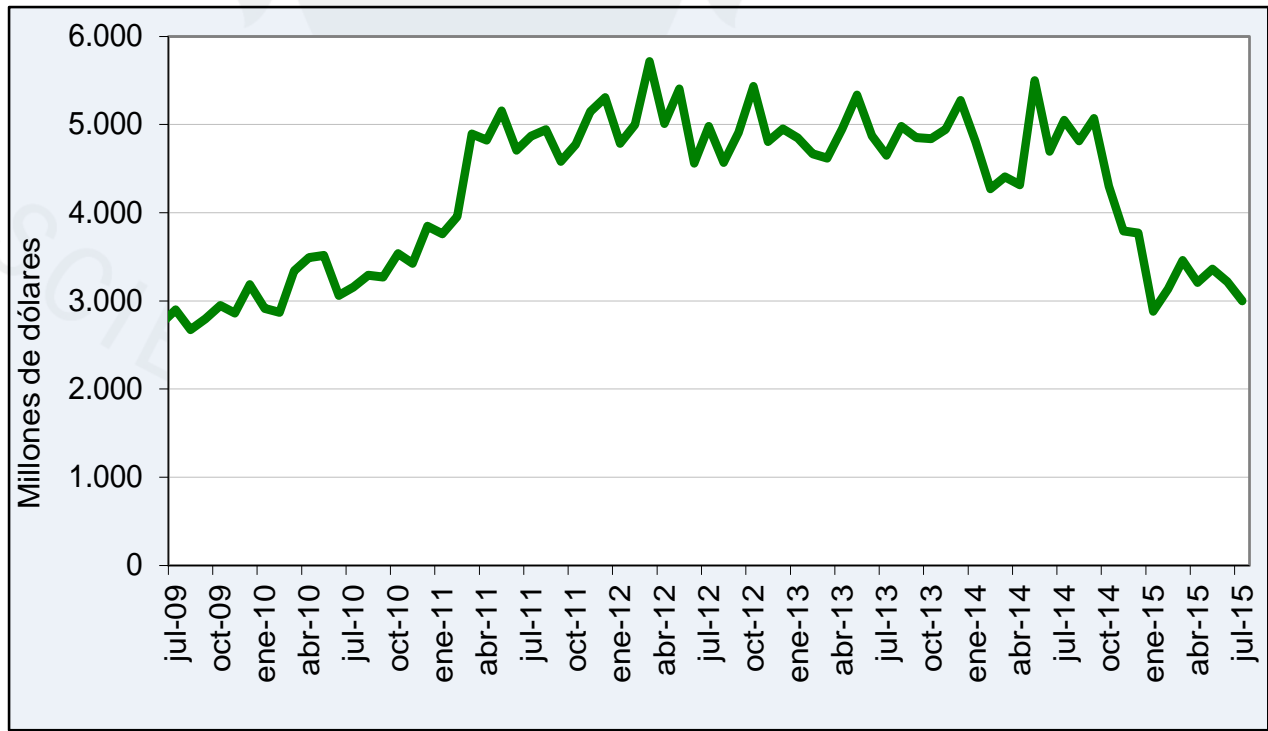

Fuente: DANE-DIAN 
Las estadísticas de Exportaciones mostraron que en agosto de 2015 las ventas externas del país disminuyeron 41,6 \% con relación al mismo mes del año anterior, al pasar de US\$4.813,1 millones FOB a US\$2.809, 1 millones FOB.

Gráfico 15. Importaciones mensuales

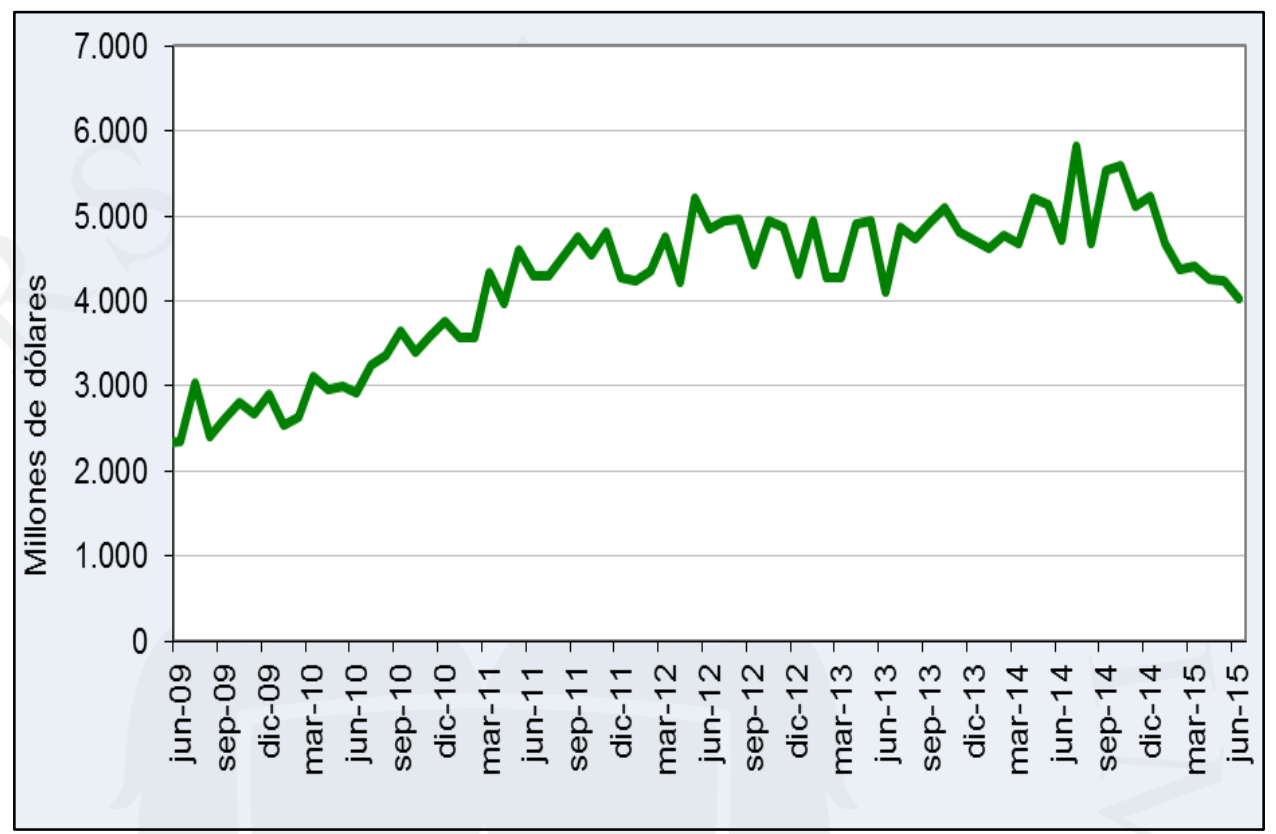

Fuente: DANE-DIAN

En julio de 2015 las compras externas del país disminuyeron 18,3\% con relación al mismo mes de 2014, al pasar de US\$ 6.084,2 millones CIF en 2014 a US\$ 4.967,8 millones CIF en 2015.

Asimismo, vale hacer hincapié en que el Perú es uno de los principales proveedores de Colombia, y que dentro de las principales importaciones desde este país destacan los aceites esenciales, perfumería y cosméticos. 
Gráfico 16. Balanza comercial mensual

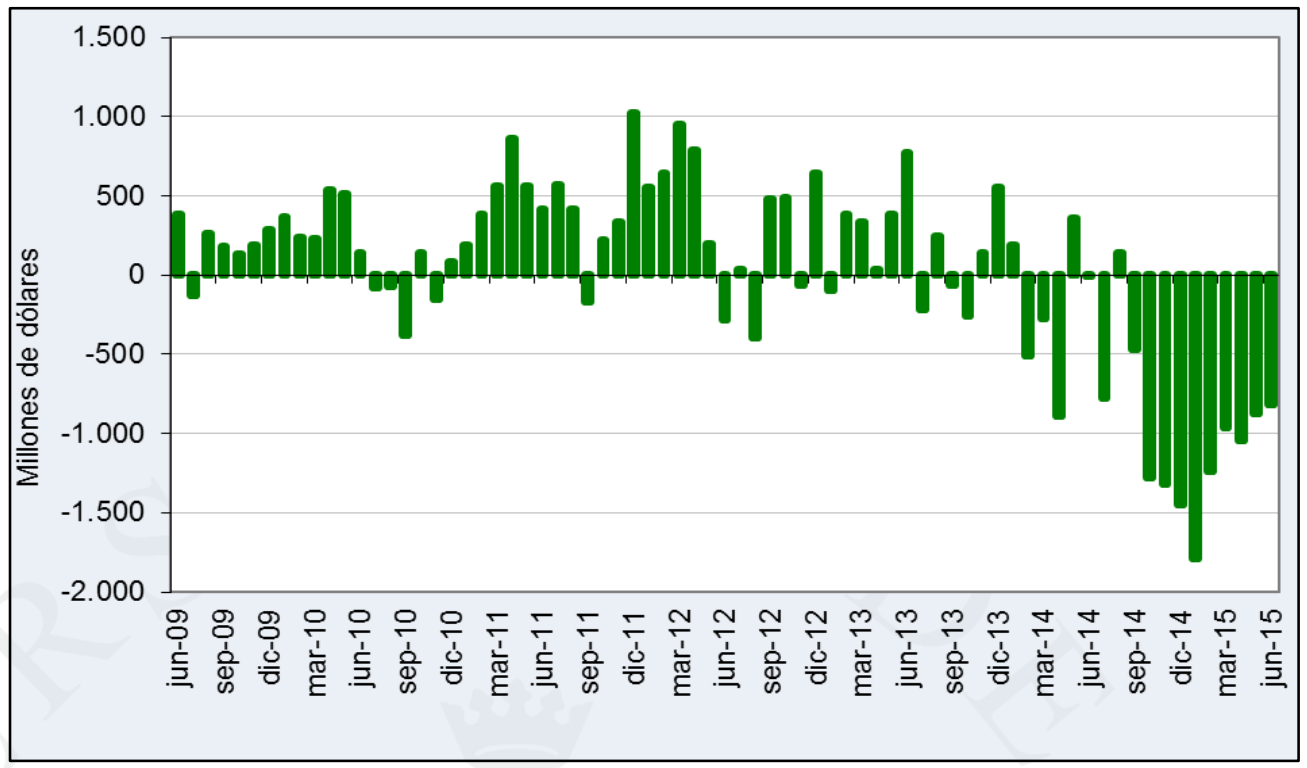

Fuente: DANE-DIAN

La balanza comercial es la diferencia que existe entre el total de las exportaciones e importaciones de un país. En este sentido se puede apreciar en el gráfico que en los últimos trimestres (precisamente a partir de septiembre) la balanza comercial de Colombia presenta un déficit.

\section{Gráfico 17. Flujo trimestral de inversión extranjera directa en Colombia}

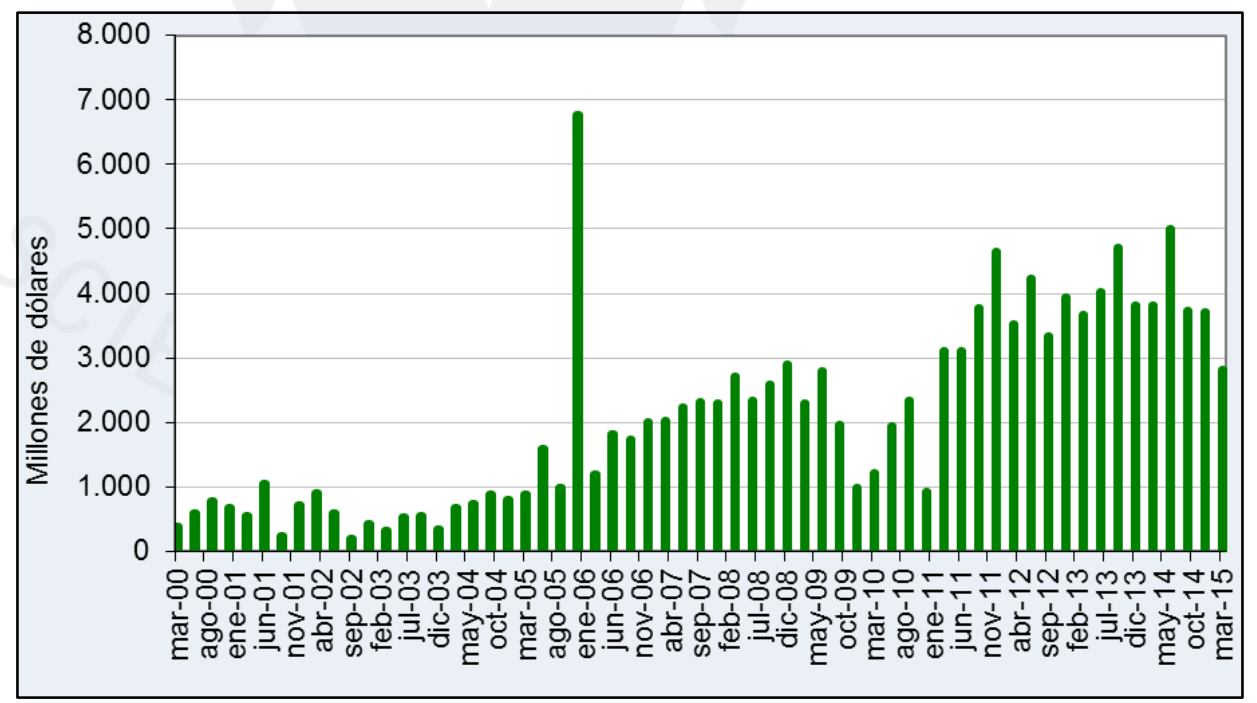

Fuente: Banco de la República, Subgerencia de Estudios Económicos 
La inversión directa es una categoría de la inversión internacional asociada con el significativo grado de control que un extranjero (o nacional) adquiere sobre una empresa residente (o fuera del país). El grado de control se define teniendo en cuenta criterios como la activa participación del inversionista extranjero en la gestión de la empresa y el porcentaje de sus acciones en la misma. La inversión directa es una transacción de largo plazo que se diferencia del resto de flujos financieros por su mayor estabilidad y menor dependencia de factores coyunturales. (BANCO CENTRAL DE COLOMBIA, 2015)

Según estadísticas del Banco Central de Colombia, dentro los principales países que invierten en Colombia se encuentran Estados Unidos, seguido por Panamá y Chile.

Gráfico 18. Distribución \% de la IED en Colombia por sectores

\section{Enero-marzo del 2015}

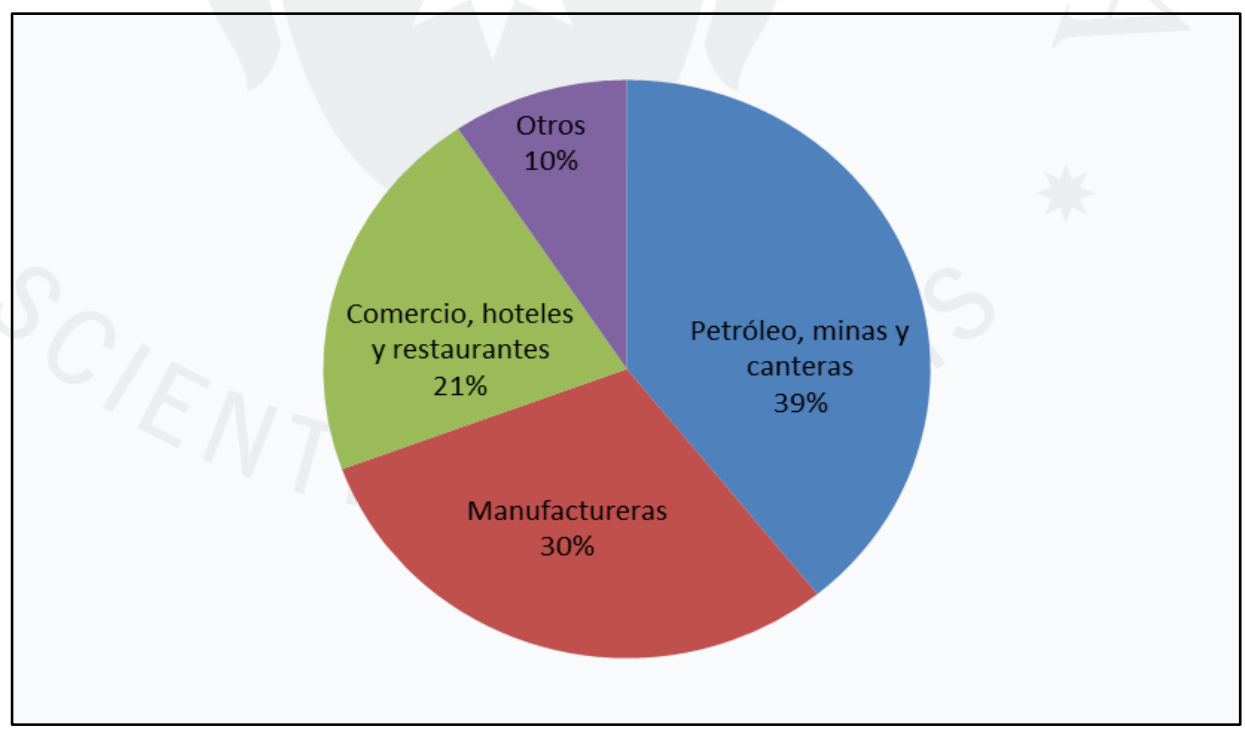

Fuente: Banco de la República, Subgerencia de Estudios Económicos 
La IED en Colombia se encuentra concentrada en el sector de Petróleo, minas y canteras (39\%); en el sector Manufacturero (30\%); Comercio, hoteles y restaurantes $(21 \%)$ y otros $(10 \%)$.

\section{Tipo de Cambio}

Tasa de cambio del peso colombiano (TRM)

La tasa de cambio representativa del mercado (TRM) es la cantidad de pesos colombianos por un dólar de los Estados Unidos (antes del 27 de noviembre de 1991 la tasa de cambio del mercado colombiano estaba dada por el valor de un certificado de cambio). La TRM se calcula con base en las operaciones de compra y venta de divisas entre intermediarios financieros que transan en el mercado cambiario colombiano, con cumplimiento el mismo día cuando se realiza la negociación de las divisas. Actualmente la Superintendencia Financiera de Colombia es la que calcula y certifica diariamente la TRM con base en las operaciones registradas el día hábil inmediatamente anterior. (Banco de la República, 2015)

Tabla 14. Tipo de Cambio, Serie de datos promedio anual

\begin{tabular}{|c|c|c|c|c|}
\hline $\mathbf{2 0 1 0}$ & $\mathbf{2 0 1 1}$ & $\mathbf{2 0 1 2}$ & $\mathbf{2 0 1 3}$ & $\mathbf{2 0 1 4}$ \\
\hline$\$ 1.897,89$ & $\$ 1.848,17$ & $\$ 1.798,23$ & $\$ 1.868,90$ & $\$ 2.000,68$ \\
\hline
\end{tabular}

Fuente: Banco Central de Colombia

Según data de Bancolombia, para el cierre del mes de Noviembre del 2015 el tipo de cambio estaba a un nivel de \$3.101,10 por dólar americano. Es decir, la moneda colombiana se ha debilitado respecto al dólar, esto repercute de manera negativa las importaciones del país, 
debido a que se necesitarán de más pesos colombianos para poder cancelar el monto transado por la compra de bienes provenientes del exterior, puesto que los precios internacionales se fijan en dólares. Lo contrario ocurre para el caso de las exportaciones.

\subsubsection{Fuerzas sociales, culturales y demográficas (S)}

Perfil Demográfico

Colombia es un país que está atravesando por una transformación demográfica, ambiental y cultural. La tasa de crecimiento de la población y la tasa de fecundidad relativamente altas le convierten en uno de los países de mayor desarrollo relativo de América Latina. (Universidad del Valle Colombia, 2014)

La población económicamente activa tiende a aumentar progresivamente, de modo que crece la población joven que demanda servicios de educación y empleo.

Otro fenómeno demográfico con gran importancia es la tendencia al envejecimiento de la población, o el crecimiento del número absoluto y la proporción de personas mayores de sesenta años, de lo cual se desprende la necesidad de crear infraestructuras de servicios de salud, educación, cultura y entretenimiento adecuadas a las nuevas demandas, así como también una provisión mayor de seguridad social y bienestar. 
De otra parte, el patrón de la distribución regional de la población se mantiene constante pero sostenido. La actividad productiva del país se mantiene concentrada en el llamado "Trapecio Andino" y las tendencias actuales muestran la conformación de un mapa con nuevas escalas de urbanización en el país. Ha aumentado el tamaño medio urbano y ha crecido la importancia de las ciudades intermedias y los centros subregionales, lo cual conlleva un mayor deterioro Ambiental y de los ecosistemas estratégicos, afectando fuertemente la dotación de recursos naturales de trascendental importancia geopolítica como la biodiversidad y el recurso hídrico.

Población, crecimiento y estructura etaria Población Total 2015 : 48.203.405

Población mujeres : 24.403.726 (50,6\%)

Población Hombres : $23.799 .679(49,4 \%)$

Tasa de crecimiento poblacional $\quad: 1.04 \%$

Gráfico 19. Distribución etaria 


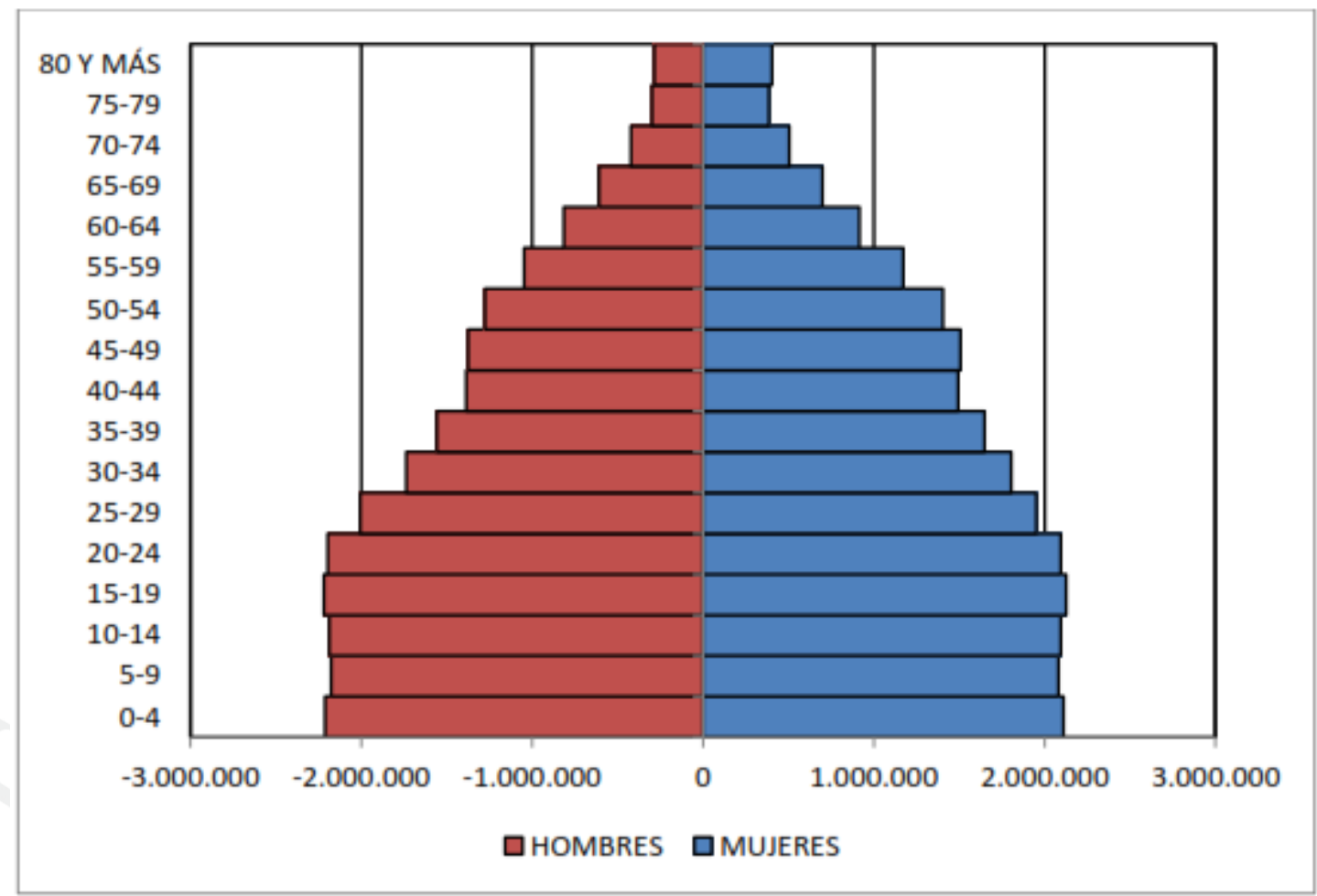

Fuente: Estimación y proyección de población nacional, departamental y municipal por sexo, grupos quinquenales de edad y edades simples de 0 a 26 años 1985-2020. DANE P datos preliminares.

$\begin{array}{ll}\text { No de nacimientos } 2013 & : 659.202 \\ \text { Esperanza de vida al nacer } & : 78,54 \text { años Mujeres } \\ & : \text { 72,07 años Hombres } \\ \text { Grupos Étnicos } & : \text { Rom } 0,01 \% \\ & : \text { Indígenas } 3.34 \% \\ & : \text { Afrocolombiano } 10,62 \% \\ & : \text { Sin pertenecía étnica } 85,94 \% \\ \text { Alfabetización } & : 94.7 \% \\ \text { Tasa de desempleo } & : 219 \%\end{array}$

Religión e idioma

En Colombia existe libertad de culto, sin embargo un $90 \%$ de la población se reconoce como católica apostólica romana. Respecto del 
idioma, el español es el idioma oficial del país, sin embargo poseen otras 65 lenguas indígenas que generalmente se concentran en los sectores rurales de la nación. Entre ellos se destaca el palenque, lengua criolla heredada de los esclavos negros de Cartagena. (PROCHILE, 2015)

\section{Análisis Hofstede}

Si se explora la cultura colombiana a través del lente del Modelo de las 6 Dimensiones de Hofstede, podemos obtener una buena visión general de los factores profundos de su cultura en relación con otras culturas del mundo. 
Gráfico 20. Colombia - Análisis Hofstede

Colombia

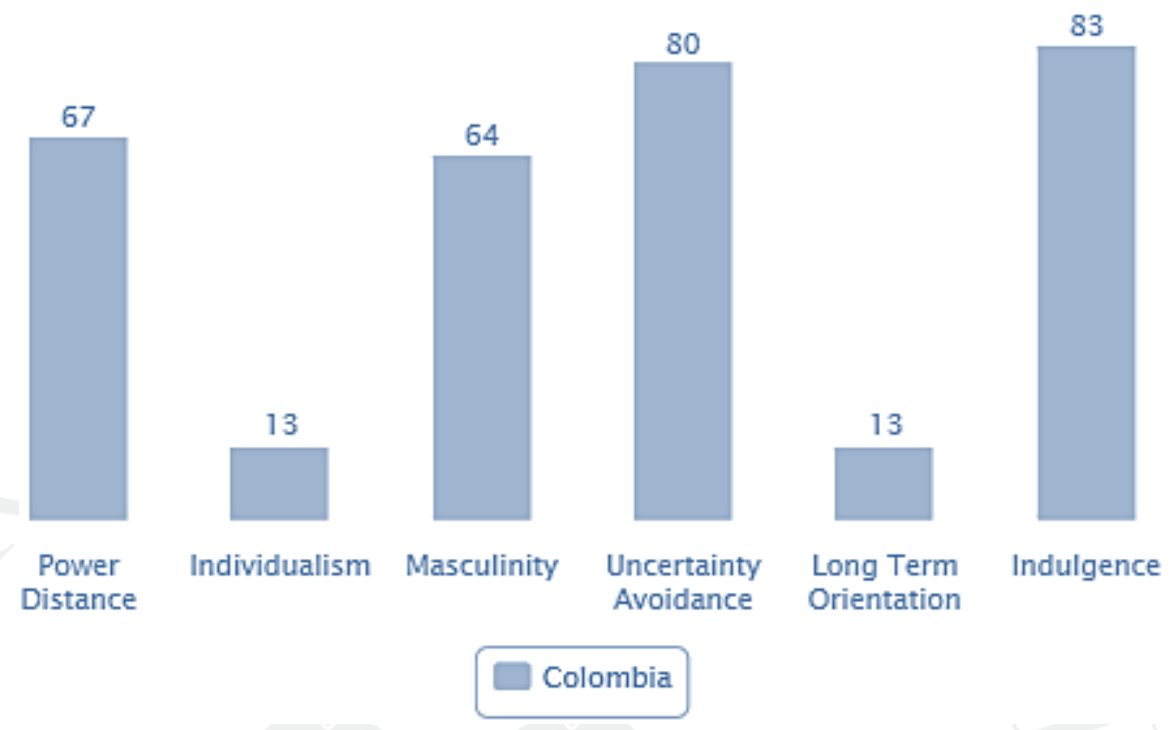

Fuente: http://geert-hofstede.com/colombia.html

\section{Distancia al Poder}

Esta dimensión aborda el hecho de que todos los individuos en las sociedades no son iguales - expresa la actitud de las personas miembros de esa cultura hacia este tipo de desigualdades. Esta dimensión se define como el grado en que los menos poderosos miembros de las instituciones y organizaciones dentro de un país esperan y aceptan que el poder se distribuya de manera desigual. (The Hofstede Centre)

Al obtener un puntaje de 67, Colombia está en lo alto de la escala, por lo que es una sociedad que cree que las desigualdades entre las personas son simplemente un hecho de vida. Esta desigualdad es aceptada en todas los niveles de la sociedad; esto se puede observar entre los líderes empresariales y entre los más altos cargos en el gobierno. 


\section{Individualismo vs. Colectivismo}

La cuestión fundamental abordada por esta dimensión es el grado de interdependencia que una sociedad mantiene entre sus miembros. Si la autoimagen de cada una de las personas que conforman este país se define en términos del "yo" o del "nosotros". En las sociedades individualistas se supone que la gente se preocupa por cuidar de sí mismos y principalmente de su familia directa. En las sociedades colectivistas las personas pertenecen a 'grupos' que se cuidan entre ellos y en donde la lealtad es muy arraigada. (The Hofstede Centre)

Con un puntaje de 13 en esta dimensión, Colombia está dentro de los países menos individualistas; en otras palabras se encuentra entre las culturas más colectivistas del mundo, superada únicamente por Ecuador, Panamá y Guatemala.

Alinearse a la opinión del grupo es muy importante. Combinado con la alta puntuación que obtuvo este país para la dimensión de 'Distancia al poder', esto significa que la población está fuertemente ligada y se siente identificada a la clase o grupo social al que pertenecen. Se evitan los conflictos, a fin de mantener la armonía del grupo y conservar la lealtad.

\section{Masculinidad}

Una puntuación alta (Masculinidad) en esta dimensión indica que la sociedad se verá impulsada por la competencia, el logro y el éxito; el éxito se define por el ganador / mejor en el campo - un sistema de 
valores que comienza en la escuela y continúa durante toda la vida organizacional. (The Hofstede Centre)

Una puntuación baja (Feminidad) en la dimensión significa que los valores dominantes en la sociedad están enfocados en el cuidado a los demás y la calidad de vida. Una sociedad femenina es uno donde la calidad de vida es el signo de éxito y sobresalir de la multitud no es admirable. (The Hofstede Centre)

Con un puntaje de 64 Colombia es una sociedad masculina - altamente orientada e impulsada al éxito. Los colombianos son competitivos y orientados al status, sin embargo colectivistas más que individualistas. Esto significa que la competencia está dirigida a los miembros de otros grupos (o clases sociales), no hacia los que se perciben como miembros de su propio grupo.

La gente busca la pertenencia a grupos que les dan estatus y recompensas ligadas al rendimiento, y a menudo sacrifican ocio contra el trabajo, siempre y cuando esto sea apoyado por la pertenencia al grupo y por quienes ostentan el poder.

\section{Aversión a la Incertidumbre}

La dimensión de control de la incertidumbre tiene que ver con la forma en que una sociedad trata del hecho de que el futuro es incierto: ¿Debemos tratar de controlar el futuro o simplemente dejar que suceda? 
Esta ambigüedad trae consigo la ansiedad y diferentes culturas han aprendido a lidiar con esta ansiedad de diferentes maneras. (The Hofstede Centre)

Con un puntaje de 80 Colombia tiene una puntuación alta en control de la incertidumbre lo que significa que, como nación, están buscando mecanismos para evitar ambigüedades. Las emociones se expresan abiertamente; hay reglas para todo y el conservadurismo social goza de muchos seguidores. Esto también se refleja en la religión, que es respetada, conservadora y seguida por muchos.

Sin embargo, cabe resaltar que a veces a pesar de que todo debe de ser planificado a detalle, al momento de ser concretado muchas veces no se lleva a la práctica lo estipulado.

\section{Orientación a Largo Plazo}

Esta dimensión describe cómo cada sociedad tiene que mantener algunos vínculos con su propio pasado en el trato con los desafíos del presente y el futuro. (The Hofstede Centre)

Con una puntuación baja de 13, la cultura colombiana se clasifica como normativa. La gente en esas sociedades tiene una fuerte preocupación por el establecimiento de la verdad absoluta; son normativas en su pensamiento. Presentan un gran respeto por las tradiciones, una parte 
relativamente pequeña propensión a ahorrar para el futuro, y un enfoque en el logro de resultados rápidos.

\subsubsection{Fuerzas tecnológicas y científicas ( $\mathrm{T}$ )}

El avance de la industria cosmética y de aseo en Colombia es tan vertiginoso y dinámico, que no solo se está posicionando como uno de los sectores más promisorios a escala mundial, sino que está generando desarrollos productivos sustentables e innovadores a partir de características nacionales como biodiversidad, saber indígena, campesino y capacidades de las comunidades académica y empresarial. (Universidad Nacional de Colombia, 2014)

La estructura empresarial que comprende el sector de cosméticos en Colombia en los últimos años ha sufrido cambios debido a transiciones en la demanda; asimismo, respecto a la oferta, esta se encuentra focalizada en un número reducido de empresas, lo que representa una estructura de mercado tipo oligopólico, es por ello que este pequeño grupo de oferentes juegan un rol fundamental en la definición de los precios y el nivel de producción en esta industria. Según el INVIMA en Colombia se mantienen operando alrededor de 400 empresas de este tipo, pero únicamente 10 concentran el $65 \%$ de la producción.

Las características de la industria de cosméticos en Colombia son particulares y complejas, debido a la gran gama de productos que se fabrican, variedad de insumos, usos y procesos de producción. Es por ello que las empresas que son parte de este sector van desde las 
artesanales hasta las tecnológicamente sofisticadas a nivel de procesos y líneas de producción, las empresas de capital foráneo como ColgatePalmolive, Procter and Gamble Colombia Ltda., Johnson and Johnson de Colombia S.A., Bell Star y Pro Nova Ltda (Avon) son las que más destacan en este sector, y las empresas nacionales que son de mediano tamaño se enfocan especialmente en productos de maquillaje y tratamientos capilares y dermatológicos. Dentro de este grupo de empresas nacionales se destacan Prebel, Capill'france S.A., Laboratorios de Cosméticos Vogue S.A. y Mercantil de Belleza, S.A., entre otras, las cuales centralizan su estrategia en la diferenciación por calidad a precios módicos para los mercados populares vendiendo de manera masiva. Tanto el grupo de empresas nacionales como filiales de empresas extranjeras compran del exterior la mayoría de los insumos para sus procesos. (estudiosocieconomico, 2014)

Los procesos productivos para la fabricación de cosméticos son diversos y en la mayoría de casos de baja complejidad tecnológica, generalmente, los procesos son la mezcla de materias primas y ensamble, para lo cual se emplean molinos, mezcladoras, moldeadoras y compactadoras, entre otros. Para la presentación de empaques existe cierta tecnificación y sistematización aunque el empaque manual sigue siendo utilizado por estas empresas.

El sector de cosméticos en Colombia desde sus inicios no ha mostrado una tendencia hacia el comercio exterior, solo después del proceso de 
apertura comercial y económica el flujo de las importaciones y exportaciones del sector ha mostrado una tendencia creciente, convirtiéndose en un atractivo para la inversión extranjera, lo cual se vio promovido debido a que este sector fue uno de los primeros en suscribir un convenio de competitividad con el gobierno dentro del marco de la política nacional para la productividad. La producción a nivel nacional de cosméticos tiene ventajas tanto comparativas como competitivas para hacer frente a los productos importados; principalmente dado los bajos costos de capital humano, redes de comercialización interna y elementos de diferenciales de sus productos. (Propaís, 2014)

Dentro del sector de cosméticos y aseo en Colombia el $66 \%$ de la producción corresponde a cosméticos y el 34\% restante a productos de aseo. Dentro del sector de cosméticos el $16 \%$ corresponde a champúes, el $12 \%$ a cremas de dientes, el $10 \%$ a perfumes, otro $10 \%$ a jabones de tocador, el $7 \%$ a cremas de tocador y el $45 \%$ restante a los demás.

Según datos de la Cámara Sectorial de Cosméticos de la ANDI (Asociación Nacional de Industriales), el mercado de Cosméticos en Colombia creció alrededor de $7.15 \%$ durante los últimos años, porcentaje muy superior al crecimiento de la industria (3.75\%). Es por este motivo que el crecimiento de este sector ha sido casi el doble que el crecimiento de la industria en sí y además permaneció poco vulnerable en relación a la depresión económica que experimentó el país a finales de los 90. Este crecimiento tan marcado del tamaño del mercado se explica en gran parte 
por la evolución de las importaciones después de la apertura económica, que ha tenido una tasa de crecimiento anual promedio del $27.5 \%$. Por esto se puede concluir que el mercado colombiano crecerá influenciado por el mercado externo durante los próximos años.

\section{Elementos necesarios y/o indispensables para competir en el sector}

En base a diferentes estudios, se puede inferir que la producción nacional no compite de manera directa con las multinacionales en el mercado colombiano, debido a que las empresas locales cuentan con importantes ventajas comparativas tales como los bajos precios en la mano de obra, redes de comercialización interna y elementos diferenciales de su oferta. Además, otros estudios aseveran que por el crecimiento económico que ha tenido el país en los últimos 10 años, el consumidor colombiano encuentra mayor preocupación por el cuidado personal y la apariencia física, esto dado un incremento del poder adquisitivo de la población, relativo incremento de la clase media, influencia cada vez mayor de las actividades promocionales de las multinacionales así como la repercusión que tienen los medios de comunicación e incremento de la población urbana. Por estas razones la ANDI sostiene que la competencia es cada vez más enérgica entre empresas nacionales y multinacionales.

Según la Oficina Económica y Comercial de la Embajada de España en Bogotá, los factores de decisión al momento de la compra por parte del consumidor colombiano son el precio y el posicionamiento de la marca, 
por lo tanto estos dos puntos se deben considerar como los elementos necesarios para competir en el sector de cosméticos en Colombia.

Otros elementos clave se derivan del nivel de competencia entre empresas y la rápida evolución de la moda, las empresas deben desarrollar una gran capacidad de especialización y diferenciación, lo que a su vez genera nuevos targets de mercado. Las grandes multinacionales han acaparado el mercado con estrategias de posicionamiento de marca, reubicación de producción, lo cual ha traído como consecuencia que las empresas locales deban rediseñar sus líneas de acción, primariamente reenfocarse a los negocios de maquila.

De igual manera es fundamental conocer el sistema de distribución y comercialización en la industria, para que las empresas puedan tener la flexibilidad de adaptarse a rápidos e imprevistos cambios del mercado.

Por otro lado, se debe de tener en cuenta que la legislación sanitaria tiene un rol importante en la planeación estratégica de las empresas de este sector, debido a que será mandatorio cumplir las normas y estándares de calidad exigidos a nivel nacional e internacional.

\subsubsection{Fuerzas ecológicas y ambientales (E)}

El creciente comercio internacional de productos de la biodiversidad está reflejado en transacciones que superan los 750 mil millones dólares al año; incluyendo plantas medicinales, ingredientes naturales, gomas, 
látex, resinas y tintes naturales; muchos de ellos empleados en el desarrollo de la industria cosmética y cosmecéutica. (Universidad Nacional de Colombia, 2014)

"La biodiversidad es una de las grandes ventajas competitivas, así como la oferta, pues hay variedad y los productores nacionales ajustan sus productos a las necesidades de los compradores, aprovechando nichos de mercado con valor agregado y así expandir esta industria para su internacionalización”, señaló María Claudia Lacouture, presidente de PROCOLOMBIA.

La tendencia naturista en el sector cosmético a nivel mundial es la relacionada con los productos de origen natural. Los productos naturales han ido tomando importancia en el ámbito económico nacional e internacional, dado el crecimiento de la demanda por estos productos en los que Colombia posee una ventaja comparativa por su inmensa riqueza en recursos naturales. Colombia se muestra como uno de los países líderes en el mundo para la innovación en productos basados en insumos naturales. 


\subsection{Matriz de Evaluación de Factores Externos (EFE).}

Tabla 15. Matriz EFE

\begin{tabular}{|l|c|c|c|}
\hline & PESO & VALOR & PUNTAJE PONDERADO \\
\hline OPORTUNIDADES (+) & 0.18 & 4 & 0.72 \\
\hline Evolución del PBI nacional & 0.10 & 4 & 0.40 \\
\hline Poder adquisitivo & 0.05 & 4 & 0.20 \\
\hline Crecimiento de la población & 0.02 & 4 & 0.08 \\
\hline Regulaciones Arancelarias - CAN & 0.08 & 4 & 0.32 \\
\hline Evolución de importaciones & 0.04 & 3 & 0.12 \\
\hline Promoción Comercial & 0.03 & 3 & 0.09 \\
\hline Tasa de inflación & 0.19 & 4 & 0.76 \\
\hline Factores culturales y psicológicos & \multicolumn{2}{|l|}{} \\
\hline AMENAZAS (-) & 0.09 & 1 & 0.09 \\
\hline Estabilidad Política & 0.05 & 2 & 0.10 \\
\hline Organismos Reguladores & 0.07 & 1 & 0.07 \\
\hline Competencia Internacional & 0.10 & 1 & 0.10 \\
\hline Posicionamiento de Grandes Marcas & $\mathbf{1}$ & $\mathbf{3 . 0 5}$ \\
\hline TOTAL &
\end{tabular}

Elaboración Propia

La matriz de evaluación de los factores externos (EFE) permite a los estrategas resumir y evaluar información económica, social, cultural, demográfica, ambiental, política, gubernamental, jurídica, tecnológica y competitiva.

A través del análisis de la Matriz de Evaluación de Factores Externos, podemos inferir que la empresa con un puntaje total de 3.05 -por encima del promedioestá compitiendo en un ramo atractivo y dispone de oportunidades externas que tienen un impacto positivo sobre la misma. 


\section{CAPITULO V. ANÁLISIS COMPETITIVO}

\subsection{Análisis de las 5 fuerzas competitivas de Michael Porter.}

El modelo de las fuerzas competitivas de Porter es probablemente una de las herramientas de uso más frecuente de la estrategia de negocio. Ha probado su utilidad en numerosas ocasiones. El modelo de Porter es particularmente fuerte en la interiorización del pensamiento estratégico. (Decisión Empresarial)

Gráfico 21. Diamante Competitivo de Porter

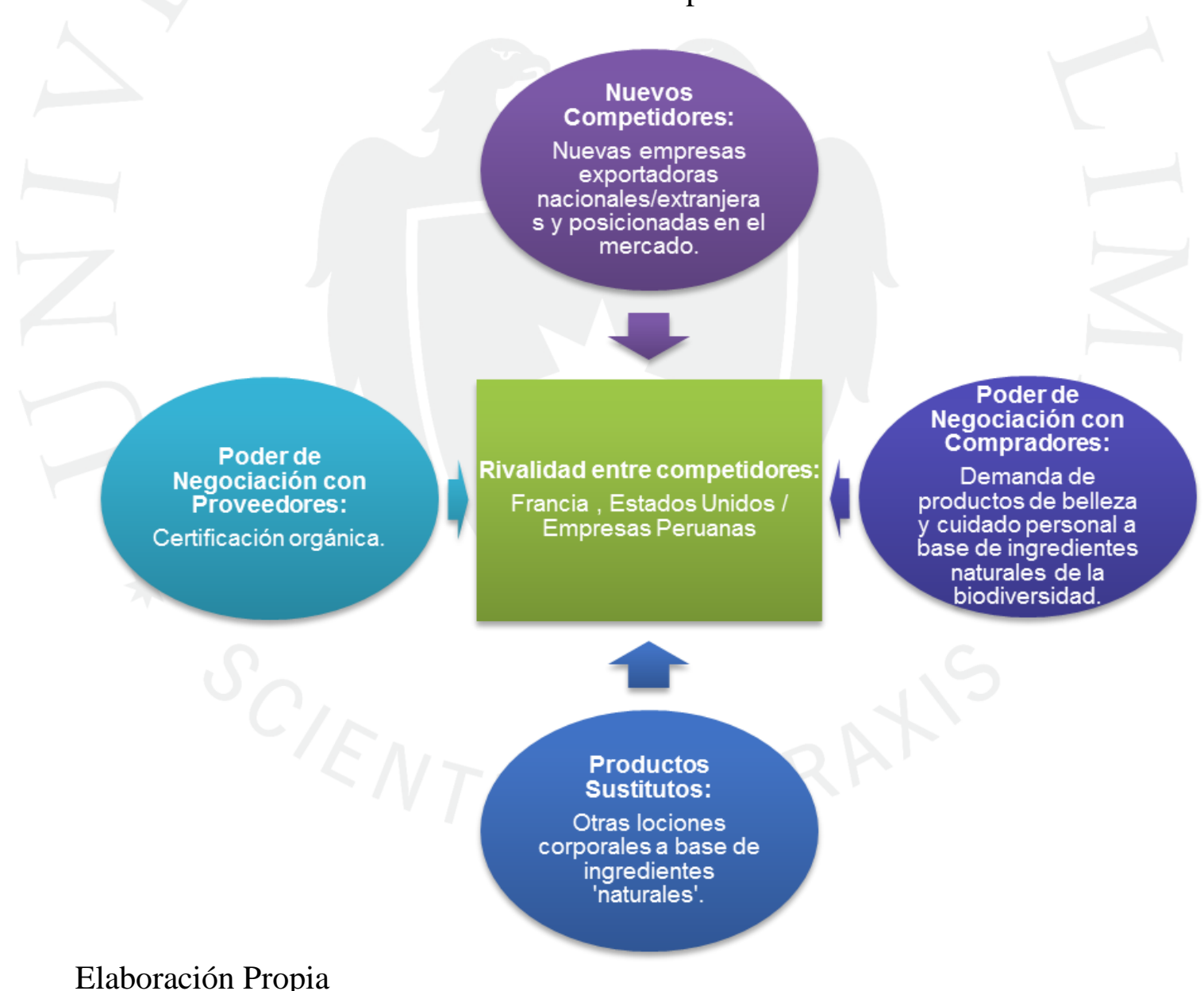




\section{Amenaza de entrada de nuevos competidores}

El número de empresas exportadoras dentro de la industria de la belleza y cuidado personal presenta una tendencia creciente; esto fundamentalmente a que los consumidores están demandando productos más innovadores, funcionales y formulados a base de ingredientes naturales, en este caso aceite de sacha inchi orgánico; siendo un producto de gran calidad, con elevado valor agregado, que responde a las exigencias del mercado y se caracteriza por ser diferenciado, en comparación a la mayoría de lociones corporales a base de ingredientes químicos.

Para este mercado la amenaza de entrada de nuevos competidores en nuestro sector es 'medio'; esto debido a que los costes de entrada al sector y la inversión que implica se encuentran en un nivel promedio; no obstante, para entrar en competencia las empresas deberán cumplir con todos los requisitos propuestos por las autoridades sanitarias locales y cumplir con las normas del INVIMA (Instituto Nacional de Vigilancia de Medicamentos y Alimentos de Colombia).

En el caso del Perú Indecopi es el responsable de elaborar y dictar las normas técnicas de certificación y control de calidad de los productos y subproductos, así como también aplicar las sanciones previamente establecidas ante el no uso de los estándares; la sanidad de los productos deberá ser calificada por el DIGEMID (Dirección General de Medicamentos Insumos y Drogas).

\section{Rivalidad entre competidores}


Colombia importa productos de belleza y cuidado personal principalmente de Estados Unidos, Perú y Francia con una participación de 17\%, 13.9\% y 13.9\% respectivamente. La ventaja de estos países frente a Perú es que son países considerados como desarrollados, posicionados como los principales exportadores de la partida a nivel mundial, y reconocidos la calidad y sofisticación de su oferta exportable.

Por otro lado cabe mencionar que gracias a ser parte de la Comunidad Andina (CAN) con Colombia, nosotros contamos con un arancel de $0 \%$ lo cual nos brinda una ventaja frente a países como Estados Unidos y Francia, con un arancel del $15 \%$.

Además, podemos encontrar empresas peruanas como UNIQUE S.A., CORSA XPORT E.I.R.L. y EURODERMA DROGUERIA S.A.C. con 95.83\%, 3.10\% y $0.55 \%$ de participación en las exportaciones peruanas de la partida arancelaria 330499. Empero, se considera como competidor directo a la empresa Unique S.A. al ofrecer un producto similar al del proyecto, Body Spa Sacha Inchi Óleo Trifásico para el cuerpo en presentación de 200ml, y posicionado en Bogotá, Colombia; pero diferenciándose por no ser un producto orgánico lo cual le otorga a nuestro producto un gran valor agregado.

Como empresa nueva es importante reforzar nuestro posicionamiento a través de productos innovadores, valores agregados, satisfacción de necesidades del mercado, buen diseño y calidad. 
Por ello, sobre la rivalidad de la competencia en nuestro sector podemos afirmar que es 'medio'.

\section{Poder de negociación de los proveedores}

Al ser nuestro insumo principal el aceite de sacha inchi y de acuerdo con información obtenida del Banco Central de Reserva del Perú (BCRP) para el último año, toda la producción de sacha inchi proviene de la zona Nororiental del país, principalmente de los departamentos de Ucayali, Loreto y San Martín.

Cabe resaltar que en cuanto a la productividad, en general, se obtiene $12 \%$ de aceite por cada kilogramo de semilla; sin embargo, este porcentaje puede variar en función del método de extracción aplicado.

Asimismo, existen dos empresas que son las principales transformadoras y comercializadoras de aceite de sacha inchi en la región de San Martín; Agroindustrias Amazónicas S.A. y Roda Selva S.A.C; siendo Agroindustrias Amazónicas S.A. la empresa que nos proveerá del principal insumo para la elaboración de la loción corporal 'aceite de sacha inchi certificado como orgánico’.

No obstante, vale mencionar que en nuestro país no todos los productores de sacha inchi y sus derivados están certificados como orgánico, únicamente unos cuántos cuentan con dicha certificación. Es por ello que el poder de negociación de los proveedores de este insumo, utilizado en la producción de nuestro producto, es 'alto'. 


\section{Poder de negociación de los compradores}

El segmento de mercado al cual se dirige este producto se caracteriza por su alta capacidad adquisitiva; principalmente mujeres dispuestas a pagar un monto mayor por productos de belleza y cuidado personal naturales y orgánicos, debido a los beneficios saludables que éstos les brindan y los estándares bajo los cuales han sido producidos.

Ello conlleva a que el comprador demande un producto de alta calidad, que cumpla con las exigencias del mercado y de buena presentación.

Por ser una pequeña-nueva empresa, nuestros clientes tendrán un elevado dominio en cuanto a términos y condiciones de venta, así como la forma y plazo de pago. Todo esto aunado a la intensidad de la competencia por parte de las empresas del sector, da como resultado un 'alto' poder de negociación por parte de nuestros clientes.

\section{Amenaza de ingreso de productos sustitutos}

En líneas generales en el mercado colombiano existe una vasta cantidad de productos de la industria de belleza y cuidado personal, particularmente, lociones corporales; no obstante, aún se mantiene relativamente pequeño el mercado que comprende este tipo de lociones a base de ingredientes naturales orgánicos.

La única empresa peruana que actualmente tiene presencia, en mínima escala, en el mercado de Colombia, particularmente Bogotá y que cuenta con una oferta de 
productos de belleza orgánicos es la empresa YANA COSMETICS S.A.C. con su marca MISHKI; asimismo podemos mencionar a la empresa CANDELA DEL PERÚ, proveedora de insumos naturales y orgánicos, como el aceite de castaña amazónica, utilizado como ingrediente para la elaboración de productos de la industria de belleza y cuidado personal.

A pesar de no contar con un producto igual al de nuestro proyecto, los consumidores podrían variar sus decisiones de compra de no encontrar la marca, presentación o tipo de producto que desean; debido a que el fin es el mismo: cuidar e hidratar la piel.

\subsection{Principales empresas exportadoras o importadoras peruanas.}

Tabla 16. Valor FOB 2014 de las principales empresas peruanas que exportan la partida 330499 al mercado colombiano

\begin{tabular}{|l|r|r|}
\hline Empresa & Peso Neto Kg. & \multicolumn{1}{c|}{$\begin{array}{c}\text { Valor FOB } \\
\text { USD }\end{array}$} \\
\hline UNIQUE S.A. & $1,006,915.82$ & $12,518,273.11$ \\
\hline CORSA XPORT E.I.R.L. & $4,520.00$ & $405,000.00$ \\
\hline $\begin{array}{l}\text { EURODERMA DROGUERIA S.A.C. - } \\
\text { EURODERMA }\end{array}$ & 812.99 & $72,386.04$ \\
\hline NOVADERMA SAC & 563.07 & $38,062.50$ \\
\hline PRODUCTOS AVON S A & $1,281.10$ & $11,408.85$ \\
\hline LABORATORIOS PORTUGAL S R L & 770.4 & $8,161.36$ \\
\hline NATURA COSMETICOS S.A. & 778.78 & $6,942.65$ \\
\hline ARDYSS INTERNATIONAL PERU S.R.L. & 140.79 & $1,631.64$ \\
\hline L'OREAL PERU S.A. & 119.71 & $1,259.69$ \\
\hline ORIFLAME PERU SA & 15.49 & 412.09 \\
\hline
\end{tabular}

Fuente: Infotrade

Como podemos observar en el cuadro anterior, la empresa UNIQUE S.A. es la principal exportadora de la partida 330499, con un valor FOB total exportado en el año 2014 de más de 12 millones de dólares, representando un $95.83 \%$ de 
participación en el total de las exportaciones hacia Colombia. Cabe resaltar que es la única empresa de la lista que ofrece un producto similar al desarrollado en el proyecto; un Body Spa Sacha Inchi Óleo Trifásico para el cuerpo en presentación de 200ml, no obstante, este producto está elaborado con ingredientes químicos y no cuenta con ningún tipo de certificación orgánica.

Asimismo, encontramos a la empresa CORSA XPORT E.I.R.L. con un valor FOB total de 405 mil dólares y una participación del 3.10\% en las exportaciones hacia Colombia en el 2014; seguido de la empresa EURODERMA con un valor FOB total de más de 72 mil dólares y una participación del $0.55 \%$. 
5.3. Análisis de la competencia internacional.

Gráfico 22. Lista de los mercados proveedores para un producto importado por Colombia en 2014

Producto: 3304 Preparaciones de belleza, maquillaje y para el cuidado de la piel

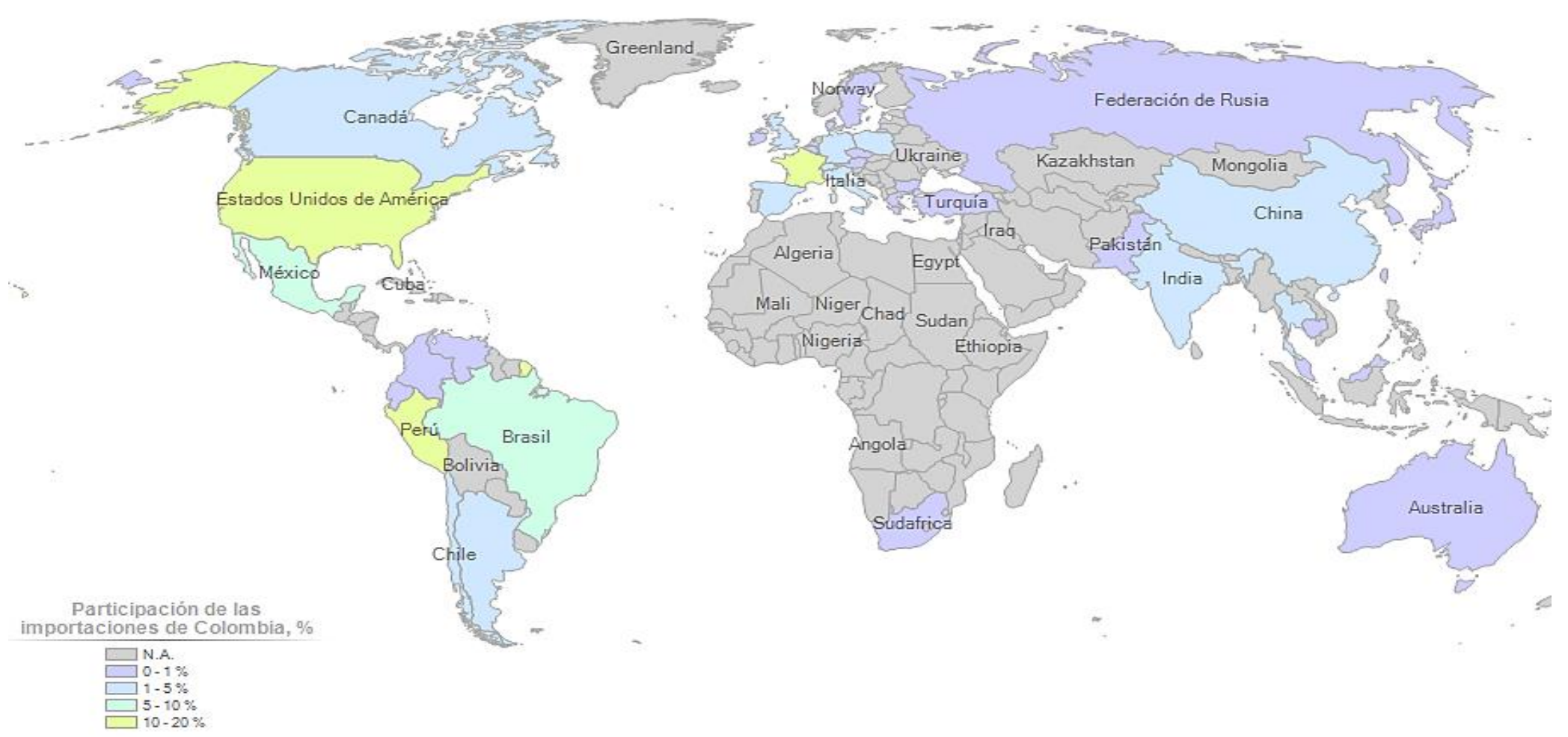

Fuente: TradeMap 
Como principales competidores a nivel internacional encontramos a Estados

Unidos y Francia, analizados anteriormente.

\subsection{Principales empresas del sector.}

Tabla 17. Participación de Mercado de las principales 10 compañías del sector de cuidado de la piel, Categoría ‘General Purpose’ - Según valor 2011 - 2014

\begin{tabular}{|l|l|r|r|r|r|}
\hline $\begin{array}{l}\text { \% Participación } \\
\text { (Valor) }\end{array}$ & \multicolumn{1}{|c|}{ Compañía } & $\mathbf{2 0 1 1}$ & $\mathbf{2 0 1 2}$ & $\mathbf{2 0 1 3}$ & $\mathbf{2 0 1 4}$ \\
\hline Lubriderm & Johnson \& Johnson de Colombia SA & 10.7 & 11.3 & 12.7 & 12.8 \\
\hline Esika & Belstar SA & 13.7 & 15.3 & 12.7 & 11.3 \\
\hline Natura & Natura Cosméticos SA & 5.8 & 7 & 7.8 & 10.1 \\
\hline Yanbal & Yanbal de Colombia SA & 7.1 & 7.4 & 8.1 & 8.1 \\
\hline Johnson's & Johnson \& Johnson de Colombia SA & 7.6 & 7.3 & 7.8 & 7.7 \\
\hline Nivea Happy Time & Beiersdorf (Colombia) SA & 5.5 & 7.4 & 6.7 & 7 \\
\hline Avon Care & Avon Colombia Ltda & 6.8 & 7.1 & 7.4 & 7 \\
\hline Avon Skin So Soft & Avon Colombia Ltda & 5 & 5.4 & 5.9 & 6 \\
\hline Avon Naturals & Avon Colombia Ltda & 5.5 & 4.7 & 5.2 & 5 \\
\hline Vasenol & Unilever Andina Colombia SA & 3.4 & 3.3 & 3.6 & 3.6 \\
\hline
\end{tabular}

Fuente: Euromonitor International

\subsection{Barreras arancelarias $y$ no arancelarias.}

\section{$\underline{\text { Medidas Arancelarias }}$}

Los productos peruanos no pagan aranceles para ingresar a Colombia por formar parte de la Comunidad Andina (CAN), por lo tanto, existe una zona de libre comercio. Colombia aplica el arancel externo común de la CAN a los productos importados que ingresan a su territorio, excepto a los provenientes de los países de la CAN y de los países con los cuales ha firmado acuerdos comerciales. (PROMPERÚ, 2014)

\section{$\underline{\text { Medidas No Arancelarias }}$}

Todas las mercancías importadas deben ser registradas ante el Ministerio de Comercio Exterior en un formulario "Registro de Importación" para que sean 
autorizadas de forma casi automática, a menos que se trate de productos agrícolas que están sujetos a una licencia.

Además, los productos cosméticos están sujetos a medidas fitosanitarias y el importador debe registrarse ante el Instituto Nacional de Vigilancia de Medicamentos y Alimentos. Este trámite requiere una evaluación y sustentación histórica que realiza una comisión revisora del INVIMA, así como una evaluación técnica (farmacológica) y legal que verifique la existencia legal de la empresa y las características físicas y químicas del producto. (Organización Mundial de la Salud, Oficina Regional para las Américas, Colombia)

\subsection{Matriz del Perfil Competitivo (MPC).}

Tabla 18. Matriz (MPC)

\begin{tabular}{|l|c|c|c|c|c|c|c|}
\hline Variables & PESO & \multicolumn{2}{|c|}{ UNIQUE S.A. } & \multicolumn{2}{|c|}{$\begin{array}{c}\text { BIOPERÚ } \\
\text { NATURAL } \\
\text { PRODUCTS }\end{array}$} & $\begin{array}{c}\text { YANA } \\
\text { COSMETICS } \\
\text { S.A.C. }\end{array}$ \\
\hline $\begin{array}{l}\text { Años de experiencia en el } \\
\text { negocio }\end{array}$ & 0.15 & 4 & 0.60 & 1 & 0.15 & 2 & 0.30 \\
\hline Capacidad de producción & 0.20 & 4 & 0.80 & 2 & 0.40 & 2 & 0.40 \\
\hline Gestión Económica & 0.12 & 4 & 0.48 & 2 & 0.24 & 1 & 0.12 \\
\hline Gestión Exportadora & 0.12 & 3 & 0.36 & 2 & 0.24 & 2 & 0.24 \\
\hline Precios competitivos & 0.20 & 3 & 0.60 & 3 & 0.60 & 1 & 0.20 \\
\hline $\begin{array}{l}\text { Oferta de Productos } \\
\text { Naturales u Orgánicos }\end{array}$ & 0.21 & 1 & 0.21 & 4 & 0.84 & 4 & 0.84 \\
\hline TOTAL & $\mathbf{1 . 0 0}$ & & $\mathbf{3 . 0 5}$ & & $\mathbf{2 . 4 7}$ & & $\mathbf{2 . 1 0}$ \\
\hline
\end{tabular}

Elaboración Propia

La Matriz del Perfil Competitivo (MPC) es una herramienta que permite identificar las fortalezas y debilidades de nuestros principales competidores con respecto a los factores claves de éxito (FCE) de la industria. Esto permitirá al empresario conocer el competidor que representa la mayor amenaza, así como qué FCEs representan oportunidades o amenazas para la empresa y así 
poder desarrollar estrategias que le permitan fortalecer su posición en el mercado.

Como se puede observar en los resultados, la empresa UNIQUE S.A. es el competidor más amenazador para nuestra empresa, BIOPERÚ NATURAL PRODUCTS; considerando factores como los años de experiencia en el sector de la belleza y el cuidado personal, la capacidad de producción que posee, al contar con varias plantas productivas, y la capacidad económica y financiera de esta firma multinacional. No obstante, también debemos de hacer hincapié en el hecho de que esta empresa aún no ha ingresado al mercado con una oferta de productos de belleza y cuidado personal naturales y orgánicos; es en este aspecto en el que nuestra empresa cuenta con una oportunidad de negocio, al ofrecer un producto diferenciado que destaca su funcionalidad y la naturalidad de su contenido. En consecuencia, es necesario fortalecer nuestra posición en el mercado y concretamente en los factores que marca la M.P.C., en los que UNIQUE S.A. se encuentra en desventaja. 


\section{CAPITULO VI. ELECCIÓN DE OBJETIVOS, ESTRATEGIAS Y POLÍTICAS}

\subsection{Objetivos de largo plazo.}

\section{Objetivo General}

Desarrollar un plan de negocio para la exportación de lociones corporales a base de insumos naturales de la biodiversidad peruana, que nos permita una ventaja competitiva en base a una comercialización eficiente y sostenible, cumpliendo los requisitos y exigencias del mercado.

\section{Objetivos Específicos}

a) Conseguir una participación del $1 \%$ del mercado de las lociones corporales del sector de belleza en Bogotá, Colombia.

b) Lograr un proyecto sostenible desde el punto de vista productivo y comercial.

c) Obtener un plan financiero viable de manera que los indicadores financieros sean positivos; es decir, un VAN mayor que 1 y un TIR mayor que el WACC. Se recuperará la inversión en 4 años.

\subsection{Elección de estrategias.}

La estrategia genérica elegida es la de enfoque de diferenciación. Esta consiste en que la empresa ofrece en el mercado un producto que por los motivos que sea el consumidor percibe como único y por tanto está dispuesto a pagar un 
sobreprecio por adquirido; a fin de las características intrínsecas del producto, entre las que destacan su calidad y grado de innovación.

Según el resultado de las estrategias posibles a aplicar según las características propias, el entorno en el que se desenvuelve y los factores claves del producto, habiéndose reflejado cada uno dentro de las distintas matrices descritas en los siguientes puntos desarrollados; es conveniente aplicar aquellas estrategias que se repiten más de una vez en cada uno de los análisis matriciales, a fin de que elegir aquella o aquellas que más se adapten a las características y valores del negocio.

\subsubsection{Matriz de Fortalezas, Oportunidades, Debilidades y Amenazas (FODA)}

Tabla 19. Matriz FODA

\section{Fortalezas}

- F1: Producto de calidad diferenciado y de alto valor agregado al ser su principal insumo el aceite de sacha inchi certificado orgánico.

- F2: Conocimientos en investigación de mercados.

- F3: Adaptación de envase según los criterios del mercado.

- F4: Personal capacitado en operaciones y a nivel administrativo.

- F5: Fácil capacidad de almacenaje y larga vida útil de nuestro producto harina

\section{Oportunidades}

- O1: Mercado en expansión: Aumento del poder adquisitivo por mayor inserción de la mujer en el mercado laboral y la existencia nichos de mercado.

- O2: Perú cuenta con un gran potencial en biodiversidad para el desarrollo de cosméticos y tratamientos naturales.

- O3: Arancel 0\%, en comparación con Estados Unidos y Francia (15\%).

\section{Debilidades}

D1: Poder de negociación limitado con proveedores.

D2: Capacidad de transporte interno.

D3: Dificultad de obtener financiamiento al ser una empresa 'nueva'.

D4: Necesidad en concentración de recursos para promoción internacional.

\section{Amenazas}

A1: Competidores son empresas multinacionales con representantes de marcas de prestigio mundial.

$\checkmark \quad$ A2: Fuerte competencia a nivel de líneas y categorías de productos, marcas, precios y canales de distribución.

A3: Las autoridades sanitarias colombianas, pueden solicitar alguna certificación adicional para el ingreso del producto.

Elaboración Propia 


\subsection{Objetivos de corto plazo.}

$\checkmark$ Poner en marcha el proyecto de exportación antes de que finalice el 2015.

$\checkmark$ Conseguir una cartera de clientes fija, un mínimo de 2 tiendas especializadas el primer año.

$\checkmark$ Por medio del plan de promoción y comunicación persuasiva, se busca obtener que en principio el cliente llegue a conocer las bondades y propiedades que brinda el producto a la piel.

$\checkmark$ En el primer año de ejecución se busca que al menos se lleguen a producir dos productos derivados a base de aceite de sacha inchi orgánico, como son shampoo y demás productos para cuidado capilar; cremas faciales, exfoliantes, etc.

$\checkmark$ Establecer requerimientos indispensables en la ejecución, de tal forma que se logre anticipación antes de reacción.

Desarrollar una imagen corporativa para la empresa para finales del 2015.

\subsection{Políticas.}

\section{$\checkmark$ Política de Calidad}

Nuestro compromiso es mejorar continuamente el desempeño, por medio de un equipo humano competente que mantiene altos niveles de calidad, en la producción de nuestros productos de belleza y cuidado personal. 
Contamos con la tecnología y los procesos necesarios que garantizan la calidad de nuestros productos, respaldados por un estricto control de procesos y de laboratorio y un alto nivel ético.

Garantizamos el éxito de esta política mediante la medición de nuestro desempeño, con un enfoque de cumplimiento, rendimiento y progreso; promoviendo las mejores prácticas dentro de nuestra compañía y en la industria en general.

\section{Política de Ventas}

Serán respetados los contratos de venta firmados por la Dirección de Comercio Exterior; cumpliendo con los precios consignados en el mismo una vez concretada la negociación.

Además, la empresa se compromete a cumplir con los tiempos de entrega y despacho acordados. Así como también, la empresa se compromete a entregar toda la documentación requerida por el importador (la factura comercial, certificados de análisis del producto, documentos de embarque, etc.)

\section{$\checkmark$ Política de Sostenibilidad}

La empresa ha definido su política de sostenibilidad basada en el respeto al medio ambiente en todos los eslabones de su cadena de producción. Así como también, la empresa promoverá el desarrollo profesional y ético del equipo humano que la comprende bajo un enfoque de RSE.

\subsection{Matriz de Evaluación de Factores Internos (EFI).}


La Matriz de Evaluación de Factores Internos suministra una base para analizar las relaciones internas entre las áreas de las empresas. Es una herramienta analítica de formulación de estrategia qua resume y evalúa las debilidades y fortalezas importantes de gerencia, mercadeo, finanzas, producción, recursos humanos, investigación y desarrollo.

Tabla 20. Matriz EFI

\begin{tabular}{|l|c|c|c|}
\hline \multicolumn{2}{|l|}{ PESO } & VALOR & $\begin{array}{c}\text { PUNTAJE } \\
\text { PONDERADO }\end{array}$ \\
\hline FORTALEZAS & 0.10 & 4 & 0.40 \\
\hline Calidad del producto & 0.12 & 4 & 0.48 \\
\hline Diferenciación del producto & 0.06 & 3 & 0.18 \\
\hline Políticas de precios & 0.08 & 3 & 0.24 \\
\hline Canales de distribución & 0.09 & 3 & 0.27 \\
\hline Capacidad de producción & 0.07 & 3 & 0.21 \\
\hline Calificaciones de empleados & 0.05 & 4 & 0.20 \\
\hline Investigación de mercados & & & \\
\hline DEBILIDADES & 0.08 & 1 & 0.08 \\
\hline Número de líneas de productos & 0.10 & 1 & 0.10 \\
\hline Participación del mercado & 0.07 & 2 & 0.14 \\
\hline Fuerza de ventas & 0.06 & 2 & 0.12 \\
\hline Velocidad y capacidad de respuesta & 0.05 & 1 & 0.05 \\
\hline Experiencia & 0.04 & 2 & 0.08 \\
\hline Expansibilidad del negocio & 0.03 & 2 & 0.06 \\
\hline Apalancamiento financiero & $\mathbf{1}$ & & $\mathbf{2 . 6 1}$ \\
\hline TOTAL
\end{tabular}

Elaboración Propia

El resultado total ponderado puede oscilar de un resultado bajo de 1.0 a otro alto de 4.0 siendo 2.5 el resultado promedio. Los resultados mayores de 2.5 indican una organización poseedora de una fuerte posición interna, mientras que los menores de 2.5 muestran una organización con debilidades internas.

Para el caso de nuestra empresa, al obtener un resultado total de 2.61 superior al promedio, se puede inferir que la organización consta de una estructura interna fortalecida. 


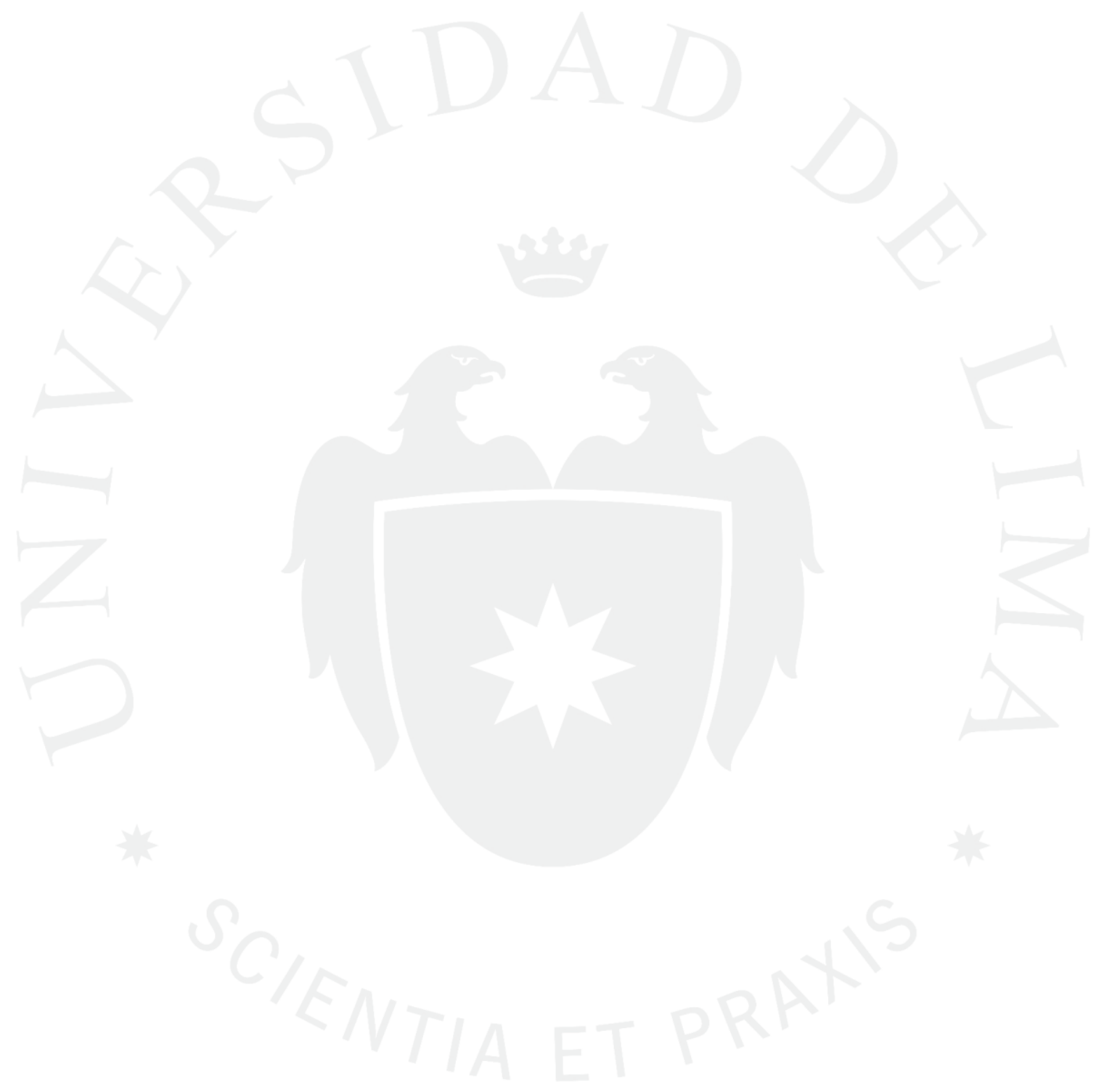




\section{CAPITULO VII. PLAN DE OPERACIONES Y/O PRODUCCIÓN}

\subsection{Objetivos de Operaciones y/o Producción.}

$\checkmark$ Entablar una relación de confianza con los proveedores del aceite de sacha inchi orgánico, el proveedor de empaques de exportación, así como con nuestro operador logístico, en un plazo de 2 a 3 años.

$\checkmark$ Exportar 8 pallets vía marítima en el primer año, lo cual debe aumentar a 10 pallets en el segundo año, 12 pallets en el tercer año, 14 pallets en el cuarto año y 16 pallets en el quinto año (Unidad de exportación LCL 2 Pallets).

$\checkmark$ Hacer hincapié en la autenticidad del producto orgánico, garantizando su calidad y certificando los beneficios derivados de éste.

$\checkmark$ Utilizar la información proporcionada por el Instituto Nacional de Vigilancia de Medicamentos y Alimento (INVIMA) para cumplir con los requisitos técnicos de exportación de nuestro producto al mercado colombiano.

\subsection{Tamaño del proyecto y factores determinantes del mismo.}

Según las proyecciones realizadas, el proyecto cuenta con una demanda potencial de 4’353,208 unidades durante el primer año; optando la empresa por apalancarse con una participación inferior al 1\% incremental progresivamente según nuestra compañía logre posicionarse y fidelizar clientes en el país de destino. 


\section{Factores determinantes}

\section{Demanda objetivo proyectada}

Existe una tendencia creciente a nivel de volúmenes del producto a exportar; en este contexto, en el primer año del proyecto, se deben producir 30,720 unidades de la loción corporal a base de aceite de sacha inchi orgánico; para el segundo año, 38,400 unidades; para el tercer año, 46,080 unidades de la loción corporal; para el cuarto año, 53,760 unidades; y para el último año, alcanzar las 61,440 unidades.

\section{Precio y elasticidad de la demanda}

Cabe resaltar, que la industria colombiana de cosméticos y cuidado personal es altamente competitiva. En una industria con barreras relativamente bajas para ingresar al mercado, las empresas manufactureras tratan de diferenciarse unas de otras utilizando diferentes estrategias. En los nichos de productos de alta calidad 'premium', los consumidores no reparan en el precio del producto; ya que, seleccionan el mismo de acuerdo a la alta satisfacción de una necesidad específica. No obstante, éstos presentan una mayor elasticidad en su demanda, como consecuencia de la fluctuación de los ingresos de los consumidores y la variación de sus precios, por la existencia de productos sustitutos de similar funcionalidad.

El auge de los ingredientes naturales en el cuidado de la piel permite que los fabricantes establezcan precios unitarios diferenciales en categorías tales como anti-gerentes, mascarillas y cremas hidratantes. 
La calidad es otro factor priorizado en esta industria, los artículos de alta calidad (o aquellos que son percibidos como tales), tienen una prima en el precio aceptada por el consumidor, lo que aumenta la rentabilidad de las empresas. Un empaque elaborado es un indicador de producto de calidad, por esta razón los últimos años, los fabricantes de productos de nivel medio han invertido recursos en la apariencia del empaque para atraer más consumidores. (Euromonitor International, 2015)

\section{Disponibilidad de insumos}

Tabla 21. Componentes de la Loción Corporal

\begin{tabular}{|c|c|c|}
\hline COMPONENTES & $\begin{array}{l}\text { INGREDIENTES } \\
\text { PRINCIPALES }\end{array}$ & PORCENTAJE (\%) \\
\hline Agua & Water & 500cc (Solvente) \\
\hline Glicerina & Glyceryl & $\begin{array}{l}50 \mathrm{cc} \quad \text { (Suavizante } \\
\text { Brillo) }\end{array}$ \\
\hline Miristrato de miristilo & Myristyl myristate & 100cc (Estabilizador) \\
\hline Alcohol cetílico & Cetyl Alcohol & 35gr (Espesante) \\
\hline Miristrato de isopropilo & Isopropyl Myristate & 30cc (Disolvente) \\
\hline Aceite de sacha inchi & Plukenetia Volubilis Seed Oil & $\begin{array}{l}\text { 100ml (Suavidad y } \\
\text { tacto) }\end{array}$ \\
\hline Extracto de miel & Honey Extract & 25cc (Lubricante) \\
\hline $\begin{array}{l}\text { Retinol de palmitato (Vitamina } \\
\text { A), Acetato de tocoferol } \\
\text { (vitamina E) }\end{array}$ & $\begin{array}{l}\text { Retinyl Palmitate \& } \\
\text { Tocopheryl Acetate }\end{array}$ & 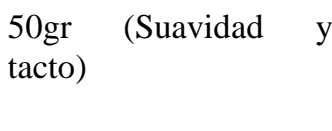 \\
\hline Metilparabeno & Methylparaben & 5 gr (Persevante) \\
\hline EDTA Disódico & Disodium EDTA & 40cc (Estabilizador) \\
\hline Fragancia Citral de Verbena & Verbena Fragrance \& Citral & 30cc (Aroma) \\
\hline
\end{tabular}

Fuente: Preparaciones cosméticas Dpto. Farmacia y Tecnología Farmacéutica Valencia Elaboración Propia 
El principal insumo necesario corresponde al aceite de sacha inchi orgánico; el sacha inchi se cultiva en la zona Nororiental del país, principalmente de los departamentos de Ucayali, Loreto y San Martín. La empresa Agroindustrias Amazónicas S.A. es una de las principales procesadoras y comercializadoras del aceite derivado de esta planta, y está certificada como orgánica; razón por la cual será nuestro principal proveedor durante todo el horizonte del proyecto; se tiene previsto realizar un contrato durante el primer año a fin de asegurar el abastecimiento a un precio fijo.

Según lo estimado, se necesitarán alrededor de $100 \mathrm{ml}$ de aceite de sacha inchi por unidad de producción de la loción corporal.

A continuación se presenta el requerimiento de aceite de sacha inchi por año para poder producir los montos proyectos a vender en unidades.

Tabla 22. Requerimiento anual de aceite de sacha inchi

\begin{tabular}{|c|c|c|c|c|c|}
\hline Ítem & AÑO 1 & AÑO 2 & AÑO 3 & AÑO 4 & AÑO 5 \\
\hline Aceite de Sacha Inchi (L) & 3,072 & 3,840 & 4,608 & 5,376 & 6,144 \\
\hline
\end{tabular}

Elaboración Propia

En lo referente al suministro de extracto de miel, hemos contactado a la empresa Apimas S.A.C. que nos proveerá este producto al por mayor.

Por último, respecto al suministro de componentes químicos, los cuales constituyen pequeñas proporciones en la elaboración de la loción corporal, contaremos con el respaldo y el asesoramiento de dos laboratorios químicos, Omnichem S.A.C. y Hexa Química S.A.C., los mismos serán nuestros 
proveedores estratégicos; ya que, nos brindarán atención y asesoramiento especializado para la elaboración de diferentes preparaciones dermatológicas.

\section{Mano de Obra}

Durante el primer y segundo año se contratará a un químico farmacéutico a tiempo completo para la elaboración, producción y control de calidad de las lociones corporales; asimismo, éste contarán con 3 operarios de apoyo en los procesos que implican el uso de máquinas como en el caso de la mezcladora, homogeneizadora, tanque; durante el llenado y empacado del PT, éstos siempre trabajarán bajo supervisión del químico farmacéutico. A partir del tercer año, y debido al aumento en los volúmenes de producción, se contratará nuevo personal, que corresponde a un químico farmacéutico más y dos operarios adicionales.

Tabla 23. Resumen del Personal Administrativo y Mano de Obra Directa

\begin{tabular}{|l|c|c|}
\hline \multicolumn{1}{|c|}{ Cargo } & $\mathbf{N}^{\circ}$ de empleados & \multicolumn{1}{c|}{ Horas de Trabajo Semanales } \\
\hline Gerente General & & $\begin{array}{l}\text { Como personal de confianza y parte del } \\
\text { staff ejecutivo de la compañía sus } \\
\text { horarios no son definidos, pueden } \\
\text { variar en fechas y horas; no obstante, } \\
\text { se requiere de su disponibilidad en los } \\
\text { días ordinarios de trabajo. }\end{array}$ \\
\hline Jefe el Área Comercial & 1 & \multicolumn{1}{c|}{$48+$ Horas Extras } \\
\hline $\begin{array}{l}\text { Jefe de Producción, Logísticas } \\
\text { y Distribución }\end{array}$ & 1 & $48+$ Horas Extras \\
\hline Químicos Farmacéuticos & 1 & $48+$ Horas Extras \\
\hline Operarios & $1^{*}$ & $48+$ Horas Extras \\
\hline
\end{tabular}

Elaboración Propia 
7.3 Diseño y distribución de planta (flujo de trabajo y flujo de materiales).

A continuación se detalla el diseño de la planta y de las oficinas administrativas y de qué manera estarán distribuidas.

Figura 2. Diseño de planta

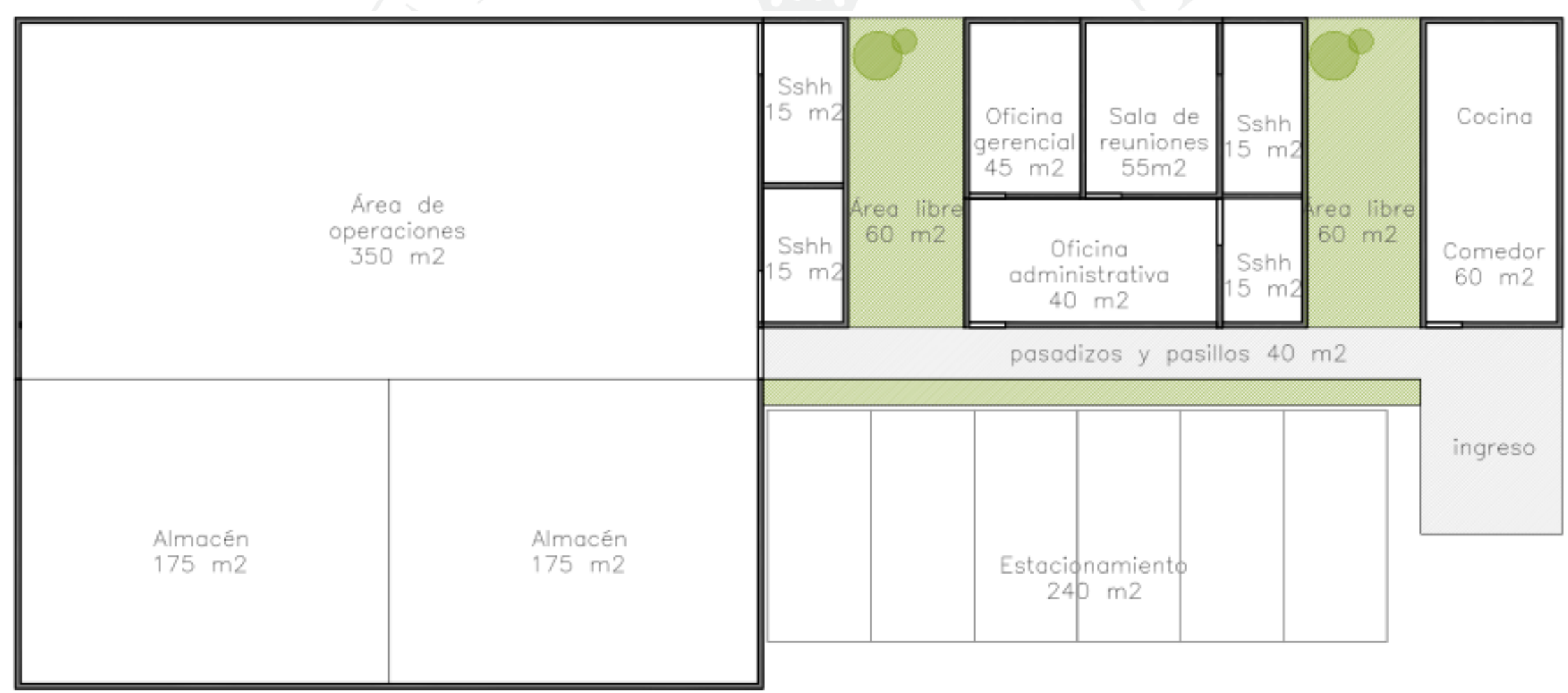

Elaboración Propia 
Tabla 24. Especificaciones del local en situación de proyecto

Distribución de Áreas en m2

\begin{tabular}{|c|c|}
\hline Ítems & m2 \\
\hline Área de operaciones & $350 \mathrm{~m} 2$ \\
\hline Oficina Administrativa & $40 \mathrm{~m} 2$ \\
\hline Oficina Gerencial & $45 \mathrm{~m} 2$ \\
\hline Almacén (x2) & $350 \mathrm{~m} 2$ \\
\hline Sala de reuniones & $55 \mathrm{~m} 2$ \\
\hline Cocina/Comedor & $50 \mathrm{~m} 2$ \\
\hline SS.HH (x4) & $60 \mathrm{~m} 2$ \\
\hline Estacionamiento & $240 \mathrm{~m} 2$ \\
\hline Pasadizos y pasillos & $40 \mathrm{~m} 2$ \\
\hline Áreas libres & $80 \mathrm{~m} 2$ \\
\hline Total & $\mathbf{1 3 0 0 ~} \mathbf{~ m 2}$ \\
\hline
\end{tabular}

Elaboración Propia

\subsection{Localización, maquinarias, equipos y mobiliario.}

\section{Macro Localización}

La planta estará ubicada en la ciudad de Lima, considerando ésta como óptima en relación a otras ciudades debido a la cercanía con nuestros proveedores clave como lo son por ej. Los laboratorios químicos con los que trabajaremos; asimismo, disponibilidad de mano de obra directa de calidad como es el caso de químicos farmacéuticos de la Facultad de Farmacia y Bioquímica de la UNMSM; facilidad de operaciones logísticas; acceso a servicios, etc.

\section{Micro Localización}

Se llevó a cabo la evaluación de 3 potenciales distritos de Lima Metropolitana a fin de decidir estratégicamente la ubicación de la planta productiva y oficinas administrativas de la empresa; todo esto sobre la base de 5 principales factores tales como disponibilidad del local, costo de alquileres, acceso a servicios y seguridad. 
Tabla 25. Escala de Valores

\begin{tabular}{|c|c|}
\hline Escala de Valores & Calificación \\
\hline Muy malo & 1 \\
\hline Malo & 2 \\
\hline Bueno & 3 \\
\hline Muy Bueno & 4 \\
\hline
\end{tabular}

Tabla 26. Matriz de Evaluación de Micro Localización de la planta

\begin{tabular}{|c|c|c|c|c|c|c|c|}
\hline \multirow{3}{*}{\begin{tabular}{|c|} 
Factores \\
Disnonibilidad del local
\end{tabular}} & \multirow{3}{*}{$\begin{array}{c}\text { Pesos } \\
0.30\end{array}$} & \multicolumn{6}{|c|}{ Distritos } \\
\hline & & \multicolumn{2}{|c|}{ Puente Piedra } & \multicolumn{2}{|c|}{ Los Olivos } & \multicolumn{2}{|c|}{$\begin{array}{c}\text { San Martín de } \\
\text { Porres }\end{array}$} \\
\hline & & 4 & 1.20 & 4 & 1.20 & 3 & 0.90 \\
\hline Costo de alquileres & 0.25 & 4 & 1.00 & 3 & 0.75 & 4 & 1.00 \\
\hline Acceso a servicios & 0.30 & 3 & 0.90 & 3 & 0.90 & 3 & 0.90 \\
\hline Seguridad & 0.15 & 3 & 0.45 & 3 & 0.45 & 2 & 0.30 \\
\hline TOTAL & 1 & \multicolumn{2}{|c|}{3.55} & \multicolumn{2}{|c|}{3.30} & \multicolumn{2}{|c|}{3.10} \\
\hline
\end{tabular}

Elaboración Propia

La matriz anterior nos indica la ventaja de alquilar un local en el Distrito de

Puente Piedra; debido a que obtuvo el mayor puntaje en la evaluación de los 4 factores que consideramos relevantes en la elección del mismo.

El local estará ubicado en el PARADERO FUNDICIÓN, ALT KM 36 PANAMERICANA NORTE.

Figura 3. Mapa de ubicación de la planta

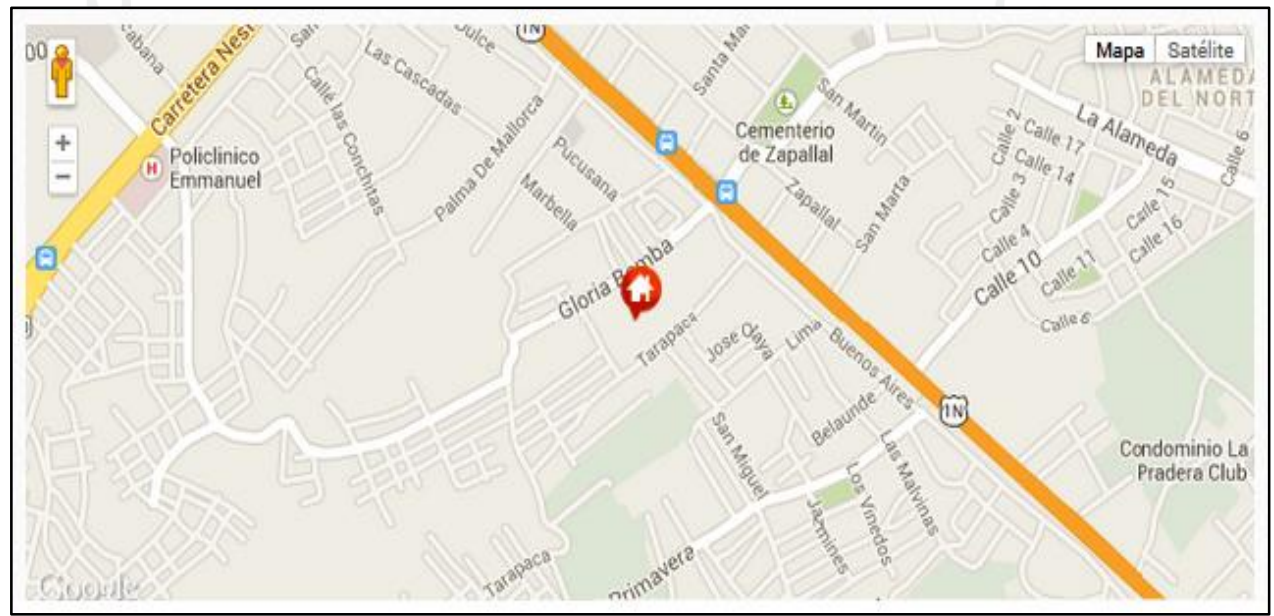


Detalle.-

Local industrial en Zapallal Puente Piedra, de fácil acceso y salida a las vías troncales como Panamericana Norte, Carretera Ventanilla. AT: 1300 M2, AC: 220 M2, cuenta con cisterna subterránea de 10 M3, tanque elevado de 2500 LT, luz trifásica y agua, paredes perimetrales de $5 \mathrm{M}$ de altura, 7 ambientes para oficinas, baños obreros y baños administrativos. Precio de alquiler: $\$ 1200$ mensual. Contacto: Cecilia Makishi 997461556/113*7407

Tabla 27. Especificación del local en situación actual

\begin{tabular}{|l|c|}
\hline \multicolumn{1}{|c|}{ Ítems } & Características \\
\hline Área & AT: $1300 \mathrm{~m} 2$, AC: $220 \mathrm{~m} 2$ \\
\hline Servicios Públicos & Agua potable, luz trifásica, acceso a telefonía, internet \\
\hline Seguridad & Baja policía \\
\hline Accesos y salidas & Carretera Panamericana Norte, Carretera Ventanilla \\
\hline Oficinas & 2 \\
\hline Sala de reuniones & 1 \\
\hline Cocina & 1 \\
\hline Almacenes & 2 \\
\hline SS.HH. & 3 \\
\hline Estacionamiento & 4 \\
\hline Pisos & Exterior cemento, interior mayólica \\
\hline $\begin{array}{l}\text { Conexiones eléctricas } \mathbf{y} \\
\text { sanitarias }\end{array}$ & En buen estado \\
\hline
\end{tabular}
Elaboración Propia

Maquinarias, equipos, herramientas y mobiliarios

\section{Requerimiento de maquinarias}

Tabla 28. Requerimiento de Maquinarias

\begin{tabular}{|c|c|c|c|}
\hline ÍTEM & CANTIDAD & CARACTERÍSTICAS & PROVEEDOR \\
\hline $\begin{array}{l}\text { Mezclador } \\
\text { planetario para } \\
\text { laboratorio }\end{array}$ & 1 & $\begin{array}{l}\text { Tipo: Mezclador Planetario 10L } \\
\text { Marca: Haidier } \\
\text { Modelo: HDR-10L } \\
\text { Fuente de energía: Eléctrico } \\
\text { Peso: } 57 \mathrm{~kg} \\
\text { Dimensión: } 460 * 480 * 680 \mathrm{~mm} \\
\text { Potencia: } 0.25 \mathrm{~kW} \\
\text { Material: Acero inoxidable }\end{array}$ & $\begin{array}{l}\text { Shijiazhuang } \\
\text { Haidier Machinery } \\
\text { Export Co., Ltd. }\end{array}$ \\
\hline $\begin{array}{l}\text { Homogeneizadora } \\
\text { de laboratorio }\end{array}$ & $\mathbf{1}$ & $\begin{array}{l}\text { Tipo: Homogeneizador de } \\
\text { Laboratorio } \\
\text { Marca: Chaoguan }\end{array}$ & $\begin{array}{l}\text { Changzhou Chaoli } \\
\text { Homogenizing } \\
\text { Pump Factory }\end{array}$ \\
\hline
\end{tabular}




\begin{tabular}{|c|c|c|c|}
\hline ÍTEM & CANTIDAD & CARACTERÍSTICAS & PROVEEDOR \\
\hline & & $\begin{array}{l}\text { Capacidad de } 301 / \mathrm{h} \\
\text { Presión nominal: } 40 \mathrm{mpa} \\
\text { Dimensiones: } \\
1.15 \times 0.8 \times 1.1 \text { metros }\end{array}$ & \\
\hline $\begin{array}{l}\text { Balanza } \\
\text { electrónica }\end{array}$ & 1 & $\begin{array}{l}\text { BALANZA DIGITAL BCH } \\
\text { 300 CS } \\
\text { Capacidad: } 300 \mathrm{Kg} \\
\text { Precisión: } \pm 50 \mathrm{~g} \\
\text { Ventanas } 3 \mathrm{LCD} \text { verde } \\
\text { Plataforma de acero inoxidable } \\
45 \times 60 \mathrm{~cm} \\
\text { AC: } 220 \mathrm{~V}-50 / 60 \mathrm{~Hz} \\
\text { DC: } \text { Batería } 6 \mathrm{~V}-5^{\mathrm{a}}\end{array}$ & Henkel \\
\hline $\begin{array}{l}\text { Balanza de } \\
\text { precision }\end{array}$ & 1 & $\begin{array}{l}\text { BALANZA DE PRESICIÓN } \\
\text { 0.001 a } 300 \text { gramos }\end{array}$ & Henkel \\
\hline $\begin{array}{l}\text { Motores eléctricos } \\
\text { de } 1 / 5 \mathrm{hp} \mathrm{con} \\
\text { agitador acoplado }\end{array}$ & 2 & $\begin{array}{l}\text { Tipo: Agitador Universal Digital } \\
\text { Potencia: } 1 / 5 \text { hp } 150 \text { watts } \\
\text { Volumen máximo: } 60 \text { litros } \\
\text { Viscosidad máxima: } 5000 \mathrm{cps} \\
\text { Alimentación: } 120 \mathrm{v}, 50 / 60 \mathrm{~Hz} \\
\end{array}$ & $\begin{array}{l}\text { LABEQUIM,S.A } \\
\text { DE C.V }\end{array}$ \\
\hline $\begin{array}{l}\text { Tanque de } \\
\text { descarga } 5 \mathrm{~L}\end{array}$ & 1 & $\begin{array}{l}\text { Tipo: Tanque de } \\
\text { almacenaje/descarga } \\
\text { Material: Acero Inoxidable } \\
\text { Marca: Mingchen } \\
\text { Capacidad: } 5 \text { - 10L }\end{array}$ & $\begin{array}{l}\text { Zhejiang Mingchen } \\
\text { Machinery } \\
\text { Technology Co., } \\
\text { Ltd. }\end{array}$ \\
\hline $\begin{array}{l}\text { Equipo de llenado } \\
\text { de cremas }\end{array}$ & 2 & $\begin{array}{l}\text { Tipo: Máquina de llenado } \\
\text { Dimensión }\left(\mathbf{L} * \mathbf{W}^{*} \mathbf{H}\right): \\
\text { 1200x500x } 800 \mathrm{cms} \\
\text { Voltaje: } 380 \mathrm{~V} / 220 \mathrm{~V} \\
\text { Peso: } 50 \mathrm{~kg} \\
\text { Grado automático: } \\
\text { Semiautomático }\end{array}$ & $\begin{array}{l}\text { Wenzhou Senao } \\
\text { Machinery Co., } \\
\text { Ltd. }\end{array}$ \\
\hline
\end{tabular}

Elaboración Propia

\section{Requerimiento de equipos}

Tabla 29. Requerimiento de Equipos

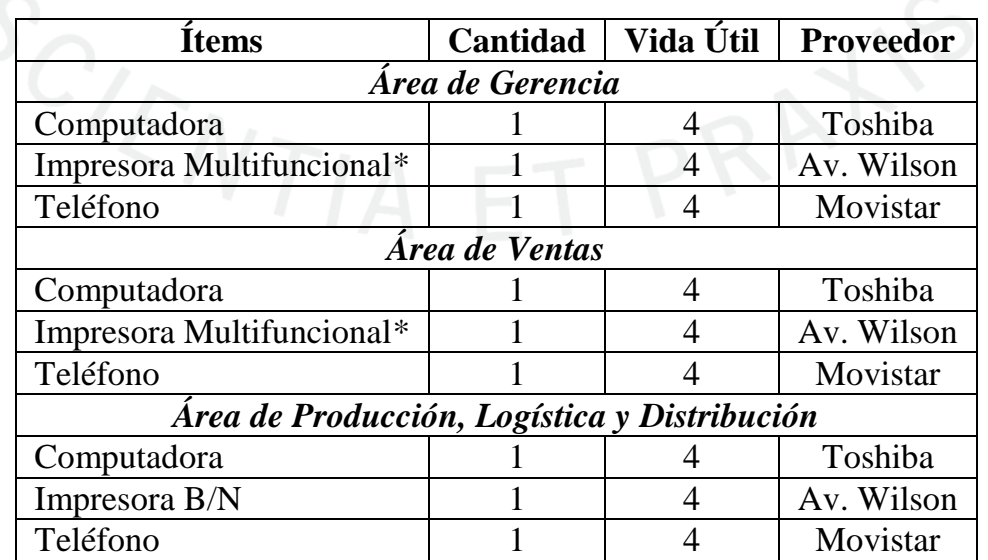

*La Impresora Multifuncional será la misma utilizada en el área de Gerencia y Ventas. Elaboración Propia 


\section{Requerimiento de herramientas}

Tabla 30. Requerimiento de Útiles y Herramientas

\begin{tabular}{|c|c|c|c|}
\hline Ítem & Cantidad & Características & Proveedor \\
\hline \multicolumn{4}{|c|}{ Área de Gerencia } \\
\hline Archivadores & 2 & Archivador Plastificado Oficio & Mercado Central \\
\hline Útiles de oficina (pack) & 1 & $\begin{array}{l}\text { Lapiceros, lápices, resaltadores, } \\
\text { perforador, engrapador, etc. }\end{array}$ & Mercado Central \\
\hline \multicolumn{4}{|c|}{ Área de Ventas } \\
\hline Archivadores & 1 & Archivador Plastificado Oficio & Mercado Central \\
\hline Útiles de oficina (pack) & 1 & $\begin{array}{l}\text { Lapiceros, lápices, resaltadores, } \\
\text { perforador, engrapador, etc. }\end{array}$ & Mercado Central \\
\hline \multicolumn{4}{|c|}{ Área de Logística } \\
\hline Archivadores & 4 & Archivador Plastificado Oficio & Mercado Central \\
\hline Útiles de oficina (pack) & 1 & $\begin{array}{l}\text { Lapiceros, lápices, resaltadores, } \\
\text { perforador, engrapador, etc. }\end{array}$ & Mercado Central \\
\hline \multicolumn{4}{|c|}{ Área de Producción } \\
\hline $\begin{array}{l}\text { Vaso de precipitado de } \\
\text { vidrio (beaker) } 250 \mathrm{~mL}\end{array}$ & 2 & Marca Pyrex & $\begin{array}{l}\text { Medic Import - } \\
\text { Emancipación }\end{array}$ \\
\hline $\begin{array}{l}\text { Vaso de precipitado de } \\
\text { vidrio (beaker) } 600 \mathrm{~mL}\end{array}$ & 2 & Marca Pyrex & $\begin{array}{l}\text { Medic Import - } \\
\text { Emancipación }\end{array}$ \\
\hline $\begin{array}{l}\text { Pipeta graduada de } 10 \\
\text { mL }\end{array}$ & 2 & Marca Pyrex & $\begin{array}{l}\text { Medic Import - } \\
\text { Emancipación }\end{array}$ \\
\hline $\begin{array}{l}\text { Pipeta graduada de } 20 \\
\text { mL }\end{array}$ & 1 & Marca Pyrex & $\begin{array}{l}\text { Medic Import - } \\
\text { Emancipación }\end{array}$ \\
\hline Probeta de $100 \mathrm{~mL}$ & 1 & Marca Pyrex & $\begin{array}{l}\text { Medic Import - } \\
\text { Emancipación }\end{array}$ \\
\hline Probeta de $250 \mathrm{~mL}$ & 1 & Marca Pyrex & $\begin{array}{l}\text { Medic Import - } \\
\text { Emancipación }\end{array}$ \\
\hline $\begin{array}{l}\text { Espátulas metálicas de } \\
\text { laboratorio }\end{array}$ & 4 & Espátulas de acero & $\begin{array}{c}\text { Av. Emancipación } \mathrm{N}^{\circ} \\
\text { 343, Stand } 210\end{array}$ \\
\hline $\begin{array}{lll}\text { Recipiente } & \text { de } & \text { acero } \\
\text { inoxidable } & & \\
\end{array}$ & 3 & Tipo bowls & $\begin{array}{l}\text { Medic Import - } \\
\text { Emancipación }\end{array}$ \\
\hline Marmita & 1 & Marmita volcable de acero & $\begin{array}{l}\text { Maquiprocesos } \\
\text { E.I.R.L. }\end{array}$ \\
\hline Phmetro & 1 & PH digital con termómetro & Alessa Import E.I.R.L. \\
\hline Otros & 1 & $\begin{array}{l}\text { Tubos de ensayo, Mechero de Bunsen, } \\
\text { Kitasato, Balón, Pinza, Soporte } \\
\text { Universal, etc. }\end{array}$ & $\begin{array}{l}\text { Av. Emancipación N }{ }^{\circ} \\
\text { 343, Stand } 210\end{array}$ \\
\hline
\end{tabular}

Elaboración Propia 
Requerimiento de mobiliario

Tabla 31. Requerimiento de Mobiliario

\begin{tabular}{|c|c|c|c|}
\hline Ítem & Cantidad & Características & Proveedor \\
\hline \multicolumn{4}{|c|}{ Área de Gerencia } \\
\hline Escritorio & 1 & Material: Vidrio y acero & Plaza Hogar - Surquillo \\
\hline $\begin{array}{l}\text { Mesa de } \\
\text { reuniones }\end{array}$ & 1 & Material: Vidrio y acero & Plaza Hogar - Surquillo \\
\hline Sillas & 7 & $\begin{array}{c}\text { Silla de Pc Negra (1) / Silla de } \\
\text { oficina simple (6) }\end{array}$ & Plaza Hogar - Surquillo \\
\hline \multicolumn{4}{|c|}{ Área de Ventas } \\
\hline Escritorio & 1 & Material: Melamina & Plaza Hogar - Surquillo \\
\hline Sillas & 3 & Silla de oficina simple & Plaza Hogar - Surquillo \\
\hline \multicolumn{4}{|c|}{ Área de Logística } \\
\hline Escritorio & 1 & Material: Melamina & Plaza Hogar - Surquillo \\
\hline Sillas & 2 & Silla de oficina simple & Plaza Hogar - Surquillo \\
\hline \multicolumn{4}{|c|}{ Área de Operaciones } \\
\hline Mesa rectangular & 2 & Material: Pino & Plaza Hogar - Surquillo \\
\hline Sillas & 6 & Sillas simple de pina & Plaza Hogar - Surquillo \\
\hline
\end{tabular}

Elaboración Propia

Requerimiento de equipos de seguridad

Tabla 32. Requerimiento de Equipos de Seguridad

\begin{tabular}{|c|c|c|c|}
\hline Materiales y Equipos & Área & Cantidad & Proveedor \\
\hline Señalizadores & Pasillos & 6 & $3 \mathrm{M}$ \\
\hline Detectores de Humo & Dentro de planta y oficinas & 4 & RILSAC \\
\hline Extintores & Pasillos y almacén & 3 & RILSAC \\
\hline Botiquín de Emergencias & Oficinas & 2 & Boticas Arcángel \\
\hline Casco de Seguridad & Planta & 6 & RILSAC \\
\hline Guantes de Seguridad & Planta & 6 & RILSAC \\
\hline Lentes de Seguridad & Planta & 6 & RILSAC \\
\hline Mandil de Seguridad & Planta & 6 & RILSAC \\
\hline
\end{tabular}

Elaboración Propia

Estos equipos son obligatorios para la obtención de La Licencia de funcionamiento, ya que previamente el local pasará por un proceso de evaluación donde los inspectores de Defensa Civil verificarán las condiciones de local. 
Es necesario considerar que los extinguidores como las medicinas y productos ubicados en el botiquín necesitan ser llenados y revisados anualmente debido a que poseen una fecha de caducidad.

\subsection{Requerimiento de factores directos.}

Requerimiento de materias primas para la producción

Tabla 33. Requerimiento de Materias Primas

\begin{tabular}{|c|c|c|c|c|c|}
\hline 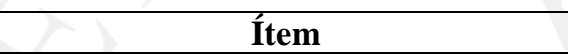 & AÑO 1 & AÑO 2 & AÑO 3 & AÑO 4 & AÑO 5 \\
\hline Glicerina $(\mathrm{Kg})$ & 1,536 & 1,920 & 2,304 & 2,688 & 3,072 \\
\hline Miristato de miristilo $(\mathrm{Kg})$ & 3,072 & 3,840 & 4,608 & 5,376 & 6,144 \\
\hline Alcohol cetílico $(\mathrm{Kg})$ & 1,075 & 1,344 & 1,613 & 1,882 & 2,150 \\
\hline Miristato de isopropilo $(\mathrm{Kg})$ & 922 & 1,152 & 1,382 & 1,613 & 1,843 \\
\hline Aceite de sacha inchi (L) & 3,072 & 3,840 & 4,608 & 5,376 & 6,144 \\
\hline Extracto de miel $(\mathrm{Kg})$ & 768 & 960 & 1,152 & 1,344 & 1,536 \\
\hline Retinol de palmitato (Vitamina A) (Kg) & 1,536 & 1,920 & 2,304 & 2,688 & 3,072 \\
\hline Acetato de tocoferol (Vitamina B) (Kg) & 1,536 & 1,920 & 2,304 & 2,688 & 3,072 \\
\hline Metilparabeno $(\mathrm{Kg})$ & 154 & 192 & 230 & 269 & 307 \\
\hline EDTA Disódico $(\mathrm{Kg})$ & 1,229 & 1,536 & 1,843 & 2,150 & 2,458 \\
\hline Fragancia Citral de Verbena (L) & 922 & 1,152 & 1,382 & 1,613 & 1,843 \\
\hline
\end{tabular}

Requerimiento de Materiales de envase, empaque y embalaje

Tabla 34. Materiales de envase, empaque y embalaje

\begin{tabular}{|l|c|l|l|}
\hline \multicolumn{1}{|c|}{ Materiales } & Requerimiento & \multicolumn{1}{|c|}{ Especificaciones } & \multicolumn{1}{c|}{ Proveedor } \\
\hline Cajas de $13 \mathrm{Kg}$. & 160 & $\begin{array}{l}\text { Cajas de cartón corrugado de } \\
\text { dimensiones de 60x40x40cm }\end{array}$ & $\begin{array}{l}\text { Sociedad Anónima } \\
\text { Papelsa }\end{array}$ \\
\hline Envases & 30,720 & $\begin{array}{l}\text { Envases de polietileno soplado de } \\
\text { 250gr. }\end{array}$ & DAMAR G\&L \\
\hline Etiquetas & 30,720 & Etiquetas autoadhesivas & $\begin{array}{l}\text { Inversiones Gráficas } \\
\text { Maricarmen E.I.R.L. }\end{array}$ \\
\hline Stretch Film & 5 & PROPACK - Rollos stretch film 18” & SODIMAC \\
\hline
\end{tabular}
Elaboración Propia

Los proveedores seleccionados cuentan con un gran prestigio en el mercado nacional y sus insumos son los más adecuados para nuestro producto; estos proveedores han sido evaluados por la calidad de materiales, el costo, el volumen requerido 
para cubrir la producción, la disponibilidad garantizada de los insumos, el buen servicio logístico y de entrega.

\subsection{Requerimiento de factores indirectos.}

Requerimiento de suministros

Tabla 35. Requerimiento de Suministros

\begin{tabular}{|c|c|c|c|}
\hline Ítem & Consumo Mensual Estimado* & Descripción & Proveedor \\
\hline Luz & $\geq 5000 \mathrm{kWs}$ & Energía eléctrica & Edelnor \\
\hline Agua & Metros cúbicos & Agua Potable & Sedapal \\
\hline Internet & Tarifa Plana & Internet 4 Mbps & Movistar \\
\hline Teléfono & Tarifa mensual + Recarga & Fono YA & Movistar \\
\hline
\end{tabular}

Elaboración Propia

\section{Requerimiento de servicios indirectos}

Tabla 36. Requerimiento de Servicios Indirectos

\begin{tabular}{|c|c|c|}
\hline Ítem & Características & Proveedor \\
\hline $\begin{array}{c}\text { Servicio } 1 \\
\text { Contador }\end{array}$ & $\begin{array}{c}\text { Contador Público } \\
\text { Colegiado }\end{array}$ & Jorge Paredes (particular) \\
\hline $\begin{array}{c}\text { Servicio } 2 \\
\text { Seguridad }\end{array}$ & Turno tarde-noche & $\begin{array}{c}\text { Protección y Resguardo } \\
\text { S.A.-PROTSSA }\end{array}$ \\
\hline $\begin{array}{c}\text { Servicio 3 } \\
\text { Limpieza }\end{array}$ & $\begin{array}{c}\text { Limpieza y mantenimiento } \\
\text { de empresa }\end{array}$ & Grupo Dmc \\
\hline $\begin{array}{c}\text { Servicio } 4 \\
\text { Celular }\end{array}$ & Servicio RPM & Movistar \\
\hline
\end{tabular}

Elaboración Propia

Asimismo, antes de llevar a cabo la producción se contratará por 3 horas diarias durante 4 días la asesoría de un dermatólogo*, para hacer las pruebas que se requieran respecto a las fórmulas y composición del producto, a fin de optimizarlo.

Otros requerimientos menores

- Trámite de registro DIGEMID.

- Uniformes de trabajo. 
Proveedor: Av. Tacna.

- Utensilios de limpieza y desinfección.

Proveedor: Uno más uno Av. Aviación.

- 2 bidones de agua de mesa (20L).

Proveedor: Agua Vida.

- Consumibles menores.

Proveedor: Bodegas.

\subsection{Diagrama de flujo del proceso de producción y tecnología.}

\section{Proceso y Tecnologías}

Descripción de los principales procesos del proyecto

Tabla 37. Descripción del proceso de producción de la Loción corporal

\begin{tabular}{|c|c|c|}
\hline PROCESO & DESCRIPCIÓN & EQUIPOS \\
\hline $\begin{array}{l}\text { Recepción y } \\
\text { documentación de } \\
\text { la MP }\end{array}$ & $\begin{array}{l}\text { Control de la MP que se adquiere, por medio } \\
\text { de un control de inventarios. }\end{array}$ & \\
\hline Peso & $\begin{array}{l}\text { El proceso comienza con la recepción de la } \\
\text { MP, la cual se le pesa. El proceso anterior y } \\
\text { éste durarán aproximadamente } 90 \text { minutos. }\end{array}$ & Balanza electrónica. \\
\hline Análisis & $\begin{array}{l}\text { Para garantizar que la MP que se recibe } \\
\text { contiene las características físico-químicas } \\
\text { propias, se realiza el análisis de la MP } \\
\text { recibida. En caso de no reunir dichas } \\
\text { características, la MP es devuelta. }\end{array}$ & $\begin{array}{l}\text { 1. Vasos de precipitado de } \\
\text { vidrio (beaker) } 2 \text { de } 250 \mathrm{~mL} \text { y } \\
2 \text { de } 600 \mathrm{~mL} \text {. } \\
\text { 2. Pipetas graduadas } 2 \text { de } 10 \\
\text { mL y una de } 20 \mathrm{~mL} \text {. } \\
\text { 3. Probeta de } 100 \mathrm{~mL} \text { y } 250 \\
\text { mL. }\end{array}$ \\
\hline Almacenamiento & $\begin{array}{l}\text { La MP se almacena para iniciar el proceso } \\
\text { de producción. }\end{array}$ & \\
\hline Repesado & $\begin{array}{l}\text { Se pesa nuevamente la MP por control de } \\
\text { calidad. }\end{array}$ & $\begin{array}{l}\text { 1. Balanza electrónica. } \\
\text { 2. Espátulas metálicas } \\
\text { para pesar. } \\
\text { 3. Balanza de precisión. }\end{array}$ \\
\hline
\end{tabular}




\begin{tabular}{|c|c|c|}
\hline PROCESO & DESCRIPCIÓN & EQUIPOS \\
\hline Re-envasado & Re-envasar los componentes & $\begin{array}{l}\text { Envases industriales } \\
\text { polietileno. }\end{array}$ \\
\hline Traslado & $\begin{array}{l}\text { Se lleva la MP al lugar de procesamiento } \\
\text { industrial. }\end{array}$ & \\
\hline Mezcla & $\begin{array}{l}\text { Los componentes se mezclan por separado } \\
\text { dependiendo de sus propiedades, ya sea } \\
\text { oleoso (aceite de sacha inchi) y acuosos } \\
\text { (demás componentes que se mezclan con el } \\
\text { agua). Este proceso dura aproximadamente } \\
10 \text { minutos. }\end{array}$ & $\begin{array}{l}\text { Recipientes de acero } \\
\text { inoxidable. } \\
\text { Dos motores eléctricos de 1/16 } \\
\text { hp con agitador acoplado. }\end{array}$ \\
\hline Emulsión & Fase de calentamiento de 70 a $75^{\circ} \mathrm{C}$ & $\begin{array}{l}\text {-Marmita. } \\
\text {-Mezclador o emulsionador: } \\
\text { Mezclador planetario. }\end{array}$ \\
\hline Homogeneización & $\begin{array}{l}\text { Se vierte la fase acuosa sobre la oleosa con } \\
\text { homogeneización rápida y en el mismo } \\
\text { sentido hasta alcanzar } 30^{\circ} \mathrm{C} \text { y hasta que éste } \\
\text { adquiera las propiedades propias físico- } \\
\text { químicas del producto (densidad, viscosidad, } \\
\text { y alcalinidad). Este proceso se lleva a cabo } \\
\text { en } 40 \text { minutos aproximadamente. }\end{array}$ & $\begin{array}{l}\text { Dos motores eléctricos de } 1 / 5 \\
\text { hp con agitador acoplado. } \\
\text {-Homogeneizador: } \\
\text { Homogeneizadora de presión. }\end{array}$ \\
\hline $\begin{array}{l}\text { Agregar fragancias } \\
\text { y extractos }\end{array}$ & $\begin{array}{l}\text { Se continúa con el proceso hasta lograr el } \\
\text { aroma deseado. }\end{array}$ & Tanque de descarga. \\
\hline $\begin{array}{c}\text { Aprobación de } \\
\text { Control de Calidad }\end{array}$ & $\begin{array}{l}\text { Análisis de las características físicas y } \\
\text { químicas del producto terminado (densidad, } \\
\text { viscosidad, alcalinidad y aroma), con el fin } \\
\text { de verificar que la loción corporal posea } \\
\text { todas las características del aceite natural de } \\
\text { sacha inchi (densidad, viscosidad, } \\
\text { alcalinidad y aroma). En caso de no reunir } \\
\text { las características requeridas se regresa para } \\
\text { ser procesado nuevamente. } \\
\text { El control de calidad se desarrolla en un } \\
\text { tiempo promedio de } 20 \text { minutos. }\end{array}$ & $\begin{array}{l}\text { Phmetro. } \\
\text { Cristalería de laboratorio. }\end{array}$ \\
\hline $\begin{array}{l}\text { Envasado y } \\
\text { etiquetado }\end{array}$ & Proceso de llenado y sellado & $\begin{array}{l}\text {-Máquina llenadora. } \\
\text {-Mesa para taponado } \\
\text { etiquetado. }\end{array}$ \\
\hline Empacado & $\begin{array}{l}\text { Asignación del lote de acuerdo a la fecha de } \\
\text { elaboración, etiquetación y fecha de salida el } \\
\text { cliente. }\end{array}$ & \\
\hline Traslado del PT & $\begin{array}{l}\text { El PT es llevado hacia la planta del cliente } \\
\text { que se encargará de distribuir o exportar la } \\
\text { loción corporal. }\end{array}$ & \\
\hline
\end{tabular}

Fuente: Guía de Estabilidad de Productos Cosméticos. Agencia Nacional de Vigilancia Sanitaria, 2004. 
Gráfico 23. Diagrama de Flujo del proceso de producción

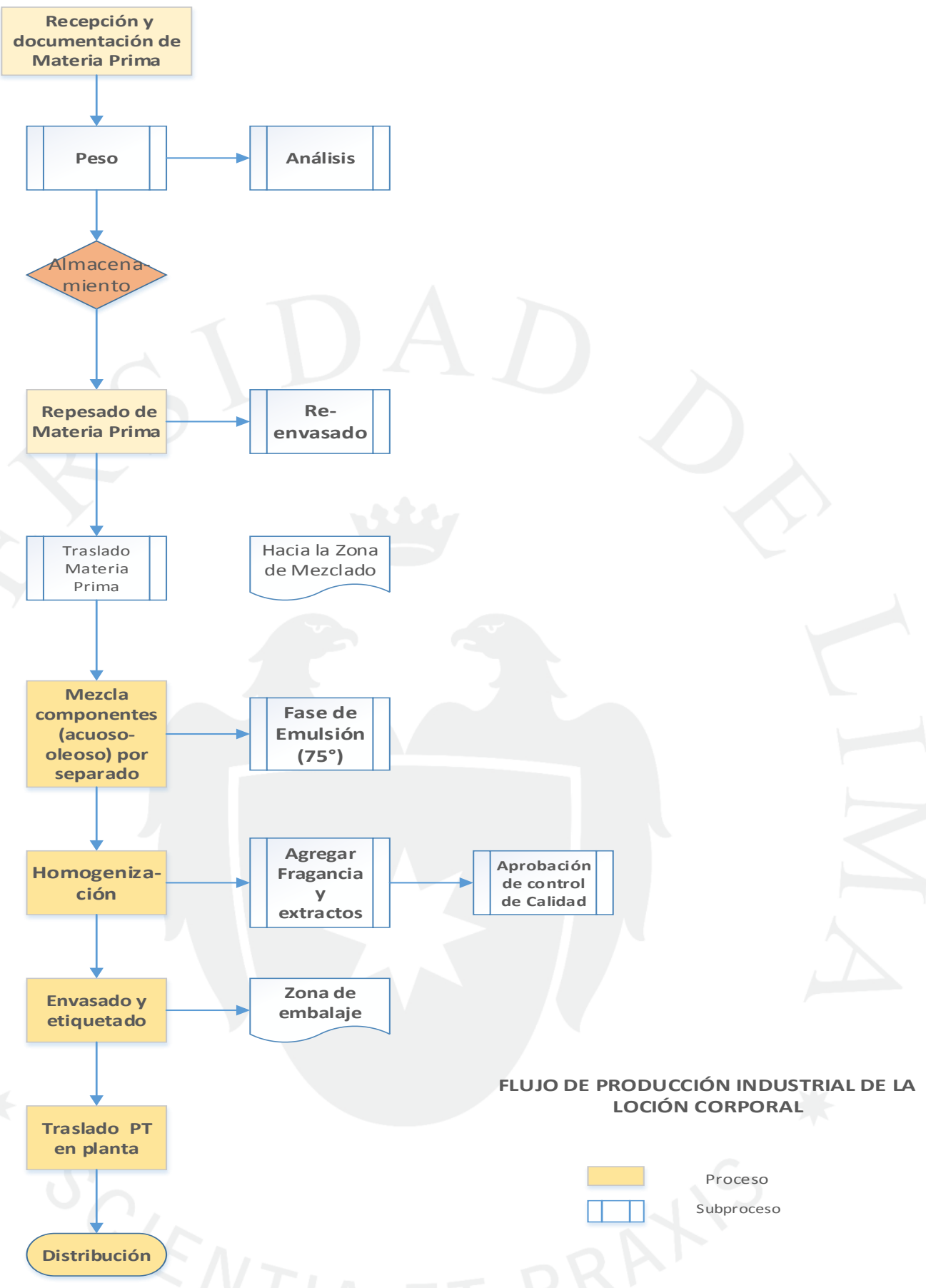

"Repetir este diagrama 5 veces para obtener $1000 \mathrm{~kg}$ "

Fuente: The Chemistry and Manufacture of Cosmetics - Estados Unidos.

La merma que se genera en el proceso productivo es mínima, fluctuando ésta entre un $1 \%$ a $1.5 \%$ según la Facultad de Ingeniería Industrial de la UNMSM. 


\section{Diagrama de Gantt del Proceso de Producción}

El tiempo de fabricación de del producto es de alrededor de 45 horas, asimismo, respecto al tiempo de envasado y etiquetado éste en promedio corresponde a 13.45 horas. (Aguilar Orozco, 2011)

Tabla 38. Diagrama de Gantt del Proceso de Producción

\begin{tabular}{|l|l|l|l|l|}
\hline \multicolumn{1}{|c|}{ Proceso } & Día 1 & Día 2 & Día 3 & Día 4 \\
\hline Recepción y documentación de la MP & & & & \\
\hline Pesado & & & & \\
\hline Análisis & & & & \\
\hline Almacenamiento & & & & \\
\hline Repesado & & & & \\
\hline Mezcla & & & & \\
\hline Emulsión & & & & \\
\hline Homogeneización & & & \\
\hline Agregar fragancias y extractos & & & \\
\hline Aprobación de Control de Calidad & & & \\
\hline Envasado y etiquetado & & & \\
\hline Empacado & & & \\
\hline Traslado del PT & & & \\
\hline *No se considera Re-envasado, ni traslado de la MP, ya que todo el proceso y almacenamiento se \\
llevará a cabo dentro de la misma planta en Puente Piedra. \\
Elaboración Propia
\end{tabular}

\subsection{Sistema de control de procesos, calidad y costos operativos.}

Para realizar nuestro control de procesos de producción, se contará a un dermatólogo, quien junto al químico farmacéutico serán los encargados del control de calidad del producto final antes de ser exportado al cliente en Colombia.

Por otro lado, cada vez que se exporte se tiene que realizar el COA o Certificado de Análisis, que comprende las especificaciones técnicas del producto y un análisis de sus propiedades físico-químicas y microbiológicas. 
7.9 Logística, gestión de existencias, compras, logística de entrada y salida, distribución de productos.

Respecto a la gestión de existencias de la empresa, se usará el método PEPS (primero en entrar, primero en salir), y de esta manera poder tener un mejor control del inventario y Kardex de la empresa. Además de tener un mejor manejo de los costos de la empresa.

7.10 Gestión de mantenimiento correctivo y preventivo, seguridad y salud en el trabajo.

\section{Gestión de mantenimiento correctivo y preventivo}

Con esta gestión, se pretende mantener en condiciones óptimas el equipo de la fábrica que comprende el proyecto, mediante la prevención de fallos o en caso extremos, realizar reparaciones ya sea de emergencia o bien programadas.

\section{Mantenimiento preventivo}

Se planificarán tareas de mantenimiento preventivo para mantener las capacidades funcionales y operacionales de nuestros equipos; así como para controlar el cumplimiento de los contratos de mantenimiento suscritos con empresas externas. Está enfocado en mantener la vida útil de nuestros equipos, evitando fallas tempranas y minimizar cualquier impacto en los requerimientos operacionales. (solmicroexpertis, 2014)

\section{Mantenimiento correctivo}

Este tipo de mantenimiento se utiliza sobre artículos desgastados o que han presentado algún fallo para posteriormente poder reintegrarlos a las órdenes de 
producción. Las actividades del mantenimiento correctivo pueden consistir en: reparaciones, restauraciones o bien remplazo del equipo; estas son resultado de una inspección regular con la que se identifican los fallos de los artículos, a tiempo para el mantenimiento correctivo que será planificado o programado y que posteriormente se realizará durante una rutina de "paro" por mantenimiento. (solmicroexpertis, 2014)

\section{Seguridad y salud en el trabajo}

Según el Reglamento Nacional de Seguridad y Salud en el Trabajo, respaldado bajo el Decreto Supremo No 009-2005-TR, la persona a cargo del proyecto, dígase empleador, deberá ejercer un firme liderazgo y manifestar su respaldo a las actividades de su empresa en materia de seguridad y salud en el trabajo; asimismo, debe estar comprometido a fin de proveer y mantener un ambiente de trabajo seguro y saludable en concordancia con las mejores prácticas y con el cumplimiento de las normas de seguridad y salud en el trabajo.

El objetivo es garantizar la seguridad y la salud de los trabajadores en el desempeño de todos los aspectos relacionados con su labor, a través del desarrollo de acciones permanentes con el fin de perfeccionar los niveles de protección al personal.

Se capacitarán y entrenarán anticipada y debidamente a los trabajadores; se practicarán exámenes médicos antes, durante y al término de la relación laboral a los trabajadores, acordes con los riesgos a que están expuestos en sus labores. 
Asimismo, se dispondrá de equipo de seguridad para evitar accidentes dentro de la planta y se procederá con la señalización de las zonas de riesgo y seguridad dentro de la fábrica, entre otras acciones que se consideren necesarias. 


\section{CAPITULO VIII. PLAN DE MARKETING}

\subsection{Objetivos de Marketing.}

- Lograr una tasa de crecimiento anual de ventas del 25\% para el segundo año, $20 \%$ para el tercer año, $17 \%$ para el cuarto año y $14 \%$ para el quinto año.

- Captar 10 clientes potenciales para el primer año.

- Posicionarnos en el plazo de 3 años como proveedores de alta calidad de insumos y preparados naturales y orgánicos de productos de cuidado personal.

- Participar en ferias internacionales durante los primeros 5 años tales como "Feria Belleza y Salud Bogotá: Feria de Belleza Colombia” y "Colombia Beauty Show Medellín”; con el fin de conocer a mayor profundidad el mercado colombiano, tener acceso a posibles compradores y conocer la competencia mundial tanto directa como indirecta.

- Utilizar las facilidades prestadas por instituciones peruanas relacionadas a exportaciones para tener asesoramientos de ingreso al mercado colombiano y desarrollarse en él.

\subsection{Mercado potencial y objetivo.}

- Mercado Potencial: Existen 1’319,154 mujeres que podrían comprar nuestros producto en Bogotá, Colombia. 
- Mercado Objetivo: El mercado objetivo es el 11\% de la población femenina de Bogotá, Colombia; target del mercado que comprende el estrato socioeconómico medio-alto.

- Mercado Meta: Es el $0.705 \%$ del mercado objetivo al cual le podemos ofrecer el producto desarrollado en el presente proyecto.

\subsection{Segmentación.}

$\checkmark$ Segmentación Geográfica: Hemos identificado que los potenciales consumidores son las mujeres habitantes de la ciudad de Bogotá, Colombia.

$\checkmark$ Segmentación Demográfica: Mujeres entre el rango de edades de 25 a 45 años de los segmentos socioeconómicos medio-alto.

\subsection{Posicionamiento.}

El posicionamiento se utiliza para diferenciar el producto y asociarlo con los atributos deseados por el consumidor. Para ello se requiere tener una idea realista sobre lo que opinan los clientes de lo que ofrece la compañía y también saber lo que se quiere que los clientes meta piensen de nuestra mezcla de marketing y de la de los competidores. (Grupo Deimon, 2014)

\section{Posicionamiento por calidad del producto}

Se busca posicionar al producto como una loción corporal que destaca la naturalidad de su contenido y la funcionalidad que comprenden sus 
ingredientes para el cuidado de la piel. En comparación con otras lociones corporales que se comercializan en el mercado, el sacha inchi \& verbena body lotion, contiene como insumo principal el aceite de sacha inchi orgánico componente caracterizado por sus propiedades para reestructurar y proteger la piel.

Asimismo, las vitaminas que son parte de su fórmula representan componentes activos de promueven la regeneración y los ácidos grasos insaturados nutren, previenen y tratan los problemas de la piel.

\subsection{Posturas Competitivas.}

Dentro de las posturas competitivas que existen, nosotros hemos analizado que la mejor opción para nuestro producto es: Estrategia de ocupante de nicho de mercado para los 5 años.

Según el tamaño y capacidad de la empresa aplica la estrategia de ocupante de un segmento de mercado específico por medio de diferenciación de producto, de modo que pueda especializarse en sus necesidades y preferencias; del mismo modo, coger el territorio dentro del cual la industria de cosméticos, se encuentra mucho más desarrollada, en Bogotá - Colombia.

\subsection{Producto (ficha técnica, envase, embalaje, etiquetado).}

Ficha técnica del producto

Tabla 39. Ficha técnica de la loción corporal de Sacha Inchi 


\begin{tabular}{|c|c|}
\hline PRODUCTO & Sacha Inchi Body Lotion. \\
\hline $\begin{array}{l}\text { INGREDIENTE } \\
\text { PRINCIPAL }\end{array}$ & $\begin{array}{l}\text { Nombre común: Sacha Inchi. } \\
\text { Nombre científico: Plukenetia volúbilis L. } \\
\text { Tipo: Oleaginosa. } \\
\text { Periodo Vegetativo: } 06 \text { a } 08 \text { meses después del trasplante. } \\
\text { Rendimiento: } 08-2 \text { t/ha. } \\
\text { Ubicación Geográfica: Amazonía (San Martín., Huánuco, Amazonas, Junín, } \\
\text { Ayacucho). } \\
\text { Origen: Se ha encontrado vestigios de su uso por las culturas pre-colombinas en } \\
\text { ceramios. }\end{array}$ \\
\hline $\begin{array}{l}\text { LISTA DE } \\
\text { COMPONENTES }\end{array}$ & $\begin{array}{l}\text { Water, Glyceryl, Myristyl myristate, Cetyl Alcohol, Isopropyl Myristate, } \\
\text { Plukenetia Volubilis Seed Oil, Honey Extract, Retinyl Palmitate \& Tocopheryl } \\
\text { Acetate, Methylparaben, Disodium EDTA, Verbena Fragrance \& Citral. }\end{array}$ \\
\hline MODO DE USO & $\begin{array}{l}\text { Aplicar de forma abundante sobre el cuerpo masajeando circularmente; las veces } \\
\text { que sea necesario durante el día. Gracias a su fórmula única de rápida absorción } \\
\text { y suave textura, brindando a la piel humectación intensa, suavizando por más } \\
\text { tiempo y protegiéndola de la resequedad. }\end{array}$ \\
\hline ENVASE & $\begin{array}{l}\text { Capacidad de } 250 \text { gr. } \\
\text { Tubo de plástico rígido, resistente, de fácil manejo y portabilidad. } \\
\text { Composición Química: } \\
\text { 1. Capa de impresión: Polietileno coloreado. } \\
\text { 2. Capa de unión: Biopolímero. } \\
\text { 3. Barrera: Foil de aluminio o EVOH. } \\
\text { 4. Capa de unión: Biopolímero. }\end{array}$ \\
\hline PRECAUCIONES & $\begin{array}{l}\text { Solo para uso externo, evite el contacto con los ojos, si esto ocurre enjuagar con } \\
\text { abundante agua, no aplicar sobre piel irritada o lastimada. Mantener fuera del } \\
\text { alcance de los niños. }\end{array}$ \\
\hline ADVERTENCIAS & $\begin{array}{l}\text { Si observa alguna reacción desfavorable, suspenda su uso. En caso de que } \\
\text { persista, consulte a su médico. }\end{array}$ \\
\hline $\begin{array}{l}\text { CONDICIONES } \\
\text { DE } \\
\text { ALMACENAMIEN } \\
\text { TO }\end{array}$ & Mantener el envase bien cerrado y mantener en un lugar fresco y seco. \\
\hline $\begin{array}{l}\text { VIDA DEL } \\
\text { PRODUCTO }\end{array}$ & $8-10$ meses aproximado. \\
\hline $\begin{array}{l}\text { FIN DEL USO DEL } \\
\text { PRODUCTO }\end{array}$ & Depende de la frecuencia del consumidor. \\
\hline
\end{tabular}

Elaboración Propia

\section{Envase}

Material: Plástico. Rígido, Resistencia al impacto y humedad, estabilidad térmica.

Tipo: Tubo. Envase versátil (fácil manejo) y de fácil portabilidad. 


\section{Composición Química:}

1. Capa de impresión: Polietileno coloreado.

2. Capa de unión: Biopolímero.

3. Barrera: Foil de aluminio o EVOH.

4. Capa de unión: Biopolímero.

Figura 4.Prototipo de envase de la loción de sacha inchi

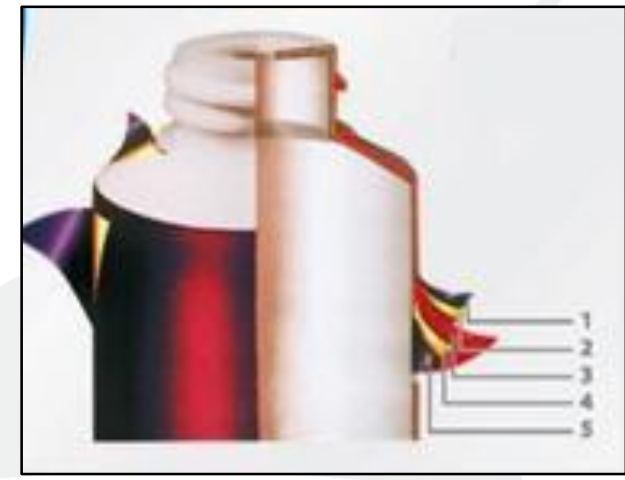

Fuente: Plasthermo, S.A. De C.V.

\section{Etiquetado}

El contenido comprendido en las etiquetas o empaques de los productos cosméticos, deben ser acordes a la naturaleza de éste y expresar información mínima como:

$\checkmark \quad$ Nombre del producto.

$\checkmark$ Nombre del laboratorio fabricante y del importador, según el caso, y su domicilio.

$\checkmark$ Número de registro sanitario expedido por la Autoridad Sanitaria.

$\checkmark$ Composición cualitativa del producto.

$\checkmark$ Instrucciones de empleo.

Advertencias y precauciones en caso necesario.

$\checkmark$ Número de lote de fabricación. 
Las demás que, a juicio técnico del INVIMA, se consideren convenientes.

Si en las etiquetas o empaques se incluyen propiedades especiales del producto, deben ser sustentadas con la información técnica que se ha presentado en el momento de obtener la evaluación farmacéutica.

Cuando no sea posible colocar la totalidad de la información anteriormente mencionada, ya sea porque los productos se comercializan en forma individual o de tamaño muy pequeño, deberá aparecer siempre el nombre del producto, el número del lote y el número de registro.

En cuanto a las frases explicativas que figuren en las etiquetas, rótulos y empaques deberán aparecer en español, especialmente las indicaciones para su uso y precauciones en los productos importados.

De igual manera no se aceptan como nombre para los cosméticos las denominaciones estrambóticas, exageradas, o que induzcan a engaño o error, o que no se ajusten a la realidad del producto, ni que tenga nombres de santos y concernientes a temas religiosos. (Organización Mundial de la Salud, Oficina Regional para las Américas, 2014) 
Figura 5. Prospecto de etiqueta de la loción corporal de sacha inchi

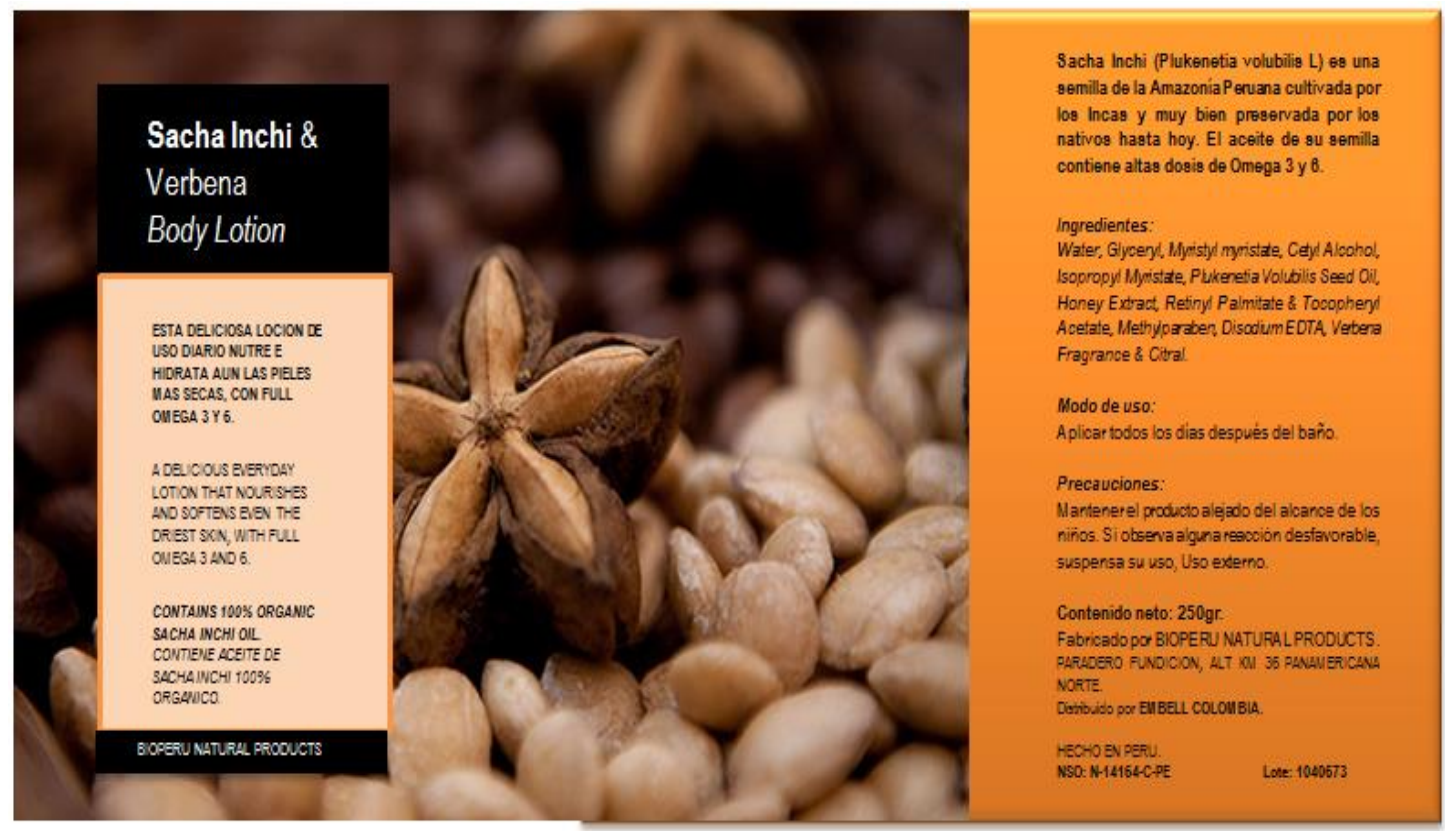

Elaboración Propia

8.7 Precio (método para determinar precios, medios de pago).

\section{Determinación del nivel de precios}

PAR - Ni totalmente alto ni totalmente bajo.

Metodología para establecer el Precio

\section{- Objetivo de la fijación:}

Con el precio PAR buscamos en un principio la supervivencia en el ingreso al mercado, ya que es un nuevo producto a base de una semilla poco conocida por los colombianos de tal manera que el impacto de promoción del producto pretenderá ser significante, debido a que a largo plazo se espera una generación de ventas y tener un crecimiento del valor del producto; maximizar el mercado es otro objetivo, con un producto de calidad media-alta a un precio intermedio 
con el fin de obtener el rendimiento esperado tanto en utilidades satisfactorias como en la participación progresiva-ascendente en mercado objetivo y control de su estabilidad en lapsos de tiempo determinados, al igual que enfrentarse a situaciones de impacto directo relacionando el precio de la competencia y su influencia inmediata con el precio y venta de la crema de sacha inchi, estableciendo claramente las diferencias intrínsecas que ofrece dicho producto y las grandes ventajas sobre otros.

\section{- Determinantes a partir de la demanda:}

La coyuntura económica es un factor importante a tomar en cuenta a la hora de escoger a Colombia como mercado objetivo, la trayectoria que este país ha venido desarrollando en su economía ha mejorado con respecto a tiempos anteriores, ahora lo encontramos como un país foco de inversión y buenas retribuciones, las ventas han aumentado a medida del tiempo y la compra y preferencia de las mujeres por productos cosméticos ha tenido un incremento sustancial, posicionándolo como uno de los países de mayor consumo de dichos productos, por tal motivo el interés y la demanda tienen cifras significativamente favorables.

Las mujeres colombianas se caracterizan por su alto consumo en productos cosméticos muchas veces sin escatimar costos, el precio no será totalmente alto, siendo así, se espera un equilibrio entre las unidades de crema producidas y las unidades demandadas. 


\section{- Estimación según los costos:}

El costo unitario total de la crema se compone de varios tipos de costos, reaccionando de forma directa al variar las cantidades producidas. Los costos fijos se mantienen, los costos variables pueden reflejarse un poco altos en las primeras cantidades producidas pero a medida que se establezca una producción sostenible en posibles grandes cantidades y descuentos que puedan surgir, dichos costos pueden disminuir y no ser tan significativos, a través de economías de escala.

La demanda ya establece el límite superior para el precio que se puede cobrar por la crema. El costo de producirla, establecerá el límite inferior de precio de la crema, buscando cubrir su costo de producción, distribución y venta del producto, y que incluya un rendimiento justo por su esfuerzo y riesgo.

\section{- Determinantes de factores externos:}

Es importante tomar como parte de la estructura de fijación y analizar, a qué precio están vendiendo las cremas corporales nuestros competidores directos y tener en cuenta que al ser una crema nueva a base de un producto parcialmente nuevo para el mercado colombiano, contamos con una oferta de crema similar a la de un competidor importante entonces se considerará un precio cercano al de este competidor con el fin de no perder ventas. La crema no puede ser vendida a un precio mayor que los competidores. Se puede implementar un precio igual o más bajo. Para que nuestros consumidores tomen nuestra crema como opción de compra. 
- Método de fijación de precios:

Tendremos en cuenta dos principales características en cuanto al método.

\section{Fijación de precios basada en las condiciones del mercado}

Según el tipo de vida que llevan nuestros consumidores y las características de compra y preferencias a la hora de escoger productos para cuidado y uso corporal.

Por tal motivo estamos respondiendo a la gran demanda que existe en Colombia por parte de las mujeres hacia los productos cosméticos, en especial a las cremas corporales que brinden beneficios a la salud y cuidado de la piel. Y sobre todo fijándonos en que dicho mercado no tiene un límite de precio al pagar por una crema, sabiendo que la crema de sacha inchi tendrá un precio par, los resultados que se han de esperar tienden a ser positivos.

Por otro lado cabe acotar que las cremas a base de frutos autóctonos o exóticos presentan una tendencia crecientes en países emergentes como es el caso del mercado colombiano y sumado a esto el auge que en los últimos años han tenidos los Spas como consecuencia del ritmo de vida acelerado de las grandes Metrópolis como el caso de Bogotá y el estrés de la vida cotidiana han hecho que cada vez más personas busquen alternativas de relajación. Hoy en los centros de estética o salud conocidos como Spas recurre un gran porcentaje de la población en búsqueda de bienestar para su cuerpo lo cual nos presenta una ventaja y mercado atractivo para el Sacha Inchi Body Lotion.

Por último mencionar que el precio promedio al que la competencia vende productos de este tipo, lociones corporales, fluctúa entre \$5-\$6 FOB. (Consejo de Asociaciones de la Industria de Cosméticos Latinoamericana, 2014) 


\section{Método de Pago}

Grandes Volúmenes: Una vez realizada las negociaciones con el futuro importador/distribuidor, habiendo enviando previamente la Proforma Invoice y estando de acuerdo ambas partes con el precio, INCOTERM y fecha pactadas; el método de pago recomendable sería utilizar una Carta de Crédito Irrevocable para mayor seguridad. En el primer año la condición será 50\% del monto total exportado contra presentación del B/L y el $50 \%$ a 30 días. Se aplicarán descuentos por grandes volúmenes (Container Basis).

\subsection{Plaza.}

Descripción de los canales de distribución

\section{$\checkmark \quad$ Punto de Venta en Colombia}

Figura 6. Potencial Punto de Venta de la loción corporal de sacha inchi en Colombia.

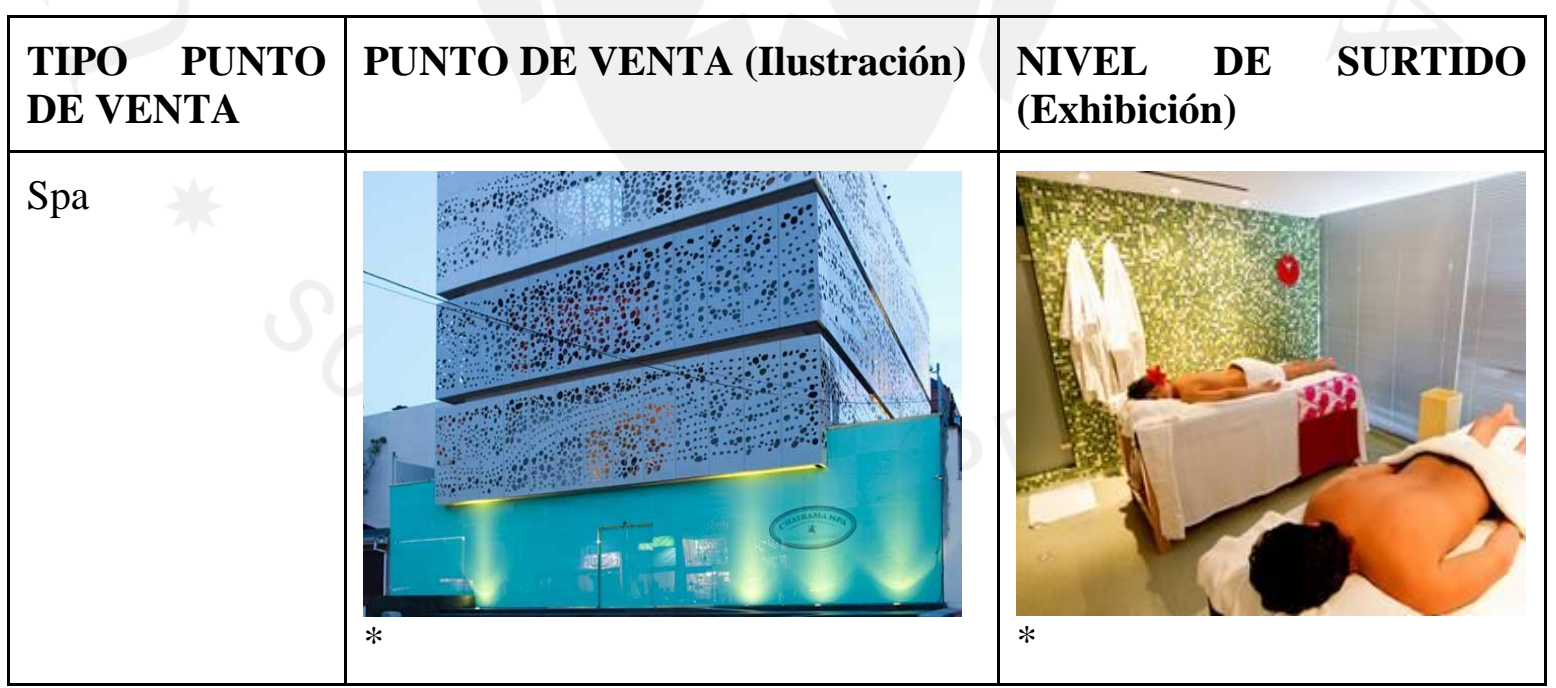

Fuente: Spa Chairama

Elaboración Propia 


\section{$\checkmark \quad$ Gestión de Intermediarios}

Con el fin de que el producto llegue en buenas condiciones y a tiempo al lugar requerido, en este caso los diferentes centros de estética o Spas, se ha realizado contacto con la empresa $\mathrm{O}$ Boticário, la cual es una comercializadora de productos de belleza diferenciados en la ciudad de Bogotá. Esta empresa tiene la experiencia de conocer el manejo y el sector cosmético y de belleza, no sólo para centros de estética, también salas de belleza y cada uno de sus sectores, con la posibilidad de ampliar el número de clientes.

Dentro de las obligaciones de O Boticário, están: obtener la mercancía en el punto pactado y distribuirla a tiempo en el lugar indicado, asegurándose el buen estado de las mismas, con el fin de cumplirle al cliente con su pedido, en cuanto a cantidad y tiempo pactado.

\subsection{Promoción (estrategias de ingreso al mercado).}

\section{Estrategias Push para promoción del producto}

El objetivo de la estrategia Push es suscitar una cooperación voluntaria del distribuidor que, en razón de los incentivos y de las condiciones de venta que se le ofrecen, va naturalmente a privilegiar o a empujar el producto cada vez que pueda. Y la fuerza de venta o la comunicación personal, será el elemento más importante. 
Gráfico 24. Estrategia Push

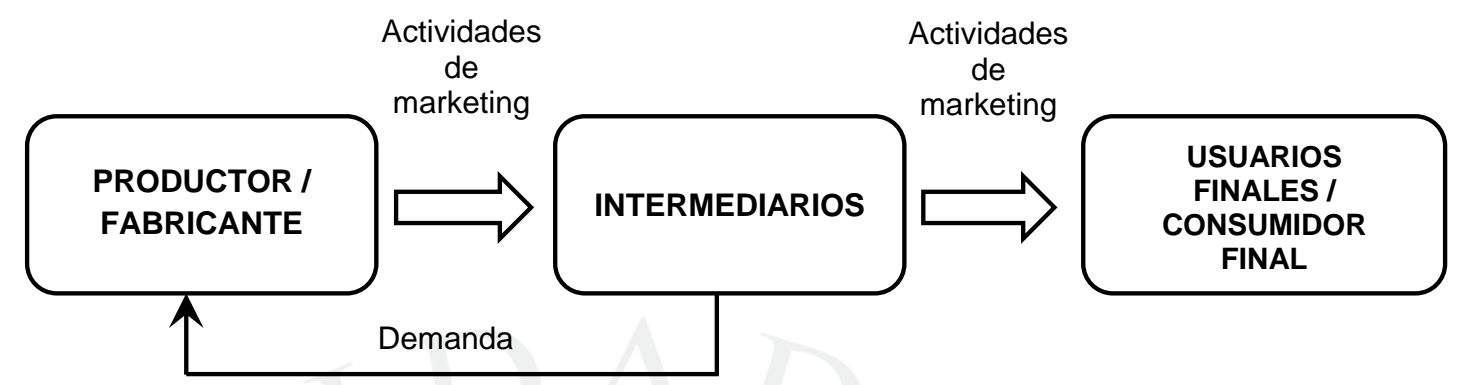

Elaboración Propia

Las herramientas primordiales que se necesitan son:

- Desarrollo de una nueva imagen corporativa enfocada en el sector de belleza y cuidado personal (tarjetas personales, brochure, papel membretado, etc.).

- Desarrollo de una página web.

- Participación y visitas a ferias especializadas del sector de belleza y cuidado personal.

- Visitas personales a compradores potenciales (distribuidores), con el apoyo de PROMPERÚ.

- Marca País PROMPERÚ. 
Participación en ferias especializadas

\section{FERIA BELLEZA SALUD BOGOTÁ: FERIA DE BELLEZA COLOMBIA}

Figura 7.Logo de Feria Belleza y Salud 2015

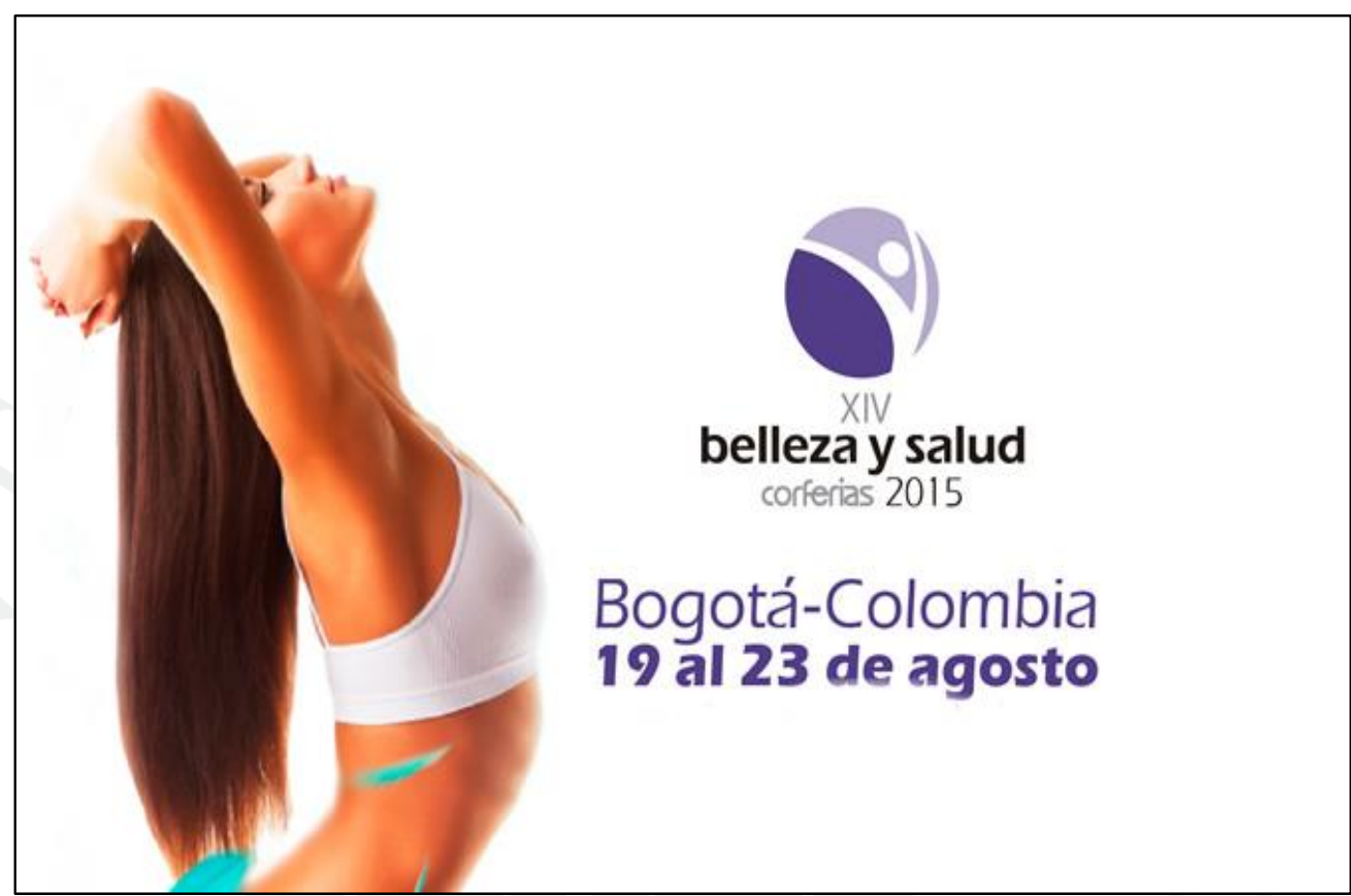

Fuente: http://feriabellezaysalud.com/

En la Feria Belleza y salud en Bogotá nos podremos encontrar con las últimas tendencias y novedades en: estética, cosmetología, cosmiatría, peluquería, aseo personal, cuidado de la piel, cirugía plástica, salud natural, nutrición y gimnasia medicina tradicional, medicina alternativa, entre otras.

La feria Belleza y salud es una de las ferias más importantes del sector en Colombia, de ahí que cuente con la presencia de los mejores profesionales que mostrarán sus últimas novedades e innovaciones en todo lo referente a la industria de la belleza y el cuidado personal. 
La Feria Belleza y salud es una plataforma que pretende proyectar la industria dedicada al cuidado integral del hombre y la mujer, reuniendo a fabricantes, representantes y distribuidores de productos, equipos y/o servicios del sector, en un evento orientado al lanzamiento de nuevos productos, presentación de tendencias y perfeccionamiento de los profesionales del área.

\section{Sectores y Productos:}

$\checkmark$ Cosmética, cuidado personal, y de la piel.

$\checkmark$ Accesorios y aparatología para peluquería.

$\checkmark$ Estética dental, cosmiatría y aparatología.

$\checkmark$ Medicina Alternativa y salud natural.

Nutrición y dietética.

Salud tradicional.

Confecciones (fajas, uniformes y ropa blanca).

$\checkmark$ Equipos y mobiliario (Estética Corporal, facial, Gimnasia pasiva, equipos para gimnasios, spa y relajación, aparatología estética en general) y mucho más.

- Localización: Bogotá, Colombia.

- Recinto: CORFERIAS: Centro internacional de negocios y exposiciones.

- Página web: $\underline{w w w . f e r i a b e l l e z a y s a l u d . c o m ~}$ 


\section{COLOMBIA BEAUTY SHOW}

Figura 8. Logo de la Feria Colombia Beauty Show

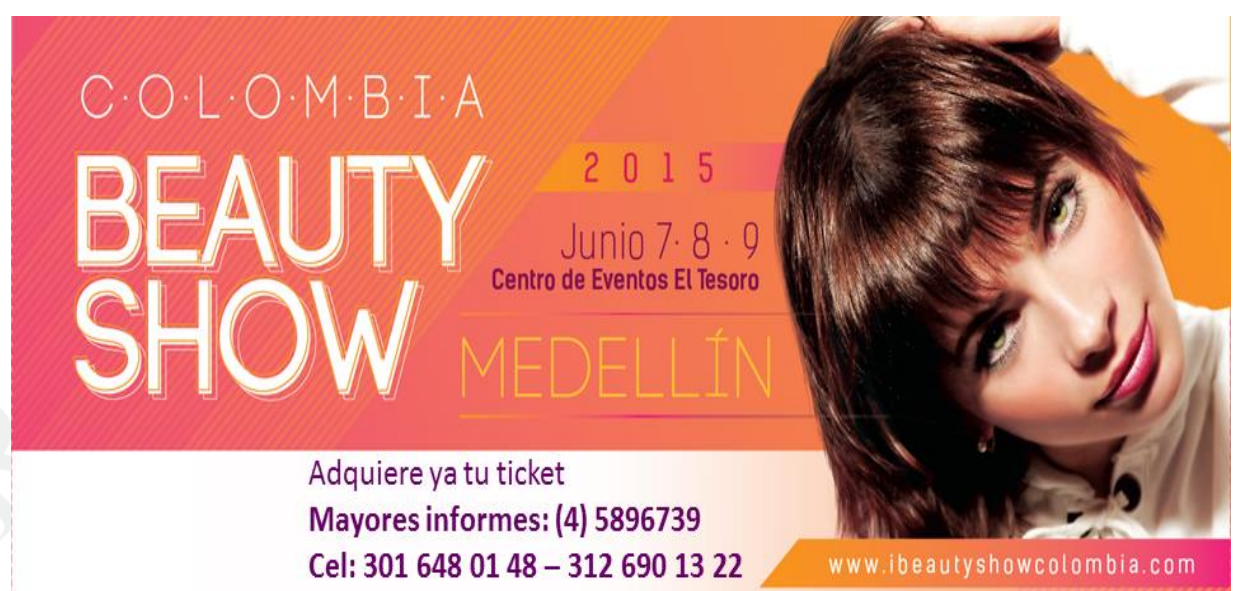

Fuente: http://www.ibeautyshowcolombia.com/

EI Colombia Beauty Show Medellín, es el evento en educación para profesionales de la belleza. El éxito de este evento a nivel internacional nos brinda el escenario ideal para que apliquemos nuestro modelo en Colombia.

Colombia Beauty Show ofrece las mejores marcas nacionales e internacionales de este mercado para muestras comerciales, demostraciones en vivo y además brindar educación al público objetivo como lo son las peluquerías, estéticas, centros dermatológicos, cosméticas, Spas, entre otros.

Ofreciendo lo mejor de la industria de la belleza en:

$\checkmark$ Cabello-Hair.

Uñas - Nails.

Cuidado de la Piel - Skin Care.

Estética.

$\checkmark$ Maquillaje-Make up. 
Barberías - Barbering.

$\checkmark$ Salud-Health

$\checkmark$ Clases - Hands On Workshops.

$\checkmark$ Negocios-Business.

- Localización: Medellín, Colombia.

- Recinto: Centro de eventos El Tesoro.

- Página web: $\underline{w w w . i b e a u t y s h o w . c o m . c o / i n d e x / ~}$

\subsection{Presupuesto de Marketing.}

La actividad de promoción tiene dos etapas: pre operativo y la operativa.

- Pre - Operativo:

Se tiene que crear la imagen corporativa de la empresa (logo de la empresa, tarjetas personales, brochure, hojas membretadas y página web), y se tiene que realizar la visita comercial a Colombia para poder concretar nuestra primera venta.

- Operativo:

Anualmente se tiene un presupuesto de marketing asignado, que será utilizado para solventar gastos como: visitas a ferias, visitas a clientes y otros tipos de actividades de publicidad promoción y ventas. A partir del 3er año este presupuesto será incremental en un $10 \%$. 
Tabla 40. Presupuesto de Marketing, Año 1

\begin{tabular}{|l|l|}
\hline \multicolumn{2}{|c|}{ PRE OPERATIVO } \\
\hline ACTIVIDAD & USD \\
\hline Tramitación del Dominio Web & 53.57 \\
\hline Diseño de Pagina Web & 482.14 \\
\hline Diseño Publicitario & 553.57 \\
\hline Viaje Comercial Colombia & $2,000.00$ \\
\hline \multicolumn{2}{|c|}{ OPERATIVO } \\
\hline ACTIVIDAD & USD \\
\hline Publicidad, Promoción y Ventas & $8,474.58$ \\
\hline TOTAL & $\mathbf{1 1 , 5 6 3 . 8 6}$ \\
\hline & Elaboración Propia
\end{tabular}

El presupuesto asignado a Publicidad, Promoción y Ventas comprende solventar pasajes aéreos del Jefe del Área Comercial para su participación en ferias del sector en Colombia; asimismo, el envío de muestras a clientes potenciales, gastos de representación, entre otros.

Además comprende gastos referidos a preparación de merchandising y publicidad en el punto de venta en alianza con el distribuidor, Makerting Below the Line. 


\section{CAPITULO IX. PLAN LOGÍSTICO}

\subsection{Manejo de mercancía.}

\section{a. Embalaje}

\section{Pallets}

Se usarán cajas de cartón corrugado resistente de dimensiones de 60x40x40 cm (largo x ancho x alto), en la cuales habrán 192 unidades de loción corporal de Sacha Inchi. Sobre una estiba se pondrán 5 cajas con 4 niveles (20 cajas en total), con un peso total de $960 \mathrm{Kgs}$. Al interior de cada una de las cajas habrá medios de fijación y separador, el papel Kraft, esquineros de foam, y el sellado debe ser con cintas adhesivas adecuadas. Para mayor seguridad el pallet estará cubierto de stretch film.

\section{Gráfico 25. Ejemplo.- Modelo de Pallet}

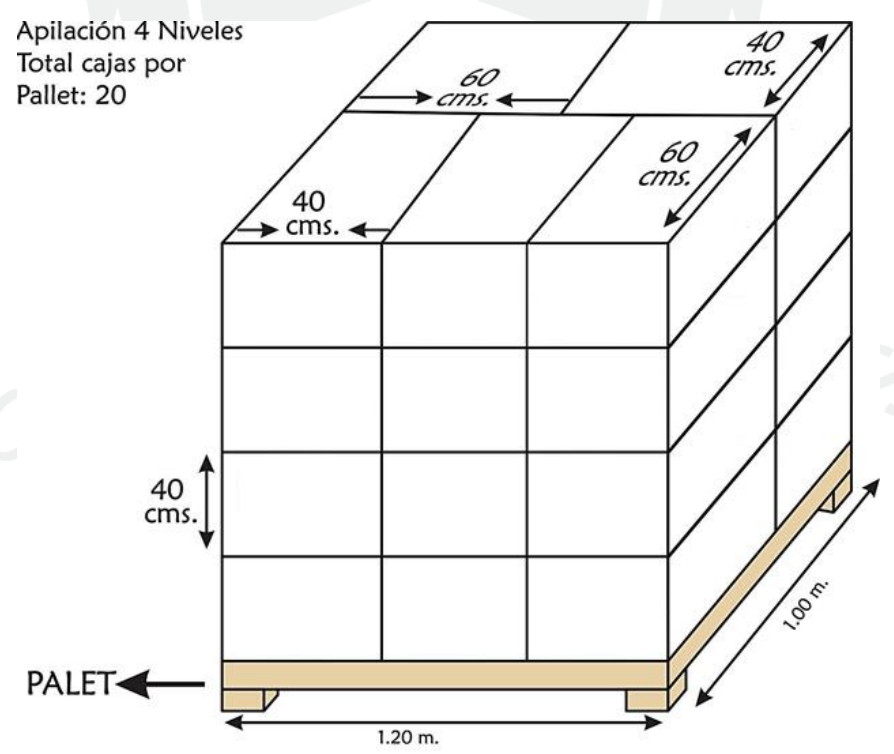

Fuente: PALLET MAKER 


\section{Contenedores}

Nuestra unidad principal de venta equivale a 2 pallets dentro de un LCL; $\sin$ embargo, en caso se pueda concretar la venta de un contenedor, tenemos que analizar las cantidades que ingresarán.

Según las medidas estándar de un pallet, en un contenedor seco de 20 pies ingresan 10 pallets. Eso quiere decir que pueden ingresar un total de 38,400 unidades de lociones corporales de 250 gr.

\section{b. Medio de transporte}

Figura 9. Rutas Marítimas Callao - Colombia

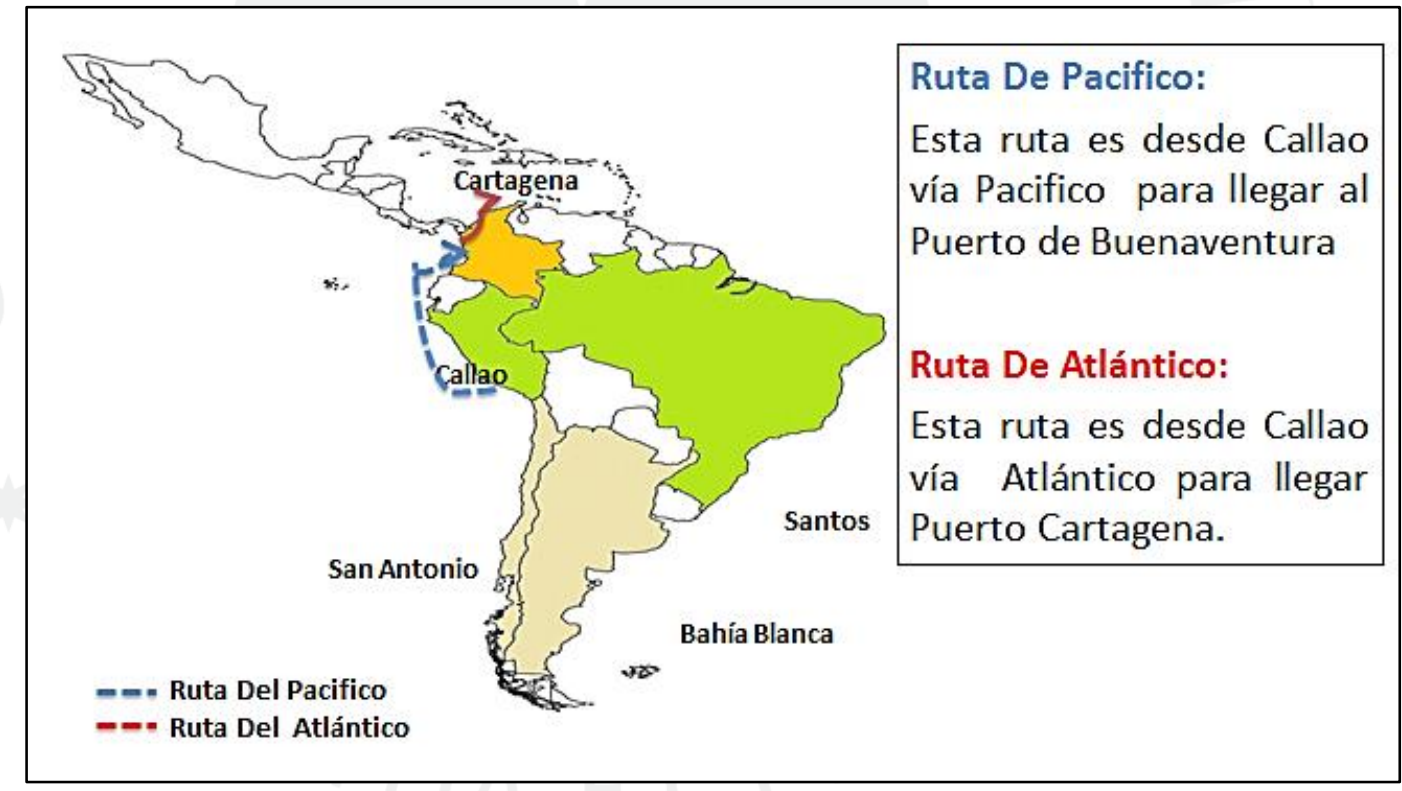

Fuente: Siicex 
Figura 10. Mapa de ubicación del Corredor vial Bogotá - Buenaventura

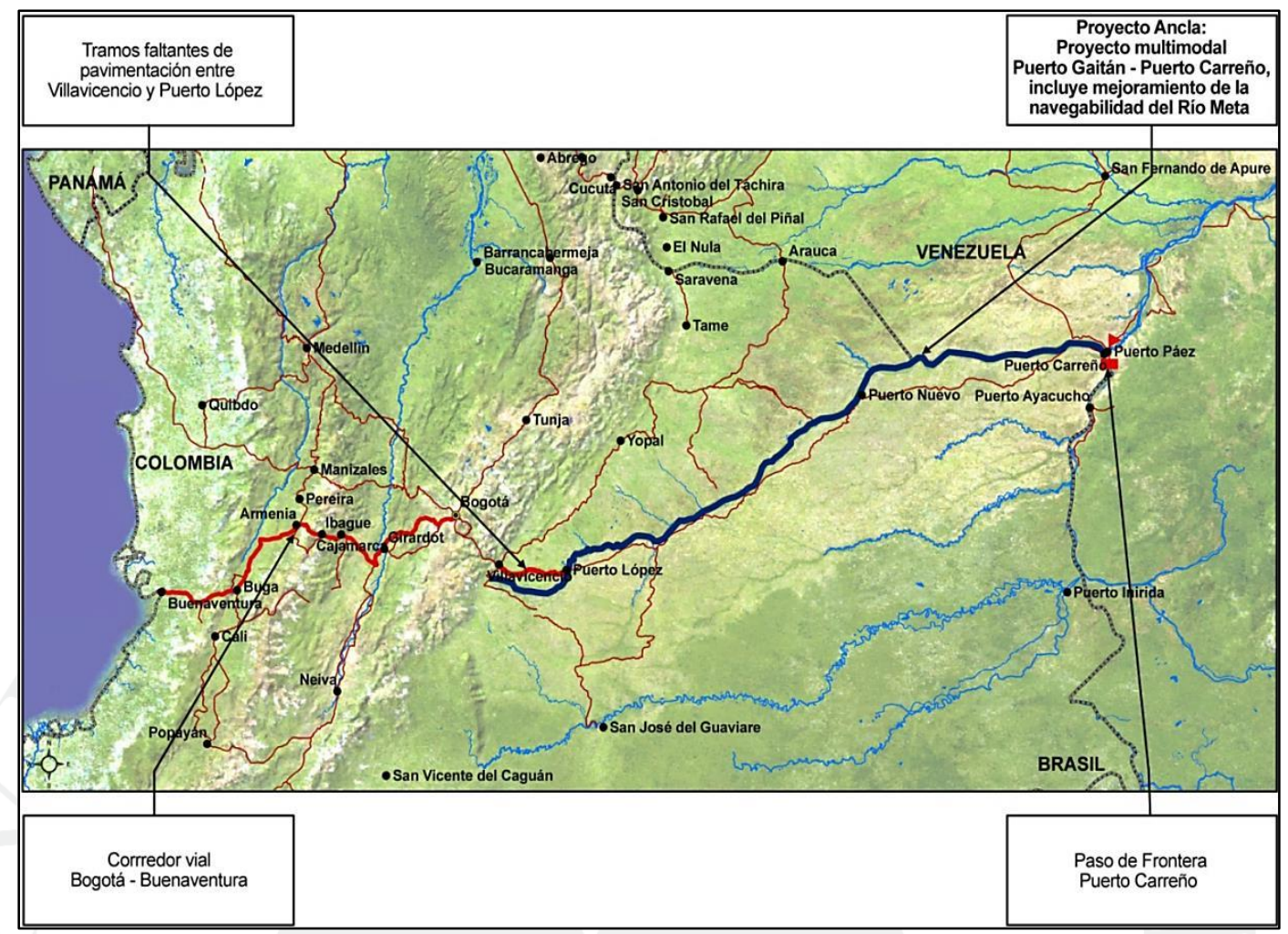

Fuente: PROMPERÚ

Mediante este gráfico, podemos observar que la principal entrada a Colombia es a través del Puerto de Buenaventura, luego se traslada la mercancía a través del Corredor Vial Buenaventura-Bogotá, es así como llegaría la mercancía a Bogotá. Por otro lado, podemos afirmar que Bogotá es la ciudad principal para introducir el Sacha Inchi Body Lotion debido a la gran demanda por productos de belleza y cuidado personal que presenta esta ciudad.

\section{c. Agentes logísticos}

La empresa "BIOPERÚ NATURAL PRODUCTS" trabajará con Port Logistics S.A.C. como Agente y Operador Logístico. A ellos les enviaremos 
las Instrucciones de Embarque para realizar la carga de la mercancía en el contenedor asignado y gestionar los trámites de exportación.

\section{d. Tramitación aduanal}

Los trámites de aduana serán tercerizados y realizados por Port Logistics

S.A.C. Los documentos de exportación necesarios son:

- Factura Internacional.

- Documento de transporte internacional.

- Certificado de análisis (COA).

- Packing List.

- Certificado de Origen.

- Certificado DIGEMID.

- Otros 'Statements' de ser requeridos.

\section{e. Seguros Internacionales}

BIOPERÚ NATURAL PRODUCTS trabajará con el INCOTERM FOB. No se pagará el seguro internacional.

\section{f. Trazabilidad}

BIOPERÚ NATURAL PRODUCTS realizará la trazabilidad a través del agente de carga. Él nos mantendrá informado del estado de la mercancía mientras sale del territorio peruano. 


\section{CAPITULO X. PLAN DE ADMINISTRACIÓN Y RECURSOS HUMANOS}

10.1 Objetivos de Administración y Recursos Humanos.

$\checkmark$ A nivel Corporativo: La administración de los Recursos Humanos tiene como objetivo básico contribuir al éxito de la empresa o corporación.

$\checkmark$ A nivel funcional: Mantener la contribución del departamento de recursos humanos a un nivel apropiado a las necesidades de la organización, es una prioridad absoluta.

$\checkmark$ A nivel social: Debe responder ética y socialmente a los desafíos que presenta la sociedad en general y reducir al mínimo las tensiones o demandas negativas que la sociedad pueda ejercer sobre la organización.

$\checkmark$ A nivel del personal: Cada uno de los integrantes de la organización aspira a lograr ciertas metas personales legítimas. En la medida en que el logro de estas metas contribuya al objetivo común de alcanzar las metas de la organización, el departamento de recursos humanos reconoce que una de sus funciones es apoyar las aspiraciones de quienes componen la empresa. 
10.2 El organigrama y descripción de puestos por área.

Gráfico 26. Organigrama

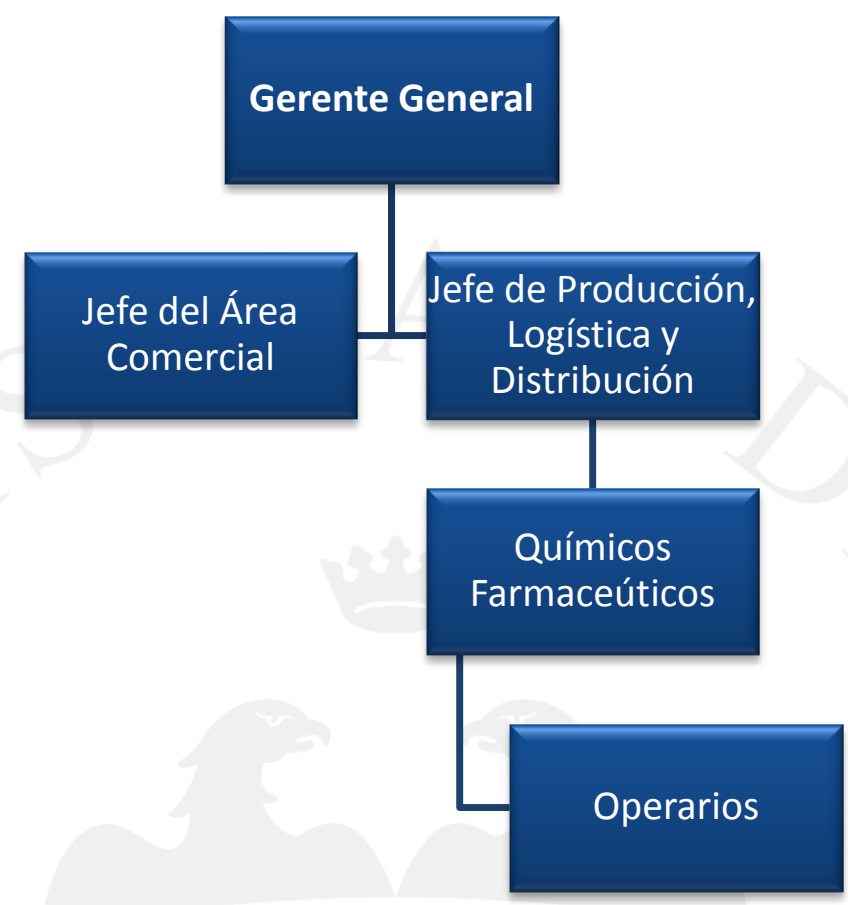

Elaboración Propia

- Gerente General:

Es el representante de la empresa, quien liderará la formulación y aplicación del Plan de Negocios.

Encargado de liderar la gestión estratégica, dirigiendo y coordinando a las distintas áreas para asegurar la rentabilidad, competitividad, continuidad y sustentabilidad de la empresa, cumpliendo con los lineamientos estratégicos de la empresa y las normativas y reglamentos vigentes.

- Jefe del Área Comercial:

Encargado de manejar las estrategias de ventas y plan de mercadeo (marketing mix). Está a cargo de evaluar las oportunidades del mercado meta y hacer prospección a nuevos clientes. 
Manejará la cartera de clientes y definirá tácticas para fidelizar a los mismos.

- Jefe de Producción, Logística y Distribución:

El jefe de producción supervisará la línea de producción durante todo el proceso; estará a cargo del correcto funcionamiento de las maquinarias en planta, de capacitar al personal y deberá conocer muy bien las normativas de seguridad e higiene a cumplir. Asimismo, realizará la atención a los proveedores (manejo del abastecimiento) y de la logística de salida de la mercadería (logística de entrada y salida).

- Químicos Farmacéuticos:

Encargados de la elaboración de las fórmulas del producto. Estarán a cargo del control de calidad del producto, realizando evaluaciones físico-químicas y microbiológicas para garantizar su inocuidad y propiedades.

\section{Operarios:}

Encargados del manejo de las máquinas para la producción de las lociones corporales, procesos de llenado y etiquetado del producto final.

\subsection{Definición del perfil del puesto y evaluación de desempeño.}

\section{Perfil del Gerente General:}

La posición de gerente general es una que requiere una combinación de habilidades, experiencia y educación. Un gerente general exitoso tendrá habilidades superiores de liderazgo, trabajará bien con un equipo y tendrá la 
capacidad de trabajar de forma independiente con poca supervisión o ninguna.

El candidato debe tener habilidades superiores en la toma de decisiones, habilidades de resolución de problemas y habilidades de gestión de conflictos.

Él debe tener un conocimiento profundo de la empresa, su cultura y sus productos y servicios. También debe ser capaz de trabajar con todos los niveles de gestión y tener una formación superior y capacidades de delegación.

Los candidatos deben tener un mínimo de cinco años de experiencia en gestión y un título de licenciatura o maestría en un campo de estudio relacionado.

- Titulado de la Carrera de Negocios Internacionales.

- De preferencia con estudios de especialización.

\section{Perfil del Jefe del Área Comercial:}

Profesionales de las carreras de Ingeniería Industrial, Administración o Negocios Internacionales, con experiencia de 2 años en posiciones similares, en empresas de exportación de productos de belleza yo cuidado personal, con domino del idioma inglés a nivel Avanzado (Hablado y escrito).

Dentro de sus competencias deben primar el liderazgo, iniciativa, trabajo en equipo, capacidad de análisis y capacidad de planificación. 
Perfil del Jefe de Producción, Logística y Distribución:

Profesional de la carrera de Ingeniería Industrial con capacidad de manejo de personal operario. Con destreza para la gestión y planificación de producción, elaboración de flujos de proceso y requerimientos de materiales; manejar rendimientos y productividad. Promotor del cumplimiento de los estándares de calidad. Control de mantenimiento de maquinarias y equipo.

\subsection{Política de selección, contratación, capacitación y desarrollo.}

- La persona a contratar debe cumplir con el perfil de cargo establecido para la vacante.

- Antes de iniciar con el proceso de reclutamiento, la empresa analizará la posibilidad de realizar alguna promoción o rotación interna acorde a la vacante establecida.

- Todos los candidatos deberán someterse a entrevista y a los exámenes laborales y deberán obtener resultados satisfactorios de acuerdo a las necesidades de cada caso para ser considerados como aptos para una vacante.

- No se podrá realizar ninguna contratación de personal que no haya cumplido con el proceso de selección.

- No es posible contratar a menores de edad.

- Ningún trabajador se verá discriminado por razones de edad, sexo, estado civil, origen racional o étnico, condición social, religioso o convicciones, ideas políticas, orientación sexual, afiliación o no a un sindicato, discapacidad, así como por razón de lengua. 
- El trabajador debe guardar absoluta discreción con la información confidencial de la empresa.

- El trabajador no podrá efectuar negociaciones relacionadas con los activos de la empresa en los cuales pueda tener un interés real o potencial.

- No tener antecedentes judiciales y penales.

- La administración será responsable de integrar los expedientes de personal y manejar confidencialmente su información, así como de elaborar los contratos respectivos, solicitando para tal efecto la siguiente documentación: Hoja de vida con las certificaciones laborales acorde a la experiencia acreditada, copia de DNI vigente, certificaciones que avalen los estudios realizados, carta de no antecedentes policiales y penales, presentar la documentación que le solicite la empresa para verificar su capacidad para el empleo.

- Los datos y referencias que proporcionen los trabajadores serán verificados por la empresa, quedando entendido que de comprobarse la falsedad de los mismos, no será admitido en el trabajo, o, si ya estuviese trabajando, le podrá ser rescindido el contrato Individual del trabajo, sin responsabilidad alguna de la empresa.

- Toda persona contratada para realizar una función en la empresa, deberá firmar un contrato de trabajo, que contenga todas las informaciones requeridas por la ley y según las políticas internas, la empresa podrá contratar de manera temporal a un trabajador que por la naturaleza del trabajo, sólo dure una parte del año. Este tipo de contratos se denomina "por cierto tiempo" y termina sin responsabilidad por parte de la empresa en la fecha de término estipulada en el mismo. 
- Una vez suscrito el contrato, el empleado, queda comprometido con la empresa, a prestar sus servicios personales, en el nivel que le corresponda en la organización, cumpliendo las cláusulas del contrato y las leyes laborales y reglamentos que regulan las relaciones de trabajo.

- La inducción al puesto será impartida y coordinada por la Parte Administrativa de la Empresa a través de proyección de una presentación, folleto y evaluación escrita, en donde se dará a conocer aspectos generales de la empresa, del puesto, y de los sistemas de calidad y ambiental así como aspectos de seguridad establecidos para el buen desarrollo de cada una de las actividades desarrolladas por la organización.

- Todo empleado nuevo será sometido a un período probatorio, este será de tres meses, al finalizar este período el jefe directo inmediato deberá hacer la evaluación y recomendará o no su contratación, a la gerencia técnica y/o administración, para fines de confirmación en el cargo. 
10.5 Descripción de los principales procesos del negocio - Flujograma.

\section{PROCESO 1}

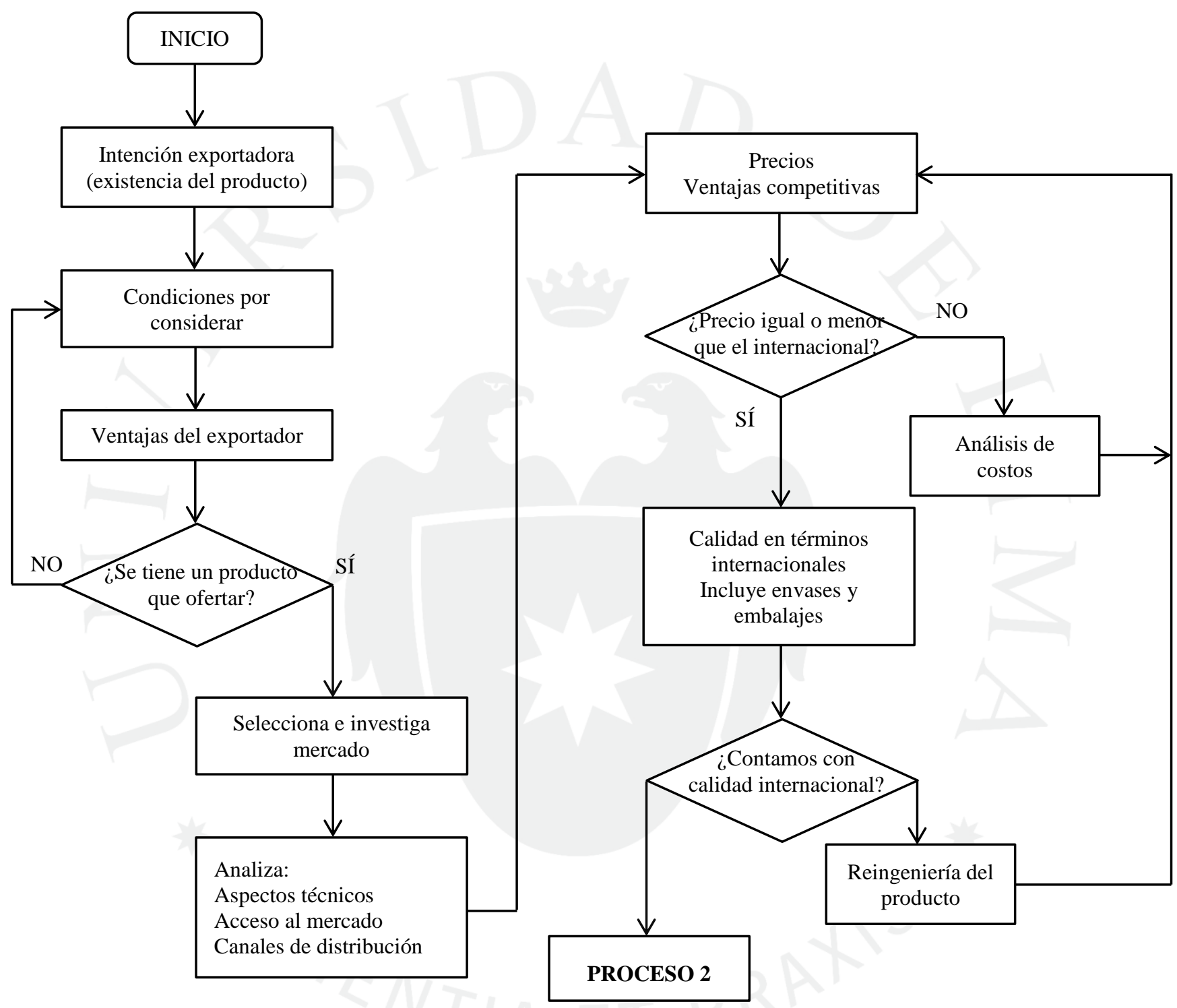




\section{PROCESO 2}

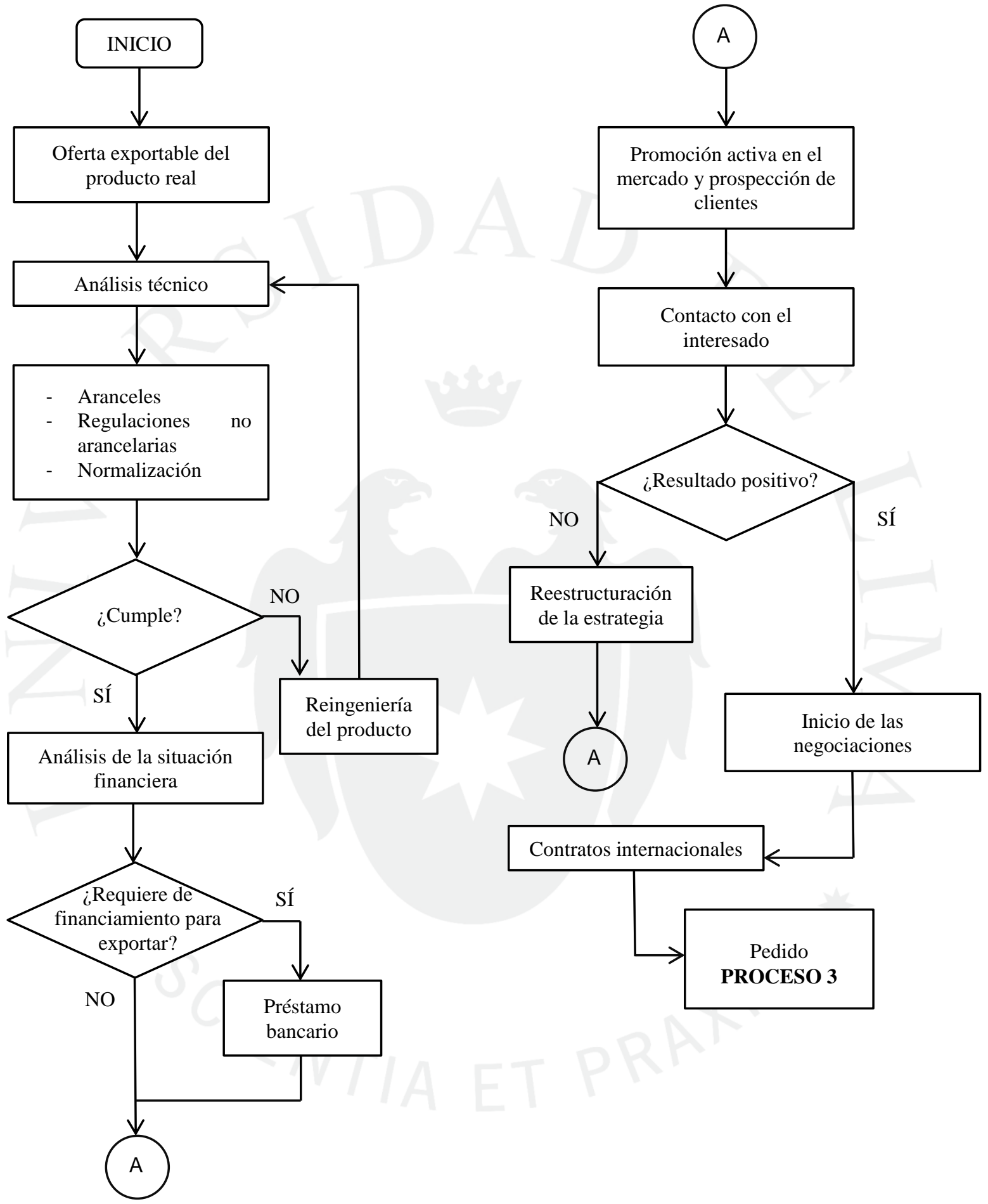


PROCESO 3

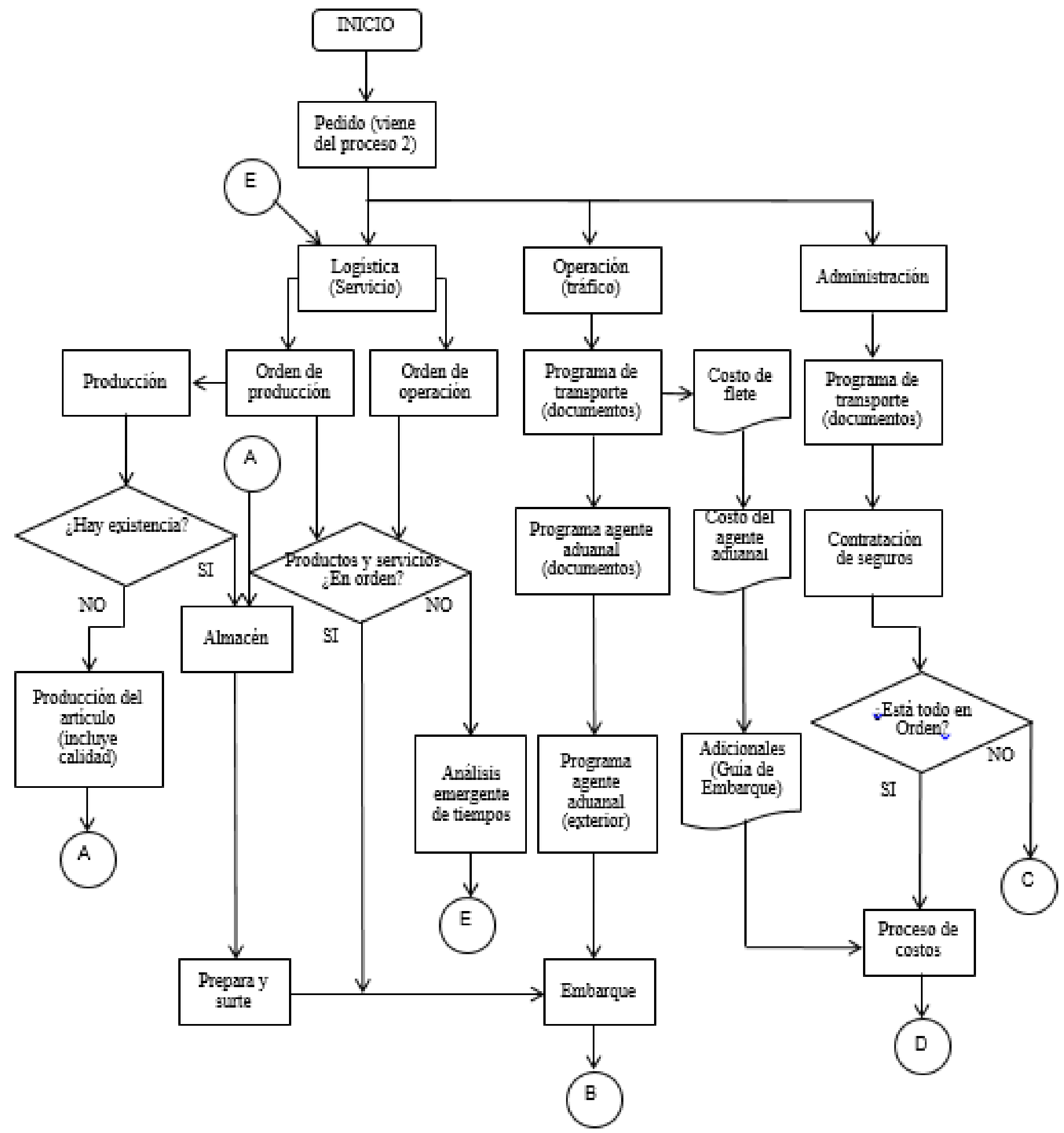




\section{PROCESO 3 (CONTINUACIÓN)}

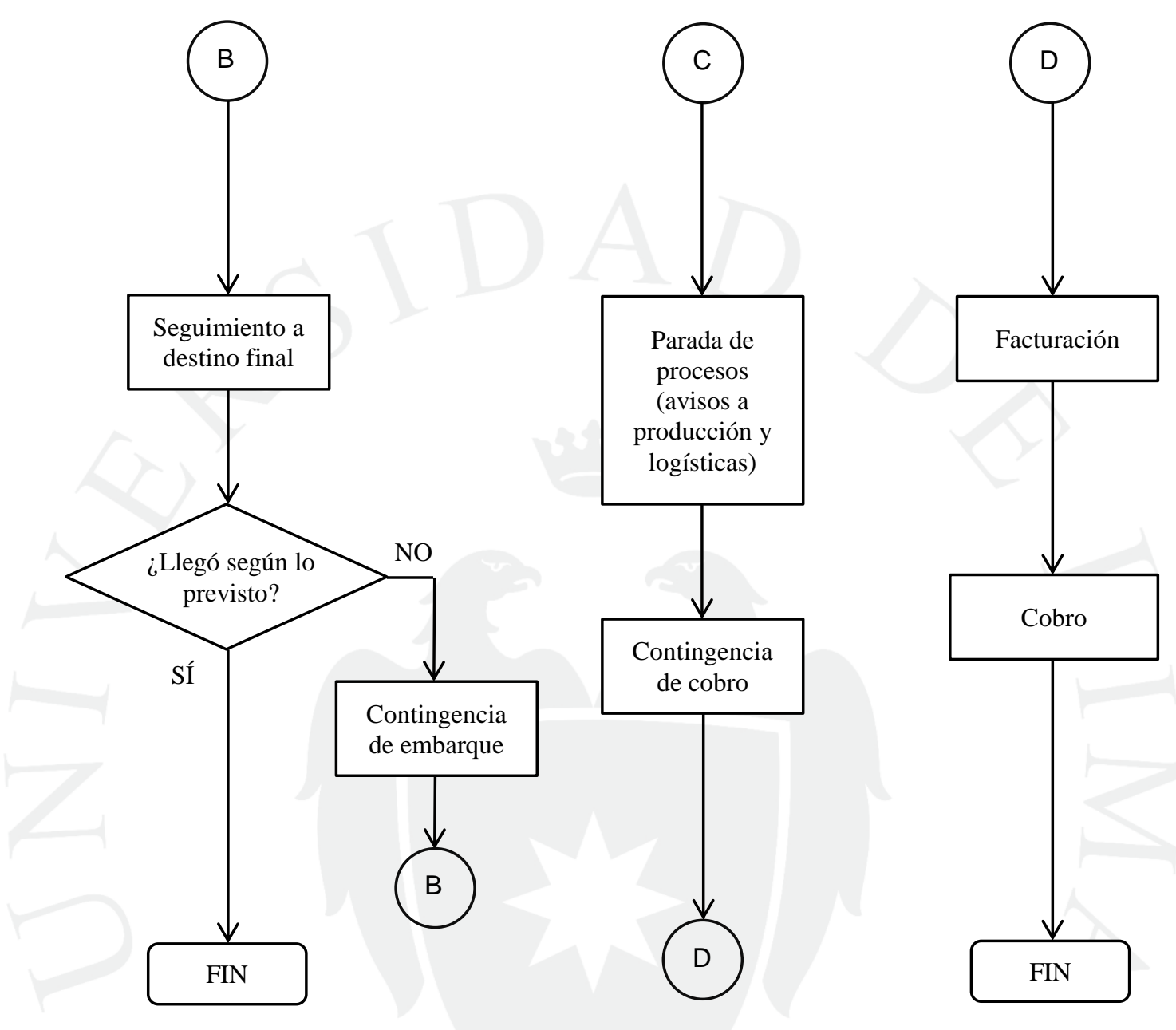

Fuente: Guía Básica del Exportador 12ava Edición, Banco Nacional de Comercio Exterior, S.N.C.

Elaboración Propia 
10.6 Diseño de las principales herramientas y/o formatos de control.

1. Diseño hoja de control de calidad del producto:

El control de calidad es vital para la supervivencia de un negocio. Es importante para las certificaciones de nuestra empresa y para mantener a los clientes satisfechos. Diseñar un formulario u hoja de control de calidad detallada garantizará que todos los empleados sepan qué esperar y los inspectores sabrán exactamente qué buscar. Se utilizarán hojas de control de calidad para las inspecciones del producto, así como para las interacciones del servicio al cliente.

2. Diagrama Causa - Efecto:

Este diagrama causal es un tipo de diagrama que muestra gráficamente las entradas o inputs, el proceso, y las salidas u outputs de un sistema (causaefecto), con su respectiva retroalimentación (feedback) para el subsistema de control.

Gráfico 27. Diagrama Causa Efecto

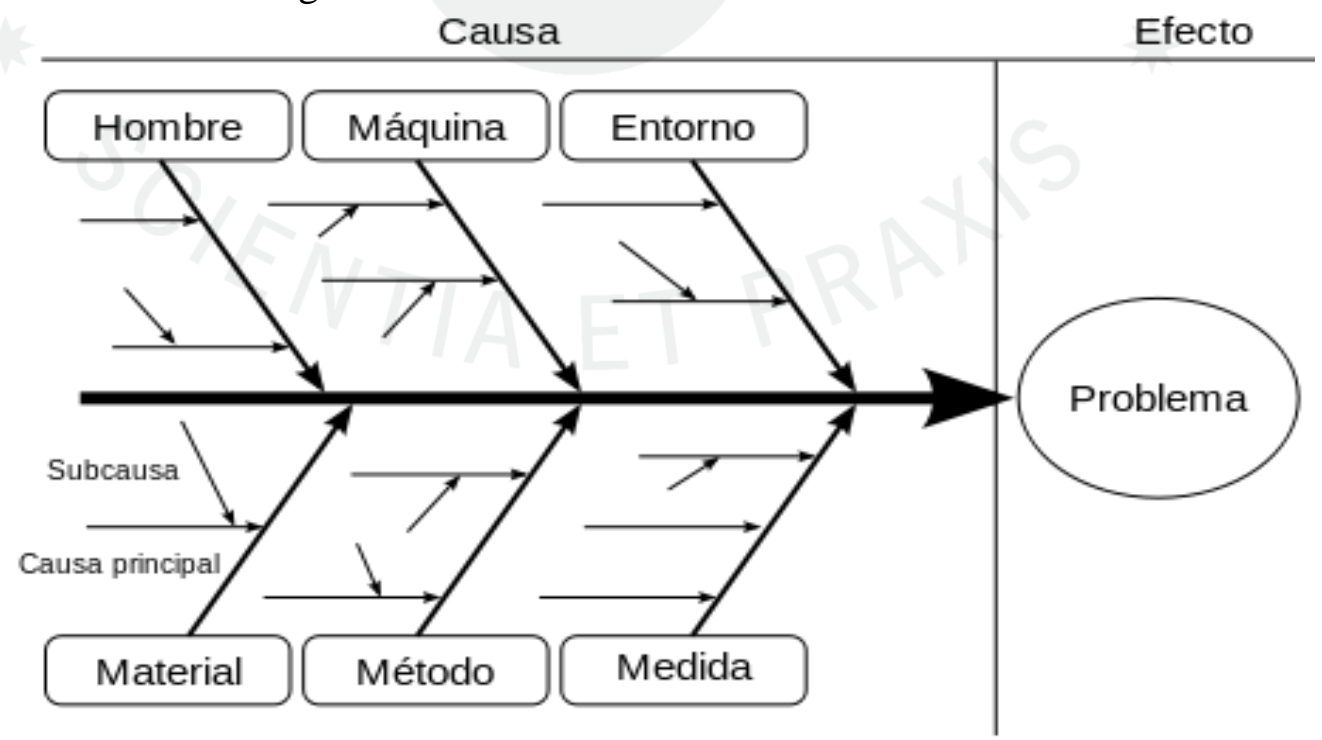

Fuente: Las 7 Herramientas Básicas de la Calidad, SPC Consulting Group 
3. Formato de evaluación del desempeño

A través de listas de verificación, método tradicional de evaluación de desempeño basado en una relación de factores de evaluación que se deben considerar (checklist) en cada empleado.

Cada uno de estos factores de desempeño recibe una evaluación cuantitativa.

La lista de verificación funciona como una especie de recordatorio para que el gerente evalúe las características principales de un empleado. 


\section{CAPITULO XI. GESTIÓN DE CALIDAD}

\subsection{Política de calidad.}

BIOPERÚ NATURAL PRODUCTS tiene en claro que la calidad es una variable importante para competir a nivel internacional, constituyéndose como una de sus principales ventajas competitivas conjuntamente con la diferenciación de sus productos.

- INTEGRIDAD PERSONAL como expresión de disciplina, orden, respeto, honestidad y entusiasmo.

- CREATIVIDAD E INNOVACIÓN como parte de nuestro reto diario para el mejoramiento continuo.

- PRODUCTIVIDAD en nuestro trabajo y en el empleo de los recursos materiales.

- CONSCIENCIA en la práctica de un trabajo libre de errores bajo estrictas normas de calidad nacional e internacional.

- COMPROMISO leal con nuestros stakeholders.

\subsection{Análisis de las principales herramientas de control de calidad.}

Gráfico 28. Flujo del control de actividades fundamentales en la gestión de calidad

Elaboración Propia 
Hoja de control (Hoja de recogida de datos): es necesario que sea detallada para que el resultado sea o más preciso posible, evitando errores y favoreciendo al procesamiento de información más rápido, al igual que el posterior análisis.

$\checkmark$ Histograma: Análisis de las variables de gestión de calidad establecida por la empresa, en cuanto a frecuencia de ocurrencia y efectividad.

Diagrama de Pareto: Ayuda determinar el origen de los hechos que suceden, considerando frecuencia, costo de oportunidad, impacto e importancia.

Análisis por Estratificación: Evalúa la información recopilada, basada en el desempeño de los elementos que participan en su ejecución.

$\checkmark$ Diagrama de causa efecto: Analiza a profundidad las causas de un problema, no sólo propios de las operaciones de la empresa, sino aquellos externos, que afectan directamente el desempeño de calidad del producto.

$\checkmark$ Diagrama de Dispersión: Herramienta estadística que permite analizar el comportamiento entre una variable de control de calidad y una causa identificada que afecte directamente dicha variable.

Gráfica de control: Permite identificar si la ejecución de las variables se dan estable o inestablemente, si perduran o no, agrupa el análisis por procesos, 
dando como resultado la información necesaria para determinar si el desempeño actual de los empleados es el más adecuado.

\subsection{Programa de gestión de calidad para el futuro del negocio.}

BIOPERÚ NATURAL PRODUCTS continuando con el crecimiento empresarial y desarrollo de una mejor imagen, plantea implementar diferentes sistemas para poder brindar mayor confianza en sus clientes o potenciales clientes.

ISO 9001: La norma ISO 9001 de sistemas de gestión de la calidad proporciona la infraestructura, procedimientos, procesos y recursos necesarios para ayudar a las organizaciones a controlar y mejorar su rendimiento y conducirles hacia la eficiencia, servicio al cliente y excelencia en el producto.

ISO 26000: serán aplicados los principios fundamentales, que son siete, de carácter no certificable ni obligatorio, pero que es fundamental para realizar y asegurar una gestión basada en la visión y misión fundamental del negocio. (ISO 26000, 2015)

1. Rendición de cuentas: responsable de sus actos.

2. Transparencia: en la información de las políticas, decisiones y actividades.

3. Comportamiento ético: basado en honestidad, equidad e integridad.

4. Respeto a los intereses de las partes interesadas: No solo de los dueños sino de intereses específicos de otros individuos relacionados con la organización. 
5. Respeto a la ley: Ninguna organización está encima de la ley.

6. Respeto a la normatividad internacional de comportamiento: y a la vez respeto a la ley.

7. Respeto a los derechos humanos: reconocer su importancia y su universalidad. 


\section{CAPITULO XII. PLAN DE FINANZAS (PRESUPUESTOS}

\section{PROYECTADOS Y ANÁLISIS DE RENTABILIDAD)}

\subsection{Presupuesto de Ventas.}

La unidad de exportación como se mencionó anteriormente corresponde a 2 pallets de 40 cajas, totalizando una cantidad de 7,680 envases de loción corporal de sacha inchi orgánico, por un valor FOB de USD 141,312 durante el primer año del proyecto en el cual se estima hacer un total de 4 envíos de la U.E., siendo éstos incrementales en un envío cada año.

Tabla 41. Proyección de ventas de la empresa

BIOPERÚ NATURAL PRODUCTS S.A.C.

\begin{tabular}{|c|c|c|c|c|c|}
\hline & AÑNO 1 & AÑO 2 & AÑ̃ 3 & AÑ̃ 4 & AÑ̃ 5 \\
\hline Kilos & 7,680 & 9,600 & 11,520 & 13,440 & 15,360 \\
\hline Envases & 30,720 & 38,400 & 46,080 & 53,760 & 61,440 \\
\hline Cajas & 160 & 200 & 240 & 280 & 320 \\
\hline LCL (2 Pallets) & 4 & 5 & 6 & 7 & 8 \\
\hline USD & 141,312 & 176,640 & 211,968 & 247,296 & 282,624 \\
\hline
\end{tabular}

Elaboración Propia

A continuación se presenta la proyección de ventas mensuales por cada año del proyecto, en cajas, pallets y el monto en dólares. 
Tabla 42. Proyección de ventas mensuales Año 1

\begin{tabular}{|c|c|c|c|c|c|c|c|c|c|c|c|c|c|}
\hline AÑO 1 & MES 1 & MES 2 & MES 3 & MES 4 & MES 5 & MES 6 & MES 7 & MES 8 & MES 9 & MES 10 & MES 11 & MES 12 & TOTAL \\
\hline Cajas (x 192 unids.) & 40 & 0 & 0 & 40 & 0 & 0 & 40 & 0 & 0 & 40 & 0 & 0 & 160 \\
\hline LCL (2 Pallets) & 1 & & & 1 & & & 1 & & & 1 & & & 4 \\
\hline USD & $35,328.00$ & 0.00 & 0.00 & $35,328.00$ & 0.00 & 0.00 & $35,328.00$ & 0.00 & 0.00 & $35,328.00$ & 0.00 & 0.00 & $141,312.00$ \\
\hline
\end{tabular}

Elaboración Propia

Tabla 43. Proyección de ventas mensuales Año 2

\begin{tabular}{|c|c|c|c|c|c|c|c|c|c|c|c|c|c|}
\hline AÑO 2 & MES 1 & MES 2 & MES 3 & MES 4 & MES 5 & MES 6 & MES 7 & MES 8 & MES 9 & MES 10 & MES 11 & MES 12 & TOTAL \\
\hline Cajas (x 192 unids.) & 40 & 0 & 0 & 40 & 0 & 0 & 40 & 0 & 0 & 40 & 0 & 40 & 200 \\
\hline LCL (2 Pallets) & 1 & 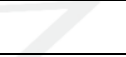 & & 1 & & & 1 & & & 1 & & 1 & 5 \\
\hline USD & $35,328.00$ & 0.00 & 0.00 & $35,328.00$ & 0.00 & 0.00 & $35,328.00$ & 0.00 & 0.00 & $35,328.00$ & 0.00 & $35,328.00$ & $176,640.00$ \\
\hline
\end{tabular}

Elaboración Propia

Tabla 44. Proyección de ventas mensuales Año 3

\begin{tabular}{|c|c|c|c|c|c|c|c|c|c|c|c|c|c|}
\hline AÑ̃ 3 & MES 1 & MES 2 & MES 3 & MES 4 & MES 5 & MES 6 & MES 7 & MES 8 & MES 9 & MES 10 & MES 11 & MES 12 & TOTAL \\
\hline Cajas (x 192 unids.) & 40 & 0 & 0 & 40 & 40 & 0 & 40 & 0 & 0 & 40 & 0 & 40 & 240 \\
\hline LCL (2 Pallets) & 1 & & th & 1 & 1 & & 1 & & +2 & 1 & & 1 & 6 \\
\hline USD & $35,328.00$ & 0.00 & 0.00 & $35,328.00$ & $35,328.00$ & 0.00 & $35,328.00$ & 0.00 & 0.00 & $35,328.00$ & 0.00 & $35,328.00$ & $211,968.00$ \\
\hline
\end{tabular}

Elaboración Propia 
Tabla 45. Proyección de ventas mensuales Año 4

\begin{tabular}{|c|c|c|c|c|c|c|c|c|c|c|c|c|c|}
\hline AÑ̃ 4 & MES 1 & MES 2 & MES 3 & MES 4 & MES 5 & MES 6 & MES 7 & MES 8 & MES 9 & MES 10 & MES 11 & MES 12 & TOTAL \\
\hline Cajas (x 192 unids.) & 40 & 0 & 0 & 40 & 40 & 0 & 40 & 40 & 0 & 40 & 0 & 40 & 280 \\
\hline LCL (2 Pallets) & 1 & & 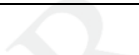 & 1 & 1 & & 1 & 1 & 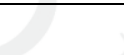 & 1 & & 1 & 7 \\
\hline USD & $35,328.00$ & 0.00 & 0.00 & $35,328.00$ & $35,328.00$ & 0.00 & $35,328.00$ & $35,328.00$ & 0.00 & $35,328.00$ & 0.00 & $35,328.00$ & $247,296.00$ \\
\hline
\end{tabular}

Elaboración Propia

Tabla 46. Proyección de ventas mensuales Año 5

\begin{tabular}{|c|c|c|c|c|c|c|c|c|c|c|c|c|c|}
\hline AÑO 5 & MES 1 & MES 2 & MES 3 & MES 4 & MES 5 & MES 6 & MES 7 & MES 8 & MES 9 & MES 10 & MES 11 & MES 12 & TOTAL \\
\hline Cajas (x 192 unids.) & 40 & 40 & 0 & 40 & 40 & 0 & 40 & 40 & 0 & 40 & 0 & 40 & 320 \\
\hline LCL (2 Pallets) & 1 & 1 & & 1 & 1 & & 1 & 1 & & 1 & & 1 & 8 \\
\hline USD & $35,328.00$ & $35,328.00$ & 0.00 & $35,328.00$ & $35,328.00$ & 0.00 & $35,328.00$ & $35,328.00$ & 0.00 & $35,328.00$ & 0.00 & $35,328.00$ & $282,624.00$ \\
\hline
\end{tabular}

Elaboración Propia

\subsection{Presupuesto de Cobranza.}

A continuación se presenta la proyección de cobranzas mensuales por los 5 años del proyecto en USD. Como se explicó anteriormente, la condición será $50 \%$ del monto total exportado contra presentación del B/L y el $50 \%$ a 30 días. 
Tabla 47. Proyección de cobranza por cada mes y año (USD)

BIOPERÚ NATURAL PRODUCTS S.A.C.

\begin{tabular}{|c|c|c|c|c|c|c|c|c|c|c|c|c|c|}
\hline AÑO 1 & MES 1 & MES 2 & MES 3 & MES 4 & MES 5 & MES 6 & MES 7 & MES 8 & MES 9 & MES 10 & MES 11 & MES 12 & TOTAL \\
\hline Contado & $17,664.00$ & 0.00 & 0.00 & $17,664.00$ & 0.00 & 0.00 & $17,664.00$ & 0.00 & 0.00 & $17,664.00$ & 0.00 & 0.00 & $70,656.00$ \\
\hline Total USD & $17,664.00$ & $17,664.00$ & 0.00 & $17,664.00$ & $17,664.00$ & 0.00 & $17,664.00$ & $17,664.00$ & 0.00 & $17,664.00$ & $17,664.00$ & 0.00 & $141,312.00$ \\
\hline
\end{tabular}

Elaboración Propia

\begin{tabular}{|c|c|c|c|c|c|c|c|c|c|c|c|c|c|}
\hline AÑO 2 & MES 1 & MES 2 & MES 3 & MES 4 & MES 5 & MES 6 & MES 7 & MES 8 & MES 9 & MES 10 & MES 11 & MES 12 & TOTAL \\
\hline Contado & $17,664.00$ & 0.00 & 0.00 & $17,664.00$ & 0.00 & 0.00 & $17,664.00$ & 0.00 & 0.00 & $17,664.00$ & 0.00 & $17,664.00$ & $88,320.00$ \\
\hline Crédito 30 días & 0.00 & $17,664.00$ & 0.00 & 0.00 & $17,664.00$ & 0.00 & 0.00 & $17,664.00$ & 0.00 & 0.00 & $17,664.00$ & 0.00 & $70,656.00$ \\
\hline Total USD & $17,664.00$ & $17,664.00$ & 0.00 & $17,664.00$ & $17,664.00$ & 0.00 & $17,664.00$ & $17,664.00$ & 0.00 & $17,664.00$ & $17,664.00$ & $17,664.00$ & $158,976.00$ \\
\hline
\end{tabular}

Elaboración Propia

\begin{tabular}{|c|c|c|c|c|c|c|c|c|c|c|c|c|c|}
\hline AÑO 3 & MES 1 & MES 2 & MES 3 & MES 4 & MES 5 & MES 6 & MES 7 & MES 8 & MES 9 & MES 10 & MES 11 & MES 12 & TOTAL \\
\hline Contado & $17,664.00$ & 0.00 & 0.00 & $17,664.00$ & $17,664.00$ & 0.00 & $17,664.00$ & 0.00 & 0.00 & $17,664.00$ & 0.00 & $17,664.00$ & $105,984.00$ \\
\hline Crédito 30 días & $17,664.00$ & $7,664.00$ & 0.00 & 0.00 & $17,664.00$ & $17,664.00$ & 0.00 & $17,664.00$ & 0.00 & 0.00 & $17,664.00$ & 0.00 & $105,984.00$ \\
\hline Total USD & $35,328.00$ & $17,664.00$ & 0.00 & $17,664.00$ & $35,328.00$ & $17,664.00$ & \begin{tabular}{|l|}
$17,664.00$ \\
\end{tabular} & $17,664.00$ & 0.00 & $17,664.00$ & $17,664.00$ & $17,664.00$ & $211,968.00$ \\
\hline
\end{tabular}

Elaboración Propia 


\begin{tabular}{|c|c|c|c|c|c|c|c|c|c|c|c|c|c|}
\hline & & & & MES 4 & MES 5 & MES 6 & MES 7 & MES 8 & MES 9 & MES 10 & MES 11 & MES 12 & TOTAL \\
\hline & & & & & & & & & & & & & \\
\hline & & & & & & & & & & & & & \\
\hline otal USD & $35,328.00$ & $7,664.00$ & 0 & $17,664.00$ & $35,328.00$ & $17,664.00$ & $17,664.00$ & $35,328.00$ & $17,664.00$ & $17,664.00$ & $17,664.00$ & $17,664.00$ & $247,296.00$ \\
\hline
\end{tabular}

Elaboración Propia

\begin{tabular}{|c|c|c|c|c|c|c|c|c|c|c|c|c|c|}
\hline AÑO 5 & MES 1 & MES 2 & MES 3 & MES 4 & MES 5 & MES 6 & MES 7 & MES 8 & MES 9 & MES 10 & MES 11 & MES 12 & TOTAL \\
\hline Contado & $17,664.00$ & $17,664.00$ & 0.00 & $17,664.00$ & $7,664.00$ & 0.00 & $17,664.00$ & $17,664.00$ & 0.00 & $17,664.00$ & 0.00 & $17,664.00$ & $141,312.00$ \\
\hline Total USD & $35,328.00$ & $35,328.00$ & $17,664.00$ & $17,664.00$ & $35,328.00$ & $17,664.00$ & $17,664.00$ & $35,328.00$ & $17,664.00$ & $17,664.00$ & $17,664.00$ & $17,664.00$ & $282,624.00$ \\
\hline
\end{tabular}

Elaboración Propia

\subsection{Presupuesto de Producción.}

A continuación se presenta el presupuesto de producción de la loción corporal de sacha inchi en unidades, para los cinco años del proyecto. 
Tabla 48. Proyección de Producción (en unidades)

BIOPERÚ NATURAL PRODUCTS S.A.C.

\begin{tabular}{|c|c|c|c|c|c|c|c|c|c|c|c|c|c|}
\hline AÑO 1 & MES 1 & MES 2 & MES 3 & MES 4 & MES 5 & MES 6 & MES 7 & MES 8 & MES 9 & MES 10 & MES 11 & MES 12 & TOTAL \\
\hline Unidades & 7,680 & 0 & 0 & 7,680 & 0 & 0 & 7,680 & 0 & 0 & 7,680 & 0 & 0 & $\mathbf{3 0 , 7 2 0}$ \\
\hline AÑO 2 & MES 1 & MES 2 & MES 3 & MES 4 & MES 5 & MES 6 & MES 7 & MES 8 & MES 9 & MES 10 & MES 11 & MES 12 & \\
\hline Unidades & 7,680 & 0 & 0 & 7,680 & 0 & 0 & 7,680 & 0 & 0 & 7,680 & 0 & 7,680 & $\mathbf{3 8 , 4 0 0}$ \\
\hline AÑO 3 & MES 1 & MES 2 & MES 3 & MES 4 & MES 5 & MES 6 & MES 7 & MES 8 & MES 9 & MES 10 & MES 11 & MES 12 & \\
\hline Unidades & 7,680 & 0 & 0 & 7,680 & 7,680 & 0 & 7,680 & 0 & 0 & 7,680 & 0 & 7,680 & $\mathbf{4 6 , 0 8 0}$ \\
\hline AÑO 4 & MES 1 & MES 2 & MES 3 & MES 4 & MES 5 & MES 6 & MES 7 & MES 8 & MES 9 & MES 10 & MES 11 & MES 12 & \\
\hline Unidades & 7,680 & 0 & 0 & 7,680 & 7,680 & 0 & 7,680 & 7,680 & 0 & 7,680 & 0 & 7,680 & $\mathbf{5 3 , 7 6 0}$ \\
\hline AÑO 5 & MES 1 & MES 2 & MES 3 & MES 4 & MES 5 & MES 6 & MES 7 & MES 8 & MES 9 & MES 10 & MES 11 & MES 12 & \\
\hline Unidades & 7,680 & 7,680 & 0 & 7,680 & 7,680 & 0 & 7,680 & 7,680 & 0 & 7,680 & 0 & 7,680 & $\mathbf{6 1 , 4 4 0}$ \\
\hline
\end{tabular}

Elaboración Propia 


\subsection{Presupuesto de Compras de Materiales de Producción.}

A continuación, se presentan los requerimientos de insumos para producir una unidad de la loción corporal de sacha inchi; así como también, el valor de venta según unidad de medida.

Tabla 49. Precio-Insumo

\begin{tabular}{|l|c|c|}
\hline \multicolumn{1}{|c|}{ Ítem } & Valor de Venta & Requerimiento \\
& (x unid.) & x PT \\
\hline Glicerina (Kg) & 1.10 & 0.050 \\
\hline Miristato de miristilo (Kg) & 1.08 & 0.100 \\
\hline Alcohol cetílico (Kg) & 1.70 & 0.035 \\
\hline Miristato de isopropilo (Kg) & 1.09 & 0.030 \\
\hline Aceite de sacha Inchi (L) & 3.65 & 0.100 \\
\hline Extracto de miel (Kg) & 2.60 & 0.025 \\
\hline Retinol de palmitato (Vitamina A) (Kg) & 2.50 & 0.050 \\
\hline Acetato de tocoferol (Vitamina E) (Kg) & 2.30 & 0.050 \\
\hline Metilparabeno (Kg) & 0.82 & 0.005 \\
\hline EDTA Disódico (Kg) & 1.68 & 0.040 \\
\hline Fragancia Citral de Verbena (L) & 2.40 & 0.030 \\
\hline
\end{tabular}

Elaboración Propia 
Tabla 50. Presupuesto de Compras de Materiales de Producción

BIOPERÚ NATURAL PRODUCTS S.A.C.

\begin{tabular}{|c|c|c|c|c|c|}
\hline Ítem & AÑO 1 & AÑO 2 & AÑO 3 & AÑO 4 & AÑO 5 \\
\hline Glicerina $(\mathrm{Kg})$ & $1,689.60$ & $2,112.00$ & $2,534.40$ & $2,956.80$ & $3,379.20$ \\
\hline Miristato de miristilo $(\mathrm{Kg})$ & $3,317.76$ & $4,147.20$ & $4,976.64$ & $5,806.08$ & $6,635.52$ \\
\hline Alcohol cetílico $(\mathrm{Kg})$ & $1,827.84$ & $2,284.80$ & $2,741.76$ & $3,198.72$ & $3,655.68$ \\
\hline Miristato de isopropilo $(\mathrm{Kg})$ & $1,004.54$ & $1,255.68$ & $1,506.82$ & $1,757.95$ & $2,009.09$ \\
\hline Aceite de sacha Inchi (L) & $11,212.80$ & $14,016.00$ & $16,819.20$ & $19,622.40$ & $22,425.60$ \\
\hline Extracto de miel $(\mathrm{Kg})$ & $1,996.80$ & $2,496.00$ & $2,995.20$ & $3,494.40$ & $3,993.60$ \\
\hline Retinol de palmitato (Vitamina A) (Kg) & $3,840.00$ & $4,800.00$ & $5,760.00$ & $6,720.00$ & $7,680.00$ \\
\hline Acetato de tocoferol (Vitamina E) (Kg) & $3,532.80$ & $4,416.00$ & $5,299.20$ & $6,182.40$ & $7,065.60$ \\
\hline Metilparabeno $(\mathrm{Kg})$ & 125.95 & 157.44 & 188.93 & 220.42 & 251.90 \\
\hline EDTA Disódico (Kg) & $2,064.38$ & $2,580.48$ & $3,096.58$ & $3,612.67$ & $4,128.77$ \\
\hline Fragancia Citral de Verbena (L) & $2,211.84$ & $2,764.80$ & $3,317.76$ & $3,870.72$ & $4,423.68$ \\
\hline TOTAL USD & $32,824.32$ & $41,030.40$ & $49,236.48$ & $57,442.56$ & $65,648.64$ \\
\hline
\end{tabular}

\subsection{Presupuesto de Compras de Materiales de Empaque.}

Los materiales de empaque que se necesitan son envases, etiquetas y cajas. A continuación se presenta las cantidades necesarias y los costos respectivos.

Tabla 51. Precios Materiales de Empaque y Embalaje

\begin{tabular}{|l|r|}
\hline \multicolumn{1}{|c|}{ Ítem } & $\begin{array}{c}\text { Valor de Venta }(\mathbf{x} \\
\text { unid.) }\end{array}$ \\
\hline Cajas & 0.06 \\
\hline Envases & 0.3 \\
\hline Etiquetas & 0.008 \\
\hline Stretch Film & 5.08 \\
\hline
\end{tabular}

Elaboración Propia 
Tabla 52. Requerimiento anual de Materiales de Empaque y Embalaje

\begin{tabular}{|l|c|c|c|c|c|}
\hline \multicolumn{1}{|c|}{ Ítem } & AÑO 1 & AÑO 2 & AÑO 3 & AÑO 4 & AÑO 5 \\
\hline Cajas & 160 & 200 & 240 & 280 & 320 \\
\hline Envases & 30,720 & 38,400 & 46,080 & 53,760 & 61,440 \\
\hline Etiquetas & 30,720 & 38,400 & 46,080 & 53,760 & 61,440 \\
\hline Stretch Film & 5 & 5 & 6 & 6 & 7 \\
\hline
\end{tabular}

Elaboración Propia

Tabla 53. Presupuesto de Compras de Materiales de Empaque

BIOPERÚ NATURAL PRODUCTS S.A.C.

\begin{tabular}{|l|c|c|c|c|c|}
\hline \multicolumn{1}{|c|}{ Ítem } & AÑO 1 & AÑO 2 & AÑO 3 & AÑO 4 & AÑO 5 \\
\hline Cajas & 9.60 & 12.00 & 14.40 & 16.80 & 19.20 \\
\hline Envases & $9,216.00$ & $11,520.00$ & $13,824.00$ & $16,128.00$ & $18,432.00$ \\
\hline Etiquetas & 245.76 & 307.20 & 368.64 & 430.08 & 491.52 \\
\hline Stretch Film & 25.40 & 25.40 & 30.48 & 30.48 & 35.56 \\
\hline TOTAL USD & $\mathbf{9 , 4 9 6 . 7 6}$ & $\mathbf{1 1 , 8 6 4 . 6 0}$ & $\mathbf{1 4 , 2 3 7 . 5 2}$ & $\mathbf{1 6 , 6 0 5 . 3 6}$ & $\mathbf{1 8 , 9 7 8 . 2 8}$ \\
\hline
\end{tabular}

Elaboración Propia

12.6 Presupuesto de Mantenimiento.

Se llevarán a cabo mantenimientos semestrales en la planta de producción.

A continuación se presenta el presupuesto de gasto de mantenimiento para el horizonte del proyecto.

Tabla 54. Presupuesto de Mantenimiento

BIOPERÚ NATURAL PRODUCTS S.A.C.

\begin{tabular}{|l|c|c|c|c|c|}
\hline Ítem & $\mathbf{2 0 1 5}$ & $\mathbf{2 0 1 6}$ & $\mathbf{2 0 1 7}$ & $\mathbf{2 0 1 8}$ & $\mathbf{2 0 1 9}$ \\
\hline Gastos de Mantenimiento & 500.00 & 500.00 & 500.00 & 500.00 & 500.00 \\
\hline
\end{tabular}




\subsection{Presupuesto de Gastos de Mano de Obra.}

A continuación se presentan los gastos de mano de obra calculados para cada año del Proyecto. Estos están compuestos por el pago de los químicos farmacéuticos y operarios que se necesitan en la línea de producción.

Tabla 55. Presupuesto de Gastos de Mano de Obra

BIOPERÚ NATURAL PRODUCTS S.A.C.

\begin{tabular}{|l|c|c|c|c|c|}
\hline & AÑO 1 & AÑO 2 & AÑO 3 & AÑO 4 & AÑ 5 5 \\
\hline Químico Farmacéutico 1 & $6,428.57$ & $6,428.57$ & $6,428.57$ & $6,428.57$ & $6,428.57$ \\
\hline Químico Farmacéutico 2 & 0.00 & 0.00 & $6,428.57$ & $6,428.57$ & $6,428.57$ \\
\hline Operario 1 & $3,214.29$ & $3,214.29$ & $3,214.29$ & $3,214.29$ & $3,214.29$ \\
\hline Operario 2 & $3,214.29$ & $3,214.29$ & $3,214.29$ & $3,214.29$ & $3,214.29$ \\
\hline Operario 3 & $3,214.29$ & $3,214.29$ & $3,214.29$ & $3,214.29$ & $3,214.29$ \\
\hline Operario 4 & 0.00 & 0.00 & $3,214.29$ & $3,214.29$ & $3,214.29$ \\
\hline Operario 5 & 0.00 & 0.00 & $3,214.29$ & $3,214.29$ & $3,214.29$ \\
\hline Total Sueldos & $16,071.43$ & $16,071.43$ & $28,928.57$ & $28,928.57$ & $28,928.57$ \\
\hline Vacaciones & $2,678.57$ & $2,678.57$ & $4,821.43$ & $4,821.43$ & $4,821.43$ \\
\hline CTS & 0.00 & 0.00 & 0.00 & 0.00 & 0.00 \\
\hline EsSalud (9\%) & $1,446.43$ & $1,446.43$ & $2,603.57$ & $2,603.57$ & $2,603.57$ \\
\hline Total Empresa & $\mathbf{2 0 , 1 9 6 . 4 3}$ & $\mathbf{2 0 , 1 9 6 . 4 3}$ & $\mathbf{3 6 , 3 5 3 . 5 7}$ & $\mathbf{3 6 , 3 5 3 . 5 7}$ & $\mathbf{3 6 , 3 5 3 . 5 7}$ \\
\hline Elaboración Propia & \multicolumn{5}{|l}{}
\end{tabular}

\subsection{Presupuesto de Gastos Indirectos.}

A continuación se presentan los gastos indirectos en los que se incurrirán por cada año del Proyecto. Estos están compuestos por el pago de (1) luz, agua, teléfono e internet; (2) gastos de alquiler; y (3) pago por servicios terceros. 
Tabla 56. Presupuesto de Gastos Indirectos

BIOPERÚ NATURAL PRODUCTS S.A.C.

\begin{tabular}{|l|r|r|r|r|r|}
\hline Ítem & \multicolumn{1}{c|}{$\mathbf{2 0 1 5}$} & $\mathbf{2 0 1 6}$ & $\mathbf{2 0 1 7}$ & $\mathbf{2 0 1 8}$ & \multicolumn{1}{c|}{$\mathbf{2 0 1 9}$} \\
\hline Luz & $2,363.93$ & $2,542.32$ & $2,567.74$ & $2,593.42$ & $2,619.35$ \\
\hline Agua & $1,418.32$ & $1,525.44$ & $1,526.45$ & $1,527.46$ & $1,528.47$ \\
\hline Internet & 537.83 & 504.84 & 504.84 & 504.84 & 504.84 \\
\hline Teléfono & 93.49 & 72.60 & 72.60 & 72.60 & 72.60 \\
\hline Alquiler & $10,169.52$ & $10,169.52$ & $10,678.00$ & $11,211.90$ & $11,772.49$ \\
\hline Servicio 1 Contador & $4,285.71$ & $4,285.71$ & $4,285.71$ & $4,285.71$ & $4,285.71$ \\
\hline Servicio 2 Seguridad & $3,428.57$ & $3,428.57$ & $3,428.57$ & $3,428.57$ & $3,428.57$ \\
\hline Servicio 3 Limpieza & $3,428.57$ & $3,428.57$ & $3,428.57$ & $3,428.57$ & $3,428.57$ \\
\hline Servicio 4 Celular & $1,155.00$ & 887.14 & 887.14 & 887.14 & 887.14 \\
\hline TOTAL & $\mathbf{2 6 , 8 8 0 . 9 5}$ & $\mathbf{2 6 , 8 4 4 . 7 2}$ & $\mathbf{2 7 , 3 7 9 . 6 3}$ & $\mathbf{2 7 , 9 4 0 . 2 2}$ & $\mathbf{2 8 , 5 2 7 . 7 6}$ \\
\hline \multicolumn{7}{|l}{ Elaboración Propia } & & &
\end{tabular}

\subsection{Presupuesto de Gastos de Administración.}

A continuación se presentan los gastos de administración, compuestos por los gatos del pago de los salarios del personal administrativo, dícese del pago al Gerente General, Jefe del Área Comercial y Jefe de Logística. A partir del cuarto año se incrementarán en $10 \%$.

Tabla 57. Presupuesto de Gastos de Administración

BIOPERÚ NATURAL PRODUCTS S.A.C.

\begin{tabular}{|l|c|c|c|c|c|}
\hline Ítem & $\mathbf{2 0 1 5}$ & $\mathbf{2 0 1 6}$ & $\mathbf{2 0 1 7}$ & $\mathbf{2 0 1 8}$ & $\mathbf{2 0 1 9}$ \\
\hline Sueldo 2 (ADMINISTRATIVO) & $32,314.29$ & $32,314.29$ & $32,314.29$ & $35,545.71$ & $39,100.29$ \\
\hline
\end{tabular}

Elaboración Propia 


\subsection{Presupuesto de Gatos de Ventas.}

A continuación se presenta los gastos de ventas, compuesto por el gasto en Publicidad, Promoción y Ventas. A partir del tercer año el presupuesto asignado se incrementará en $10 \%$.

Tabla 58. Presupuesto de Gastos de Ventas

BIOPERÚ NATURAL PRODUCTS S.A.C.

\begin{tabular}{|l|c|c|c|c|c|}
\hline Ítem & $\mathbf{2 0 1 5}$ & $\mathbf{2 0 1 6}$ & $\mathbf{2 0 1 7}$ & $\mathbf{2 0 1 8}$ & $\mathbf{2 0 1 9}$ \\
\hline Publicidad, promoción y ventas & $8,474.58$ & $8,474.58$ & $9,322.04$ & $10,254.24$ & $11,279.67$ \\
\hline
\end{tabular}

Elaboración Propia

\subsection{Presupuesto de Gastos Financieros.}

Los gastos financieros que se proyectan tener, nacen del préstamo bancario que se va a realizar. La tasa de interés anual es de $16.5 \%$ del Banco Banbif, Garantía Extra Negocio.

Tabla 59. Presupuesto de Gastos Financieros

BIOPERÚ NATURAL PRODUCTS S.A.C.

\begin{tabular}{|c|c|c|c|c|c|c|}
\hline & AÑO 0 & AÑO 1 & AÑO 2 & AÑO 3 & AÑO 4 & AÑO 5 \\
\hline SALDO & $15,697.21$ & $15,697.21$ & $12,047.35$ & $6,482.76$ & 0.00 & 0.00 \\
\hline INTERÉS & & $2,229.59$ & $1,470.45$ & 552.29 & & \\
\hline AMORTIZACION & & $3,649.85$ & $5,564.60$ & $6,482.76$ & & \\
\hline PAGO & & $5,879.44$ & $7,035.05$ & $7,035.05$ & & \\
\hline
\end{tabular}

Elaboración Propia 


\subsection{Presupuesto de Tributos.}

A continuación se presentan los tributos a pagar por año proyectados.

Tabla 60. Presupuesto de Gastos de Tributos

BIOPERÚ NATURAL PRODUCTS S.A.C.

\begin{tabular}{|c|c|c|c|c|c|c|}
\hline & AÑNO 0 & AÑNO 1 & AÑO 2 & AÑO 3 & AÑO 4 & AÑO 5 \\
\hline Impuestos & 0.00 & $-2,119.68$ & $-2,649.60$ & $-3,179.52$ & $-3,709.44$ & $-4,239.36$ \\
\hline
\end{tabular}

Elaboración Propia

\subsection{Flujo de Caja Económico y Financiero Proyectado.}

A continuación se presenta el Flujo de Caja Económico y Financiero del Proyecto.

Tabla 61. Flujo de Caja Económico y Financiero Proyectado BIOPERÚ NATURAL PRODUCTS S.A.C.

\begin{tabular}{|c|c|c|c|c|c|c|}
\hline CONCEPTO & 0 & 1 & 2 & 3 & 4 & 5 \\
\hline \multicolumn{7}{|l|}{ INGRESOS } \\
\hline Ventas & & $141,312.00$ & $158,976.00$ & $211,968.00$ & $247,296.00$ & $282,624.00$ \\
\hline & & & & & & \\
\hline \multicolumn{7}{|l|}{ FLUJO DE INVERSIONES } \\
\hline Inversiones Equipo & $-11,019.65$ & & & & & \\
\hline Capital de Trabajo & $-45,105.83$ & & & 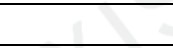 & 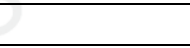 & \\
\hline Recuperación del Capital de Trabajo & & & & 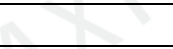 & & $45,105.83$ \\
\hline Gastos Pre Operativos & $-6,663.34$ & & & +2 & & \\
\hline & & 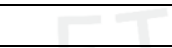 & the & & & \\
\hline EGRESOS & 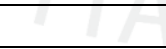 & & +2 & & & \\
\hline (-) Costo de Producción & & $-62,517.51$ & $-73,091.43$ & $-99,827.57$ & $-110,401.49$ & $-120,980.49$ \\
\hline (-) Gastos Administrativos y Ventas & & $-70,623.32$ & $-71,200.47$ & $-73,196.22$ & $-78,533.82$ & $-84,314.73$ \\
\hline (-) Impuesto a la Renta (1.5\% Mensual) & & $-2,119.68$ & $-2,649.60$ & $-3,179.52$ & $-3,709.44$ & $-4,239.36$ \\
\hline FLUJO ECONÓMICO & $-62,788.82$ & $6,051.49$ & $12,034.50$ & $35,764.69$ & $54,651.25$ & $118,195.25$ \\
\hline Préstamo Bancario & $15,697.21$ & & & & & \\
\hline Amortización Deuda & & $-3,649.85$ & $-5,564.60$ & $-6,482.76$ & & \\
\hline Gastos Financieros & & $-2,229.59$ & $-1,470.45$ & -552.29 & & \\
\hline FLUJO FINANCIERO & $-47,091.62$ & 172.05 & $4,999.45$ & $28,729.64$ & $54,651.25$ & $118,195.25$ \\
\hline
\end{tabular}

Elaboración Propia 
A través del cuadro $\mathrm{N}^{\circ} \mathrm{X}$ correspondiente al Flujo de Caja Económico y Financiero Proyectado, se puede observar que la empresa BIOPERÚ NATURAL PRODUCTS S.A.C. contará con flujos de efectivo positivos desde el primer año de operaciones, los cuales serán incrementales durante todo el horizonte del proyecto, pudiéndose recuperar el capital de trabajo invertido equivalente a USD 45,105.83.

\subsection{Estructura de Costos Fijos y Variables.}

Costos y Gastos Variables

Tabla 62. Estructura de Costos y Gastos Variables

BIOPERÚ NATURAL PRODUCTS S.A.C.

\begin{tabular}{|c|c|c|c|c|c|}
\hline Ítem & AÑO 1 & AÑO 2 & AÑO 3 & AÑO 4 & AÑO 5 \\
\hline Glicerina $(\mathrm{Kg})$ & $1,689.60$ & $2,112.00$ & $2,534.40$ & $2,956.80$ & $3,379.20$ \\
\hline Miristato de miristilo $(\mathrm{Kg})$ & $3,317.76$ & $4,147.20$ & $4,976.64$ & $5,806.08$ & $6,635.52$ \\
\hline Alcohol cetílico $(\mathrm{Kg})$ & $1,827.84$ & $2,284.80$ & $2,741.76$ & $3,198.72$ & $3,655.68$ \\
\hline Miristato de isopropilo $(\mathrm{Kg})$ & $1,004.54$ & $1,255.68$ & $1,506.82$ & $1,757.95$ & $2,009.09$ \\
\hline Aceite de sacha Inchi (L) & $11,212.80$ & $14,016.00$ & $16,819.20$ & $19,622.40$ & $22,425.60$ \\
\hline Extracto de miel $(\mathrm{Kg})$ & $1,996.80$ & $2,496.00$ & $2,995.20$ & $3,494.40$ & $3,993.60$ \\
\hline Retinol de palmitato (Vitamina A) (Kg) & $3,840.00$ & $4,800.00$ & $5,760.00$ & $6,720.00$ & $7,680.00$ \\
\hline Acetato de tocoferol (Vitamina E) (Kg) & $3,532.80$ & $4,416.00$ & $5,299.20$ & $6,182.40$ & $7,065.60$ \\
\hline Metilparabeno $(\mathrm{Kg})$ & 125.95 & 157.44 & 188.93 & 220.42 & 251.90 \\
\hline EDTA Disódico (Kg) & $2,064.38$ & $2,580.48$ & $3,096.58$ & $3,612.67$ & $4,128.77$ \\
\hline Fragancia Citral de Verbena (L) & $2,211.84$ & $2,764.80$ & $3,317.76$ & $3,870.72$ & $4,423.68$ \\
\hline Cajas & 9.60 & 12.00 & 14.40 & 16.80 & 19.20 \\
\hline Envases & $9,216.00$ & $11,520.00$ & $13,824.00$ & $16,128.00$ & $18,432.00$ \\
\hline Etiquetas & 245.76 & 307.20 & 368.64 & 430.08 & 491.52 \\
\hline Stretch Film & 25.40 & 25.40 & 30.48 & 30.48 & 35.56 \\
\hline TOTAL & $42,321.08$ & $52,895.00$ & $63,474.00$ & $74,047.92$ & $84,626.92$ \\
\hline C.U. Materiales & 1.38 & 1.38 & 1.38 & 1.38 & 1.38 \\
\hline
\end{tabular}

Elaboración Propia 


\begin{tabular}{|c|c|c|c|}
\hline Costos Logísticos. y de Exportación. (Por envío) & Valor de Venta & IGV & Precio \\
\hline Certificado DIGEMID & $\$ 84.75$ & $\$ 15.25$ & $\$ 100.00$ \\
\hline Transporte al puerto & $\$ 127.12$ & $\$ 22.88$ & $\$ 150.00$ \\
\hline Llenado de contenedor & $\$ 59.32$ & $\$ 10.68$ & $\$ 70.00$ \\
\hline Agente de Aduana & $\$ 169.49$ & $\$ 30.51$ & $\$ 200.00$ \\
\hline THC-Callao & $\$ 76.27$ & $\$ 13.73$ & $\$ 90.00$ \\
\hline Servicio 1 Dermatólogo (Certif. DIGEMID) & $\$ 53.57$ & & \\
\hline Servicio 2 Servicios Logísticos & $\$ 42.86$ & & \\
\hline Total & $\$ 613.38$ & $\$ 93.05$ & $\$ 610.00$ \\
\hline G.U. x Envío & $\$ 0.08$ & & \\
\hline
\end{tabular}

Elaboración Propia

\begin{tabular}{|c|c|c|c|c|c|}
\hline C.U. Materiales & $\$ 1.38$ & $\$ 1.38$ & $\$ 1.38$ & $\$ 1.38$ & $\$ 1.38$ \\
\hline G.U. $x$ Envío & $\$ 0.08$ & $\$ 0.08$ & $\$ 0.08$ & $\$ 0.08$ & $\$ 0.08$ \\
\hline (C.U. + G.U) VARIABLE & $\$ 1.46$ & $\$ 1.46$ & $\$ 1.46$ & $\$ 1.46$ & $\$ 1.46$ \\
\hline
\end{tabular}

Elaboración Propia

Costos y Gastos Fijos

Tabla 63. Estructura de Costos y Gastos Fijos

BIOPERÚ NATURAL PRODUCTS S.A.C.

\begin{tabular}{|l|c|c|c|c|c|}
\hline Ítem & $\mathbf{2 0 1 5}$ & $\mathbf{2 0 1 6}$ & $\mathbf{2 0 1 7}$ & $\mathbf{2 0 1 8}$ & $\mathbf{2 0 1 9}$ \\
\hline Sueldo 1 MOD & $20,196.43$ & $20,196.43$ & $36,353.57$ & $36,353.57$ & $36,353.57$ \\
\hline Sueldo 2 (ADMINISTRATIVO) & $32,314.29$ & $32,314.29$ & $32,314.29$ & $35,545.71$ & $39,100.29$ \\
\hline Servicio 1 Contador & $4,285.71$ & $4,285.71$ & $4,285.71$ & $4,285.71$ & $4,285.71$ \\
\hline Servicio 2 Seguridad & $3,428.57$ & $3,428.57$ & $3,428.57$ & $3,428.57$ & $3,428.57$ \\
\hline Servicio 3 Limpieza & $3,428.57$ & $3,428.57$ & $3,428.57$ & $3,428.57$ & $3,428.57$ \\
\hline Servicio 4 Celular & $1,155.00$ & 887.14 & 887.14 & 887.14 & 887.14 \\
\hline Publicidad, promoción y ventas & $8,474.58$ & $8,474.58$ & $9,322.04$ & $10,254.24$ & $11,279.67$ \\
\hline Gastos de Mantenimiento & 500.00 & 500.00 & 500.00 & 500.00 & 500.00 \\
\hline Luz & $2,363.93$ & $2,542.32$ & $2,567.74$ & $2,593.42$ & $2,619.35$ \\
\hline Agua & $1,418.32$ & $1,525.44$ & $1,526.45$ & $1,527.46$ & $1,528.47$ \\
\hline Internet & 537.83 & 504.84 & 504.84 & 504.84 & 504.84 \\
\hline Teléfono & 93.49 & 72.60 & 72.60 & 72.60 & 72.60 \\
\hline Alquiler & $10,169.52$ & $10,169.52$ & $10,678.00$ & $11,211.90$ & $11,772.49$ \\
\hline Gasto x Depreciación & $2,507.89$ & $2,507.89$ & $2,507.89$ & $2,507.89$ & $2,507.89$ \\
\hline \multicolumn{1}{|c|}{ TOTAL (C) + G) } & $\mathbf{9 0 , 8 7 4 . 1 3}$ & $\mathbf{9 0 , 8 3 7 . 9 1}$ & $\mathbf{1 0 8 , 3 7 7 . 4 2}$ & $\mathbf{1 1 3 , 1 0 1 . 6 4}$ & $\mathbf{1 1 8 , 2 6 9 . 1 7}$ \\
\hline (C.U. + G.U.) FIJO & $\mathbf{2 . 9 6}$ & $\mathbf{2 . 3 7}$ & $\mathbf{2 . 3 5}$ & $\mathbf{2 . 1 0}$ & $\mathbf{1 . 9 2}$ \\
\hline
\end{tabular}

Elaboración Propia 
12.15 Margen bruto y determinación de precio de venta FOB.

\begin{tabular}{|c|c|c|}
\hline Precio FOB & $\$ 4.60$ & $100.00 \%$ \\
\hline Costos Fijos & $\$ 1.13$ & $24.52 \%$ \\
\hline Costos Variables & $\$ 1.46$ & $31.68 \%$ \\
\hline Total & $\$ 2.59$ & $56.20 \%$ \\
\hline Utilidad Bruta & $\$ 2.01$ & $43.80 \%$ \\
\hline
\end{tabular}

\subsection{Capital de Trabajo.}

A continuación se detalla el Capital de Trabajo que deberá manejar la empresa en el primer año para garantizar el curso de sus operaciones.

Se considera la cobertura por dos meses de Costos y Gastos Variables y tres meses de Costos y Gastos Fijos.

Tabla 64. Capital de Trabajo Proyectado

BIOPERÚ NATURAL PRODUCTS S.A.C.

\begin{tabular}{|c|c|c|c|}
\hline CAPITAL DE TRABAJO & MONTO USD & MES & TOTAL USD \\
\hline Costos y gastos variables & $11,193.65$ & 2 & $22,387.30$ \\
\hline Costos y gastos fijos & $7,572.84$ & 3 & $22,718.53$ \\
\hline \multicolumn{2}{|c|}{ CAPITAL DE TRABAJO (USD) } & $\mathbf{4 5 , 1 0 5 . 8 3}$ \\
\hline
\end{tabular}

Elaboración Propia

\subsection{Estructura de la inversión.}

A continuación se detalla la estructura de la inversión para poner en marcha el Proyecto desarrollado. 
Tabla 65. Estructura de Inversión del Proyecto

BIOPERÚ NATURAL PRODUCTS S.A.C.

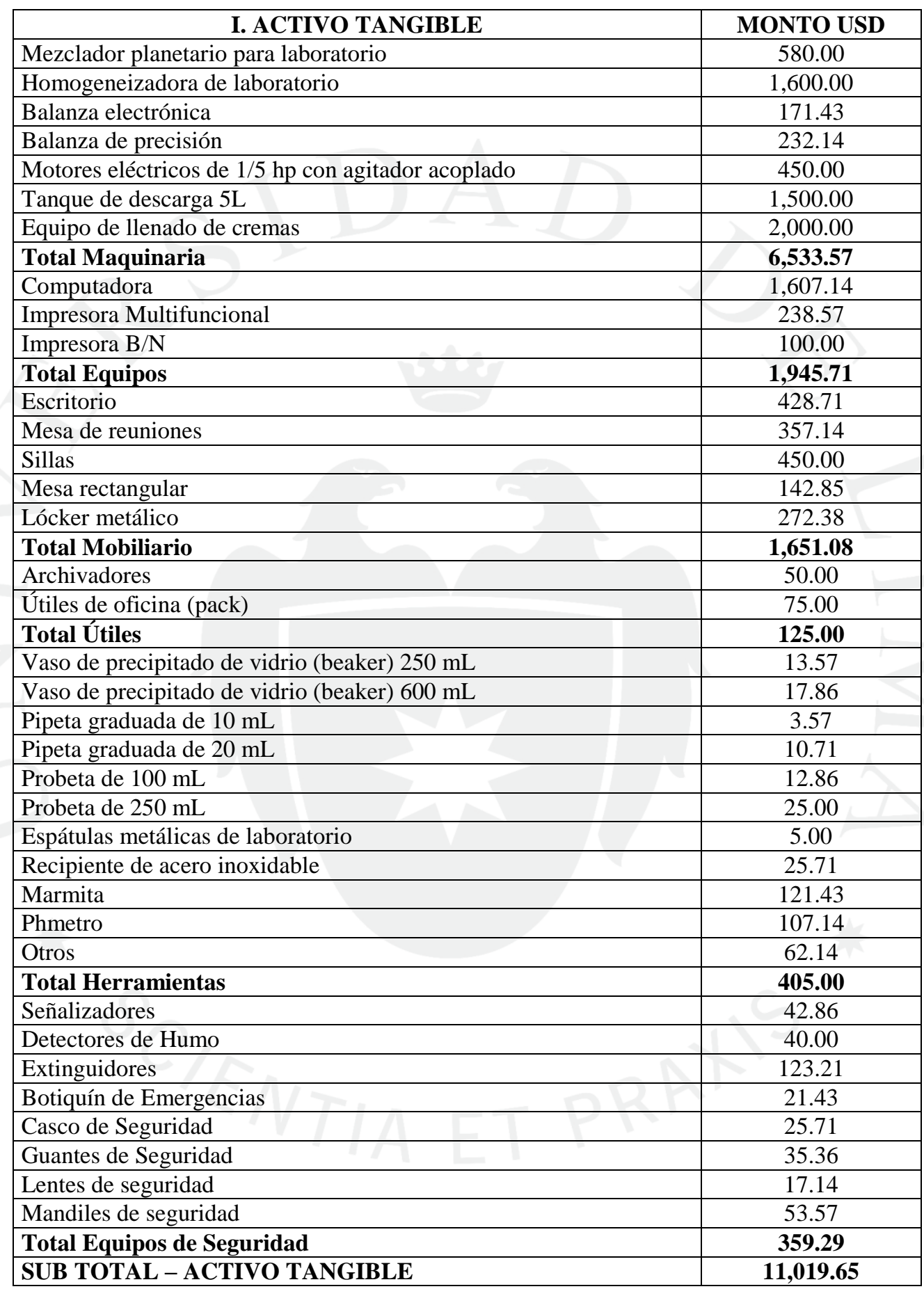

Elaboración Propia 
Tabla 66. Capital de trabajo

\begin{tabular}{|c|c|c|c|}
\hline II. CAPITAL DE TRABAJO & MONTO USD & MES & TOTAL USD \\
\hline Costos y gastos variables & $11,193.65$ & 2 & $22,387.30$ \\
\hline Costos y gastos fijos & $7,572.84$ & 3 & $22,718.53$ \\
\hline \multicolumn{2}{|c|}{ SUBTOTAL - CAPITAL DE TRABAJO } & $\mathbf{4 5 , 1 0 5 . 8 3}$ \\
\hline
\end{tabular}

Elaboración Propia

Tabla 67. Gastos Preoperativos

\begin{tabular}{|l|c|}
\hline \multicolumn{1}{|c|}{ III. GASTOS PREOPERATIVOS } & MONTO USD \\
\hline Búsqueda de Nombre en Indecopi & 18.96 \\
\hline Inspección Técnica Defensa Civil & 170.68 \\
\hline Licencia de Funcionamiento & 84.29 \\
\hline Inscripción Legal de la Empresa & 208.61 \\
\hline Tramitación del RUC & 177.00 \\
\hline Inscripción de la Marca en Indecopi & 168.57 \\
\hline Legalización de Libros Contables & 25.00 \\
\hline Tramitación del Dominio Web & 53.57 \\
\hline Garantía por alquiler (3 meses) & $2,542.38$ \\
\hline Diseño Publicitario & 553.57 \\
\hline Registro DIGEMID para planta & 178.57 \\
\hline Diseño de Pagina Web & 482.14 \\
\hline Misión Comercial Colombia & $2,000.00$ \\
\hline SUBTOTAL - GASTOS PREOPERATIVOS & $\mathbf{6 , 6 6 3 . 3 4}$ \\
\hline
\end{tabular}

Elaboración Propia

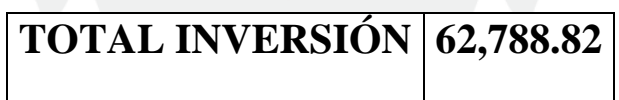

12.18 Financiamiento de la inversión.

Tabla 68. Financiamiento de la inversión

BIOPERÚ NATURAL PRODUCTS S.A.C.

\begin{tabular}{|c|c|c|}
\hline CONCEPTO & USD & PART \% \\
\hline Capital Propio & $47,091.62$ & $75 \%$ \\
\hline Préstamo Bancario & $15,697.21$ & $25 \%$ \\
\hline TOTAL INVERSIÓN & $\mathbf{6 2 , 7 8 8 . 8 2}$ & $\mathbf{1 0 0 \%}$ \\
\hline
\end{tabular}

Elaboración Propia 


\subsection{Estado de Pérdidas y Ganancias.}

Tabla 69. Estado de Pérdidas y Ganancias

BIOPERÚ NATURAL PRODUCTS S.A.C.

\begin{tabular}{|l|c|c|c|c|c|c|}
\hline CONCEPTO & $\mathbf{0}$ & $\mathbf{1}$ & $\mathbf{2}$ & $\mathbf{3}$ & $\mathbf{4}$ & $\mathbf{5}$ \\
\hline Ventas & $100 \%$ & $141,312.00$ & $176,640.00$ & $211,968.00$ & $247,296.00$ & $282,624.00$ \\
\hline (-) Costo de Producción & & $62,517.51$ & $73,091.43$ & $99,827.57$ & $110,401.49$ & $120,980.49$ \\
\hline Utilidad Bruta & $56 \%$ & $\mathbf{7 8 , 7 9 4 . 4 9}$ & $\mathbf{1 0 3 , 5 4 8 . 5 7}$ & $\mathbf{1 1 2 , 1 4 0 . 4 3}$ & $\mathbf{1 3 6 , 8 9 4 . 5 1}$ & $\mathbf{1 6 1 , 6 4 3 . 5 1}$ \\
\hline & & & & & & \\
\hline (-) Gastos Administrativos y Ventas & & $70,623.32$ & $71,200.47$ & $73,196.22$ & $78,533.82$ & $84,314.73$ \\
\hline EBIDTA & $6 \%$ & $\mathbf{8 , 1 7 1 . 1 7}$ & $\mathbf{3 2 , 3 4 8 . 1 0}$ & $\mathbf{3 8 , 9 4 4 . 2 1}$ & $\mathbf{5 8 , 3 6 0 . 6 9}$ & $\mathbf{7 7 , 3 2 8 . 7 8}$ \\
\hline & & & & & & \\
\hline (-) Gastos Financieros & & $2,229.59$ & $1,470.45$ & 552.29 & 0.00 & 0.00 \\
\hline (-) Depreciación & & $2,507.89$ & $2,507.89$ & $2,507.89$ & $2,507.89$ & $2,507.89$ \\
\hline EBIT & $2 \%$ & $\mathbf{3 , 4 3 4}$ & $\mathbf{2 8 , 3 7 0}$ & $\mathbf{3 5 , 8 8 4}$ & $\mathbf{5 5 , 8 5 3}$ & $\mathbf{7 4 , 8 2 1}$ \\
\hline & & & & & & \\
\hline (-) Impuesto a la Renta & & $2,119.68$ & $2,649.60$ & $3,179.52$ & $3,709.44$ & $4,239.36$ \\
\hline Resultado del Ejercicio & & $\mathbf{1 , 3 1 4 . 0 1}$ & $\mathbf{2 5 , 7 2 0 . 1 5}$ & $\mathbf{3 2 , 7 0 4 . 5 0}$ & $\mathbf{5 2 , 1 4 3 . 3 6}$ & $\mathbf{7 0 , 5 8 1 . 5 3}$ \\
\hline & & & & & \\
\hline Resultado Acumulado & & $\mathbf{1 , 3 1 4 . 0 1}$ & $\mathbf{2 7 , 0 3 4 . 1 6}$ & $\mathbf{5 9 , 7 3 8 . 6 6}$ & $\mathbf{1 1 1 , 8 8 2 . 0 2}$ & $\mathbf{1 8 2 , 4 6 3 . 5 4}$ \\
\hline \multicolumn{2}{|l|}{} & & & & \\
\hline \% Rentabilidad Neta & & $\mathbf{0 . 9 3 \%}$ & $\mathbf{1 4 . 5 6 \%}$ & $\mathbf{1 5 . 4 3 \%}$ & $\mathbf{2 1 . 0 9 \%}$ & $\mathbf{2 4 . 9 7 \%}$ \\
\hline Reserva Legal del Periodo & & $\mathbf{1 3 1 . 4 0}$ & $\mathbf{1 , 1 6 0 . 0 0}$ & $\mathbf{2 , 1 1 7 . 5 3}$ & $\mathbf{3 , 0 6 0 . 9 3}$ & $\mathbf{3 , 9 8 3 . 0 1}$ \\
\hline Reserva Legal Acumulada & & $\mathbf{1 3 1 . 4 0}$ & $\mathbf{1 , 2 9 1 . 4 0}$ & $\mathbf{3 , 4 0 8 . 9 3}$ & $\mathbf{6 , 4 6 9 . 8 7}$ & $\mathbf{1 0 , 4 5 2 . 8 8}$ \\
\hline
\end{tabular}

Elaboración Propia

Se puede observar en el cuadro $\mathrm{N}^{\circ} \mathrm{X}$ que la empresa BIOPERÚ NATURAL PRODUCTS S.A.C. obtendrá ganancias desde el primer año, obteniendo en los cinco primeros años un resultado acumulado de USD 182,463.54.40. Por lo tanto, y tomando como referencia los flujos e indicadores analizados anteriormente el proyecto es considerado rentable al lograr recuperar el capital invertido por los socios.

\subsection{Balance General.}

A continuación se presenta el balance general proyectado para cada año del proyecto. 
Tabla 70. Balance General

BIOPERÚ NATURAL PRODUCTS S.A.C.

\begin{tabular}{|c|c|c|c|c|c|c|}
\hline CONCEPTO & $\mathbf{0}$ & 1 & 2 & 3 & 4 & 5 \\
\hline \multicolumn{7}{|l|}{ ACTIVO } \\
\hline \multicolumn{7}{|l|}{ Activo Corriente } \\
\hline Caja y Bancos & $45,105.83$ & $45,277.88$ & $49,719.11$ & $77,815.53$ & $131,908.57$ & $204,364.78$ \\
\hline Cuentas $\mathrm{x}$ cobrar & & 0.00 & $17,664.00$ & $17,664.00$ & $17,664.00$ & $17,664.00$ \\
\hline Total Activo Corriente & $45,105.83$ & $45,277.88$ & $67,383.11$ & $95,479.53$ & $149,572.57$ & $222,028.78$ \\
\hline \multicolumn{7}{|l|}{ Activo No Corriente } \\
\hline Inversión Fija Tangible & $17,682.99$ & $17,682.99$ & $15,733.31$ & $13,858.63$ & $11,908.95$ & $10,034.28$ \\
\hline Depreciación & & $2,507.89$ & $2,507.89$ & $2,507.89$ & $2,507.89$ & $2,507.89$ \\
\hline Inversión Fija Intangible & & 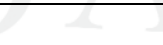 & & & & \\
\hline Total Activo No Corriente & $17,682.99$ & $15,175.10$ & $13,225.42$ & $11,350.74$ & $9,401.06$ & 7,526.38 \\
\hline Total Activo & $62,788.82$ & $60,452.97$ & $80,608.53$ & $106,830.27$ & $158,973.63$ & $229,555.16$ \\
\hline \multicolumn{7}{|l|}{$\underline{\text { PASIVO }}$} \\
\hline \multicolumn{7}{|l|}{ Pasivo Corriente } \\
\hline Deuda Corriente de Préstamo & & $3,649.85$ & $5,564.60$ & $6,482.76$ & $\bar{T}$ & \\
\hline Pago de la Deuda & & $-3,649.85$ & $-5,564.60$ & $-6,482.76$ & 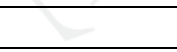 & \\
\hline Total Pasivo Corriente & & 0.00 & 0.00 & 0.00 & 0.00 & 0.00 \\
\hline Pasivo No Corriente & & & & & & \\
\hline Préstamo & $15,697.21$ & $12,047.35$ & $6,482.76$ & 0.00 & & \\
\hline Total Pasivo No Corriente & & $12,047.35$ & $6,482.76$ & 0.00 & 0.00 & 0.00 \\
\hline Total Pasivo & $15,697.21$ & $12,047.35$ & $6,482.76$ & 0.00 & 0.00 & 0.00 \\
\hline \multicolumn{7}{|l|}{ PATRIMONIO NETO } \\
\hline Capital Social & $47,091.62$ & $47,091.62$ & $47,091.62$ & $47,091.62$ & $47,091.62$ & $47,091.62$ \\
\hline Utilidades del periodo & & $1,314.01$ & $25,720.15$ & $32,704.50$ & $52,143.36$ & $70,581.53$ \\
\hline Utilidades retenidas & & & $1,314.01$ & $27,034.16$ & $59,738.66$ & $111,882.02$ \\
\hline Total Patrimonio Neto & $47,091.62$ & $48,405.62$ & $\mathbf{7 4 , 1 2 5 . 7 7}$ & $106,830.27$ & $158,973.63$ & $229,555.16$ \\
\hline Total Pasivo y Patrimonio Neto & $62,788.82$ & $60,452.97$ & $80,608.53$ & $106,830.27$ & $158,973.63$ & $229,555.16$ \\
\hline
\end{tabular}

- Al constituirse la empresa, nuestros activos totales están conformados por el dinero que ingresa a caja y bancos, el cual se usará como capital de trabajo, USD 45,105.83 y la inversión en tangibles, la cual es USD 17,682.99. En su contraparte, están los pasivos y patrimonios. El primero está conformado por el préstamo bancario que se realizará (USD 15,697.21) y el aporte de los accionistas (USD 47,091.62).

- Al terminar el primer año del proyecto, las cuentas del balance van a variar. El total activo disminuirá a USD 60,452.97. Esto se debe a que el flujo de caja es de USD 172.05, y durante el año, se realizará el pago del préstamo, 
el cual se hace con el dinero que habrá en caja y bancos. Además se debe tener en cuenta que los activos tangibles se depreciarán.

- Para los siguientes años, el balance general se modificará positivamente, el total activo aumentará debido al ingreso de mayor flujo de dinero en caja y bancos. Y los pasivos se reducirán debido a que el préstamo se irá pagando año tras año.

- Al término del quinto año, el balance general quedará de la siguiente manera: Total Activos USD 229,555.16, Total Pasivos USD 0.00 y Total Patrimonio USD 229,555.16.

\subsection{Evaluación Económica y Financiera del Negocio (TIR, TIRF, VAN Y} VANF).

El costo del patrimonio se ha calculado utilizando el método del CAPM.

El Modelo de Valoración del Precio de los Activos Financieros o Capital Asset Pricing Model (conocido como modelo CAPM) es una de las herramientas más utilizadas para determinar la tasa de rentabilidad teóricamente requerida para un cierto activo. 
Tabla 71. Cálculo del COK Y el WACC

\begin{tabular}{|c|c|}
\hline \multicolumn{2}{|l|}{ Costo del Patrimonio (CAPM) } \\
\hline Componente & Valor \\
\hline $\begin{array}{l}\text { Tasa libre de riesgo (RfUS) } \\
\text { Bonos del tesoro de EE.UU a } 5 \text { años } \\
\text { Fuente: Mercado de Valores Universidad de Lima }\end{array}$ & $1.70 \%$ \\
\hline $\begin{array}{l}\text { Prima de riesgo país (CRP) } \\
\text { La empresa operará en Perú por lo que es necesario ajustar la tasa de } \\
\text { descuento para reflejar el riesgo país } \\
\text { Fuente: Mercado de Valores Universidad de Lima }\end{array}$ & $1.48 \%$ \\
\hline $\begin{array}{l}\text { Beta (Bl) } \\
\text { Utilizamos el Beta del sector Health Care } \\
\text { Fuente: Damodaran }\end{array}$ & 1.30 \\
\hline $\begin{array}{l}\text { Prima de riesgo de mercado } \\
\text { (RmUS-RfUS) } \\
\text { Fuente: Mercado de Valores Universidad de Lima }\end{array}$ & $8.71 \%$ \\
\hline CAPM: $K e=$ Rfus + Bapalancado $x($ Rmus - Rfus $) \times \lambda+$ CRP & $16.77 \%$ \\
\hline
\end{tabular}

Elaboración Propia

\begin{tabular}{|l|c|}
\hline \multicolumn{2}{|c|}{ Costo de la Deuda } \\
\hline Componente & Valor \\
\hline $\begin{array}{l}\text { Tasa de deuda ponderada } \\
\text { Fuente: BanBif }\end{array}$ & $\mathbf{1 6 . 5 0 \%}$ \\
\hline Tasa impositiva & $\mathbf{3 0 . 0 0 \%}$ \\
\hline Costo de deuda post impuesto & $\mathbf{1 1 . 5 5 \%}$ \\
\hline
\end{tabular}

Elaboración Propia

\begin{tabular}{|l|c|}
\hline \multicolumn{2}{|c|}{ WACC } \\
\hline Componente & Valor \\
\hline WACC: $(\mathrm{D} / \mathrm{D}+\mathrm{E}) *(1-\mathrm{t}) *(\mathrm{Rd})+(\mathrm{E} / \mathrm{D}+\mathrm{E}) *(\mathrm{COK})$ & $15.46 \%$ \\
\hline
\end{tabular}

Elaboración Propia

Respecto a indicadores como el TIRE (Tasa Interna de Retorno Económica), COK (Costo de Oportunidad de Capital) y el VANE (Valor Actual Neto Económico), la empresa cuenta con el siguiente resultado: 
Tabla 72. TIRE, COK y VANE de la empresa BIOPERÚ NATURAL

PRODUCTS S.A.C.

\begin{tabular}{|c|c|}
\hline \multicolumn{2}{|c|}{ RATIOS ECONOMICOS } \\
\hline TIRE & $38.12 \%$ \\
\hline COK & $16.77 \%$ \\
\hline VANE & $\$ 57,530.90$ \\
\hline
\end{tabular}

Elaboración Propia

Por otro lado, para los indicadores financieros, se utilizó como tasa de descuento el WACC, para la determinación del VAN financiero, ya que, el WACC integra en su estructura la composición Deuda-Patrimonio, al igual que el flujo financiero, que considera los gastos generados por el crédito.

Tabla 73. TIRF, WACC y VANF de la empresa BIOPERÚ NATURAL PRODUCTS

\section{S.A.C.}

\begin{tabular}{|c|c|}
\hline \multicolumn{2}{|c|}{ RATIOS ECONOMICOS } \\
\hline TIRF & $41.60 \%$ \\
\hline WACC & $15.46 \%$ \\
\hline VANF & $\$ 63,814.83$ \\
\hline
\end{tabular}

Elaboración Propia

En ambos casos los indicadores, tanto económicos, como financieros, demuestran que la ejecución del proyecto es rentable.

El WACC y el COK, del negocio, son similares debido a que el nivel de financiamiento adquirido es de solo $25 \%$, mientras que el aporte propio es de $75 \%$, esto determina que existe mayor poder de capital que el de apalancamiento financiero. 


\section{CAPITULO XIII. EVALUACIÓN Y CONTROL}

\subsection{Balanced Scorecard (Identificación de Indicadores).}

Esta herramienta de administración de la gestión sobre el desarrollo de un plan estratégico, permite obtener una imagen amplia de diversos ámbitos pertenecientes al negocio, a fin de analizar el desempeño de cada una de las variables que se tomaron en cuenta, como fundamentales para lograr el objetivo por el cual se estableció el plan de acción; dicha herramienta permite identificar qué puntos no se están cumpliendo según lo esperado, y si es necesario un mayor énfasis en la asignación de recursos y supervisión constante de desempeño. Incluye los objetivos a lograr en el corto y largo plazo. Para el caso del negocio se enfoca en temas de rentabilidad, participación de mercado y gestión. (Álvarez Medina, 2013)

\subsubsection{Finanzas}

Es fundamental para la empresa fortalecer su propio patrimonio con los ingresos que va generando años tras año, debido a que pertenece a la categoría de microempresa, lograr superar los 5 años de ejecución es una meta. 
Tabla 74. Balanced Scorecard, Análisis Financiero

\begin{tabular}{|c|c|c|c|c|}
\hline Perspectiva & $\begin{array}{l}\text { Objetivos de } \\
\text { Largo Plazo } \\
\quad 2019\end{array}$ & $\begin{array}{c}\text { Objetivos de Corto Plazo } \\
2015\end{array}$ & Medida & Meta 2015 \\
\hline \multirow{4}{*}{ 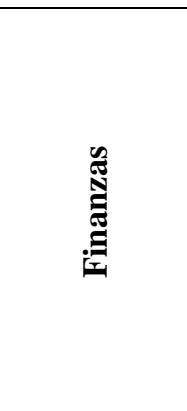 } & \multirow{2}{*}{$\begin{array}{l}\text { 1. Generación } \\
\text { de Valor }\end{array}$} & $\begin{array}{l}\text { 1.1 Procurar una rentabilidad } \\
\text { positiva e incremental }\end{array}$ & Margen Neto/Ventas & $0.93 \%$ \\
\hline & & $\begin{array}{l}\text { 1.2 Retener utilidades para } \\
\text { fortalecer el patrimonio }\end{array}$ & $\begin{array}{l}\text { Porcentaje de } \\
\text { utilidades retenidas }\end{array}$ & $100 \%$ \\
\hline & \multirow{2}{*}{$\begin{array}{l}\text { 2. Financiami } \\
\text { ento de } \\
\text { terceros }\end{array}$} & $\begin{array}{l}2.1 \text { Adquirir financiamiento } \\
\text { de terceros a una tasa } \\
\text { competitiva }\end{array}$ & $\begin{array}{ll}\text { Índice } & \text { Gastos } \\
\text { Financieros/ } & \\
\text { Ventas } & \\
\end{array}$ & $1.57 \%$ \\
\hline & & $\begin{array}{l}2.2 \text { Tomar ventaja del } \\
\text { escudo fiscal para ampliar el } \\
\text { margen de utilidad }\end{array}$ & $\begin{array}{l}\text { Índice Impuesto a la } \\
\text { Renta/Ventas }\end{array}$ & $1.50 \%$ \\
\hline
\end{tabular}

Elaboración Propia

\subsubsection{Clientes}

En este ámbito del negocio es de suma importancia mantener supervisado el desempeño y logros de la empresa -debido a que el producto es relativamente nuevo en el mercado colombiano- debiendo cumplirse las estrategias planteadas de penetración y desarrollo de mercado.

Se ha de evaluar si su cumple con los requerimientos no sólo del cliente sino también con las regulaciones que Colombia establece para la categoría de productos de la industria cosmética; en temas de calidad, inocuidad y trazabilidad. 
Tabla 75. Balanced Scorecard, Análisis de Percepción de Clientes

\begin{tabular}{|c|c|c|c|c|}
\hline Perspectiva & $\begin{array}{c}\text { Objetivos de } \\
\text { Largo Plazo } 2019\end{array}$ & $\begin{array}{c}\text { Objetivos de } \\
\text { Corto Plazo } 2015\end{array}$ & Medida & Meta 2015 \\
\hline \multirow{7}{*}{$\stackrel{\stackrel{\mathscr{U}}{0}}{\stackrel{0}{0}}$} & \multirow[b]{2}{*}{$\begin{array}{l}\text { 3. Satisfacción de } \\
\text { la calidad del } \\
\text { producto }\end{array}$} & $\begin{array}{l}3.1 \text { Incremento } \\
\text { constante del nivel } \\
\text { de ventas }\end{array}$ & $\begin{array}{l}\text { Índice de } \\
\text { crecimiento } \\
\text { de ventas }\end{array}$ & NA \\
\hline & & $\begin{array}{lr}3.2 \text { Adquirir mayor } \\
\text { captación } & \text { de } \\
\text { interés por } & \text { el } \\
\text { producto y y } & \text { sus } \\
\text { bondades } & \\
\end{array}$ & $\begin{array}{l}\text { Indicador de } \\
\text { rotación de } \\
\text { inventarios } \\
\text { (veces al año) }\end{array}$ & 2.38 aprox. \\
\hline & \multirow{3}{*}{$\begin{array}{l}\text { 4. Satisfacción en } \\
\text { el cumplimiento } \\
\text { de } \\
\text { requerimientos } \\
\text { demandados } \\
\text { por el cliente }\end{array}$} & $\begin{array}{l}4.1 \text { Evaluación del } \\
\text { envase }\end{array}$ & $\begin{array}{l}\text { Encuesta de } \\
\text { evaluación } \\
\text { del producto }\end{array}$ & $90 \%$ \\
\hline & & $\begin{array}{l}4.2 \text { Evaluación de } \\
\text { etiquetado }\end{array}$ & $\begin{array}{l}\text { Encuesta de } \\
\text { evaluación } \\
\text { del producto }\end{array}$ & $90 \%$ \\
\hline & & $\begin{array}{l}4.3 \text { Evaluación de } \\
\text { calidad } \\
\text { producto }\end{array}$ & $\begin{array}{l}\text { Encuesta de } \\
\text { evaluación } \\
\text { del producto }\end{array}$ & $80 \%$ \\
\hline & \multirow{2}{*}{$\begin{array}{l}\text { 5. Conocimiento } \\
\text { del producto y } \\
\text { sus propiedades }\end{array}$} & $\begin{array}{l}5.1 \text { Incremento en } \\
\text { el nivel de ventas }\end{array}$ & $\begin{array}{l}\text { Índice de } \\
\text { crecimiento } \\
\text { de ventas } \\
\end{array}$ & NA \\
\hline & & $\begin{array}{ll}5.2 & \text { Inversión } \\
\text { activa y } & \text { constante } \\
\text { en } & \text { promoción } \\
\text { comercial }\end{array}$ & $\begin{array}{l}\text { Gastos de } \\
\text { ventas/Ventas }\end{array}$ & $6 \%$ \\
\hline
\end{tabular}

Elaboración Propia

\subsubsection{Operaciones}

Mantener la supervisión dentro de área de operaciones, incluyendo el abastecimiento, al igual que el almacenamiento y envasado, tomando en cuenta el desempeño y rendimiento de cada uno de los empleados; dándoles a conocer las responsabilidades e importancia que tiene cada uno dentro de la cadena operativa del negocio.

Por otro, lado el hecho de gestionar adecuadamente las órdenes de comprar permitirá a la empresa, determinar cantidades y tiempos 
requeridos con mayor precisión, de modo que se eviten perdidas por merma o incumplimiento a tiempo de entrega de mercancía.

El gestionar tiempos con el operador logístico establecido es fundamental para cumplir con el proceso de distribución física internacional sin percances, por lo tanto deberá haber comunicación plena con este agente, por si es requerido algún certificado o inspección del producto para su ingreso por la aduana colombiana.

Tabla 76. Balanced Scorecard, Análisis de Operatividad

\begin{tabular}{|c|c|c|c|c|}
\hline Perspectiva & $\begin{array}{c}\text { Objetivos de Largo Plazo } \\
2019\end{array}$ & $\begin{array}{c}\text { Objetivos de Corto Plazo } \\
2015\end{array}$ & Medida & $\begin{array}{l}\text { Meta } \\
2015\end{array}$ \\
\hline \multirow{5}{*}{ 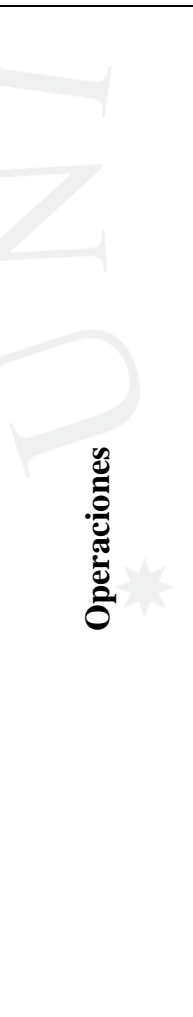 } & \multirow{3}{*}{$\begin{array}{l}\text { 6. Gestionar y supervisar } \\
\text { la ejecución para } \\
\text { cumplir con el Plan } \\
\text { Estratégico planteado }\end{array}$} & $\begin{array}{llr}6.1 \text { Dar a conocer a los } \\
\text { operarios } & \text { cuales } & \text { son las } \\
\text { tareas que } & \text { deberán } \\
\text { desarrollar } & \text { y } & \text { sus } \\
\text { responsabilidades } & & \\
\end{array}$ & $\begin{array}{ll}\text { Entrega } & \text { de } \\
\text { manual } & \text { de } \\
\text { procesos } & \end{array}$ & $100 \%$ \\
\hline & & $\begin{array}{l}6.2 \text { Identificar la capacidad y } \\
\text { rendimiento productivo por } \\
\text { cada operario }\end{array}$ & $\begin{array}{l}\text { Capacidad de } \\
\text { producción por } \\
\text { operario/mes }\end{array}$ & $\begin{array}{c}\text { Kgs./ } \\
\text { unidades }\end{array}$ \\
\hline & & $\begin{array}{l}6.3 \text { Mantener un margen } \\
\text { mínimo de merma }\end{array}$ & $\begin{array}{ll}\text { Índice } & \text { de } \\
\text { rendimiento } & \\
\end{array}$ & $99 \%$ \\
\hline & $\begin{array}{l}\text { 7. Proceso y registro de } \\
\text { Órdenes de Compra el } \\
\text { mismo día de su } \\
\text { colocación }\end{array}$ & $\begin{array}{l}7.1 \text { Lograr al menos que se } \\
\text { demore de entre } 2 \text { a } 3 \text { días, } \\
\text { debido a la confirmación de } \\
\text { requerimientos por parte del } \\
\text { cliente }\end{array}$ & $\begin{array}{l}\text { Tiempos } \\
\text { Respuesta }\end{array}$ & 2 días \\
\hline & 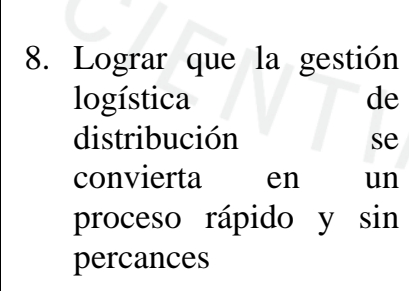 & $\begin{array}{l}\text { 8.1 Supervisar que el } \\
\text { proceso de distribución } \\
\text { física internacional se } \\
\text { ejecute según los tiempos } \\
\text { planteados por el Operador } \\
\text { Logístico }\end{array}$ & ETD \& ETA & $\begin{array}{l}10-12 \\
\text { días }\end{array}$ \\
\hline
\end{tabular}

Elaboración Propia 


\subsubsection{Recursos Humanos}

Rol importante, dado que, si los trabajadores laboran en un ambiente agradable, mejor será la satisfacción que perciban, por lo tanto, mejor será su rendimiento y productividad.

Es por ello que la supervisión debe de darse con énfasis, se deberá que definir si es necesario una modificación o capacitación, dentro de cualquiera de los factores claves definidos, para no afectar el desempeño del plan establecido; para este caso se pretende integrar por medio de la comunicación plena entre los diferente ordenes jerárquicos (horizontal), para que se convierta el negocio en una gestión participativa y colaborativa en todos los niveles.

A partir de los resultados se realizarán medidas correctivas o de mejora, según sea el caso.

Tabla 77. Balanced Scorecard, Análisis de Recursos Humanos

\begin{tabular}{|c|c|c|c|c|}
\hline Perspectiva & $\begin{array}{c}\text { Objetivos de } \\
\text { Largo Plazo } 2019 \\
\end{array}$ & Objetivos de Corto Plazo 2015 & Medida & $\begin{array}{l}\text { Meta } \\
2015 \\
\end{array}$ \\
\hline \multirow{4}{*}{ 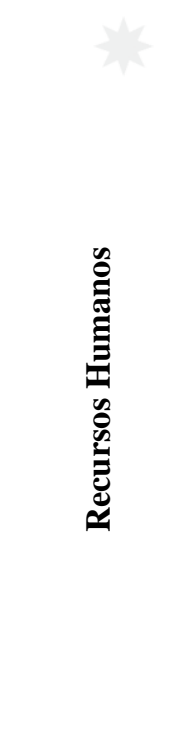 } & \multirow{4}{*}{$\begin{array}{l}\text { 9. Lograr un } \\
\text { ambiente de } \\
\text { trabajo } \\
\text { agradable, con } \\
\text { trabajadores } \\
\text { comprometidos } \\
\text { con los } \\
\text { objetivos de la } \\
\text { empresa y que } \\
\text { perduren en el } \\
\text { tiempo. }\end{array}$} & $\begin{array}{l}\text { 9.1 Los trabajadores están } \\
\text { comprometidos y se alinean a } \\
\text { los principios éticos y valores } \\
\text { del negocio. }\end{array}$ & $\begin{array}{lr}\text { Entrega } & \text { de } \\
\text { manual } & \text { de } \\
\text { procesos } & \text { y } \\
\text { posterior } & \\
\text { evaluación } & \text { del } \\
\text { desempeño } & \end{array}$ & $85 \%$ \\
\hline & & $\begin{array}{l}\text { 9.2 Los trabajadores contratados } \\
\text { deberán de haberse } \\
\text { desempeñado cumpliendo con } \\
\text { los resultados obtenidos del } \\
\text { proceso de selección }\end{array}$ & $\begin{array}{l}\text { Información } \\
\text { recaudada de } \\
\text { cada contratado y } \\
\text { hoja de vida }\end{array}$ & $90 \%$ \\
\hline & & $\begin{array}{l}\text { 9.3 Desarrollar un programa de } \\
\text { actividades que permita integrar } \\
\text { a todos los niveles jerárquicos }\end{array}$ & $\begin{array}{l}\text { Encuesta de } \\
\text { satisfacción } \\
\text { laboral }\end{array}$ & $85 \%$ \\
\hline & & $\begin{array}{l}\text { 9.4 Haber obtenido ideas por } \\
\text { parte de los trabajadores que } \\
\text { permitan la retroalimentación }\end{array}$ & $\begin{array}{l}\text { Encuesta } \\
\text { reuniones } \\
\text { mensuales }\end{array}$ & $80 \%$ \\
\hline
\end{tabular}




\section{CONCLUSIONES}

A través de este Proyecto de Exportación se observa que existe un mercado en crecimiento para los productos de belleza y cuidado personal elaborados a base de insumos naturales de la biodiversidad peruana en la ciudad de Bogotá, Colombia, por los siguientes motivos:

$\checkmark$ Se ha confirmado que existe un desenvolvimiento con tendencias positivas actuales y a futuro, del sector de belleza y cuidado personal en Colombia.

El mercado colombiano presenta una gran oportunidad para la inserción de este producto; debido a que, según las estadísticas recabas el sector del cuidado de la piel, ha mostrado un crecimiento sostenido durante los últimos años y se prevé que continuará con este ritmo. Cabe resaltar que el producto analizado en el proyecto destaca la naturalidad de su contenido. Los consumidores de esta categoría son más sensibles a la denominación de 'natural', ya que hay una creencia en el poder de los ingredientes naturales ancestrales en la salud y el bienestar. Asimismo, Colombia presenta la tasa más alta de participación de América Latina de las mujeres económicamente activas, con un 55,3\%, y en comparación con la mujer europea, el gasto en cosméticos es el doble, sobre todo la mujer que vive en los centros urbanos dedican gran parte de su dinero a la belleza y a la apariencia física.

Hoy en día la mayoría de mujeres y hombres colombianos son más exigentes y demandantes de productos de belleza y cuidado personal a base de ingredientes 
naturales; generándose así un mercado que se debe explotar, ofreciendo un producto diferenciado y de gran calidad.

A su vez, las importaciones colombianas de la partida arancelaria del proyecto (3304990000, Preparaciones de belleza, maquillaje y para el cuidado de la piel, excepto los medicamentos, incluidas las preparaciones anti-solares y las bronceadoras; preparaciones para manicuras o pedicuros, hidratantes corporales) muestran una tendencia creciente que se verá reflejada en las cantidades que serán demandadas del producto final en un lapso de 5 años desde el año 2015 hasta el 2019; siendo Colombia el primer país de destino de nuestras exportaciones, resaltando la ventaja que tenemos al tener un arancel de entrada del $0 \%$ en comparación con nuestros principales competidores, empresas de Estados Unidos y Francia, cuyos productos están gravados con un 15\% Ad Valorem, lo cual genera mayores oportunidades de penetración y competitividad de nuestro producto en el mercado de destino.

A pesar del hecho que el mayor volumen de mercado es impulsado por la gran base de consumidores de bajos y medios ingresos, a través de la competencia entre las empresas locales y las multinacionales que operan en base al Retail y Venta Directa, el mercado Premium ha mostrado un fuerte crecimiento gracias al aumento de consumidores de altos ingresos y el crecimiento de las compras aspiracionales de la clase media.

Los insumos que conforman la loción corporal están disponibles todo el año. Cabe resaltar que estableceremos una alianza estratégica con el distribuidor de 
nuestro insumo principal, el aceite de sacha inchi orgánico, que es comercializado por la empresa Agroindustrias Amazónicas S.A., proveedora que cuenta con las certificaciones HACCP, NSF AGRICULTURA, BPMG, ORGÁNICA; lo que nos avala contar con un insumo de alta calidad.

Por último, con esta investigación se determina que la implementación de una empresa para exportar lociones corporales a base de insumos de la biodiversidad peruana es factible tanto comercial, logística como económicamente.

Comercialmente hacer referencia al aumento de demanda de productos del sector de belleza y cuidado personal a base de ingredientes naturales. Logísticamente es gracias a la cercanía con este país, las facilidades de acceso al mismo y la disponibilidad de transporte como medio para lograr que nuestro producto llegue a importadores en la zona de influencia. Económicamente se debe a la viabilidad del proyecto por contar con indicadores financieros positivos, ratificados mediante un análisis realizado empleando el programa Risk Simulator el cuál se muestra adjunto en el Apéndice $\mathrm{N}^{\circ} 8$. 


\section{RECOMENDACIONES}

- Para el eminente acceso del producto al mercado colombiano, es recomendable enviar muestras del producto final para que puedan ser analizadas por un laboratorio peruano y colombiano, a fin de comprobar al $100 \%$ los beneficios y propiedades derivados para el cuidado de la piel.

- Se recomienda analizar periódicamente el mercado meta, comportamiento del cliente, requerimientos, requisitos para ingresar al mercado, variaciones culturales y demás a fin de poder adaptarnos a los cambios y ofrecerle al cliente un producto que satisfaga sus necesidades.

- Se debe de estar al pendiente de las fluctuaciones de los precios de mercado para productos sustitutos o similares al ofertado, a fin de mantenernos en un nivel de precios competitivos y no perder participación en el mercado.

- Para garantizar el posicionamiento de la imagen de la empresa en el mercado colombiano y garantizar un flujo constante de exportaciones a lo largo del año; se recomienda ampliar la cartera de productos que ofrece la empresa; insertando nuevas presentaciones y empleando como ingredientes otros insumos derivados de la biodiversidad peruana tales como la quinua, el camu camu, castaña amazónica, etc.

- Mantener la inversión en ferias internacionales a lo largo de la ejecución del proyecto, es indispensable, para que los clientes potenciales, laboratorios y centros 
de cosmética, así como, distribuidores en Colombia, logren conocer el producto y en especial las propiedades que este ofrece para la piel; a fin de ampliar las ventas futuras.

- Es imprescindible seguir con la búsqueda de más empresas proveedoras del aceite de sacha inchi, que cuenten con certificaciones orgánicas, para cumplir con el posible incremento de la demanda.

- Buscar la mejor fuente de financiamiento, para obtener el monto de inversión necesario.

- Evaluación constante del desempeño del plan estratégico, a partir de las variables más importantes establecidas en el Balanced Scorecard.

- Por último, se recomienda aprovechar los parecidos en gustos y preferencias del mercado de Bogotá con el hispano, siendo también utilizado como beachhead market o mercado estratégico el cual logra darle a BIOPERÚ NATURAL PRODUCTS S.A.C. una oportunidad de aprendizaje que puede usarla para otros mercados similares. Lo que se pretende con ello es lograr conocer el movimiento del mercado, determinación de consumo y comportamiento de clientes para aplicarlo en mercados parecidos y obtener respuestas equivalentes, teniendo que cambiar solo ciertos aspectos de adaptación al mercado. 


\section{REFERENCIAS}

Aguilar Orozco, C. A. (Agosto de 2011). http://biblioteca.usac.edu.gt. Recuperado el Agosto de 2014, de http://biblioteca.usac.edu.gt/tesis/08/08_2373_IN.pdf Alianza del Pacífico. (2015). https://alianzapacifico.net. Recuperado el Noviembre de 2015, de https://alianzapacifico.net/que-es-la-alianza/\#valor-estrategico

Álvarez Medina, M. T. (2013). itson.mx. Recuperado el Noviembre de 2015, de http://www.itson.mx/publicaciones/pacioli/Documents/no66/17ael_bsc_una_herramienta_para_la_planeacion_estrategicax.pdf América Económica. (2014). América Económica. Recuperado el 2015, de http://www.americaeconomia.com/negocios-industrias/conozca-las-ultimastendencias-en-la-industria-de-belleza-y-cuidado-personal-en-

Asociación Nacional de Empresarios de Colombia. (2014). andi.com.co. Recuperado el 2015, de

http://www.andi.com.co/SitEco/Documents/Balance\%202014\%20y\%20perspect ivas\%202015.pdf

BANCO CENTRAL DE COLOMBIA. (Marzo de 2015). banrep.gov.co. Recuperado el Septiembre de 2015, de http://www.banrep.gov.co/es/inversion-directa

Banco de la República. (2015). Banco Central de Colombia.

Banco Mundial. (2013). La Movilidad Económica y el Crecimiento de la Clase Media en América Latina. Recuperado el 19 de Diciembre de 2015, de https://openknowledge.worldbank.org/bitstream/handle/10986/11858/97808213 97527.pdf

Cámara Industrial de Cosméticos y Aseo. (2012). Informe de Sostenibilidad 2012. 
Castro, J. (5 de Agosto de 2015). Portafolio.co. Recuperado el Septiembre de 2015, de http://www.portafolio.co/economia/consumo-productos-belleza-cosmeticos

Consejo de Asociaciones de la Industria de Cosméticos Latinoamericana. (2014). casicla.org. Recuperado el Julio de 2015, de http://www.casic-

la.org/noticias/noticias-institucionales.html

Consejo de Asociaciones de la Industria de Cosméticos Latinoamericana, CASIC. (2014).

Cosmética Natural Kem's S.A.C. (s.f.). Recuperado el Julio de 2015, de http://www.kemsperu.com/index.php?option=com_content\&view=article\&id=1 Decisión Empresarial. (s.f.). http://decisionempresarial.com. Recuperado el Marzo de 2015, de http://decisionempresarial.com/co/index.php/recurso/admonempresarial/84-inteligencia-empresarial/124-cinco-fuerzas-competitivas

Departamento Administrativo Nacional de Estadística. (2015). dane.gov.co.

Recuperado el Agosto de 2015, de http://www.dane.gov.co/index.php/estratificacionsocioeconomica/generalidades

El Mundo. (2014). Beauty also moves the economy.

estudiosocieconomico. (Agosto de 2014). Recuperado el Septiembre de 2015, de http://estudiosocieconomico.blogspot.pe/

Euromonitor International. (2014). siicex.gob.pe. Recuperado el Septiembre de 2015, de http://www.siicex.gob.pe/siicex/documentosportal/alertas/documento/doc/52124 6423rad59815.pdf

Euromonitor International. (Mayo de 2015). Skin Care Colombia. 
Grupo Deimon. (2014). deimon. Obtenido de

http://www.deimon.com.ar/pdf/posicionamiento_de_mercado/posicionamiento_ de_mercado_definicion.pdf

ISO 26000. (2015). iso.org. Recuperado el Septiembre de 2015, de http://www.iso.org/iso/iso_26000_project_overview-es.pdf

LEGISCOMEX. (2014). Inteligencia de mercados- Cosméticos. Recuperado el Julio de 2015, de

http://www.legiscomex.com/BancoMedios/Documentos\%20PDF/col_est_cosme ticos_8.pdf

Mercado de Dinero. (8 de Julio de 2014). Mercadodedinero.com.co. Recuperado el Septiembre de 2015, de http://www.mercadodedinero.com.co/Economia/7084la-belleza-un-mercado-muy-movido-en-colombia.html

Naciones Unidas. (2015). colombiaun.org. Recuperado el Septiembre de 2015

Organización Internacional del Trabajo. (2014). Panorama Laboral 2014, América Latina y el Caribe.

Organización Mundial de la Salud, Oficina Regional para las Américas. (2014). http://www.col.ops-oms.org. Recuperado el Septiembre de 2014, de http://www.col.ops-oms.org/medicamentos/Documentos/dec677_95.htm

Organización Mundial de la Salud, Oficina Regional para las Américas, Colombia. (s.f.). paho.org/col/. Recuperado el Noviembre de 2014, de http://www.col.opsoms.org/medicamentos/Documentos/dec677_95.htm

PORTAFOLIO. (13 de Noviembre de 2014). portafolio.co. Recuperado el Septiembre de 2015, de http://m.portafolio.co/node/900170/\%3Ftamano\%3Dgrande 
PROCHILE. (2015). prochile.gob.cl. Recuperado el Julio de 2015, de http://www.prochile.gob.cl/wpcontent/blogs.dir/1/files_mf/1438352450Colombia_Guia_Pais_2015.pdf PROMPERÚ. (2013). Estudio de Mercado para el Sector de Productos Naturales Cosméticos y de Cuidado Personal, Proyecto Biocomercio Andino.

PROMPERÚ. (2014). Costos Logísticos de envío de carga a Colombia: Sector Confecciones.

PROMPERÚ. (2014). Guía de Mercado Colombia.

Propaís. (2014). propais.org.co. Recuperado el Agosto de 2015, de http://propais.org.co/biblioteca/inteligencia/sector-cosmeticos-en-colombia.pdf Rioja. (2012). Recuperado el Diciembre de 2014, de http://www.rioja.com.pe/noticia_el-sacha-inchi-o-mani-incaico-y-sus-grandesbeneficios-para-salud.html

solmicroexpertis. (2014). Recuperado el Octubre de 2015, de http://www.solmicroexpertis.com/ExpertisElearning/D19_MantenimientoCorrec tivoPreventivo/MtoCorrectivoPreventivo_Manual_50.pdf

SUNAT. (2015). Guía Tributaria. Recuperado el Septiembre de 2015, de http://guiatributaria.sunat.gob.pe/tipos-de-contribuyente/regimen-especial-derenta-rer.html

The Hofstede Centre. (s.f.). http://geert-hofstede.com. Recuperado el Septiembre de 2015, de http://geert-hofstede.com/colombia.html

Universidad del Valle Colombia. (2014). univalle.edu.co. Recuperado el Julio de 2015, de http://saberesygeneros.univalle.edu.co/plandesarrollo20052015/contenido/2.analisis-entorno/2-nacional.html 
Universidad Nacional de Colombia. (2014). PROSPECTIVA DEL SECTOR COSMÉTICO NATURAL EN COLOMBIA. Palmira.

Universidad Nacional de Colombia. (2014). unperiodico.unal.edu.co. Recuperado el Septiembre de 2015, de http://www.unperiodico.unal.edu.co/dper/article/cosmeticos-colombianos-conproyeccion-mundial.html 
APÉNDICES 


\section{APÉNDICE 1}

\section{MISHKI PERÚ}

Yana Cosmetics S.A.C.

\section{Entrevista a Valerie Barbier, Gerente General}

Jueves 12 de junio del 2014

9:30am.

La Aurora - Miraflores, Lima

\section{GUÍA DE PREGUNTAS}

1. ¿Cómo surgió la idea del negocio?

2. ¿Cuáles son los factores y/o oportunidades que considera existen para el desarrollo de un negocio de ese tipo?

3. ¿Cuál considera que es su visión?

4. ¿Cuál es su misión?

5. ¿Qué productos conforman su oferta exportable?

6. ¿A qué países exporta?, ¿Por qué?

7. ¿Cuáles son sus fortalezas?

8. ¿Cuáles son sus debilidades?

9. ¿Qué mejoraría de sus productos?

10. ¿Con cuánto de inversión inicial comenzó su negocio?

11. ¿Considera que éste es rentable en el tiempo?

12. ¿Cuáles son sus expectativas de comportamiento de la demanda de este sector?

13. ¿Cuáles son los retos a futuro para posicionarse en el negocio de manera competitiva?

14. ¿Cuál es su proceso productivo? 
15. ¿Qué de innovador implementaría en el mismo?

16. ¿Con qué proveedores trabaja?

17. ¿A qué precios vende sus productos (según mercados)?

18. ¿Cuál es su estrategia de distribución?

19. ¿Cuál es su estrategia de promoción?

20. ¿Cómo ve su empresa de aquí a 5 años?, ¿Piensa ampliar su portafolio de productos?, ¿Lanzar nuevos?

Recomendaciones finales 
1.- Todo empezó en el año 2004, cuando la Srta. Valerie estuvo de visita en el Perú apoyando a una ONG por un par de meses, luego volvería a Bruselas ese mismo año, pero ya que le interesaría emprender un negocio en el país, tuvo la idea de regresar a quedarse por el periodo de un año, todo esto debido a la influencia que tuvo un documental transmitido en Europa respecto a Sudamérica gran parte del cuál describía nuestra cultura y la existencia de gran biodiversidad en la misma. Cuando volvió participó de un taller de la papa en Huancayo y sería a partir de éste que desarrollaría investigaciones respecto a las propiedades que ofrecen este tipo de insumos en el desarrollo de productos estéticos.

2.- El Perú como país rico en recursos naturales, su biodiversidad ofrece un campo muy amplio de posibilidades, debido a la gran cantidad de plantas con propiedades muy especiales para la salud, nutrición e incluso la estética. Asimismo, el trabajo conjunto con comunidades andinas a través de la extracción de los mismos respetando el medio ambiente y preservando la calidad para generar sostenibilidad a futuro.

Por otro lado, el hecho de que la gestora principal del negocio sea de nacionalidad francesa, es un factor que indirectamente respalda la imagen - garantía - de los productos ofertados y facilita el acceso a los negocios en los mercados internacionales.

Por último, considerar que los productos se elaboran a base de ingredientes orgánicos y los procesos productivos se rigen a los estándares de buenas prácticas de manufactura.

3.- La visión de la empresa es trabajar con insumos de la biodiversidad peruana el desarrollo de una oferta exportable de productos naturales y orgánicos de cuidado 
personal; asimismo, ampliar su portafolio de producto ej. Cremas de cuerpo, bloqueadores y suplementos empleando otras plantas nativas.

4.- La misión es trabajar y apoyar al desarrollo de productos de alto valor agregado, a través del aprendizaje y desarrollo de competencias de las comunidades con las que trabaja la empresa conjuntamente; asimismo, respetar el medio ambiente.

5.- Detalle.-

- Jabón exfoliante a base de la pepa de la fruta - ungurahui - de la Selva Peruana.

- Loción de limpieza a base de extracto de papa nativa de la Sierra Peruana.

- Agua tónica a base de una planta - muña - de la Sierra Peruana.

- Mascarilla de pétalos de Caléndula de la Sierra Peruana.

- Aceite de jojoba de la Costa Peruana.

- Crema hidratante a base de una papa nativa de la Sierra Peruana - Cutis normal a graso.

- Crema hidratante a base de un aceite esencial extraído de una planta de la Sierra Peruana - muña - Cutis graso.

- Crema hidratante a base de un aceite natural extraído de una fruta de la Selva Peruana - ungurahui - Cutis normal a seco.

6.- España, Francia, Finlandia, Ecuador, EE.UU., Corea del Sur, Colombia.

\section{7.- Fortalezas}

- Creación y desarrollo de un producto diferenciado de alta calidad.

- Trabajo conjunto con un buen laboratorio químico. 
- Alianzas con proveedores.

- Acceso al mercado europeo a través de red de contactos.

- Notas de prensa nacionales e internacionales realizadas a la empresa.

8.- Debilidades

- Cosos en investigación y desarrollo.

- Empresa pequeña.

- Trámites burocráticos.

9.- Mejoraría la presentación de sus envases.

10.- El negocio comenzó con una inversión de $\$ 30,000$ aprox.

11.- Sí es rentable en el tiempo; ya que, existe una demanda creciente en el sector de cuidado personal y belleza, más aún una tendencia enfocada a productos a base de ingredientes naturales.

12.- La demanda crecerá hasta un punto en que se estabilice; sin embargo, existen muchos canales para explotar y lograr una inserción de este tipo de productos ej. Spas, gyms, centros de belleza, centros de yoga, etc.

13.- Diversificar la oferta exportable, entrar a nuevos mercados, incrementar herramientas de marketing, homologar proveedores, mejorar procesos de gestión. 
14.- El proceso productivo abarca desde la recepción de la materia prima, desarrollo de fórmulas con el apoyo de dos químicos farmacéuticos de la Facultad de Farmacia y Bioquímica de UNMSM, procesamiento de la misma a través de la tercerización de los servicios del laboratorio químico, Química Suiza, envasado y etiquetado; para el almacenamiento de los PT cuentan con un depósito ubicado en San Martín de Porres, y, por último, la exportación de los mismos.

15.- Detalle.-

- Implementar un laboratorio propio de alta tecnología.

- Desarrollo de la cadena productiva integral bajo exigentes estándares de calidad internacionales.

- Certificar el producto terminado como orgánico.

16.- No especifica.

17.- Detalle.-

- Mercado Nacional: S/. $45.00-$ S/. 50.00

- $\quad$ Mercado Internacional: \$6.5FOB aprox.

18.- Venta a distribuidores en diferentes países; asimismo, ocasionalmente realizan ventas directas a tiendas especializadas y spas. Se ha contactado directamente con una reconocida cadena de supermercados y está evaluando la posibilidad de entrar en este canal de distribución (no especificó más detalles respecto a lo último mencionado).

19.- Su estrategia de promoción consiste en la participación en ferias nacionales como PerúNatura que se desarrolla bajo el marco de la Expoalimentaria; así como también, 
participación en ferias internacionales, todo esto es posible ya que cuenta con el respaldo de PROMPERÚ.

La Sra. Valerie hace viajes cada cierto tiempo a Francia donde visita y contacta a clientes.

También hace publicidad a través de su página web y en facebook.

20.- Se ve como una empresa consolidada, con un mejor posicionamiento y reconocimiento en el mercado internacional, sobre la base de la calidad, funcionalidad e innovación de sus productos. 


\section{APÉNDICE 2}

Cotización de Agroindustrias Amazónicas S.A. para nuestro principal insumo, aceite de sacha inchi orgánico

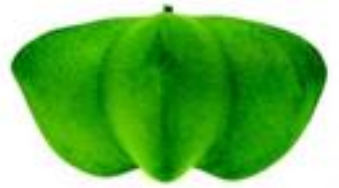
AGROINDUSTRIAS AMAZONICAS

\section{Factura Proforma en Nuevos Soles}

Fecha :

Destinatario:

Atención:

Lugar de entrega:

Fecha de Entrega:

Forma de pago:
Lima, 04 de Junio del 2014.

Ferrostaal Perú SAC

Lucia Gallori

dirección del cliente por coordinar en Lima

7 días de la orden de compra confirmada

$50 \%$ depósito bancario con la orden de compra confirmada y $50 \%$ antes de la entrega de la mercadería a favor de:

Agroindustrias Amazónicas S.A.

BANCO CONTINENTAL

Cuenta Corriente en Soles № 0111870100014104

\begin{tabular}{|c|c|r|r|}
\hline Cantidad & Descripción & $\begin{array}{r}\text { Precio } \\
\text { Unitario }\end{array}$ & $\begin{array}{r}\text { TOTAL } \\
\text { SOLES }\end{array}$ \\
\hline 1,000 & $\begin{array}{l}\text { litros de aceite Inca Inchi convencional } \\
\text { contenidos en 3 cilindros de 216 litros cada uno }\end{array}$ & 10.56 & $10,560.00$ \\
\hline & I.G.V. 18\% & $1,900.80$ \\
\hline & TOTAL EN NUEVOS SOLES & & $12,460.80$ \\
\hline
\end{tabular}

Proforma valida por $\mathbf{3 0}$ días

Patricia Aguilar

Agroindustrias Amazónicas S.A. 


\section{APÉNDICE 3}

Cotización materiales/herramientas de laboratorio, Av. Emancipación $\mathbf{N}^{\circ} 343$

\section{Stand 205}

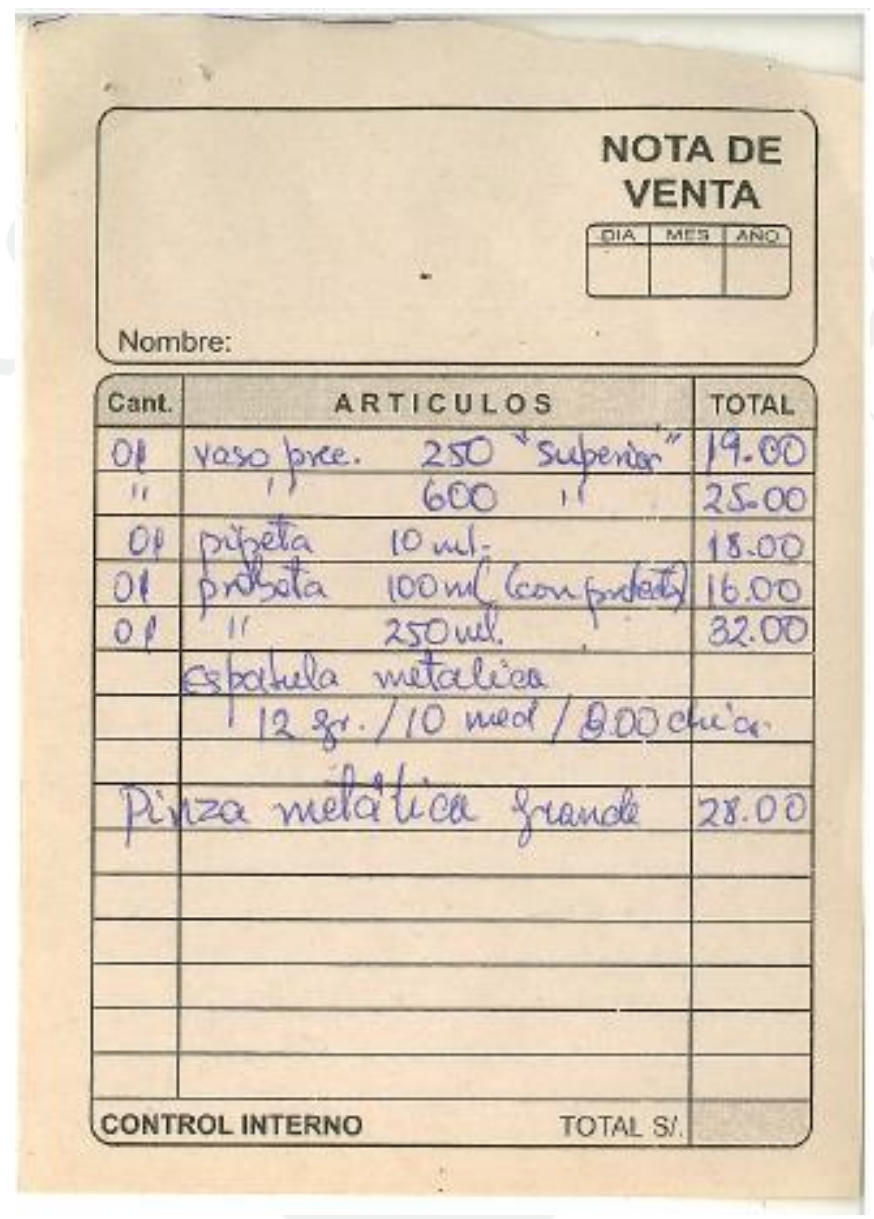




\section{APÉNDICE 4}

\section{Proforma de MEDIC IMPORT para materiales/herramientas de laboratorio}

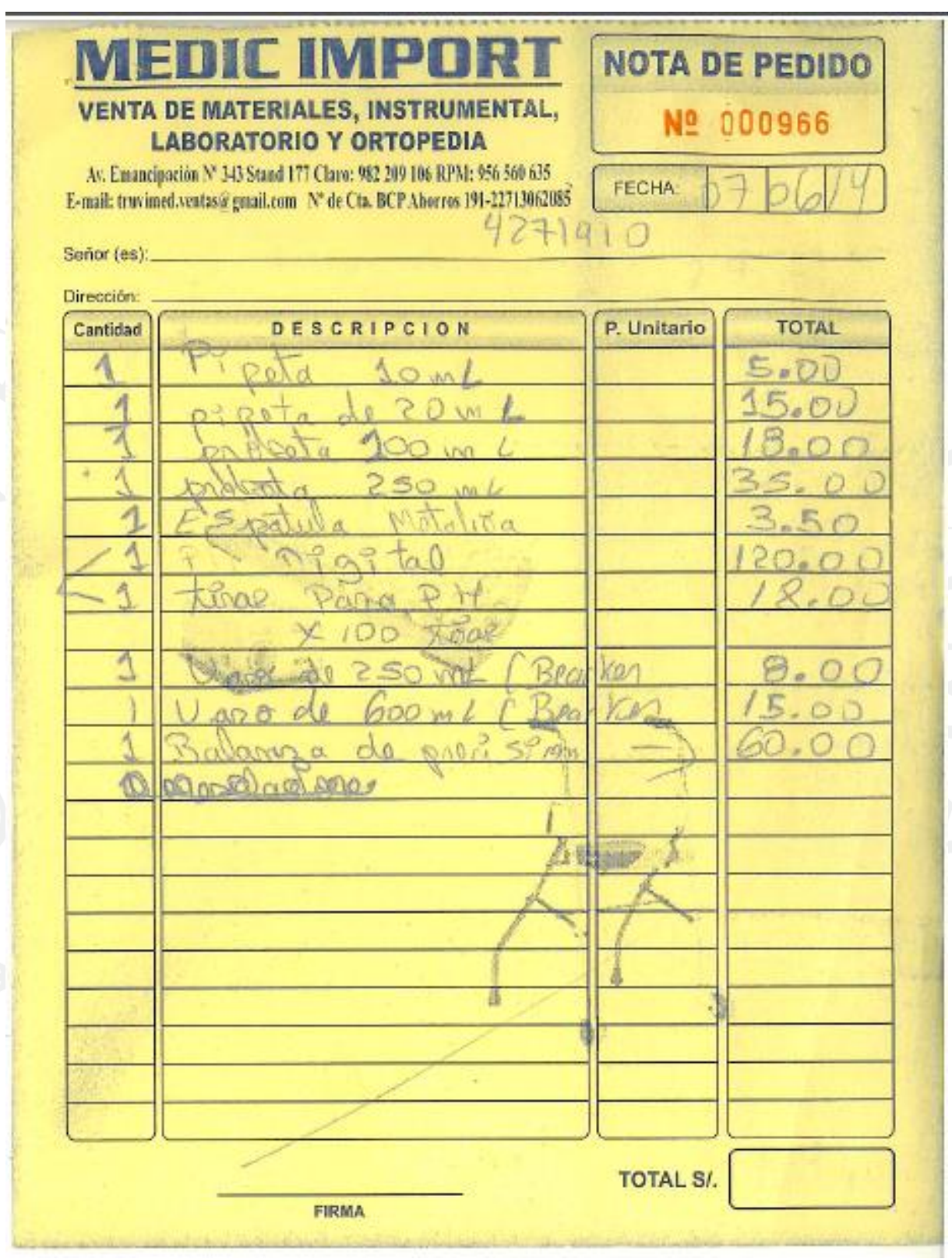




\section{APÉNDICE 5}

\section{Proforma de Señales 906 para equipos de seguridad}

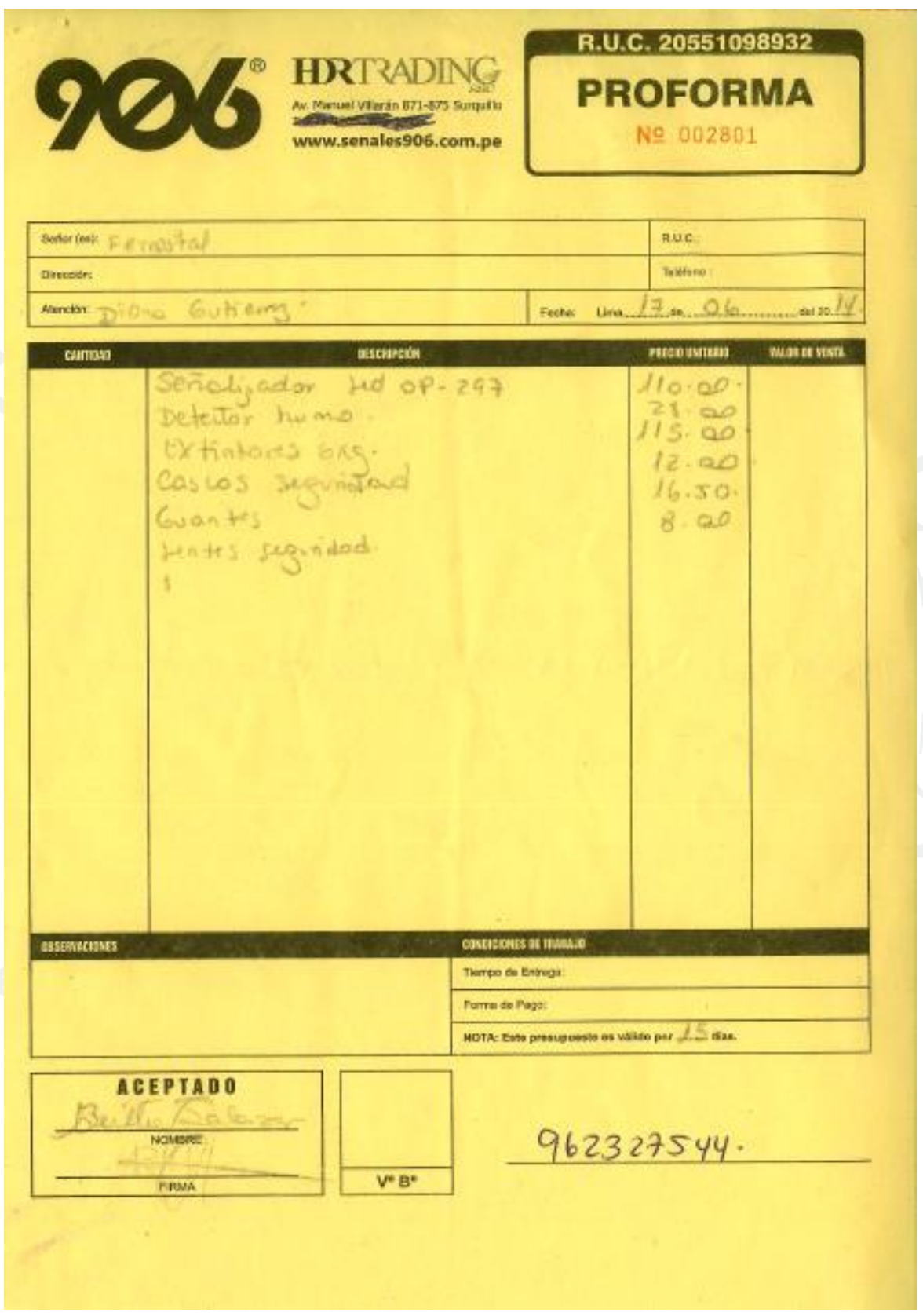




\section{APÉNDICE 6}

Proforma de Alessa Import E.I.R.L. para equipos y herramientas

$\underline{\text { (Balanza electrónica, balanza de precisión, Phmetro) }}$
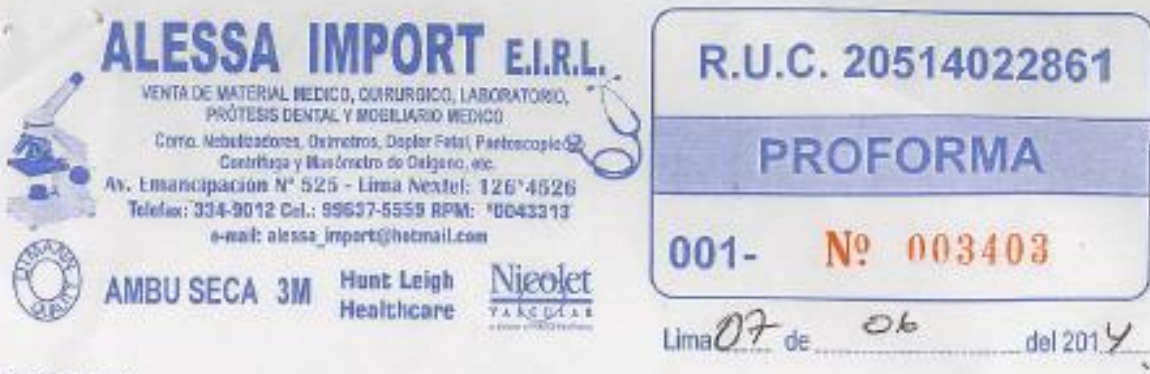

Señor(es)

Dirección:

R.U.C

Telf:

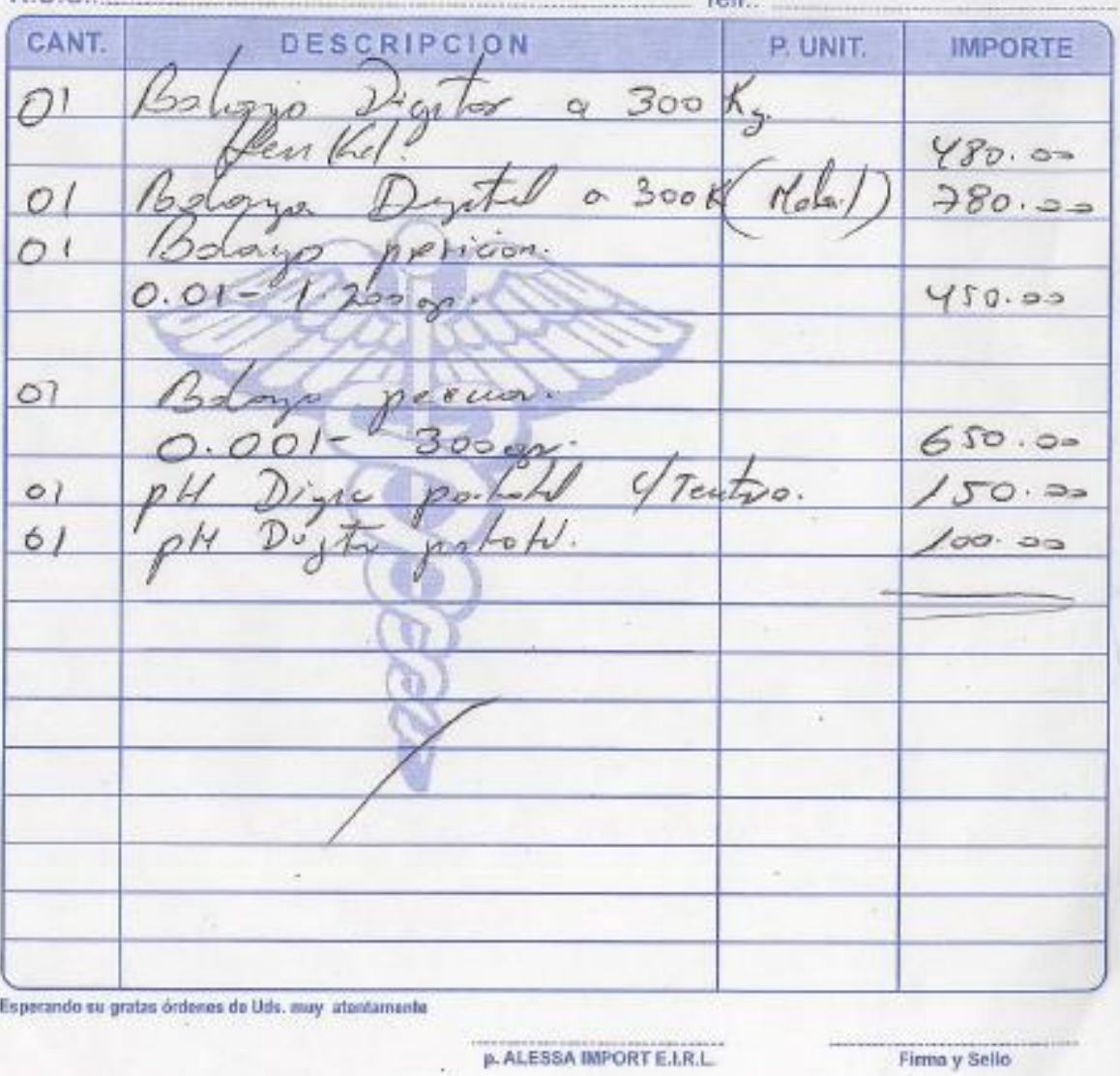




\section{APÉNDICE 7}

$\underline{\text { Especificaciones técnicas de Alessa Import E.I.R.L. para equipos y herramientas }}$

cotizados

From: julio yerson luque palomino [mailto:alessa import@hotmail.com]

Sent: Sábado, 07 de Junio de 2014 04:52 PM

To: Gallori, Lucia (Ferrostaal Perú S.A.C.)

Subject: CATALOGOS

BUENAS TARDES, LE ADJUNTO LAS CARACTERÍSTICAS DE LOS EQUIPOS SOLICITADOS SOLICITADAS.

* BALANZA DIGITAL BCH 300 CS ( TABLERO CON CUBIERTA DE PLÁSTICO ) 480.00 SOLES

* balanza digital yKST 300 P ( TABLERO CON CUBIERTA DE METAL) 780.00 SOles

* BALANZA DE PRESICION 0.01 a 1200 gramos 450.00 SOLES

* BALANZA DE PRESICION 0.01 a 2000 gramos 550.00 SOLES

* BALANZA DE PRESICION 0.001 a 300 gramos 650.00 SOLES

* PH DIGITAL CON TERMOMETRO 150.00 SOLES

RAZÓN SOCIAL: ALESSA IMPORT E.I.R.L

ENTIDAD BANCARIA: BANCO DE CRÉDITO

CUENTA CORRIENTE: 191-1901673-0-17

ATTE. JULIO LUQUE

TEL. 3349012

NEXT $126 * 4526$

CEL 996375559

RPM. ${ }^{*} 0043313$

4 archivos adjuntos
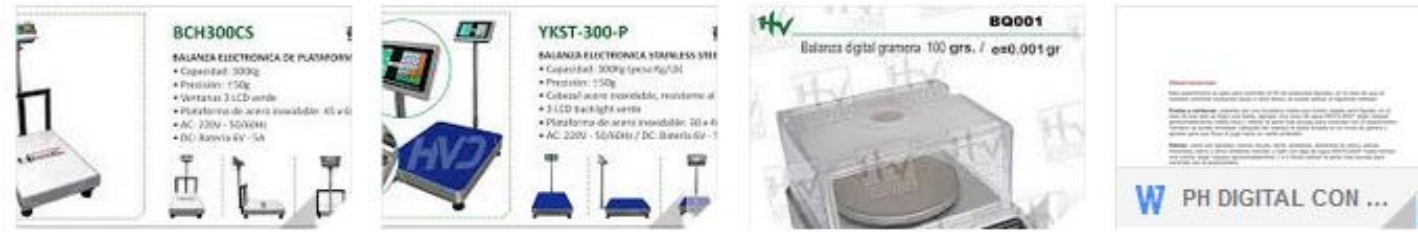

W PH DIGITAL CON 


\section{APÉNDICE 8}

\section{$\underline{\text { Risk Simulator }}$}

\section{$\underline{\text { Análisis Tornado }}$}

A través del Análisis Tornado identificamos y evaluamos la sensibilidad o grado de incidencia de las variables explicativas sobre la variable endógena.

\begin{tabular}{|c|c|c|c|c|c|c|}
\hline \multirow[b]{2}{*}{ Precedent Cell } & \multicolumn{3}{|c|}{ Base Value: 57530.89} & \multicolumn{3}{|c|}{ Input Changes } \\
\hline & $\begin{array}{c}\text { Output } \\
\text { Downside }\end{array}$ & $\begin{array}{l}\text { Output } \\
\text { Upside }\end{array}$ & $\begin{array}{c}\text { Effective } \\
\text { Range }\end{array}$ & $\begin{array}{c}\text { Input } \\
\text { Downside }\end{array}$ & $\begin{array}{c}\text { Input } \\
\text { Upside }\end{array}$ & $\begin{array}{l}\text { Base } \\
\text { Case } \\
\text { Value }\end{array}$ \\
\hline CUBICAJE!(L16) & -4896.3304 & 119958.13 & 124854.46 & S/. 4.14 & S/. 5.06 & S/. 4.60 \\
\hline CUBICAJE!(L18) & 15607.352 & 99454.447 & 83847.10 & 1.8 & 2.2 & 2 \\
\hline COK Y WACC!(F10) & 63293.155 & 52114.55 & 11178.61 & 1.17 & 1.43 & 1.30 \\
\hline COSTOS Y GASTOS VARIABLES!(H10) & 62966.53 & 52095.269 & 10871.26 & 0.090 & 0.110 & 0.100 \\
\hline COSTOS Y GASTOS VARIABLES!(E10) & 62966.53 & 52095.269 & 10871.26 & 3.29 & 4.02 & 3.65 \\
\hline
\end{tabular}

Elaboración Propia

Se puede observar por los resultados del análisis que las variables que más incidencia tienen sobre el VAN corresponden a la celda CUBICAJE! (L16), que contiene el Precio Unitario del producto en dólares FOB. Debido a que si el precio disminuyera en un $10 \%$, el VAN caería hasta llegar a ser negativo como se puede observar en la columna Output Downside; de igual manera, si el precio aumentara en un $10 \%$ el VAN se dispararía hasta alcanzar casi el doble del valor que se maneja como base en el proyecto analizado. 
Por otro lado encontramos a la variable CUBICAJE!(L18), correspondiente a nuestra unidad de exportación, si aumentáramos el número de cajas vendidas del producto o si disminuyeran, esto tendría un gran impacto en el VAN del proyecto, lo cual es lógico y se puede apreciar en valores en la tabla precedente.

También está la variable COK Y WACC!(F10), referente al beta como base para el cálculo del costo del patrimonio; esta variable representa el riesgo sistémico de la empresa en el mercado, y, aumenta/disminuye conforme aumenta/disminuye el riesgo de la acción (volatilidad).

Asimismo, están las variables COSTOS Y GASTOS VARIABLES!(H10) y COSTOS Y GASTOS VARIABLES!(E10), que comprenden la cantidad requerida de aceite de sacha inchi por unidad de producción, así como su valor de venta; siendo éste nuestro insumo principal, la volatilidad en sus precios afectará el valor del VAN.

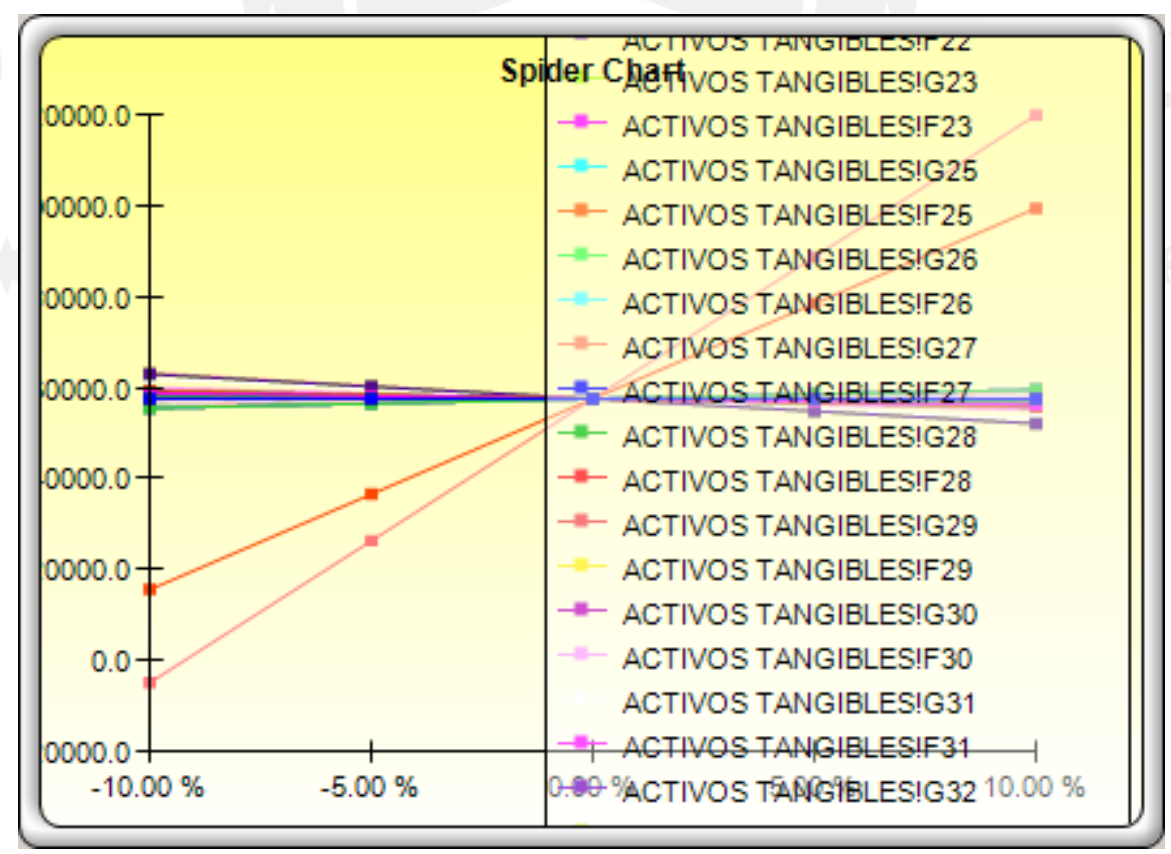




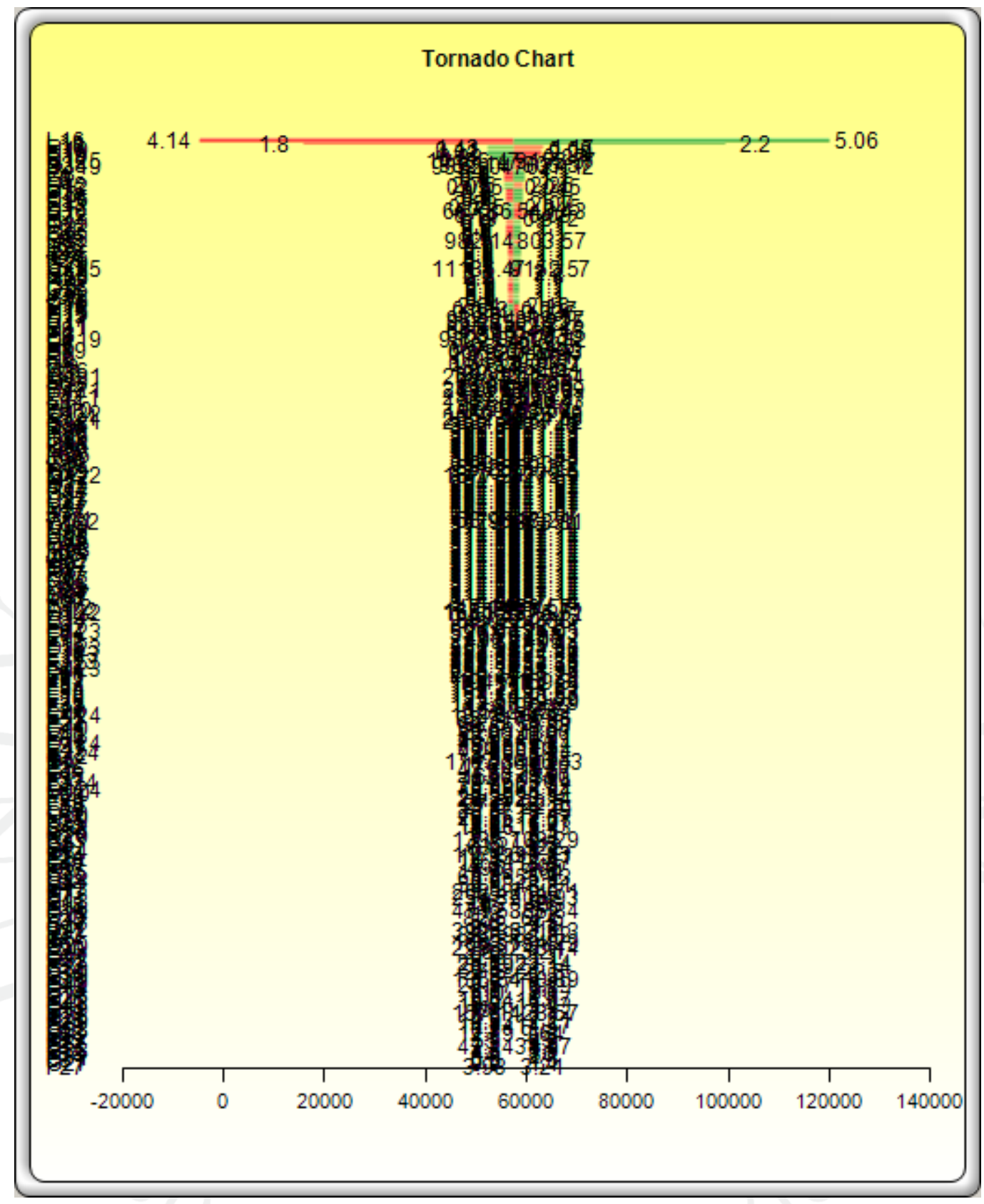




\section{SUPUESTOS}

\section{VARIABLE \#1: Ventas}

Se hizo un SET INPUT ASSUMPTION para cada uno de los valores de las ventas anuales para el horizonte del proyecto, utilizando el análisis de distribución TRIANGULAR; se le dio tres escenarios a las ventas:

Menos 5\%, valor calculado y más 5\%.

\section{VARIABLE \#2: Costos de Producción}

Asimismo, se hizo un SET INPUT ASSUMPTION para cada uno de los valores correspondientes a los costos de producción anual, utilizando el análisis de distribución TRIANGULAR; para un escenario de $+/-5 \%$.

VARIABLE \#3: Gastos Administrativos y de Ventas

Por último, se hizo un SET INPUT ASSUMPTION para cada uno de los valores correspondientes a los Gastos Administrativos y de Ventas anuales, utilizando el análisis de distribución TRIANGULAR; para un escenario de +/-5\%. 
Esto se puede ver resumido en el siguiente cuadro:

\begin{tabular}{|c|c|c|c|}
\hline \multicolumn{4}{|c|}{ VENTAS } \\
\hline AÑ̃ & MIN (-5\%) & ACTUAL & $\operatorname{MAX}(+5 \%)$ \\
\hline 1 & $134,246.40$ & $141,312.00$ & $148,377.60$ \\
\hline 2 & $167,808.00$ & $176,640.00$ & $185,472.00$ \\
\hline 3 & $201,369.60$ & $211,968.00$ & $222,566.40$ \\
\hline 4 & $234,931.20$ & $247,296.00$ & $259,660.80$ \\
\hline 5 & $268,492.80$ & $282,624.00$ & $296,755.20$ \\
\hline \multicolumn{4}{|c|}{ COSTO DE PRODUCCIÓN } \\
\hline 1 & $59,391.63$ & $62,517.51$ & $65,643.38$ \\
\hline 2 & $69,436.86$ & $73,091.43$ & $76,746.00$ \\
\hline 3 & $94,836.19$ & $99,827.57$ & $104,818.95$ \\
\hline 4 & $104,881.42$ & $110,401.49$ & $115,921.57$ \\
\hline 5 & $114,931.47$ & $120,980.49$ & $127,029.52$ \\
\hline \multicolumn{4}{|c|}{ GASTOS ADMINISTRATIVOS Y VENTAS } \\
\hline 1 & $67,092.16$ & $70,623.32$ & $74,154.49$ \\
\hline 2 & $67,640.45$ & $71,200.47$ & $74,760.50$ \\
\hline 3 & $69,536.41$ & $73,196.22$ & $76,856.03$ \\
\hline 4 & $74,607.13$ & $78,533.82$ & $82,460.51$ \\
\hline 5 & $80,098.99$ & $84,314.73$ & $88,530.47$ \\
\hline
\end{tabular}

Elaboración Propia 
Posteriormente se seteó los OUTPUT FORECAST con un nivel de confianza del $95 \%$ y margen de error del $5 \%$.

Se seteó como OUTPUT el VAN Económico y Financiero, y se obtuvieron los siguientes reportes:

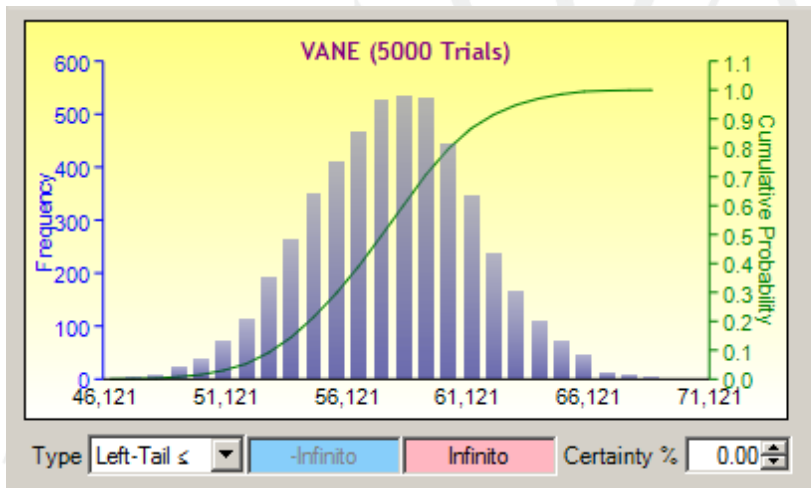

\begin{tabular}{|l|r|}
\hline Statistics & Result \\
\hline Number of Trials & 5000 \\
\hline Mean & $57,570.2118$ \\
\hline Median & $57,620.0155$ \\
\hline Standard Deviation & 3.426 .5026 \\
\hline Variance & 11.740 .920 .3052 \\
\hline Coefficient of Variation & 0.0595 \\
\hline Maximum & 68.737 .9997 \\
\hline Minimum & $45,516.9141$ \\
\hline Range & $23,221.0856$ \\
\hline Skewness & -0.0300 \\
\hline Kurtosis & -0.0972 \\
\hline $25 \%$ Percentile & $55,224.3224$ \\
\hline $75 \%$ Percentile & $59,900.9956$ \\
\hline Percentage Error Precision at 95\% Confidence & $0.1650 \%$ \\
\hline
\end{tabular}

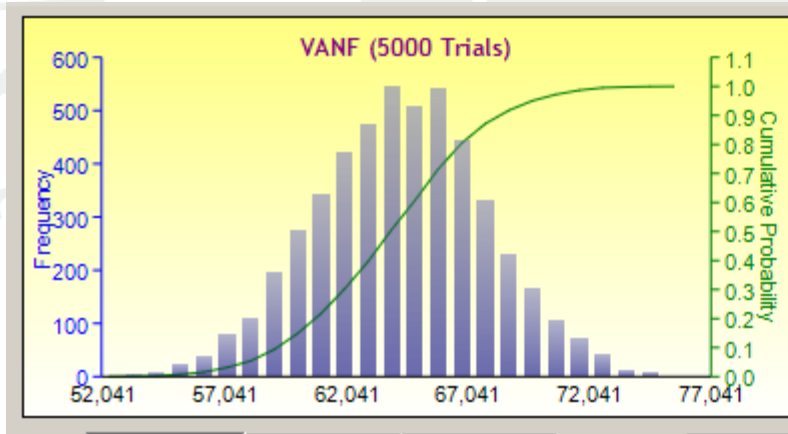

\begin{tabular}{|c|c|}
\hline Statistics & Result \\
\hline Number of Trials & 5000 \\
\hline Mean & $63,855.7550$ \\
\hline Median & $63,906.6289$ \\
\hline Standard Deviation & $3,537.9983$ \\
\hline Variance & $12,517,431.7672$ \\
\hline Coefficient of Variation & 0.0554 \\
\hline Maximum & $75,497.5640$ \\
\hline Minimum & 51.415 .0804 \\
\hline Range & $24,082.4836$ \\
\hline Skewness & -0.0304 \\
\hline Kurtosis & -0.0993 \\
\hline $25 \%$ Percentile & 61.427 .4792 \\
\hline $75 \%$ Percentile & $66,277.3713$ \\
\hline Percentage Error Precision at 95\% Confidence & $0.1536 \%$ \\
\hline
\end{tabular}


En ambos casos se les hizo una prueba de cola izquierda con valor cero, es decir, se midió la probabilidad de que el proyecto presente un VANE o VANF negativo y el resultado fue de $0 \%$ de probabilidad en ambos casos.

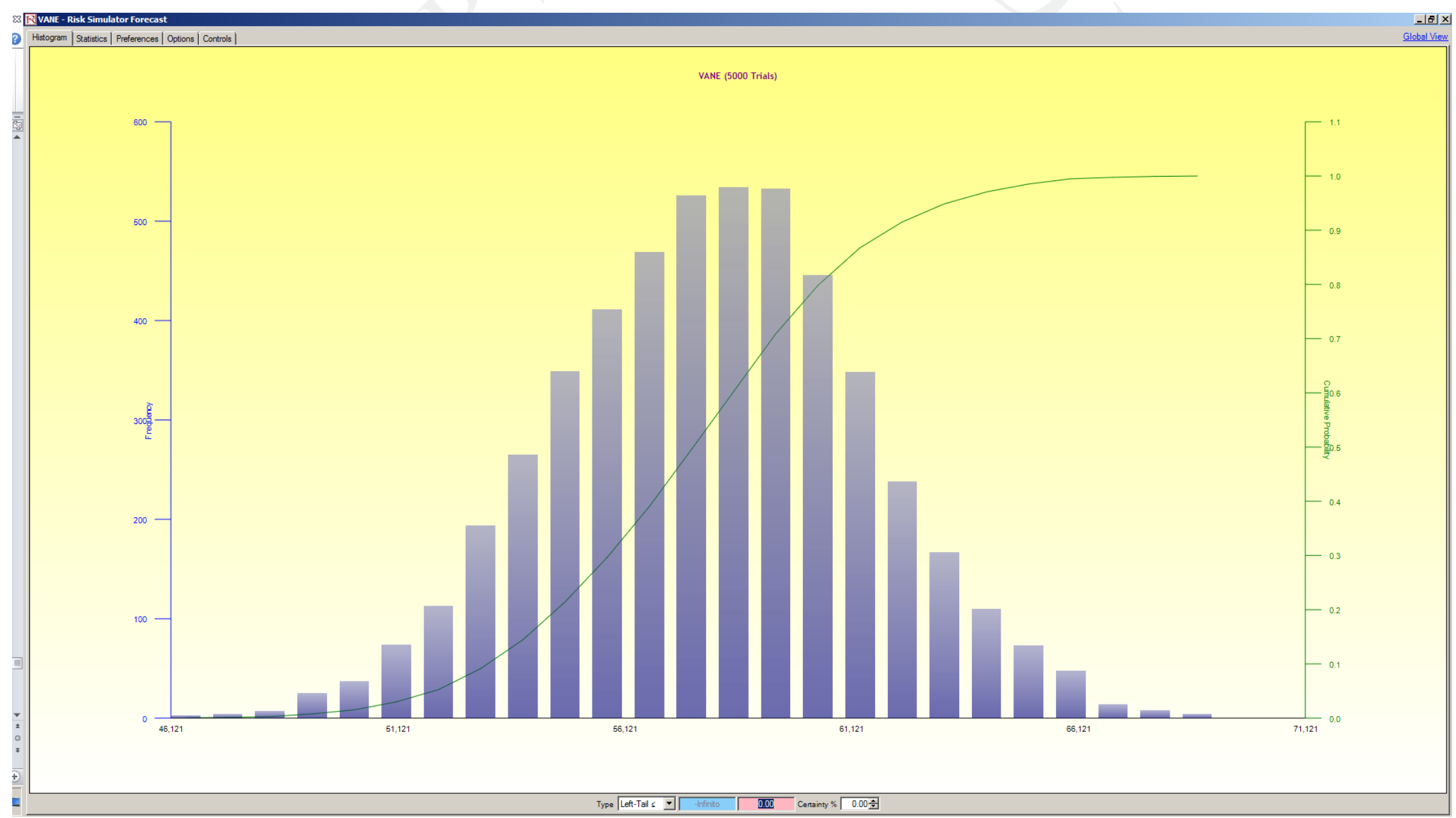


Lógicamente, si hacemos el análisis y obtenemos como resultado una probabilidad del 0\% de tener un VANF o un VANE negativos, hay un $100 \%$ de probabilidad de tener uno positivo. Se realizó la prueba respectiva y se comprobó.

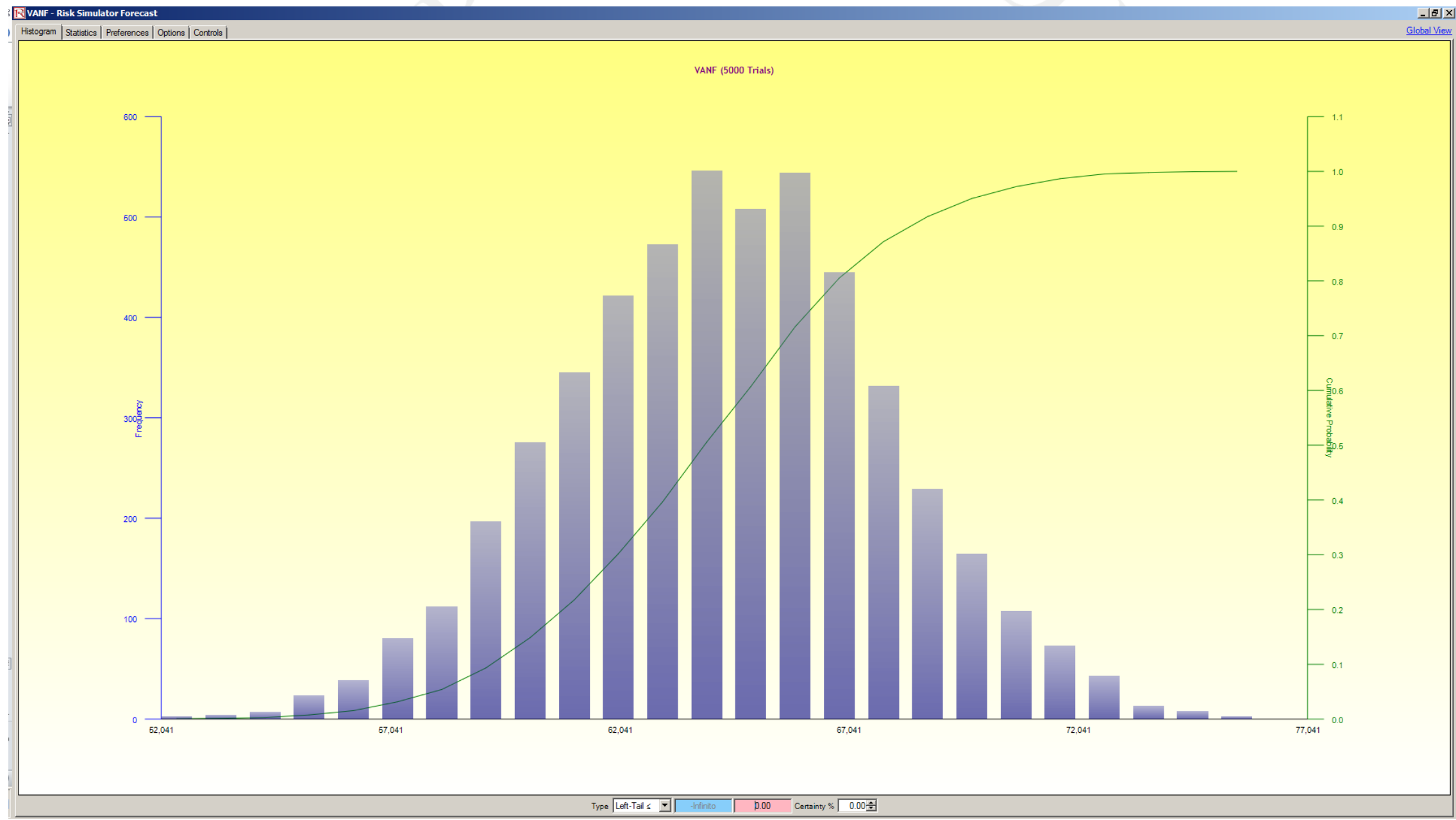


Por último, se hicieron pruebas de cola izquierda para medir la probabilidad de que el proyecto presente un VANE o VANF igual al estimado en el Análisis Financiero realizado, el resultado fue de $48.82 \%$ y $48.92 \%$ de probabilidad respectivamente.
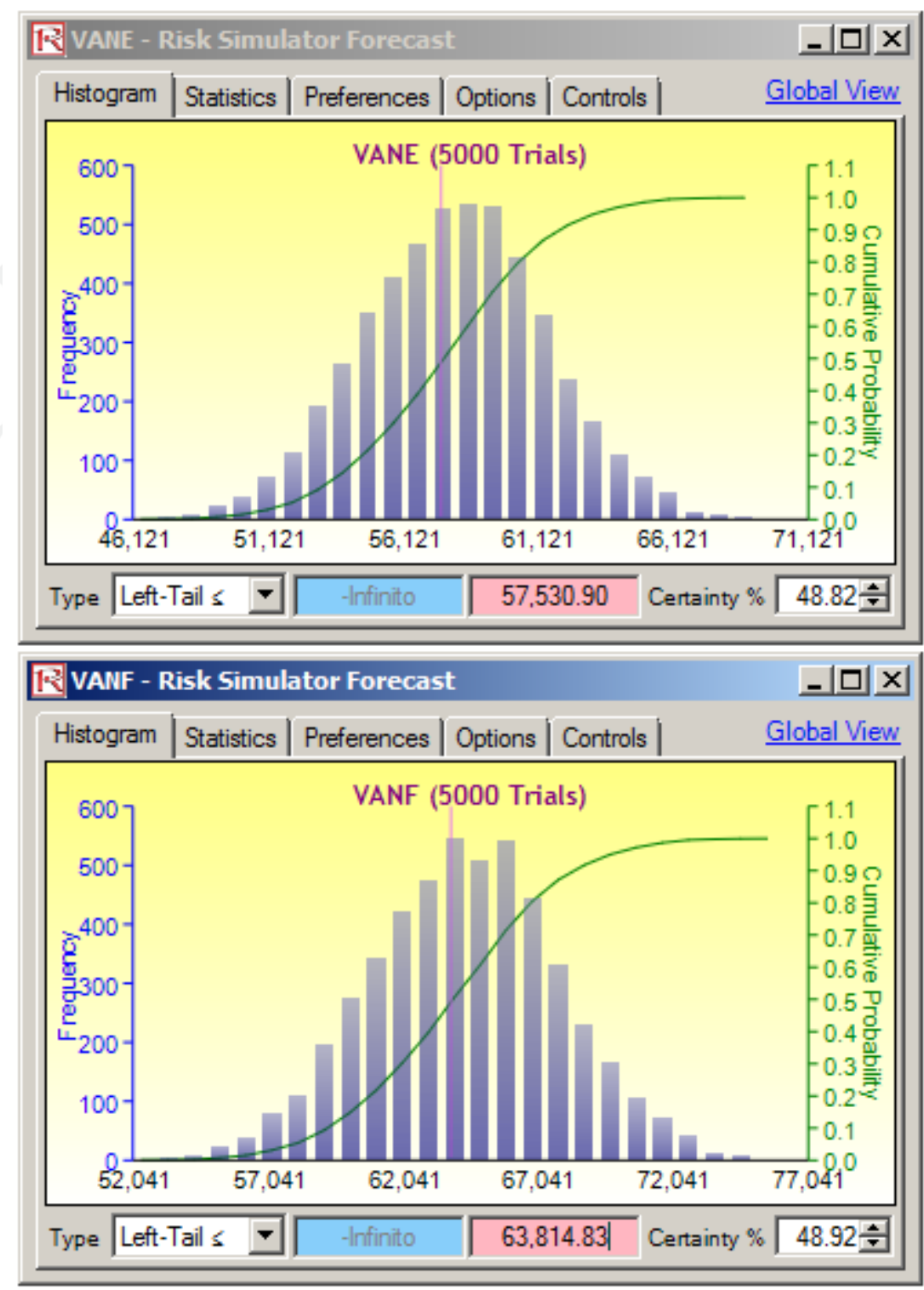